\title{
water
}

Advances in

In Situ Biological

and Chemical

Groundwater

Treatment

Edited by

Sabrina Saponaro, Snežana Maletić and Elena Sezenna

Printed Edition of the Special Issue Published in Water 
Advances in In Situ Biological and Chemical Groundwater Treatment 



\section{Advances in In Situ Biological and Chemical Groundwater Treatment}

Editors

Sabrina Saponaro

Snežana Maletić

Elena Sezenna

\section{MDPI}


Editors

Sabrina Saponaro

Politecnico di Milano

Italy

\section{Snežana Maletić \\ University of Novi Sad}

Serbia
Elena Sezenna

Politecnico di Milano

Italy

Editorial Office

MDPI

St. Alban-Anlage 66

4052 Basel, Switzerland

This is a reprint of articles from the Special Issue published online in the open access journal Water (ISSN 2073-4441) (available at: https://www.mdpi.com/journal/water/special_issues/ groundwater_treatment).

For citation purposes, cite each article independently as indicated on the article page online and as indicated below:

LastName, A.A.; LastName, B.B.; LastName, C.C. Article Title. Journal Name Year, Article Number, Page Range.

ISBN 978-3-03943-432-9 (Hbk)

ISBN 978-3-03943-433-6 (PDF)

(C) 2020 by the authors. Articles in this book are Open Access and distributed under the Creative Commons Attribution (CC BY) license, which allows users to download, copy and build upon published articles, as long as the author and publisher are properly credited, which ensures maximum dissemination and a wider impact of our publications.

The book as a whole is distributed by MDPI under the terms and conditions of the Creative Commons license CC BY-NC-ND. 


\section{Contents}

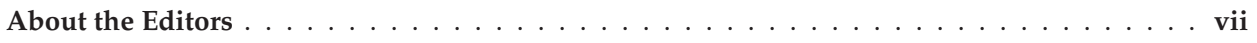

Preface to "Advances in In Situ Biological and Chemical Groundwater Treatment" . . . . . . ix

Jan Němeček, Kristýna Marková, Roman Špánek, Vojtěch Antoš, Petr Kozubek,

Ondřej Lhotský and MiroslavČerník

Hydrochemical Conditions for Aerobic/Anaerobic Biodegradation of Chlorinated Ethenes-A

Multi-Site Assessment

Reprinted from: Water 2020, 12, 322, doi:10.3390/w12020322 . . . . . . . . . . . . . . . .

Gabriele Beretta, Matteo Daghio, Anna Espinoza Tofalos, Andrea Franzetti, Andrea Filippo Mastorgio, Sabrina Saponaro and Elena Sezenna

Microbial Assisted Hexavalent Chromium Removal in Bioelectrochemical Systems

Reprinted from: Water 2020, 12, 466, doi:10.3390/w12020466 . . . . . . . . . . . . . . . 19

Marko Šolić, Snežana Maletić, Marijana Kragulj Isakovski, Jasmina Nikić, Malcolm Watson, Zoltan Kónya and Jelena Tričković

Comparing the Adsorption Performance of Multiwalled Carbon Nanotubes Oxidized by Varying Degrees for Removal of Low Levels of Copper, Nickel and Chromium(VI) from Aqueous Solutions

Reprinted from: Water 2020, 12, 723, doi:10.3390/w12030723 . . . . . . . . . . . . . . . 35

Jasmina Nikić, Aleksandra Tubić, Malcolm Watson, Snežana Maletić, MarkoŠolić, Tatjana Majkić and Jasmina Agbaba

Arsenic Removal from Water by Green Synthesized Magnetic Nanoparticles

Reprinted from: Water 2019, 11, 2520, doi:10.3390/w11122520 . . . . . . . . . . . . . . . . . . 53

Martin V. Maier, Yvonne Wolter, Daniel Zentler, Christian Scholz, Charlotte N. Stirn and Margot Isenbeck-Schröter

Phosphate Induced Arsenic Mobilization as a Potentially Effective In-Situ Remediation Technique-Preliminary Column Tests

Reprinted from: Water 2019, 11, 2364, doi:10.3390/w11112364 _ . . . . . . . . . . . . 71

Aleksandra Tubić, Maja Lončarski, Snežana Maletić, Jelena Molnar Jazić, Malcolm Watson, Jelena Tričković and Jasmina Agbaba

Significance of Chlorinated Phenols Adsorption on Plastics and Bioplastics during Water Treatment

Reprinted from: Water 2019, 11, 2358, doi:10.3390/w11112358 . 



\section{About the Editors}

Sabrina Saponaro (Ph.D. in Environmental and Sanitary Engineering) is Associate Professor of Soil Remediation, School of Civil and Environmental Engineering, Department of Civil and Environmental Engineering, Politecnico di Milano (I). She has been working at Politecnico di Milano on sanitary engineering topics since 1996, dealing with fate and transport problems of pollutants in soil and groundwater; health and environmental risk assessment; and traditional and innovative remediation techniques for polluted groundwater, soil, and sediments. A full list of her significant publications can be found at https://orcid.org/0000-0002-9358-6586. Since 2010, she has been scientific coordinator of three projects and local unit head of one project funded on a competitive basis by national and regional funds. She has been a member of the Scientific Committee of the International Symposium on Sediment Management (Ecole des Mines de Douai) since 2010 and the Scientific Committee of RemTech Expo (Ferrara Fiere Congressi) since 2011. She served on the Technical Steering Committee of the 8th International Conference on Remediation and Management of Contaminated Sediments (Battelle) in 2014. Her bibliometric indexes (Scopus) are as follows: 41 publications; 625 citations by 575 papers; h-index 13; 2 patents (as of June 2020).

Snežana Maletić Ph.D. in Chemistry) is Associate Professor of University of Novi Sad, Faculty of Sciences. She has based her career on a multidisciplinary approach, with expertise in environmental science; remediation technology; environmental chemistry; bioavailability and biodegradability of organic contaminants; water, soil, and sediment analysis; and environmental risk assessment. A full list of her significant publications can be found at https:// http://orcid.org/0000-0002-5026-3365. She was coordinator of two projects related to the characterization of biochar and its application as a soil/sediment amendment in order to reduce the bioavailability of toxic organic pollutants. She has participated in 25 national and international projects in the fields of environmental science, environmental risk assessment, and remediation technology. She has been involved in more than 40 studies related to research in environmental protection and technology. Since 2012, she has been Head of the Laboratory for Environmental Chemical Analysis, which is accredited according to ISO 17025 protocols. Her bibliometric indexes (Scopus) are as follows: 46 publications; 450 citations by 412 papers; H-index 13 (as of September 2020).

Elena Sezenna (Ph.D. Environmental and Sanitary Engineering) is Assistant Professor at the Department of Civil and Environmental Engineering at Politecnico di Milano. Her research activity mostly focuses on technologies for remediation of polluted groundwater, soil, and sediments, with special reference to experimental studies of bio-electrochemical processes and electrode-based remediation. The scope of her work extends to fate and transport modeling of contaminants (including emerging pollutants and biodegradable plastics) in soil and groundwater, and she has also been studying human health and environmental risk assessment for the management of contaminated sites, including methods to improve risk estimates and methodologies for the prioritization of remedial efforts. She has been involved as a research participant in various international and national projects since 2003. She is co-author of over 80 publications (21 Scopus-indexed) with 348 citations, and her h-index is 7. 



\section{Preface to "Advances in In Situ Biological and Chemical Groundwater Treatment"}

Groundwater contamination generically refers to modifications in biological, physical, or chemical characteristics; radioactivity; or the presence of undesirable solutes at significant concentrations. In terms of undesirable solutes, inorganic or organic chemical mixtures frequently occur, including metals and semi-metals, such as chromium and arsenic, and volatile chlorinated hydrocarbons (e.g., tetrachloroethene, trichloroethene).

"Pump and treat" is a common method for cleaning up groundwater contaminated with dissolved chemicals. Groundwater is pumped from wells to an above-ground treatment system that removes the contaminants. Pump and treat may last from a few years to several decades, with the actual cleanup time being long when the concentrations of the contaminants are high, the pollution source has not been completely removed, or the groundwater flow is slow.

The increasing availability of scientific studies has progressively drawn attention to in situ technologies for groundwater remediation. Most of them are innovative compared to the pump-and-treat approach, allowing the remediation time to be reduced and the remediation sustainability to be increased. In situ bioremediation of groundwater involves the encouragement of indigenous bacterial populations to metabolize target contaminants through the addition of various amendments, or the use of selected strains of bacteria in the subsurface to help treatment. Bacteria perform coupled oxidation/reduction reactions to live, and bioremediation exploits all these reactions to remove contaminants from groundwater. Aerobic bioremediation most commonly takes place in the presence of oxygen, and it is most effective in treating non-halogenated organic compounds. Anaerobic reductive bioremediation takes place in the absence of oxygen and promotes the bioreduction of oxidized contaminants such as chlorinated solvents.

Microbes or their enzymes may also effectively remediate toxic heavy metal contamination via their metal-resistance mechanisms, including the transformation of metals into less toxic species, biosorption to the cell wall, entrapment in extracellular capsules, or precipitation.

Nanotechnology is a multidisciplinary field that has gained significant momentum in recent years. The use of nanomaterials, such as zero-valent iron and carbon nanotubes, in the cleanup of groundwater is relatively new and has a great potential for providing efficient, cost-effective, and environmentally acceptable solutions to face the increasing requirements of stringent quality standards. The large surface area of these nanoparticles results in high sorption capacity, along with the ability to be functionalized for the enhancement of their affinity and selectivity. Nanoand microplastics have received widespread attention in recent years as they can sorb various organic contaminants.

Sabrina Saponaro, Snežana Maletić, Elena Sezenna 

Article

\title{
Hydrochemical Conditions for Aerobic/Anaerobic Biodegradation of Chlorinated Ethenes-A Multi-Site Assessment
}

\author{
Jan Němeček ${ }^{1,2, *}$, Kristýna Marková ${ }^{2}$, Roman Špánek ${ }^{2}$, Vojtěch Antoš ${ }^{2}$, Petr Kozubek ${ }^{1}$, \\ Ondřej Lhotský ${ }^{3,4}$ and Miroslav Černík ${ }^{2}$ \\ 1 ENACON s.r.o., Krčská 16, CZ-140 00 Prague 4, Czech Republic; kozubek@enacon.cz \\ 2 Institute for Nanomaterials, Advanced Technologies and Innovation, Technical University of Liberec, \\ Studentská 2, CZ-461 17 Liberec, Czech Republic; kristyna.markova2@tul.cz (K.M.); \\ roman.spanek@tul.cz (R.Š.); vojtech.antos@tul.cz (V.A.); miroslav.cernik@tul.cz (M.Č.) \\ 3 DEKONTA a.s., Volutová 2523, CZ-158 00 Prague 5, Czech Republic; lhotsky@dekonta.cz \\ 4 Faculty of Science, Charles University, Benátská 2, CZ-128 01 Prague 2, Czech Republic \\ * Correspondence: nemecek@enacon.cz or jan.nemecek1@tul.cz
}

Received: 3 December 2019; Accepted: 19 January 2020; Published: 22 January 2020

Abstract: A stall of cis-1,2-DCE and vinyl chloride (VC) is frequently observed during bioremediation of groundwater chloroethenes via reductive dechlorination. These chloroethenes may be oxidised by aerobic methanotrophs or ethenotrophs co-metabolically and/or metabolically. We assessed the potential for such oxidation at 12 sites ( 49 groundwater samples) using hydrochemical and molecular biological tools. Both ethenotroph ( $\mathrm{etnC}$ and $e t n E$ ) and methanotroph ( $m m o X$ and $p m o A$ ) functional genes were identified in $90 \%$ of samples, while reductive dehalogenase functional genes $(v c r A$ and $b v c A$ ) were identified in $82 \%$. All functional genes were simultaneously detected in $78 \%$ of samples, in actively biostimulated sites in $88 \%$ of samples. Correlation analysis revealed that cis-1,2-DCE concentration was positively correlated with $v c r A$, etnC and $\operatorname{etn} E$, while VC concentration was correlated with $\operatorname{etn} C$, $e t n E, v c r A$ and $b v c A$. However, feature selection based on random forest classification indicated a significant relationship for the $v c r A$ in relation to $c i s-1,2-\mathrm{DCE}$, and $v c r A, b v c A$ and $e t n E$ for VC and no prove of relationship between cis-1,2-DCE or VC and the methanotroph functional genes. Analysis of hydrochemical parameters indicated that aerobic oxidation of chloroethenes by ethenotrophs may take place under a range of redox conditions of aquifers and coincide with high ethene and VC concentrations.

Keywords: chlorinated solvents; biological reductive dechlorination; aerobic oxidation; qPCR; ethenotrophs; methanotrophs

\section{Introduction}

Chloroethene tetrachloroethene (PCE) and trichloroethene (TCE) are amongst the most abundant pollutants of groundwater and soil due to their frequent use in industrial applications. These pollutants can be biodegraded through natural or enhanced anaerobic reductive dechlorination, where chloroethenes serve as electron acceptors and molecular hydrogen and acetate, both released as by-products of organic substrate fermentation reactions, are used by the dechlorinating bacteria as electron donors and as carbon sources, respectively [1]. During this process, PCE is converted stepwise to TCE by removing one chlorine atom and replacing it with a hydrogen atom; likewise, trichloroethene (TCE), is primarily converted to cis-1,2-DCE, then to vinyl chloride (VC), and finally to ethene [2].

Anaerobic reductive dechlorination of chloroethenes is restricted to just a few bacterial genera (hereafter collectively referred to as anaerobic dechlorinators). Those capable of sequentially 
dechlorinating PCE or TCE down to cis-1,2-DCE include Dehalobacter [3,4], Dehalospirilum [5], Desulfuromonas [6,7], Geobacter [8], Sulfurospirrilium [9] and Desulfitobacterium [10]. Dehalococcoides mccartyi $[11,12]$ and Dehalogenimonas species [13] are anaerobic dechlorinators known to gain energy through dechlorination of DCE to VC and eventually to ethene using the reductive dehalogenase enzymes BvcA and VcrA [14] or similar ones in the case of Dehalogenimonas spp. Despite the presence of anaerobic dechlorinators, cis-1,2-DCE and VC often accumulate in groundwater as the sequential steps of the reductive dechlorination process are less and less favourable thermodynamically and kinetically [15], and/or the conditions for complete dechlorination are not always optimal.

Under aerobic conditions, chloroethenes can be oxidised both cometabolically and metabolically. During cometabolic oxidation, chloroethenes are only degraded into non-toxic end-products fortuitously when degrading enzymes are produced for degradation of bacterial growth substrates such as methane, ethene, ammonium or aromatic pollutants. Cometabolic degradation has been shown for all chloroethenes, though only rarely described for PCE [16]. Aerobic cometabolic oxidation is related to certain aerobic bacteria, such as ethene-oxidisers (etheneotrophs) and methane-oxidisers (methanotrophs) [17-19]. Methanotrops employ soluble and particulate methane monooxygenases (sMMO and pMMO, respectively) to oxidise methane as a primary growth substrate. Both sMMO and pMMO are also capable of fortuitous oxidation of chloroethenes. The sMMO have a broader substrate range than PMMO, and are more efficient at degrading chlorinated ethenes [20]. The gene mmoX, which encodes the sMMO $\alpha$ subunit, and $p m o A$, which encodes the $\mathrm{pMMO} \alpha$ subunit, are used as biomarkers of chloroethene cometabolic potential in groundwater [20-22].

Etheneotrophs can cometabolise VC and DCE when growing on ethene as a primary growth substrate, while several pure etheneotrophic strains, such as Mycobacterium and Nocardiodes, can also utilise $\mathrm{VC}$ as their sole carbon and energy source [18]. Etheneotrophs, when growing on ethene and $\mathrm{VC}$, express a soluble alkene monooxygenase (AkMO), transforming VC to epoxide chlorooxirane, which is further metabolised to 2-chloro-2-hydroxyethyl-CoM by epoxyalkane:coenzyme M transferase (EaCoMT) $[19,23]$. The genes etn $C$ and etnE encode the $\alpha$ subunit of AkMO and the EaCoMT, respectively, and serve as emerging biomarkers for ethenotroph-mediated aerobic biodegradation potential, though they do not distinguish between metabolic and cometabolic biodegradation pathways [20,24].

Two degradation pathways have been proposed as regards aerobic metabolic degradation of cis-1,2-DCE. Both of them involve degradation through monooxygenase-catalysed epoxidation [25], with the initial step catalysed by cytochrome P450 monooxygenase. Epoxides can be degraded subsequently either by epoxyalkane, coenzyme M transferase or through formation of glutathione conjugates $[26,27]$.

Only a few studies have focused on parallel presence of anaerobic dechlorinators and aerobic methanotrophs or ethenotrophs at contaminated sites. Liang et al. [20] studied the potential for VC degradation at six contaminated sites based on abundance and expression of VC biodegradation genes, and suggested that both ethenotrophs and anaerobic VC dechlorinators simultaneously contributed to VC biodegradation at the sites with high VC attenuation rates. Richards et al. [19] investigated spatial relationships between functional genes of ethenotrophs, anaerobic VC dechlorinators and methanotrophs in aquifer soil samples collected at a contaminated site, and found that functional genes of all the three bacterial guilds coexisted in $48 \%$ of the samples that appeared to be anaerobic.

These results attracted our interest to further assess the potential of using the alternate anaerobic/aerobic biodegradation of chloroethenes as a practical remedial tool, which can eliminate frequent accumulation of cis-1,2-DCE and VC in groundwater. The goal of this study is to investigate this potential of ongoing activities of both anaerobic and aerobic chloroethene degraders at a large number of remediated sites affected by biostimulation to different levels and to estimate limiting conditions for these microbial degradation processes. For such scanning, the qPCR data and hydrogeochemical parameters were analysed by advanced statistical methods. 


\section{Materials and Methods}

\subsection{Test Sites}

This study examined 35 sampling wells situated in 16 contaminanted groundwater plumes located at 12 different sites in the Czech Republic (some of the wells were sampled repeatedly, and, thus, 49 groundwater samples were analysed in total). Location and numbering of the sites are depicted in Figure 1. Out of the 16 contaminated groundwater plumes, 12 plumes were remediated using in situ biostimulation of anaerobic biodegradation prior to or over the course of the study. Cheese whey (either in liquid form, as supplied by the Diary Čejetičky spol. s.r.o., Czech Republic, or diluted dry whey supplied by Lacnea agri s.r.o., Czech Republic) was used as an electron donor in all bioremediated plumes. Amounts of whey applied to remedial wells were determined based on the local hydrogeological settings and the target TOC concentration in groundwater $>100 \mathrm{mg} / \mathrm{L}$. However, not all the wells in the remediated contaminated groundwater plumes were affected by the applied electron donor. Information on time of whey application to the respective wells (relative to the sampling date) are given in Table 2. Bioaugmentation was not performed at any of the tested sites. On three sites (\#2, \#3 and \#5), zero-valent iron (ZVI) was injected in a pilot scale either alone or together with the whey.

Groundwater samples were collected from shallow aquifers developed mainly in Quaternary fluvial sediments or in a sandy eluvium associated with the crystalline bedrock. Only one contaminant site (\#10) was related to a fractured rock aquifer.

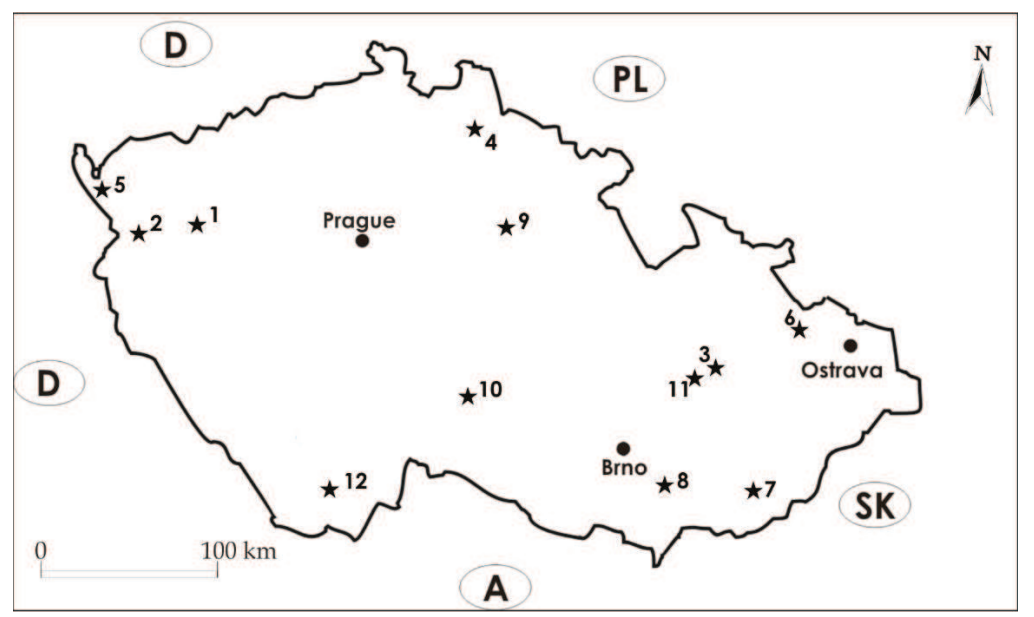

Figure 1. Location and numbering of contaminated sites tested in this study.

\subsection{Groundwater Sampling and Scope of Laboratory Analysis}

Before sampling, all wells were purged by pumping approximately three borehole casing volumes of groundwater using a Gigant submersible sampling pump (Ekotechnika, Czech Republic), according to standard procedure [28]. A range of field parameters ( $\mathrm{pH}$, oxidation-reduction potential (ORP), electrical conductivity and temperature) were recorded using a flow-through cell connected to a Multi 350i Multimeter (WTW, Germany). Samples for real-time PCR analyses were collected into $500 \mathrm{~mL}$ single-use, DNA free containers and transported together with the other samples to the laboratory within $24 \mathrm{~h}$.

Groundwater samples from all wells were analysed and monitored for the following parameters: chlorinated ethenes, ethene, ethane, methane, sulfate, hydrogen sulfide, nitrate, dissolved iron and 
manganese, total organic carbon (TOC), relative abundance of specific bacteria and functional genes using real-time PCR (see Sections 2.3 and 2.4).

\subsection{DNA Extraction and Real-Time Quantitative PCR}

Groundwater samples $(0.2-0.5 \mathrm{~L})$ were filtered through $0.22 \mu \mathrm{m}$ membrane filters (Merck Millipore, Darmstadt, Germany), after which DNA was extracted from the filters (with microorganisms) using the FastDNA Spin Kit for Soil (MP Biomedicals, Irvine, CA, USA), following the manufacturer's protocol. A Bead Blaster 24 homogenisation unit (Benchmark Scientific, Sayreville, NJ, USA) was employed for cell lysis, while the extracted DNA was quantified using a Qubit 2.0 fluorometer (Life Technologies, Carlsbad, CA, USA).

Real-time quantitative PCR (qPCR) analysis was performed in order to quantify $16 \mathrm{~S}$ rDNA of total bacteria (16S), the anaerobic dechlorinators Dehalobacter spp. (Dre), D. mccartyi (Dhc), Desulfitobacterium spp. (Dsb) and Dehalogenimonas spp. (Dhgm), and genes encoding for reductive dehalogenase $(v c r A$ and $b v c A)$, functional genes coding enzymes for ethenotroph-mediated aerobic biodegradation (i.e., alkene monooxygenase $(\operatorname{etn} C)$ and epoxyalkane, coenzyme $\mathrm{M}$ transferase $(e t n E)$ ) and functional genes for soluble methane monooxygenase $(\mathrm{mmoX})$ and particulate methane monooxygenase $(\mathrm{pmo} A)$ as biomarkers of methanotroph-mediated aerobic cometabolic biodegradation of chloroethenes. All primers used for qPCR are listed in Supplementary Table S1.

All qPCR assays were performed on a LightCycler ${ }^{\circledR} 480$ (Roche, Switzerland), using the same reaction conditions described in our previous study [29]. qPCR mixtures with a total volume of $10 \mu \mathrm{L}$ were prepared using LightCycler ${ }^{\circledR} 480$ SYBR Green I Master (Roche, Switzerland), 4 pmol of each primer (Generi Biotech, Czech Republic) and $1 \mu \mathrm{L}$ of template DNA. Each sample was analysed in duplicate in 96-well plates, including no-template controls. The qPCR thermal profile was $5 \mathrm{~min}$ at $95^{\circ} \mathrm{C}$ followed by 45 cycles at $95^{\circ} \mathrm{C}$ for $10 \mathrm{~s}, 68 / 60 / 55{ }^{\circ} \mathrm{C}$ for $15 \mathrm{~s}$, and $72{ }^{\circ} \mathrm{C}$ for $20 \mathrm{~s}$. Appropriate annealing temperatures are listed in Supplementary Table S1. To control the specificity of the qPCR amplification, a melting curve analysis $\left(72\right.$ to $98{ }^{\circ} \mathrm{C}$, ramp rate $\left.0.06{ }^{\circ} \mathrm{C} / \mathrm{s}\right)$ was performed at the end of each qPCR. The presence of PCR inhibitors was tested for in each DNA sample by serial dilution of DNA template. Detected $\mathrm{Ct}$ values were normalised to the filtration volume and sample dilution to get the final Cq values. qPCR amplification efficiency for each primer set was determined based on the slope of the curves constructed from a serial dilution of template DNA from five different environmental samples. Based on the approach used, the GPCR results were presented as relative abundances of the individual biomarkers.

\subsection{Physical and Chemical Parameters of the Groundwater}

Concentration of iron and manganese dissolved in groundwater were analysed using an Optima 2100 inductively coupled plasma-optical emission spectrometer (ICP-OES; Perkin Elmer, Waltham, MA, USA) according to ČSN EN ISO 11885 [30]. The groundwater samples were filtered through a $0.45 \mu \mathrm{m}$ membrane filter prior to analysis. Hydrogen sulfide was determined spectrophotometrically according to ČSN 83 0530-31 [31]. TOC was determined according to ČSN EN 1484 [32] using a MULTI N/C 2100S TOC analyser (Analytik Jena, Jena, Germany). Nitrate and sulfate were assessed using a ICS-90 ion chromatograph (Dionex, Sunnyvale, CA, USA) according to ČSN EN ISO 10304-1 [33]. Volatile organic carbons, including chlorinated ethenes, ethene, ethane and methane, were assessed using a Saturn 2200 CP 3800 gas chromatography-mass spectrometer (GC-MS; Varian, USA) using a VF-624ms column (Varian, Palo Alto, CA, USA), a CTC Combipal injector (CTC Analytics, Morrisville, NC, USA) and a headspace agitator.

\subsection{Data Analysis}

As an initial step, data below the limit of quantification (LOQ) were replaced with values equal to half of the LOQ of the respective method. Contents of individual chlorinated ethenes, ethene and ethane, in groundwater were converted from mass concentrations to molar concentrations. Dechlorination 
of the parent chlorinated ethenes PCE and TCE to less chlorinated forms and on to non-chlorinated ethenes through hydrogenolysis was assessed and expressed by the chlorine number ( $\mathrm{Cl}$ no.), i.e., the weighted average number of chlorine atoms per molecule of ethene [34]. Identification of prevailing redox processes was performed based a range of chemical criteria (Table 1).

Table 1. Water chemistry criteria for identifying redox processes in groundwater (modified from Chapelle et al. [35].

\begin{tabular}{|c|c|c|c|c|c|c|c|}
\hline & Predominant Redox Process & $\begin{array}{l}\mathrm{NO}_{3}^{-} \\
(\mathrm{mg} / \mathrm{L})\end{array}$ & $\begin{array}{c}\mathrm{Mn}^{2+} \\
(\mathrm{mg} / \mathrm{L})\end{array}$ & $\begin{array}{c}\mathrm{Fe}^{2+} \\
(\mathrm{mg} / \mathrm{L})\end{array}$ & $\begin{array}{l}\mathrm{SO}_{4}^{2-} \\
(\mathrm{mg} / \mathrm{L})\end{array}$ & $\mathrm{Fe} / \mathrm{H}_{2} \mathrm{~S}$ & $\begin{array}{c}\text { Methane } \\
(\mathrm{mg} / \mathrm{L})\end{array}$ \\
\hline Oxic & $\mathrm{O}_{2}$ reduction & - & $<0.05$ & $<0.1$ & - & - & - \\
\hline \multirow[t]{6}{*}{ Anoxic } & $\mathrm{NO}_{3}^{-}$reduction & $\geq 1.0$ & $<0.05$ & $<0.1$ & - & - & - \\
\hline & $\mathrm{Mn}(\mathrm{IV})$ reduction & $<1.0$ & $\geq 0.05$ & $<0.1$ & - & - & - \\
\hline & $\mathrm{Fe}(\mathrm{III})$ reduction & $<1.0$ & - & $\geq 0.1$ & $\geq 0.5$ & $>10$ & - \\
\hline & $\mathrm{Mix} \mathrm{Fe}(\mathrm{III}) / \mathrm{SO}_{4}{ }^{2-}$ reduction & $<1.0$ & - & $\geq 0.1$ & $\geq 0.5$ & $3-10$ & - \\
\hline & $\mathrm{SO}_{4}{ }^{2-}$ reduction & $<1.0$ & - & $\geq 0.1$ & $\geq 0.5$ & $<3$ & - \\
\hline & Methanogenesis & $<1.0$ & - & $\geq 0.1$ & $<0.5$ & - & $\geq 0.5$ \\
\hline
\end{tabular}

A final data set, used for further statistical analysis, was created by merging data for hydrochemical parameters and biomarker values.

All statistical analyses were performed in RStudio [36] and R software version 3.6.1 [37]. The relationship between gene abundance and hydrochemical parameters was tested using nonparametric Spearman's correlation [38]. The importance of feature selection attributes was assessed using the Boruta package [39], built on the random forest classification algorithm, which enables a search for significant and non-redundant variables. Biomarker abundance and field parameters were tested for outliers, with positive outliers treated by capping using inter quartile range (IQR = Q3 - Q1, where Q1, Q3 are 1st and 3rd quartile, respectively). Values that lay outside the $1.5 *$ IQR limits were replaced with 5th percentile. All values were subsequently log-transformed to achieve normality.

The whole dataset was also subjected to a cluster analysis with the ethenotroph functional genes $e t n C$ and $e t n E$ set as clustering variables. The dataset included field parameters $(\mathrm{pH}, \mathrm{ORP})$, parameters identifying redox processes, i.e., electron acceptors (nitrate, sulfate), and redox reaction products (iron, hydrogen sulfide, and methane), TOC, concentrations of chlorinated ethenes and their non-chlorinated metabolites ethene and ethane, and appropriate biomarkers (etnC, etnE, mmoX, pmoA, vcrA, bvcA, Dehalobacter spp., D. mccartyi, Desulfitobacterium spp., Dehalogenimonas spp.). Six sample clusters were identified representing groundwater samples with the highest and lowest abundance of $\operatorname{etn} C$ and $\operatorname{etn} E$, respectively. For each cluster, basic statistical parameters (maximum, mean, median, and minimum values) were calculated for the hydrochemical parameters. The prevailing redox processes assessed for each groundwater sample (see Section 3.1) were taken into account. Clustering of the final dataset was performed using the hierarchical clustering algorithm implemented by the hclust function in the $\mathrm{R}$ software package. The optimal number of clusters and the clustering algorithm were assessed using the clValid package [40].

\section{Results and Discussion}

\subsection{Results of Chemical Analyses}

For a full summary of the chemical analyses, see the supplementary material (Supplementary Table S2). As most samples in this study were collected from aquifers affected by historical or on-going remediation using biostimulation via delivery of organic carbon, the laboratory analysis revealed mostly anoxic redox processes. Ongoing methanogenesis was detected based on the applied criteria ( $\geq 0.5 \mathrm{mg} / \mathrm{L}$ of methane) in 30 of 49 groundwater samples analysed; however, strict methanogenesis was only detected in four samples, the remaining 26 samples displaying criteria for more than one 
redox process were, mostly including $\mathrm{Fe}(\mathrm{III})$ reduction (24 samples). Fe(III) reduction alone, or in combination with $\mathrm{Mn}(\mathrm{IV})$ or $\mathrm{NO}_{3}{ }^{-}$reduction, was only identified in nine samples.

With regard to concentrations of individual chloroethenes, the prevailing anoxic conditions, favourable for reductive dechlorination, resulted in sequential degradation of the parent contaminants (PCE and/or TCE) down to cis-1,2-DCE, VC and ethene. An average $\mathrm{Cl}$ no. of 1.5 indicated an advanced state of reductive dechlorination. In 11 of the 49 samples the $\mathrm{Cl}$ no. was even below 0.5 , showing almost complete dechlorination by biostimulation of anaerobic biodegradation performed at these sites.

In all the collected samples, cis-1,2-DCE was the dominant DCE isomer. The ratio of trans-1,2-DCE to cis-1,2-DCE was below $2.2 \%$ in all the samples (mean ratio $0.39 \%$ ) and concentrations of 1,1-DCE were similar to trans-1,2-DCE. Therefore, data for trans-1,2-DCE and 1,1-DCE were not included into the final data set for statistical analysis.

Of the 49 samples taken, 43 did not contain any other contaminants (in addition to chloroethenes) in significant concentrations (molar mass of the sum of co-contaminants below $2.5 \%$ of the molar mass of the sum of chloroethenes in the respective sample was used as the criterion). Six samples contained significant concentrations of co-occurring contaminants: at contaminated site \#6 (two samples), the main contaminants were chloroform and 1,2-dichloroethane, whereas toluene was the dominant contaminant in the samples collected at site \#12, although, historically, the site was dominantly contaminated by chloroethenes. Although co-occurring contaminants present in groundwater might affect both anaerobic reductive dechlorination and aerobic biodegradation, they were not included in the final data set for statistical analysis as their occurrence was limited and scattered.

Acetylene as an intermediate of abiotic $\beta$-elimination of chloroethenes [41] was detected in seven of the 49 samples taken. It was present at sites \#2, \#3 and \#5 where zerovalent iron materials were injected together with the whey in the past. It can be concluded that abiotic $\beta$-elimination has contributed to the degradation of chloroethenes at these sites.

For co-contaminants; trans-1,2-DCE and 1,1-DCE and acetylene concentrations, see the supplementary material (Supplementary Table S3).

\subsection{Results of $q P C R$}

qPCR revealed the frequent occurrence of both aerobic and reductive biomarkers. Presence of the ethenotroph functional genes $e t n C$ and $\operatorname{etn} E$ was confirmed in 44 of $49(90 \%)$ samples analysed, as were the methanotroph functional genes $m m o X$ and $p m o A$, while the reductive dehalogenase genes $v c r A$ and $b v c A$ were recorded in 40 of $49(82 \%)$ samples analysed (Table 2, Figure 2). All functional genes together (etnC, etnE, mmoX, pmoA, vcrA and $b v c A$ ) were detected in 38 of 49 (78\%) samples analysed, indicating that both aerobic oxidation and reductive dechlorination of chloroethenes may take place simultaneously at the same place or in close microenvironments. This finding is consistent with the study of Liang et al. [20], which detected functional genes from all three bacterial guilds (ethenotrophs, methanotrophs and reductive dechlorinators) in $99 \%$ of groundwater samples collected at six contaminated sites.

The qPCR results exhibited noticeable differences in individual biomarkers within one site or even one contaminant plume (e.g., aerobic biomarkers in contaminant plume \#10_1 or reductive biomarkers in contaminant plume \#1_1; see Table 2).

Of the 49 analysed samples, 16 were collected during the on-going remedial biostimulation (samples were collected 1 to 4 months after the last whey application, see column 6 in Table 2). Despite the fact that application of whey stimulates reductive dechlorination, all functional genes $(\operatorname{etn} C$, etnE, $m m o X, p m o A, v c r A$ and $b v c A)$ coexisted in 14 of the $16(88 \%)$ samples.

Of the anaerobic dechlorinators, Desulfitobacterium spp. were most frequent, being present in 47 of 49 samples (96\%), while D. mccartyi and Dehalogenimonas spp. were identified in 46 of 49 analysed samples (94\%). The occurrence of D. mccartyi and Dehalogenimonas spp. corresponded well with Dehalobacter spp. (see correlation analysis in Section 3.3), though the latter were only identified in $74 \%$ of samples. The lower incidence of Dehalobacter spp. in groundwater samples may reflect the fact that 
Water 2020, 12, 322

Dehalobacter spp. degrade the parent chlorinated compounds PCE and TCE [3,42], which were mostly degraded to less chlorinated metabolites at the sites tested. Frequent detection of Dehalogenimonas spp. in our samples (94\%) is consistent with the findings of Yang et al. [13], who detected Dehalogenimonas spp. in $81 \%$ of 1173 samples collected in the United States and Australia.

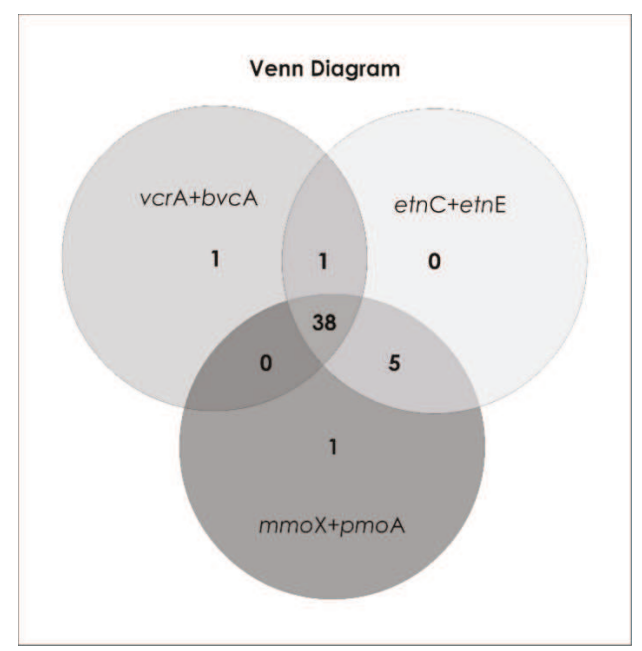

Figure 2. Venn diagram showing the numbers of groundwater samples where functional gene groups were found individually or jointly (value of $\mathrm{Cq}=40$ was used as the detection limit, see Section 2.3 for more information). 
Table 2. Summary of qPCR results (samples are identified based on the well number and time (after underline), site ID refers to Figure 1, plume ID is related to the site ID, and in case that the well was affected by whey application, the time interval is mentioned, for abbreviations see text in Section 2.3).

Date of Affected by Whey Time Elapsed after

Affected by Whey Time Elapsed after Total

Reductive Biomarkers

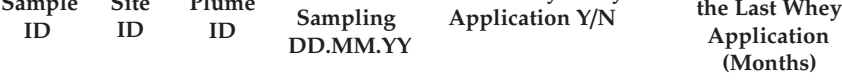

Dehalogenase Reductive Dechlorinators

Genes

Reductive Dechlorinators

\begin{tabular}{cccccc}
\hline AT-15 & 1 & $1 \_1$ & 24.01 .19 & $\mathrm{Y}$ & 1 \\
\hline AT-19 & 1 & $1 \_1$ & 01.05 .19 & $\mathrm{~N}$ & NA \\
\hline AT-20 & 1 & $1 \_1$ & 01.05 .19 & $\mathrm{~N}$ & NA \\
\hline AT-21 & 1 & $1 \_1$ & 01.05 .19 & $\mathrm{~N}$ & NA \\
\hline SV-10 & 2 & $2 \_1$ & 24.01 .19 & $\mathrm{Y}^{*}$ & 8 \\
\hline VS-5 & 2 & $2 \_1$ & 24.01 .19 & $\mathrm{Y}^{*}$ & 8 \\
\hline A_I. & 3 & $3 \_1$ & 04.02 .19 & $\mathrm{~N}$ & NA \\
\hline B_IV & 3 & $3 \_1$ & 04.02 .19 & $\mathrm{~N}^{*}$ & NA
\end{tabular}

$\infty$

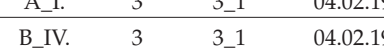

\begin{tabular}{llll} 
SM-7D & 3 & $3 \_2$ & 04.02 .19 \\
\hline V $-75-1$ & 3 & $3 \_3$ & 18.07 .17
\end{tabular}

\begin{tabular}{llll}
\hline VS-7S_1 & 3 & $3 \_3$ & 18.07 .17 \\
\hline VS-7S _ 2 & 3 & 33 & 13.10 .17
\end{tabular}

\begin{tabular}{rrrr} 
VS-7S_3 & 3 & $3 \_3$ & 12.02 .18 \\
\hline
\end{tabular}

\begin{tabular}{llll}
\hline VS-7S_4 & 3 & $3 \_3$ & 26.03 .18 \\
\hline VS-7S_5 & 3 & $3 \_3$ & 04.02 .19
\end{tabular}

\begin{tabular}{llll} 
VS-7S_5 & 3 & $3 \_3$ & 04.02 .19 \\
\hline Studna_1 & 3 & $3 \_3$ & 18.07 .17
\end{tabular}

\begin{tabular}{llll}
\hline Studna_2 & 3 & $3 \_3$ & 13.10 .17 \\
\hline
\end{tabular}

\begin{tabular}{lrrr} 
Studna_3 & 3 & $3 \_3$ & 12.02 .18 \\
\hline Studna_4 & 3 & $3 \_$ & 26.03 .18
\end{tabular}

\begin{tabular}{llll} 
Studna_4 & 3 & $3 \_3$ & 26.03 .18 \\
\hline SM-8_1 & 3 & $3 \_3$ & 18.07 .17
\end{tabular}

\begin{tabular}{llll}
\hline SM-8_2 & 3 & $3 \_3$ & 13.10 .17 \\
\hline SM-8 3 & 3 & $3 \_3$ & 12.02 .18
\end{tabular}

\begin{tabular}{llll}
\hline SM-8_4 & 3 & $3 \_3$ & 26.03 .18 \\
\hline
\end{tabular}

\begin{tabular}{ccccccccccc}
\hline $16 \mathrm{~S}$ & $e t n C$ & $e t n E$ & $m m o X$ & $p m o A$ & $b v c A$ & $v c r A$ & Dhc & Dhgm & Dsb & Dre \\
+++ & + & ++ & + & + & +++ & +++ & +++ & +++ & + & + \\
+++ & ++ & +++ & + & ++ & ++ & ++ & ++ & ++ & ++ & + \\
++ & ++ & +++ & + & + & ND & + & + & ND & ++ & ND \\
++ & ++ & ++ & ++ & ++ & +- & + & + & ++ & + & +- \\
+++ & ++ & +++ & + & + & + & ++ & + & +- & +++ & ND \\
+++ & +++ & +++ & + & + & + & + & + & + & ++ & +- \\
+ & ND & ND & ND & ND & ND & + & + & + & + & ND \\
+ & ND & ND & ND & ND & ND & + & ND & ND & ++ & ND \\
+++ & ++ & ++ & + & + & +++ & +++ & +++ & +++ & +++ & +++ \\
+++ & + & + & ++ & ++ & + & ++ & + & ++ & ++ & + \\
+++ & + & + & ++ & +++ & +++ & +++ & +++ & +++ & ++ & ++ \\
++ & ++ & ++ & + & ++ & +++ & +++ & +++ & +++ & ++ & + \\
++ & ++ & ++ & ++ & ++ & +++ & +++ & +++ & +++ & ++ & + \\
+++ & + & + & + & ND & ++ & +++ & +++ & +++ & +++ & + \\
++ & ++ & ++ & + & + & ++ & ++ & ++ & ++ & + & + \\
++ & + & + & + & + & +++ & +++ & +++ & +++ & ++ & ++ \\
+++ & + & + & + & + & ++ & +++ & +++ & ++ & + & ++ \\
+++ & + & + & + & + & ++ & +++ & +++ & ++ & + & + \\
++ & ++ & ++ & ++ & ++ & +++ & +++ & +++ & +++ & ++ & ++ \\
+++ & ++ & ++ & + & + & +++ & +++ & +++ & +++ & ++ & +++ \\
+++ & ++ & ++ & ++ & +++ & ++ & +++ & +++ & +++ & ++ & ++ \\
++ & ++ & ++ & +++ & +++ & ++ & +++ & +++ & ++ & ++ & ++ \\
\hline++
\end{tabular}


Table 2. Cont. Sample Site Plume $\begin{gathered}\text { Date of } \\ \text { Sampling }\end{gathered} \quad \begin{gathered}\text { Affected by Whey } \\ \text { Application } \mathrm{Y} / \mathrm{N}\end{gathered} \quad \begin{gathered}\text { Time Elapsed after } \\ \text { the Last Whey }\end{gathered}$ the Last Whey
Application Application
(Months)

Reductive Biomarkers

VC Reductive Reductive Dechlorinators Aerobic Biomarker Reductive Dechlorinators

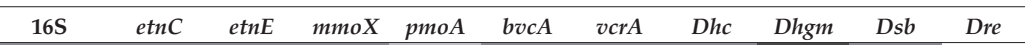

\begin{tabular}{|c|c|c|c|c|c|c|c|c|c|c|c|c|c|c|c|c|}
\hline & & & & & & 165 & $\operatorname{etn} \mathrm{C}$ & etnE & mmox & pmoA & $b v c A$ & $v c r A$ & Dhc & Dhgm & Dsb & Dre \\
\hline AP-2 & 4 & $4 \_1$ & 05.02.19 & Y & 28 & ++ & ++ & ++ & ++ & + & ++ & ++ & ++ & +++ & ++ & ND \\
\hline HV-16 & 4 & 4_1 & 09.04.19 & $\mathrm{N}$ & NA & ++ & +- & + & ++ & +++ & ++ & ++ & ++ & + & + & +- \\
\hline HV-25 & 4 & $4 \_1$ & 09.04.19 & $\mathrm{Y}$ & 50 & ++ & + & + & ++ & ++ & ++ & ++ & ++ & ++ & + & + \\
\hline HV-8_1 & 4 & 4_1 & 03.08.16 & Y & 50 & ++ & + & ++ & +++ & +++ & +++ & ++ & ++ & ++ & + & + \\
\hline HV-8_2 & 4 & $4 \_1$ & 10.10 .16 & $\mathrm{Y}$ & 1 & +++ & + & ++ & +++ & +++ & +++ & +++ & +++ & ++ & ++ & + \\
\hline HV-8_3 & 4 & $4 \_1$ & 16.01.17 & $\mathrm{Y}$ & 3 & ++ & + & + & +++ & +++ & ++ & ++ & ++ & + & ++ & +- \\
\hline HML-4S_1 & 4 & $4 \_1$ & 03.08 .16 & $\mathrm{Y}$ & 50 & ++ & + & + & + & + & ++ & ++ & ++ & +++ & ++ & + \\
\hline HML-4S_2 & 4 & $4 \_1$ & 10.10 .16 & Y & 1 & ++ & + & + & + & ++ & ++ & +++ & +++ & ++ & ++ & + \\
\hline HML-4S_3 & 4 & 4_1 & 16.01.17 & $\mathrm{Y}$ & 3 & ++ & ++ & ++ & ++ & ++ & ++ & ++ & ++ & ++ & ++ & + \\
\hline HV-53D & 4 & $4 \_2$ & 09.04.19 & Y & 30 & ++ & + & ++ & + & ++ & ++ & ++ & ++ & ++ & ++ & + \\
\hline V-5 & 5 & 5_1 & 22.01.19 & $\mathrm{Y}$ & 3 & +++ & + & ++ & + & + & ++ & +++ & +++ & ++ & ND & + \\
\hline V-11 & 5 & 5_1 & 22.01.19 & Y & 3 & +++ & + & + & + & + & + & ND & + & ++ & +++ & + \\
\hline V-13 & 5 & 5_2 & 22.01.19 & $Y^{*}$ & 3 & +++ & + & ND & + & + & ND & ++ & + & + & +++ & + \\
\hline SV-1 & 5 & $5 \_2$ & 22.01 .19 & $\mathrm{~N}$ & $\mathrm{NA}$ & ++ & ++ & + & + & ++ & ++ & ++ & ++ & ++ & ++ & ND \\
\hline HJ-4 & 6 & $6 \_1$ & 29.01.19 & $\mathrm{N}$ & NA & ++ & + & ++ & + & + & ND & ND & ND & +- & + & ND \\
\hline V-32 & 6 & 6_1 & 29.01.19 & $\mathrm{N}$ & NA & +++ & ++ & ++ & + & + & ND & + & +- & + & ++ & ND \\
\hline $\begin{array}{c}\text { MV - } \\
6 \mathrm{~A}\end{array}$ & 7 & 7_1 & 20.02 .19 & Y & 34 & + & +- & +- & + & + & + & + & + & ++ & + & ND \\
\hline$Z-4$ & 7 & 7_1 & 20.02 .19 & $\mathrm{Y}$ & 34 & ++ & ++ & ++ & ++ & ++ & ++ & ++ & ++ & ++ & + & ND \\
\hline Žd - 2 & 8 & 8_1 & 20.02.19 & $\mathrm{Y}$ & 26 & +++ & +++ & +++ & +++ & +++ & ++ & +++ & +++ & +++ & ++ & ++ \\
\hline Žd - 4 & 8 & 8_1 & 20.02 .19 & Y & 26 & +++ & +++ & +++ & ++ & +++ & +++ & +++ & +++ & ++ & +++ & +++ \\
\hline MR 4 & 9 & 9_1 & 21.02 .19 & Y & 50 & ++ & + & + & ++ & + & ++ & ++ & ++ & ++ & ++ & + \\
\hline
\end{tabular}


Table 2. Cont.

\begin{tabular}{|c|c|c|c|c|c|c|c|c|c|c|c|c|c|c|c|c|}
\hline \multirow{3}{*}{$\begin{array}{l}\text { Sample } \\
\text { ID }\end{array}$} & \multirow{3}{*}{$\begin{array}{l}\text { Site } \\
\text { ID }\end{array}$} & \multirow{3}{*}{$\begin{array}{l}\text { Plume } \\
\text { ID }\end{array}$} & \multirow{3}{*}{$\begin{array}{c}\text { Date of } \\
\text { Sampling } \\
\text { DD.MM.YY }\end{array}$} & \multirow{3}{*}{$\begin{array}{l}\text { Affected by Whey } \\
\text { Application } \mathrm{Y} / \mathrm{N}\end{array}$} & \multirow{3}{*}{$\begin{array}{l}\text { Time Elapsed after } \\
\text { the Last Whey } \\
\text { Application } \\
\text { (Months) }\end{array}$} & \multirow{3}{*}{$\begin{array}{c}\begin{array}{c}\text { Total } \\
\text { Bacteria }\end{array} \\
16 \mathrm{~S}\end{array}$} & \multirow{2}{*}{\multicolumn{4}{|c|}{ Aerobic Biomarkers }} & \\
\hline & & & & & & & & & & & \multicolumn{2}{|c|}{$\begin{array}{c}\text { VC Reductive } \\
\text { Dehalogenase } \\
\text { Genes }\end{array}$} & \multicolumn{4}{|c|}{ Reductive Dechlorinators } \\
\hline & & & & & & & $e \operatorname{tn} C$ & etnE & $\operatorname{mmoX}$ & pmoA & bvcA & vcrA & Dhc & Dhgm & $D s b$ & Dre \\
\hline ZMS 4 & 9 & 9_1 & 21.02 .19 & $\mathrm{Y}$ & 9 & ++ & + & ++ & +++ & +++ & ++ & ++ & ++ & ++ & ++ & ND \\
\hline HLV-5 & 10 & 10_1 & 04.03 .19 & $\mathrm{~N}$ & $\mathrm{NA}$ & +++ & + & ++ & +++ & ++ & ND & ++ & ++ & ++ & ++ & + \\
\hline HV-26 & 10 & 10_1 & 04.03 .19 & $\mathrm{~N}$ & $\mathrm{NA}$ & + & ND & ND & ND & ND & ND & ND & ND & ND & + & ND \\
\hline ID-2 & 11 & 11_1 & 05.03 .19 & $\mathrm{~N}$ & NA & + & ND & ND & ND & ND & + & + & + & + & ND & ND \\
\hline $\mathrm{HV}-223$ & 12 & $12 \_1$ & 09.05 .19 & $\mathrm{Y}$ & 2 & +++ & + & ++ & +++ & +++ & +++ & +++ & +++ & ++ & ++ & ++ \\
\hline HV-112 & 12 & $12 \_1$ & 09.05 .19 & $\mathrm{Y}$ & 2 & +++ & + & +- & +++ & +++ & +++ & ++ & ++ & ++ & ++ & + \\
\hline
\end{tabular}

Legend: *affected by application of ZVI

+++ high quantity

++ medium quantily

$\begin{array}{ll}+ & \text { low quantity } \\ \text { +- } & \text { close to the }\end{array}$ 


\subsection{Correlation and Feature Selection Analysis}

Correlation analysis (Figure 3) revealed that TCE was only correlated with Desulfitobacterium spp., probably as none of the enzymes tested related to the reductive or aerobic functional genes participating in biodegradation of TCE. However, cis-1,2-DCE was positively correlated with both the reductive functional gene $v \operatorname{cr} A$ and the ethenotroph functional genes $\operatorname{etn} C$ and $\operatorname{etn} E$, as well as the reductive dechlorinators Dehalogenimonas spp. and Desulfitobacterium spp. Similarly, VC concentration was positively correlated to the ethenotroph functional genes $\operatorname{etn} C$ and $\operatorname{etn} E$ and the reductive dehalogenase genes vcrA and bvcA, as well as the reductive dechlorinators D. mccartyi and Dehalogenimonas spp. The positive correlation of cis-1,2-DCE and VC to abundance of Dehalogenimonas spp., whose ability to degrade cis-1,2-DCE and VC was only recently confirmed by Yang et al. [13], indicates a potentially notable contribution of Dehalogenimonas spp. in reductive dechlorination at the sites tested.

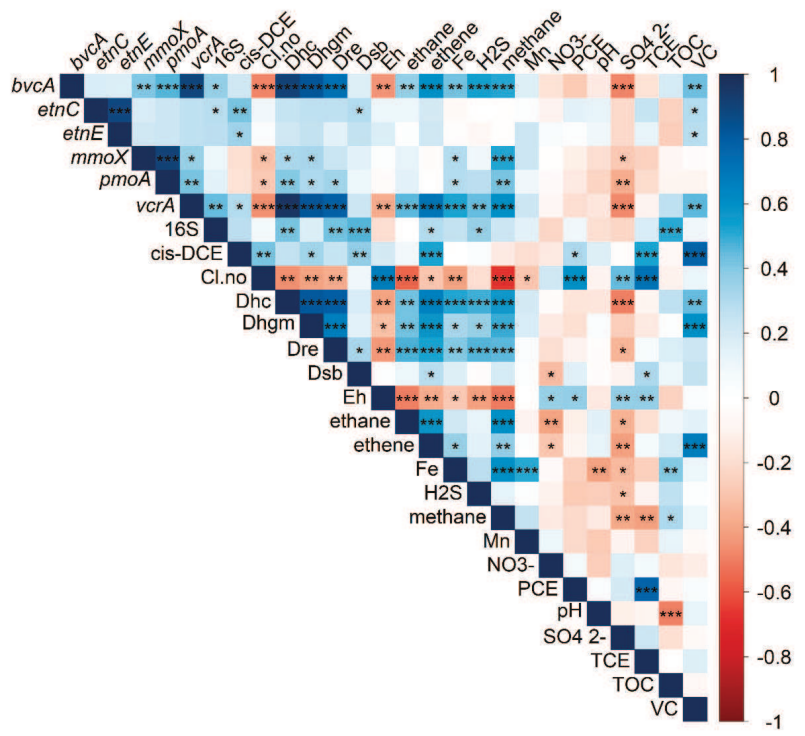

Figure 3. Results of Spearman correlation analysis (intensities of blue and red colours indicate values of positive and negative correlation coefficients, respectively; $p$-values: ${ }^{* * *}=0.001,{ }^{* *}=0.01,{ }^{*}=0.05$ ).

None of the chlorinated ethenes were correlated with the methanotroph functional genes $m m o X$ and $p m o A$.

In sum, it implies that both anaerobic reductive dechlorination and ethenotroph-mediated aerobic biodegradation could participate in biodegradation of VC and cis-1,2-DCE.

With regard to the correlation of individual functional genes with hydrochemical and field parameters, the reductive dehalogenase genes $v c r A$ and $b v c A$ were negatively correlated with ORP and sulfate and positively correlated with dissolved iron, hydrogen sulfide and methane. As has been previously noted, anaerobic reductive dechlorination of chloroethenes can occur under both nitrate-reducing and iron-reducing conditions, though the most favourable conditions for anaerobic dechlorinators are sulfate reducing and methanogenic [43]. This is also supported by a strong negative correlation of $\mathrm{Cl}$ no. with methane and positive correlation of $\mathrm{Cl}$ no. with sulfate. The methanotroph functional genes mmoX and $p m o A$ were positively correlated with dissolved iron and methane, while pmoA was negatively correlated with sulpfate. There was no correlation observed between the ethenotroph functional genes $e t n C$ and $e t n E$ and any hydrochemical and/or field parameters, suggesting that hydrochemical conditions of aquifers are not limiting factors for proliferation of ethenotrophs. 
The significance of individual cis-1,2-DCE and VC biodegradation processes was assessed using feature selection utilising the random forest classification algorithm. Only the reductive dehalogenase gene $v c r A$ exhibited significant relevance for cis-1,2-DCE (Figure 4), whereas both reductive dehalogenase genes $(v \mathrm{cr} A$ and $b v c A)$ and the ethenotroph functional gene $\operatorname{etn} E$ were significantly relevant for VC (Figure 5). In sum, feature selection provided further support for the hypothesis that both reductive dechlorinators and ethenotrophs participate in biodegradation of VC at the sites tested; however, it indicated that there was only intermediate significant involvement of ethenotrophs in biodegradation of cis-1,2-DCE.

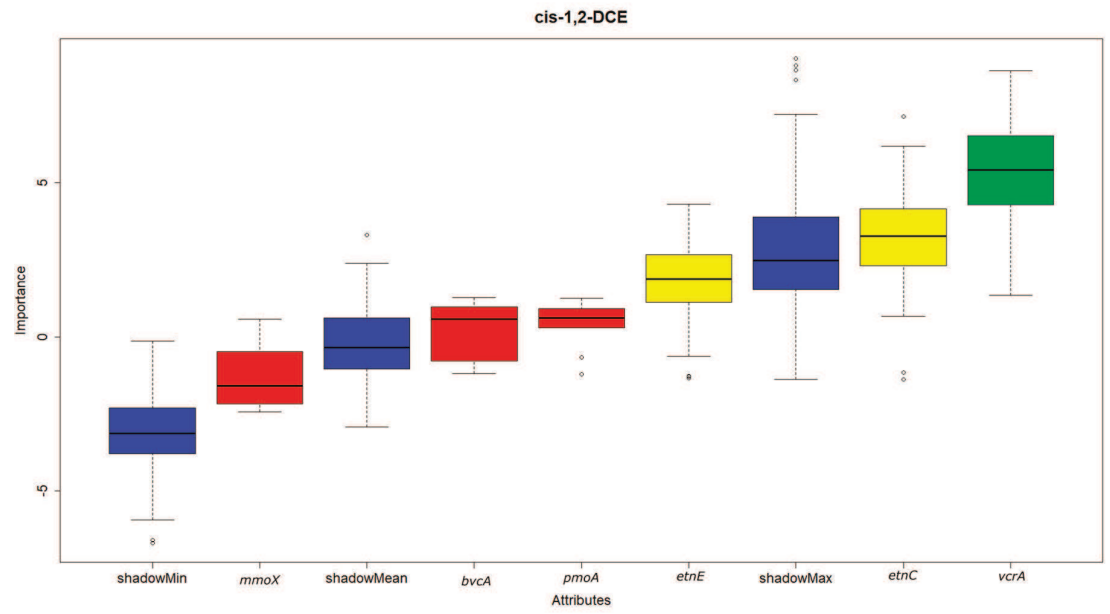

Figure 4. Importance of individual biomarkers on concentration of cis-1,2-DCE, based on the Boruta algorithm utilising the random forest classification. Green indicates significant attributes, yellow indicates attributes of intermediate significance while red indicates attributes that are not significant (blue colour indicates shadows-Boruta auxiliary features used for selection of significant attributes).

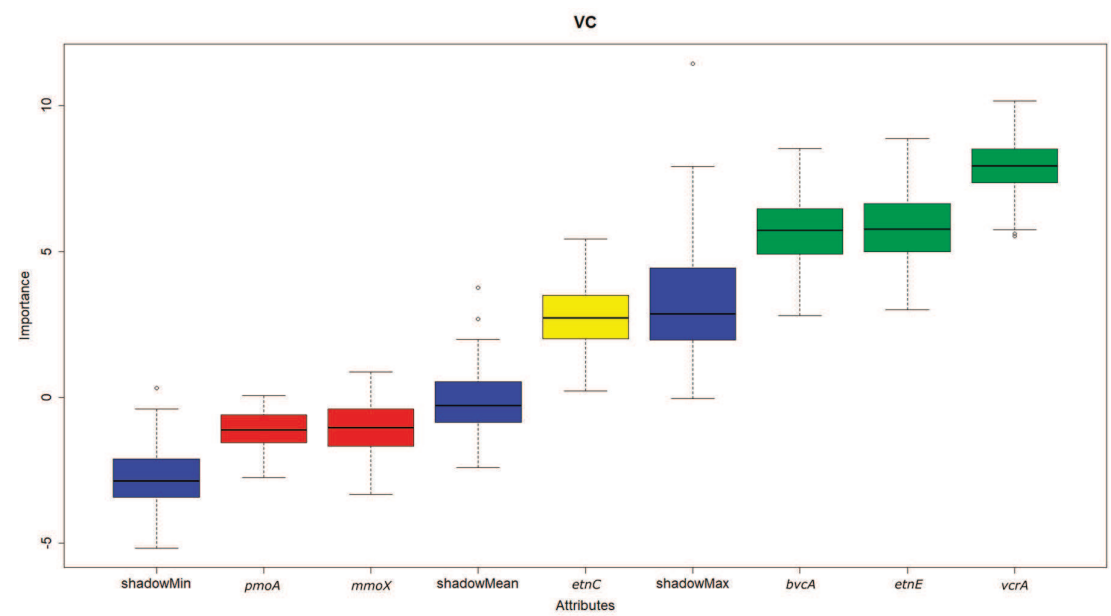

Figure 5. Importance of individual biomarkers on concentration of VC, based on the Boruta algorithm utilising the random forest classification. Green indicates significant attributes, yellow indicates attributes of intermediate significance while red indicates attributes that are not significant (blue colour indicates shadows-Boruta auxiliary features used for selection of significant attributes). 


\subsection{Hydrochemical Conditions for Aerobic Oxidation}

As aerobic (both metabolic and co-metabolic) oxidation processes in remedial practice can overcome a frequent accumulation of metabolites cis-1,2-DCE and VC generated during in-situ anaerobic reductive bioremediation, the hydrochemical conditions for these processes were assessed. First, the whole dataset was subjected to cluster analysis with the ethenotroph functional genes etn $C$ and $e t n E$ set as clustering variables. Six sample clusters were identified, with clusters \#1 and \#6 representing groundwater samples with the highest and lowest abundance of $e \operatorname{tnC}$ and $\operatorname{etnE}$, respectively. The basic statistical parameters (maximum, mean, median, and minimum values) calculated for the hydrochemical parameters for each cluster are given in graphs in the supplementary material (Supplementary Figure S1). The prevailing redox processes assessed for each groundwater sample (see Section 3.1) are given in Supplementary Table S2.

Cluster \#1, which represented the highest potential for aerobic oxidation, was comprised of three groundwater samples collected from two sites. Redox conditions were mixed, covering a wide spectrum of processes from $\mathrm{Fe}(\mathrm{III})$ reduction (iron mean concentration $33.38 \mathrm{mg} / \mathrm{L}$ ) to methanogenic (methane mean concentration $7.8 \mathrm{mg} / \mathrm{L}$ ). The groundwater samples in cluster \#1 differed from those in the other clusters, mainly in higher concentrations of VC (mean 10,314 $\mu \mathrm{g} / \mathrm{L}$ ) and of ethene (mean $4534 \mu \mathrm{g} / \mathrm{L})$.

In comparison, cluster \#6 comprised groundwater samples with lowest potential for aerobic oxidation and included 28 samples collected at eight sites. With regards to redox conditions, cluster \#6 contained samples with $\mathrm{Mn}(\mathrm{VI})$ reduction and $\mathrm{Fe}(\mathrm{III})$ reduction predominating, along with samples of mixed redox categories, covering $\mathrm{Mn}(\mathrm{VI})$ reduction down to methanogenic conditions. Mean iron and methane concentrations for cluster \#6 were 15.8 and $3.5 \mathrm{mg} / \mathrm{L}$, respectively. Groundwater samples in this cluster contained significantly lower concentrations of VC (mean $276 \mu \mathrm{g} / \mathrm{L}$ ) and ethene (mean $344 \mu \mathrm{g} / \mathrm{L}$ ); however, the degree of chloroethene dechlorination $(\mathrm{Cl}$ no.) was similar to that of cluster \#1 (mean $\mathrm{Cl}$ no. cluster \#1 = 1.5, cluster \#6 = 1.4). This indicates that aerobic oxidation of chloroethenes can take place in aquifers under a range of redox conditions, including apparently reducing environments. The most likely explanation is that the studied aquifers are not homogenous environments with one redox state only, but highly spatially and temporally heterogenous macro- and microenvironments with different redox conditions. Spatial heterogeneities may be a result of different lithology and permeability that influence migration patterns of organic substrates (electron donors), dissolved oxygen, chloroethenes and their co-occurring contaminants. This explanation is supported by the results of hotspot high-resolution characterisation performed on sites \#2, \#3, \#5, \#6, \#7, \#8 and 11 using a membrane interface probe (MIP) (Geoprobe Systems ${ }^{\circledR}$, Salina, KS, USA). MIP was used for collection of semi-quantitative data on the presence of volatile organic compounds (VOCs) and soil electric conductivity measurements indicating aquifer lithology in the vertical soil profile. MIP profiles (data not shown) from majority of the sites show presence of soil layers with different electric conductivities and levels of contamination (i.e., distinct lithological and contamination heterogeneity).

Temporal changes may result from irregular seepage of oxic rainwater, groundwater level fluctuations, and/or from discontinuous application of organic substrates at the bioremediated sites. Methanotrophs are found mainly at aerobic/anaerobic interfaces in soil and aquatic environments that are crossed by methane [44], thus inhabiting environments with low oxygen level. Similarly, ethenotrophs can survive in environments with very limited oxygen contents $[17,45,46]$. These macroand microheterogeneities and abilities of aerobic ethenotrophs to sustain low levels of oxygen are reasons for their occurrence in anaerobic aquifers containing anaerobic dechlorinators. Co-occurrence of anaerobic dechlorinators and VC assimilating bacteria was revealed also in groundwater samples from other sites [20,29], in discrete aquifer soil samples [19] as well as in surface riverbed sediment samples [47] where the TOC content in soil was found to be the critical parameter determining the dominant degradation pathway [48].

The results also suggest that high concentrations of ethene and VC (as electron donors in aerobic oxidation of chloroethenes) are correlated with the abundance of ethenotrophs. This is also supported 
by the results of correlation analysis, which indicated a positive correlation between VC and the ethenotroph functional genes $\operatorname{etn} C$ and $\operatorname{etn} E$.

\section{Conclusions}

The aim of this study is to assess the potential for aerobic oxidation of chlorinated ethenes at contaminated sites and to characterise those conditions favourable for aerobic biodegradation of VC and cis-1,2-DCE.

The main findings of this study are as follows:

1. Both the ethenotroph functional genes $e t n C$ and $e t n E$ and methanotroph functional genes $m m o X$ and $p m o A$ were identified in $90 \%$ of groundwater samples, while all functional genes $(e t n C$, etnE, $m m o X, p m o A, v c r A$ and $b v c A$ ) coexisted in $78 \%$ of samples, in actively biostimulated sites in $88 \%$ of samples.

2. The reductive dechlorinator Dehalogenimonas spp., only recently identified as capable of $c i s-1,2-\mathrm{DCE}$ and VC degradation, was detected by qPCR in $94 \%$ of samples. A positive correlation between Dehalogenimonas spp. abundance and cis-1,2-DCE and VC concentration indicates a potential contribution to reductive dechlorination at the sites tested.

3. Presence of both cis-1,2-DCE and VC was positively correlated with the reductive functional gene $v c r A$, and the ethenotroph functional genes $\operatorname{etn} C$ and $\operatorname{etn} E$, and VC additionally with the reductive functional gene $b v c A$.

4. Of all the functional genes tested, only the reductive dehalogenase functional gene vcrA was found to be significant for cis-1,2-DCE degradation by feature selection using the random forest algorithm. On the hand, both the dehalogenase functional genes $v c r A$ and $b v c A$ and the ethenotroph functional gene etnE were indicated as significant for VC.

5. No significant relationship was observed between cis-1,2-DCE and VC concentration and abundance of the methanotroph functional genes $m m o X$ and $p m o A$, because methanotrophs oxidise these contaminants cometabolically only, without any energetic benefit.

6. Cluster analysis revealed that aerobic oxidation of chloroethenes can take place under a broad range of apparent redox conditions, even under apparently methanogenic conditions, probably due to a high redox microheterogeneity of the aquifer environment, ability of ethenotrophs to survive in environments with very limited oxygen contents and high concentrations of ethene and VC (as electron donors in aerobic oxidation of chloroethenes), these being the most important hydrochemical parameters affecting abundance of ethenotrophs.

The results of this study demonstrate the potential for incorporating aerobic steps in in-situ bioremediation schemes for treatment of chloroethenes, especially when temporal stalls in carcinogenic VC may cause an on-site human health risk.

Supplementary Materials: The following are available online at http://www.mdpi.com/2073-4441/12/2/322/s1, Table S1: Primers used in qPCR, Table S2: Hydrochemical data and assessment of predominant redox processes, Table S3: Concentrations of volatile organic compounds and acetylene in groundwater, Figure S1: Graphs of hydrochemical and molecular biological data for each cluster of groundwater samples.

Author Contributions: Conceptualization, J.N.; methodology, J.N. and K.M.; Investigation, P.K. and O.L.; Laboratory analyses, V.A. and K.M.; data curation, J.N., R.Š. and K.M.; Writing—original draft preparation, J.N.; Writing-review and editing, M.Č., K.M. and O.L. All authors have read and agreed to the published version of the manuscript.

Funding: This research was funded by the Technology Agency of the Czech Republic, grant number TH04030225.

Acknowledgments: The authors acknowledge the assistance provided by Research Infrastructure NanoEnviCz (Project no. LM2015073), supported by the Ministry of Education, Youth and Sports of the Czech Republic.

Conflicts of Interest: The authors declare no conflict of interest. 


\section{References}

1. Bradley, P.M.; Chapelle, F.H. In Situ Remediation of Chlorinated Solvent Plumes; Stroo, H., Ward, C., Eds.; Springer: New York, NY, USA, 2010; Chapter 3; pp. 39-67. ISBN 978-1-4419-1400-2.

2. Stroo, H.F.; West, M.R.; Kueper, B.H.; Borden, R.C.; Major, D.W.; Ward, C.H. Chlorinated Solvent Source Zone Remediation; Kueper, B.H., Stroo, H.F., Vogel, C.M., Ward, C.H., Eds.; Springer: New York, NY, USA, 2014; Chapter 12; pp. 395-457. ISBN 978-1-4614-6921-6.

3. Holliger, C.; Hahn, D.; Harmsen, H.; Ludwig, W.; Schumacher, W.; Tindall, B.; Vazquez, F.; Weiss, N.; Zehnder, A.J. Dehalobacter restrictus gen. nov. and sp. nov., a strictly anaerobic bacterium that reductively dechlorinates tetra-and trichloroethene in an anaerobic respiration. Arch. Microbiol. 1998, 169, 313-321. [CrossRef] [PubMed]

4. Holliger, C.; Schraa, G.; Stams, A.; Zehnder, A. A highly purified enrichment culture couples the reductive dechlorination of tetrachloroethene to growth. Appl. Environ. Microbiol. 1993, 59, 2991-2997. [CrossRef]

5. Neumann, A.; Scholz-Muramatsu, H.; Diekert, G. Tetrachloroethene metabolism of Dehalospirillum multivorans. Arch. Microbiol. 1994, 162, 295-301. [CrossRef] [PubMed]

6. Krumholz, L.R.; Sharp, R.; Fishbain, S.S. A freshwater anaerobe coupling acetate oxidation to tetrachloroethylene dehalogenation. Appl. Environ. Microbiol. 1996, 62, 4108-4113. [CrossRef] [PubMed]

7. Sung, Y.; Ritalahti, K.M.; Sanford, R.A.; Urbance, J.W.; Flynn, S.J.; Tiedje, J.M.; Löffler, F.E. Characterization of two tetrachloroethene-reducing, acetate-oxidizing anaerobic bacteria and their description as Desulfuromonas michiganensis sp. nov. Appl. Environ. Microbiol. 2003, 69, 2964-2974. [CrossRef] [PubMed]

8. $\quad$ Sung, Y.; Fletcher, K.E.; Ritalahti, K.M.; Apkarian, R.P.; Ramos-Hernández, N.; Sanford, R.A.; Mesbah, N.M.; Löffler, F.E. Geobacter lovleyi sp. nov. strain SZ, a novel metal-reducing and tetrachloroethene-dechlorinating bacterium. Appl. Environ. Microbiol. 2006, 72, 2775-2782. [CrossRef] [PubMed]

9. Luijten, M.L.; de Weert, J.; Smidt, H.; Boschker, H.T.; de Vos, W.M.; Schraa, G.; Stams, A.J. Description of Sulfurospirillum halorespirans sp. nov., an anaerobic, tetrachloroethene-respiring bacterium, and transfer of Dehalospirillum multivorans to the genus Sulfurospirillum as Sulfurospirillum multivorans comb. nov. Int. J. Syst. Evol. Microbiol. 2003, 53, 787-793. [CrossRef]

10. Maillard, J.; Regeard, C.; Holliger, C. Isolation and characterization of Tn-Dha1, a transposon containing the tetrachloroethene reductive dehalogenase of Desulfitobacterium hafniense strain TCE1. Environ. Microbiol. 2005, 7, 107-117. [CrossRef]

11. Löffler, F.E.; Ritalahti, K.M.; Zinder, S.H. Bioaugmentation for Groundwater Remediation; Stroo, H., Leeson, A., Ward, C., Eds.; Springer: New York, NY, USA, 2013; Chapter 2; pp. 39-88. ISBN 978-1-4614-4114-4.

12. Maymó-Gatell, X.; Nijenhuis, I.; Zinder, S.H. Reductive dechlorination of cis-1, 2-dichloroethene and vinyl chloride by "Dehalococcoides ethenogenes". Environ. Sci. Technol. 2001, 35, 516-521. [CrossRef]

13. Yang, Y.; Higgins, S.A.; Yan, J.; Şimşir, B.; Chourney, K.; Iyer, R.; Hettlich, R.L.; Baldwin, B.; Ogles, D.M.; Löffler, F.E. Grape pomace compost harbors organohalide-respiring Dehalogenimonas species with novel reductive dehalogenase genes. ISME J. 2017, 11, 2767-2780. [CrossRef]

14. Judger, B.-E.; Ertan, H.; Lee, M.; Manefield, M.; Marquis, C.P. Reductive dehalogenases come of age in biological destruction of organohalides. Trends Biotechnol. 2015, 33, 596-608. [CrossRef]

15. Tratnyek, P.G.; Johnson, R.L.; Lowry, G.V.; Brown, R.A. Chlorinated Solvent Source Zone Remediation; Kueper, B.H., Stroo, H.F., Vogel, C.M., Ward, C.H., Eds.; Springer: New York, NY, USA, 2014; Chapter 10; pp. 307-351. ISBN 978-1-4614-6921-6.

16. Thiem, A.; Schmidt, K.R. Sequential anaerobic biodegradation of chloroethenes-Aspects of field application. Curr. Opin. Biotechnol. 2011, 22, 415-421. [CrossRef] [PubMed]

17. Coleman, N.V.; Mattes, T.E.; Gossett, J.M.; Spain, J.C. Phylogenetic and kinetic diversity of aerobic vinyl chloride-assimilating bacteria from contaminated sites. Appl. Environ. Microbiol. 2002, 68, 6162-6171. [CrossRef] [PubMed]

18. Mattes, T.E.; Alexander, A.K.; Coleman, N.V. Aerobic biodegradation of the chloroethenes: Pathways, enzymes, ecology, and evolution. FEMS Microbiol. Rev. 2010, 34, 445-475. [CrossRef]

19. Richards, P.M.; Liang, Y.; Johnson, R.; Mattes, T.E. Cryogenic soil coring reveals coexistence of aerobic and anaerobic vinyl chloride degrading bacteria in a chlorinated ethene contaminated aquifer. Water Res. 2019, 157, 281-291. [CrossRef] 
20. Liang, Y.; Liu, X.; Singletary, M.A.; Wang, K.; Mattes, T.E. Relationships between the abundance and expression of functional genes from vinyl chloride (VC)-degrading bacteria and geochemical parameters at VC-contaminated sites. Environ. Sci. Technol. 2017, 51, 12164-12174. [CrossRef]

21. Wymore, R.A.; Lee, M.H.; Keener, W.K.; Miller, A.R.; Colwell, F.S.; Watwood, M.E.; Sorenson, K.S. Field evidence for intrinsic aerobic chlorinated cometabolism by methanotrophs expressing soluble methane monooxygenase. Biorem. J. 2007, 11, 125-139. [CrossRef]

22. Paszynski, A.J.; Paidisetti, R.; Johnson, A.K.; Crawford, R.L.; Colwell, F.S.; Green, T.; Delwiche, M.; Lee, H.; Newby, D.; Brodie, E.L.; et al. Proteomic and targeted qPCR analyses of ubsurface microbial communities for presence of methane monooxygenase. Biodegradation 2011, 22, 1045-1059. [CrossRef]

23. Coleman, N.V.; Spain, J.C. Epoxyalkane: Coenzyme M transferase in the ethene and vinyl chloride biodegradation pathways of mycobacterium strain JS60. J. Bacteriol. 2003, 185, 5536-5545. [CrossRef]

24. Jin, Y.O.; Mattes, T.E. A quantitative PCR assay for aerobic, vinyl chloride- and ethene-assimilating microorganisms in groundwater. Environ. Sci. Technol. 2010, 44, 9036-9041. [CrossRef]

25. Abe, Y.; Aravena, R.; Zopfi, J.; Shouakar-Stash, O.; Cox, E.; Roberts, J.D.; Hunkeler, D. Carbon and chlorine isotope fractionation during aerobic oxidation and reductive dechlorination of vinyl chloride and cis-1, 2-dichloroethene. Environ. Sci. Technol. 2009, 43, 101-107. [CrossRef] [PubMed]

26. Jennings, L.K.; Chartrand, M.M.; Lacrampe-Couloume, G.; Lollar, B.S.; Spain, J.C.; Gossett, J.M. Proteomic and transcriptomic analyses reveal genes upregulated by cis-dichloroethene in Polaromonas sp. strain JS666. Appl. Environ. Microbiol. 2009, 75, 3733-3744. [CrossRef] [PubMed]

27. Dolinová, I.; Štrojsová, M.; Černík, M.; Němeček, J.; Macháčková, M.; Ševců, A. Microbial degradation of chloroethenes: A review. Environ. Sci. Pollut. Res. 2017, 24, 13262-13283. [CrossRef] [PubMed]

28. ČSN ISO 5667-11. Water Quality—Sampling_Part 11: Guidance on Sampling of Groundwaters; International Organization for Standardization: Geneva, Switzerland, 1993.

29. Němeček, J.; Dolinová, I.; Macháčková, J.; Špánek, R.; Ševců, A.; Lederer, T.; Černík, M. Stratification of Chlorinated Ethenes Natural Attenuation in an Alluvial Aquifer Assessed by Hydrochemical and Biomolecular Tools. Chemosphere 2017, 184, 1157-1167. [CrossRef]

30. ČSN EN ISO 11885. Water Quality_Determination of Selected Elements by Inductively Coupled Plasma Optical Emission Spectrometry (ICP-OES); International Organization for Standardization: Geneva, Switzerland, 2007.

31. ČSN 83 0530-31. Chemical and Physical Analysis of Surface Water. Determination of Sulfide and Hydrogen Sulfide; International Organization for Standardization: Geneva, Switzerland, 1980.

32. ČSN EN 1484. Water AnalysisGuidelines for the Determination of Total Organic Carbon (TOC) and Dissolved Organic Carbon (DOC); International Organization for Standardization: Geneva, Switzerland, 1998.

33. ČSN EN ISO 10304-1. Water Quality_Determination of Dissolved Anions by Liquid Chromatography of Ions—Part 1: Determination of Bromide, Chloride, Fluoride, Nitrate, Nitrite, Phosphate and Sulfate; International Organization for Standardization: Geneva, Switzerland, 2007.

34. Bewley, R.; Hick, P.; Rawcliffe, A. Meeting the challenges for bioremediation of chlorinated solvents at operational sites: A comparison of case studies. In Proceeding of the 13th International UFZ-Deltarez Conference on Sustainable Use and Management of Soil, Sediment and Water Resources, Copenhagen, Denmark, 9-12 June 2015.

35. Chapelle, F.H.; Bradley, P.M.; Thomas, M.A.; McMahon, P.B. Distinguishing iron-reducing from sulfate-reducing conditions. Ground Water 2009, 47, 300-3058. [CrossRef]

36. RStudio Team. RStudio: Integrated Development for R; RStudio, Inc.: Boston, MA, USA, 2015; Available online: http://www.rstudio.com/ (accessed on 28 November 2019).

37. R Core Team. R: A Language and Environment for Statistical Computing; R Foundation for Statistical Computing: Vienna, Austria, 2018; Available online: http://www.R-project.org/ (accessed on 28 November 2019).

38. Myers, J.L.; Well, A.D. Research Design and Statistical Analysis, 2nd ed.; Lawrence Erlbaum Associates: Mahwah, NJ, USA, 2003; p. 760. ISBN 0805840370.

39. Kursa, M.B.; Rudnicki, W.R. Feature Selection with the Boruta Package. J. Stat. Soft. 2010, 36, 1-13. [CrossRef]

40. Brock, E.; Pihur, V.; Datta, S.; Datta, S. clValid: An R Package for Cluster Validation. J. Stat. Soft. 2008, 25, 1-22. [CrossRef]

41. Roberts, A.L.; Totten, L.A.; Arnold, W.A.; Burris, D.R.; Campbell, T.J. Reductive elimination of chlorinated ethylenes by zero valent metals. Environ. Sci. Technol. 1996, 30, 2654-2659. [CrossRef] 
42. Wild, A.; Hermann, R.; Leisinger, T. Isolation of an anaerobic bacterium which reductively dechlorinates tetrachloroethene and trichloroethene. Biodegradation 1996, 7, 507-511. [CrossRef]

43. Bouwer, E.J. Bioremediation of chlorinated solvents using alternate electron acceptors. In Handbook of Bioremediation; Norris, R., Hinchee, R., Brown, R., McCarty, P., Semprini, L., Wilson, J., Kampbell, D., Reinhard, M., Borden, R., Eds.; Lewis Publishers: Boca Raton, FL, USA, 1994; pp. 149-175.

44. Ehrlich, H.L.; Newman, D.K. Geomicrobiology, 5th ed.; CRC Press, Taylor \& Francis Group: Boca Raton, FL, USA, 2009; p. 628. ISBN 978-0-8493-7906-2.

45. Schmidt, K.R.; Tiehm, A. Natural attenuation of chloroethenes: Identification of sequential reductive/oxidative biodegradation by microcosm studies. Water Sci. Technol. 2008, 58, 1137-1145. [CrossRef]

46. Gossett, J.M. Sustained aerobic oxidation of vinyl chloride at low oxygen concentrations. Environ. Sci. Technol. 2010, 44, 1405-1411. [CrossRef] [PubMed]

47. Atashgahi, S.; Maphosa, F.; Doğan, E.; Smidt, H.; Springael, D.; Dejonghe, W. Small-scale oxygen distribution determines the vinyl chloride biodegradation pathway in surficial sediments of riverbed hyporheic zones. FEMS Microbiol. Ecol. 2013, 84, 133-142. [CrossRef] [PubMed]

48. Atashgahi, S.; Lu, Y.; Ramiro-Garcia, J.; Peng, P.; Maphosa, F.; Sipkema, D.; Dejonghe, W.; Smidt, H.; Springael, D. Geochemical parameters and reductive dechlorination determine aerobic cometabolic vs. aerobic metabolic vinyl chloride biodegradation at oxic/anoxic interface of hyporheic zones. Environ. Sci. Technol. 2017, 51, 1626-1634. [CrossRef] [PubMed] 

Article

\title{
Microbial Assisted Hexavalent Chromium Removal in Bioelectrochemical Systems
}

\author{
Gabriele Beretta ${ }^{1, *}$, Matteo Daghio ${ }^{2,3}$, Anna Espinoza Tofalos ${ }^{2}$, Andrea Franzetti ${ }^{2}$, \\ Andrea Filippo Mastorgio ${ }^{1}$, Sabrina Saponaro ${ }^{1}$ and Elena Sezenna ${ }^{1}$ \\ 1 Department of Civil and Environmental Engineering, Politecnico di Milano, Piazza Leonardo da Vinci 32, \\ 20133 Milano, Italy; andreafilippo.mastorgio@polimi.it (A.F.M.); sabrina.saponaro@polimi.it (S.S.); \\ elena.sezenna@polimi.it (E.S.) \\ 2 Department of Earth and Environmental Sciences, University of Milano-Bicocca, Piazza della Scienza 1, \\ 20126 Milano, Italy; matteo.daghio@unimib.it (M.D.); anna.espinoza@unimib.it (A.E.T.); \\ andrea.franzetti@unimib.it (A.F.) \\ 3 Department of Agriculture, Food, Environment and Forestry, University of Florence, Piazzale delle Cascine \\ 18, 50144 Firenze, Italy \\ * Correspondence: gabriele.beretta@polimi.it; Tel.: +39-02-23996435
}

Received: 28 November 2019; Accepted: 5 February 2020; Published: 10 February 2020

\begin{abstract}
Groundwater is the environmental matrix that is most frequently affected by anthropogenic hexavalent chromium contamination. Due to its carcinogenicity, $\mathrm{Cr}(\mathrm{VI})$ has to be removed, using environmental-friendly and economically sustainable remediation technologies. BioElectrochemical Systems (BESs), applied to bioremediation, thereby offering a promising alternative to traditional bioremediation techniques, without affecting the natural groundwater conditions. Some bacterial families are capable of oxidizing and/or reducing a solid electrode obtaining an energetic advantage for their own growth. In the present study, we assessed the possibility of stimulating bioelectrochemical reduction of $\mathrm{Cr}(\mathrm{VI})$ in a dual-chamber polarized system using an electrode as the sole energy source. To develop an electroactive microbial community three electrodes were, at first, inserted into the anodic compartment of a dual-chamber microbial fuel cell, and inoculated with sludge from an anaerobic digester. After a period of acclimation, one electrode was transferred into a polarized system and it was fixed at $-0.3 \mathrm{~V}$ (versus standard hydrogen electrode, SHE), to promote the reduction of $1000 \mu \mathrm{g} \mathrm{Cr}(\mathrm{VI}) \mathrm{L}^{-1}$. A second electrode, served for the set-up of an open circuit control, operated in parallel. $\mathrm{Cr}(\mathrm{VI})$ dissolved concentration was analysed at the initial, during the experiment and final time by spectrophotometric method. Initial and final microbial characterization of the communities enriched in polarized system and open circuit control was performed by $16 \mathrm{~S}$ rRNA gene sequencing. The bioelectrode set at $-0.3 \mathrm{~V}$ showed high $\mathrm{Cr}(\mathrm{VI})$ removal efficiency (up to $93 \%$ ) and about $150 \mu \mathrm{g} \mathrm{L}^{-1}$ day $^{-1}$ removal rate. Similar efficiency was observed in the open circuit (OC) even at about half rate. Whereas, purely electrochemical reduction, limited to $35 \%$, due to neutral operating conditions. These results suggest that bioelectrochemical $\mathrm{Cr}(\mathrm{VI})$ removal by polarized electrode offers a promising new and sustainable approach to the treatment of groundwater $\mathrm{Cr}(\mathrm{VI})$ plumes, deserving further research.
\end{abstract}

Keywords: bioelectrochemical systems (BESs); hexavalent chromium; electrobioremediation; groundwater treatment

\section{Introduction}

Extensive use of chromium $(\mathrm{Cr})$ and its compounds in many industrial process [1] and refractory production has made it a major pollutant [2]. The mobility, bioavailability and toxicity of chromium depend on its oxidation states. In the natural environment, $\mathrm{Cr}$ (III) is most immobile, less soluble and stable. Whereas, $\mathrm{Cr}(\mathrm{VI})$ is highly mobile, soluble and bioavailable. Compared with $\mathrm{Cr}(\mathrm{III}), \mathrm{Cr}(\mathrm{VI})$ is 
also extremely toxic (by 100 times) to living organisms and it is internationally recognized as a human carcinogen, mutagen and teratogen.

To reduce its impact on human health and the environment, appropriate remedial measures and remediation interventions are needed. The recovery and removal of chromium from wastewater or groundwater is traditionally carried out by adsorption, [3,4], chemical or electrochemical reduction to $\mathrm{Cr}(\mathrm{III})$, and subsequent precipitation [5,6] or electrokinetics [7]. These methods bring with them some disadvantages that concern high-energy requirements, excessive chemical consumption, production of unwanted secondary products and residual highly concentrated toxic sludge $[1,5]$. Furthermore, some of these approaches are quite effective at the high chromium concentrations [3,7] of industrial effluents. Whereas, the removal efficiency greatly decreases at low concentrations, as typically observed in natural surface and groundwater.

Bioremediation, exploiting the huge microbial metabolic capacity to transform contaminants into harmless substances, may overcome some of the drawbacks of physical-chemical technologies, and is a low energy and cost-effective process. Microbes naturally adopt different strategies to survive in chromium polluted environment, such as biosorption, bioaccumulation and biotransformation for detoxification of $\mathrm{Cr}(\mathrm{VI})$ into the relatively safe $\mathrm{Cr}$ (III) form [8]. Bioremediation of $\mathrm{Cr}(\mathrm{VI})$ includes all these mechanisms and may be promoted through the addition of nutrients and/or electron donors to sustain microbial growth (biostimulation), or even by the injection of selected bacterial strains that are able to reduce $\mathrm{Cr}(\mathrm{VI})$ and enhance the removal process (bioaugmentation).

Recently, great attention has been also paid to Microbial Electrochemical Technology (MET) as an innovative and sustainable approach for promoting the bioremediation of contaminated sites [9]. In METs, microorganisms catalyze the oxidation or reduction of pollutants using solid-state electrodes as virtually inexhaustible electron acceptors or donors [10-12].

MET has achieved promising results in the treatment of wastewater contaminated with $\mathrm{Cr}(\mathrm{VI})$. In microbial fuel cells (MFCs), a representative of MET, $\mathrm{Cr}(\mathrm{VI})$ in industrial effluents could be effectively reduced in either, abiotic cathodic chambers, under acidic conditions [13-16] or biocathodes in the neutral $\mathrm{pH}$ range $[17,18]$, while generating electricity from low-grade anodic organic substrates. $\mathrm{Cr}(\mathrm{VI})$ can also be removed in systems relying on an external power supply for creating a bias between two electrodes or a potentiostat to supplement electrons to the cathode $[19,20]$.

Under anaerobic conditions, $\mathrm{Cr}(\mathrm{VI})$ can serve as the final electron acceptor in a process that usually involves membrane-bound reductases [21], but also soluble enzymes (e.g., c3 cytochrome in Desulfovibrio v.) [22]. Previous work has confirmed $\mathrm{Cr}(\mathrm{VI})$ autotrophic reduction in soil-aquifer that has involved different species of microorganisms (e.g., Clostridium chromiireducens sp., Pseudomonas Synxantha) that are able to use hydrogen and $\mathrm{CO}_{2} / \mathrm{NaHCO}_{3}$ as an electron donor, and carbon source, respectively [23-26]. In the wide variety of bacteria capable of efficient $\mathrm{Cr}(\mathrm{VI})$ reduction [27] some, belonging to the species Shewanella sp. [20], Desulfovibrio sp. [22], Pseudomonas sp. [28], Trichococcus sp. [18], Stenotrophomonas sp., Serratia sp., and Achromobacter sp. [29] have been in fact reported to be able to use an electrode as electron donor and $\mathrm{Cr}(\mathrm{VI})$ as electron acceptor.

The advantages to exploiting the ability of these microorganisms to bioremediate ensures issues in electron donors delivery and availability to be avoided, and improved control of parasitic reactions to avoid the formation of unwanted daughter products [9]. Moreover, the production of an electrical signal can act as a biosensor for real-time monitoring of the microbial activity [30,31].

This work aimed to determine the effectiveness of a microbial biocathode for CrVI reduction in comparison to a pure microbial and pure electrochemical control, to start exploring the possibility of effective $\mathrm{Cr}(\mathrm{VI})$ reduction in natural surface water or groundwater at lower $\mathrm{Cr}(\mathrm{VI})$ concentrations than wastewater so far investigated. Therefore, an initial concentration of $\mathrm{Cr}(\mathrm{VI})$ of $1 \mathrm{mg} \mathrm{L}^{-1} \mathrm{was}^{-}$ applied and no organic substance was added during the chromium removal phase. To minimize the total energy required and to facilitate the rapid development of an electroactive microbial biofilm, we divided our work into two phases. In the first phase, electrodes were acclimated in the anodic chamber of MFC, inoculated with anaerobic digester sludge. Once the electroactive biofilm has developed, one 
of the electrodes was transferred in a dual-chamber potentiostatically-controlled system (POL $-0.3 \mathrm{~V})$ and -0.3 V versus Standard Hydrogen Electrode (SHE) potential was imposed (unless otherwise stated, all potentials throughout the paper are relative to SHE). To approach real groundwater conditions, differently from previous studies [32-34], no organic substance was added in the working chamber, dosing carbonates as the sole carbon source.

\section{Materials and Methods}

\subsection{Reactors Set-Up and Operation}

For this study, five identical double-chamber ("H-shaped") reactors have been set up (Figure 1). Each reactor consisted of a pair of borosilicate-glass bottles, $1.2 \mathrm{~L}$ useful volume each one. The connection between anolyte and catholyte was achieved by a proton exchange membrane (PEM, $4.52 \mathrm{~cm}^{2}$, Nafion117, FuelCellsEtc, College Station, TX, USA) placed between bottles. Graphite cylinders (ATAL Grafiti, Trezzo sull'Adda, Italy, length $6 \mathrm{~cm}$, diameter $1 \mathrm{~cm}$, geometric area $18.85 \mathrm{~cm}^{2}$ ) served as electrodes, both anodes and cathodes. Stainless steel cables $(\varnothing 0.1 \mathrm{~cm})$ fixed in the centre of the graphite cylinders were used as current collectors. All cables were covered with heat-shrinkable polytetrafluoroethylene (PTFE) tubes (Sigma-Aldrich, Milan, Italy) to limit corrosion phenomena. The distance between anode and cathode within the system was about $10 \mathrm{~cm}$. In the experiments, a mineral medium $\left(7 \mathrm{~g} \mathrm{~L}^{-1} \mathrm{NaH}_{2} \mathrm{PO}_{4} \cdot 12 \mathrm{H}_{2} \mathrm{O}, 3 \mathrm{~g} \mathrm{~L}^{-1} \mathrm{KH}_{2} \mathrm{PO}_{4}, 1 \mathrm{~g} \mathrm{~L}^{-1} \mathrm{NH}_{4} \mathrm{Cl}\right.$ and $\left.0.5 \mathrm{~g} \mathrm{~L}^{-1} \mathrm{NaCl}\right)$, pre-autoclaved at $120^{\circ} \mathrm{C}$ for 30 min twice, was used as electrolyte and to support microbial growth. For the entire duration of the test, all the systems were kept at a constant temperature and $\mathrm{pH}$, respectively, $18 \pm 1{ }^{\circ} \mathrm{C}$ and $7.4 \pm 0.1$.
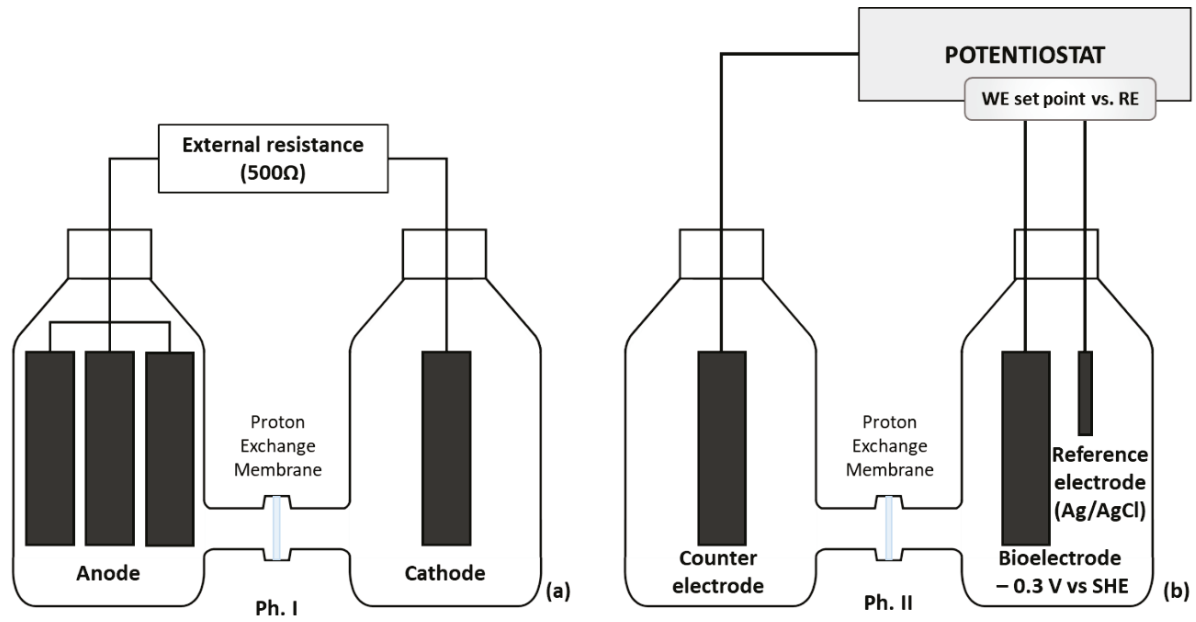

Figure 1. Schematic diagram of the reactors used in the present study. (a) In the acclimatization phase (Ph. I) of the electroactive biofilm (MFC), anode and cathode were connected by a $500 \Omega$ external resistance. (b) In the second phase (Ph. II), in the polarized reactor (POL $-0.3 \mathrm{~V})$ and in the abiotic polarized control (ABI $-0.3 \mathrm{~V})$, a potential of $-0.3 \mathrm{~V}$ versus SHE was imposed.

\subsection{Electroactive Biofilm Development in MFC}

In the first phase of the work, a MFC was set up in one of the previously described reactors, in order to develop anodic biofilm able to use the anode as the main electrons acceptor (Figure 1a). Three electrodes were placed in the anode chamber in parallel, to simultaneously develop an electroactive biofilm on all three electrodes, and one in the cathodic chamber. The anodic chamber was inoculated with anaerobic digester sludge $(0.24 \mathrm{~L}$, corresponding to $20 \%$ of the volume) and then sodium acetate 
was added, up to a concentration of $0.1 \mathrm{~g} \mathrm{~L}^{-1}$, as the carbon source for microbial growth. To establish anaerobic conditions, during the set-up, the anodic solution was flushed with nitrogen and the chamber immediately sealed with screw caps fitted with PTFE/silicone gaskets. The cathode chamber, filled with mineral medium, was kept open to air to allow oxygen diffuse into the solution.

For the entire duration of the test, in the external circuit connecting anode and cathode, a constant resistance $(500 \Omega$ ) was maintained and voltage drop continuously recorded (PicoLog 1012, Pico Technology Ltd., Eaton Socon, UK). This allowed the produced current density to be monitored over time, and to spike further sodium acetate into the anodic compartment, as soon as current density below $0.5 \mathrm{~mA} \mathrm{~m}^{-2}$ was recorded.

In this first phase, for the characterization of the microbial community, two samples were taken: A sample from anaerobic sludge, used as an inoculum in MFC ( $\mathrm{t} 0 \mathrm{Ph}$. I), and a sample of the anodic solution, used to inoculate the potentiostatically-controlled tests in the following experimental phase (t0 Ph. II).

\subsection{Polarized Bio-Electrode for Cr(VI) Removal}

Two out three graphite cylinders, acclimated in the anodic chamber of the MFC, were used to set up (i) the polarized system at $-0.3 \mathrm{~V}$ versus SHE for the removal of $\mathrm{Cr}(\mathrm{VI})$ (POL $-0.3 \mathrm{~V}$ ), and (ii) an open circuit control (OC). The configuration of the systems is the same as described above (Figure 1b). The acclimatized bio-electrode was immersed in the polarized system working chamber filled with mineral medium, $\mathrm{KHCO}_{3}\left(2 \mathrm{~g} \mathrm{~L}^{-1}\right)$ as the sole source of carbon, and $\mathrm{K}_{2} \mathrm{Cr}_{2} \mathrm{O}_{7}\left(\mathrm{Cr}(\mathrm{VI}) 1 \mathrm{mg} \mathrm{L}^{-1}\right)$. The working chamber housed an $\mathrm{Ag} / \mathrm{AgCl}$ reference electrode (0.2 V versus SHE). In addition to the biofilm on the electrode, the same chamber was inoculated with $0.24 \mathrm{~L}$ of solution from the anodic chamber of the MFC. To minimize the amount of dissolved organic carbon, the inoculum was first subjected to a washing procedure, by repeated centrifugation (10 min at $4000 \mathrm{rpm}$, Thermo Scientific) and resuspension of the pellet in fresh mineral medium. The counter electrode chamber was filled up with the same volume of mineral medium and $\mathrm{KHCO}_{3}$ as used for the working chamber. POL $-0.3 \mathrm{~V}$ has been connected to a dual-channel potentiostat controlled by an Arduino board (Politecnico di Milano I3N-DICA, 2016 Cariplo-BEvERAGE) and a potential of -0.3 V was imposed to the bioelectrode. As described in $[35,36]$, the potentiostat-board allows setting potential to the bioelectrode, that act as working electrode (WE), at set point (i.e., $-0.3 \mathrm{~V}$ versus $\mathrm{SHE}$ ) against an $\mathrm{Ag} / \mathrm{AgCl}$ reference electrode $(+0.2 \mathrm{~V}$ versus SHE) placed in the same chamber of the WE. The third electrode acts as counter electrode (CE) and potentiostat adjusts the current flow in CE to maintain the fixed potential to the WE.

The OC system, to assess the biological $\mathrm{Cr}(\mathrm{VI})$ reduction, was set up exactly like POL $-0.3 \mathrm{~V}$ without connecting the external circuit. Two abiotic control reactors were also set up (i) ABI $-0.3 \mathrm{~V}$ in which a new electrode was polarized at $-0.3 \mathrm{~V}$, to evaluate electrochemical $\mathrm{Cr}(\mathrm{VI})$ removal and (ii) ABI-OC, in which no potential was imposed to assess any absorption phenomena. The configuration of the abiotic controls was the same as the POL $-0.3 \mathrm{~V}$. The solutions were sterilized in an autoclave twice $\left(120^{\circ} \mathrm{C}\right.$ for $\left.30 \mathrm{~min}\right)$ before filling up abiotic controls.

$\mathrm{Cr}(\mathrm{VI})$ removal test POL $-0.3 \mathrm{~V}$ and OC lasted respectively 6 and 12 days, until more than $90 \%$ chromium removal was reached. Whereas abiotic tests (ABI -0.3 V and ABI-OC) lasted 12-14 days until no further changes in chromium concentrations were observed. Through these different systems, it was possible to compare the reduction of $\mathrm{Cr}(\mathrm{VI})$ exclusively by the electrochemical, biological and bio-electrochemical way.

The different phases of the experimental work, the acronyms used and their descriptions are summarized in Table 1 and Figure 2. 
Table 1. Summary table of the experimental work.

\begin{tabular}{|c|c|c|c|c|c|}
\hline Work Phase & Description & Acronym & Carbon Source & $\begin{array}{l}\text { Hexavalent } \\
\text { Chromium }\end{array}$ & $\begin{array}{c}\text { Microbial } \\
\text { Characterization }\end{array}$ \\
\hline \multirow{2}{*}{$\begin{array}{l}\text { Electroactive } \\
\text { bacteria } \\
\text { enrichment }\end{array}$} & Inoculum in MFC & t0 Ph. I & $\begin{array}{l}\text { Organic matter } \\
\text { (anaerobic } \\
\text { sludge) }\end{array}$ & - & \multirow[t]{2}{*}{ Planktonic community } \\
\hline & $\begin{array}{c}\text { MFC until 15th } \\
\text { day-inoculum of } \\
\text { POL }-0.3 \mathrm{~V} \text { and OC }\end{array}$ & t0 Ph. II & Acetate & - & \\
\hline \multirow{4}{*}{$\begin{array}{c}\mathrm{Cr}(\mathrm{VI}) \text { removal } \\
\text { tests }\end{array}$} & $\begin{array}{l}\text { Potentiostatically } \\
\text { controlled system }\end{array}$ & POL $-0.3 \mathrm{~V}$ & \multirow[t]{4}{*}{$\mathrm{KHCO}_{3}$} & \multirow{4}{*}{$\begin{array}{l}\mathrm{K}_{2} \mathrm{Cr}_{2} \mathrm{O}_{7} \\
\left(1 \mathrm{mg} \mathrm{L}^{-1}\right. \\
\mathrm{Cr}(\mathrm{VI}))\end{array}$} & $\begin{array}{l}\text { Planktonic community } \\
\text { and biofilm developed } \\
\text { on polarized electrode } \\
\text { (POL }-0.3 \mathrm{~V} \text { electrode) }\end{array}$ \\
\hline & Open circuit control & OC & & & $\begin{array}{c}\text { Planktonic community } \\
\text { and biofilm developed } \\
\text { on graphite (OC } \\
\text { graphite) }\end{array}$ \\
\hline & $\begin{array}{c}\text { Potentiostatically } \\
\text { controlled abiotic } \\
\text { system }\end{array}$ & $\mathrm{ABI}-0.3 \mathrm{~V}$ & & & - \\
\hline & $\begin{array}{l}\text { Open circuit abiotic } \\
\text { control }\end{array}$ & ABI-OC & & & - \\
\hline
\end{tabular}

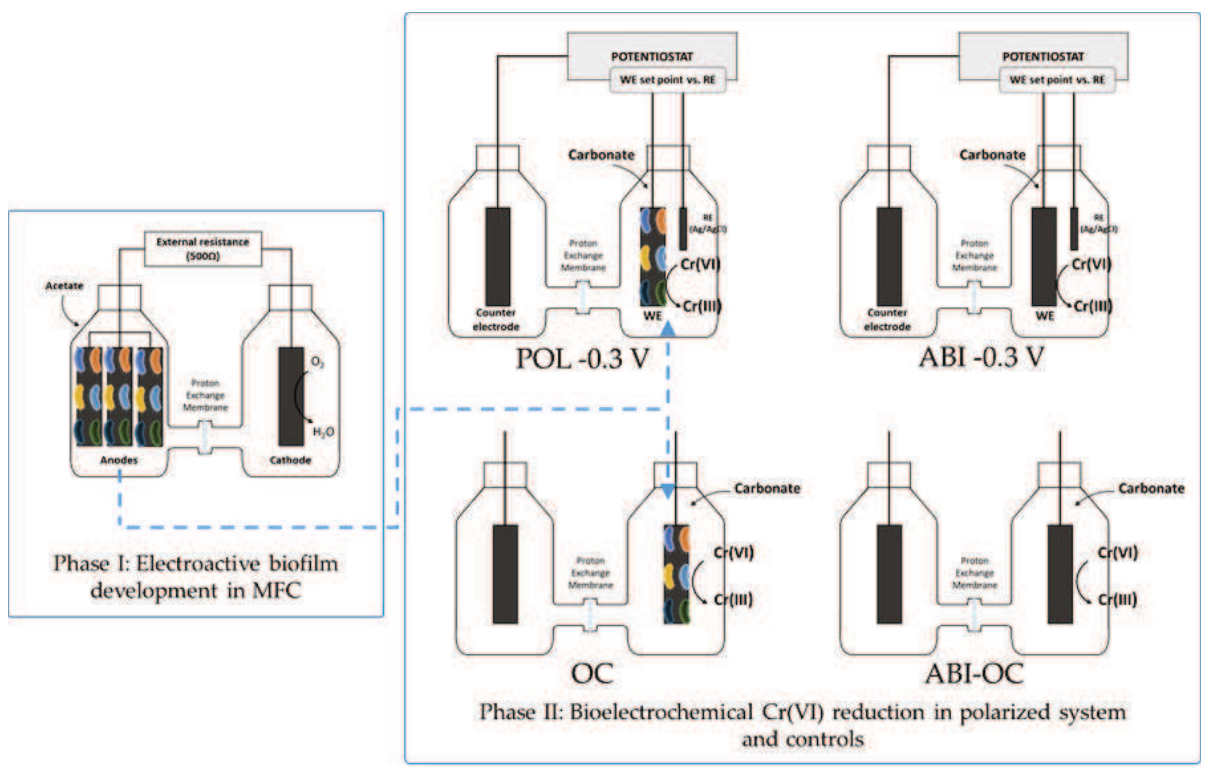

Figure 2. Conceptual model of the experimental work.

\subsection{Analyses and Data Processing}

The samples were periodically collected from all the systems for the analysis of $\mathrm{Cr}(\mathrm{VI})$ by means of a spectrophotometer (DR 6000, Hach Company, Loveland, CO, USA), according to the APHA Standard Methods 3500-B method [37]. Detection limit of spectrophotometric method was $18 \mu \mathrm{g}$ $\mathrm{Cr}(\mathrm{VI}) \mathrm{L}^{-1}$. Only $\mathrm{Cr}(\mathrm{VI})$ was monitored because of its soluble form and because the risks for human health associated with the trivalent forms of dissolved chromium are much lower, compared to $\mathrm{Cr}(\mathrm{VI})$.

To characterize the microbial communities, (i) samples of the anaerobic sludge, the anodic solution of the MFC and the solutions of OC and POL $-0.3 \mathrm{~V}$ were filtered on $0.45 \mu \mathrm{m}$ sterile paper filters and 
(ii) the biofilms attached to the POL $-0.3 \mathrm{~V}$ electrode and OC graphite were scraped with a sterile scalpel obtaining graphite powder and biofilm. The genomic DNA was extracted using the FastDNA Spin Kit for Soil (MP Biomedicals, Solon, OH, USA) according to the manufacturer's instructions. The V5-V6 hypervariable regions of the $16 \mathrm{~S}$ rRNA gene were PCR-amplified using the 783F and 1046R primers [38,39]. The bacterial PCR was performed in $20 \mu \mathrm{L}$ volume reactions with GoTaq ${ }^{\circledR}$ Green Master Mix (Promega Corporation, Madison, WI, USA) and $1 \mu \mathrm{M}$ of each primer. After the amplification, DNA quality was evaluated spectrophotometrically and DNA was quantified using Qubit ${ }^{\circledR}$ (Life Technologies, Carlsbad, CA, USA). The sequencing was carried out at Consorzio per il Centro di Biomedicina Molecolare (CBM). Bioinformatics elaborations have been performed as previously reported [40]. Classification of the representative sequences of each Operational Taxonomic Unit (OTU) was done using the RDP classifier ( $\geq 80 \%$ confidence) [41]. Rarefaction curves, OTU richness, Shannon and Chao1 alpha-diversity indices were generated for each sample using R (vegan).

\subsection{Calculations}

The MFC current was calculated as $I=V / R(\mathrm{~A})$, where $V(\mathrm{~V})$ is the voltage drop across the external resistance, $R$ (in $\Omega$ ). The current density $\left(\mathrm{mA} \mathrm{m}^{-2}\right.$ ) was calculated as $J=I / A E$ where $A E$ is the geometric area of the electrode $\left(\mathrm{m}^{2}\right)$. Coulombic efficiency (EC) is the percentage of electrons circulating in the system, compared to the total electrons theoretically present in the oxidizable organic substrate (Equation (1)). The EC of the MFC, therefore, indicates the microbial conversion efficiency of the substrate into electric current. EC was calculated by assuming the dosed acetate as the only oxidizable substrate and sole electron source in the reactors,

$$
E C=\frac{(M I \Delta t)}{\left(F b V_{a n} \Delta S\right)}
$$

where $\mathrm{M}\left(59 \mathrm{~g} \mathrm{~mol}^{-1}\right)$ is the molecular weight of $\mathrm{CH}_{3} \mathrm{COO}^{-}, I(\mathrm{~A})$ the recorded current in time $\Delta t(\mathrm{~s}) . F$ is the Faraday constant $\left(96,485.3\right.$ Coulomb mol$^{-1}$ of electrons $), b$ is the stoichiometric factor $=8$ moles of electrons per mole of acetate, $V_{a n}(\mathrm{~L})$ is the volume of the anodic compartment in the MFC and $\Delta S$ the consumed substrate over time $\left(\mathrm{g} \mathrm{L}^{-1}\right)$. The consumed substrate was calculated by assuming the complete oxidation of acetate recorded current was below $0.5 \mathrm{~mA} \mathrm{~m}^{-2}$.

Chromium removal efficiency was calculated by considering the percentage residual dissolved $\mathrm{Cr}(\mathrm{VI})$ concentration with time, or,

$$
\text { Residual } C r(V I)=\frac{C(t)}{C_{0}} \times 100
$$

where $C_{0}\left(\mu \mathrm{g} \mathrm{L}^{-1}\right)$ and $C(t)\left(\mu \mathrm{g} \mathrm{L}{ }^{-1}\right)$ are the initial concentration and concentration at time $t$ (days), respectively. $\mathrm{Cr}(\mathrm{VI})$ removal efficiency with time is therefore:

$$
C r(V I) \text { removal efficiency }=\left(1-\frac{C(t)}{C_{0}}\right) \times 100
$$

\section{Results}

\subsection{Current Density in the MFC}

The current density in the MFC, throughout the experiment, varied from a minimum of $0.5 \mathrm{~mA} \mathrm{~m}^{-2}$ to a maximum of $237 \mathrm{~mA} \mathrm{~m}^{-2}$ (Figure 3). At the beginning of the test, from the set-up (day 0) to the first spike of acetate (day 3), the current density and the EC reached the peak values of, respectively, $160 \mathrm{~mA} \mathrm{~m}^{-2}$, and $2.5 \%$. Following the third addition of acetate (day 7), both an increase in current density (max $~ 230 \mathrm{~mA} \mathrm{~m}^{-2}$ ) and in EC (18\%) was observed. Even after the fourth addition of acetate, the response of the system in terms of current density was the same for previous spikes (max $\sim 230 \mathrm{~mA} \mathrm{~m}^{-2}$ ), while the EC value (16.5\%) was slightly reduced. The decrease in EC was probably 
due to the cathodic reaction [42] limiting the overall process, and thus, favouring acetate consumption by different metabolic pathways (acetoclastic methanogenesis) instead of the anode-using ones [43].

After 15 days from the MFC set-up, two out three electrodes and $0.24 \mathrm{~L}$ of solution from the anodic chamber were removed for the set-up of POL $-0.3 \mathrm{~V}$ and open-circuit systems. The removed anolyte was replaced by an equal volume of mineral medium and acetate $\left(0.1 \mathrm{~g} \mathrm{~L}^{-1}\right)$. The current density in the cycles, following renewal, immediately reached the same peak values recorded in the previous cycles, confirming the cathodic reaction as the limiting step in the whole process. The EC, vice versa, gradually increased up to about $14 \%$. The trend in both the currents and the ECs, before, and after, electrode transfer and the renewal of the medium, shows that the microbial community from the initial inoculum, following an adaptation phase, was able to develop a biofilm able to oxidize the acetate and to transfer electrons to the anode with a discrete efficiency.

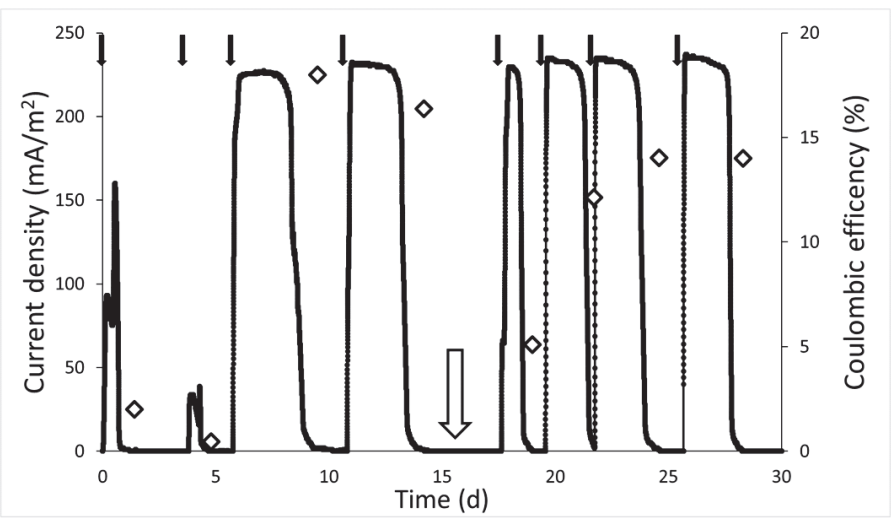

Figure 3. Current density and Coulombic Efficiency trend. Current density (black line) produced by electroactive biofilm after periodic acetate addition (black arrows) until the solution was renewed (white arrow) and two of the three electrodes used to set up POL $-0.3 \mathrm{~V}$ and OC. The EC was calculated (empty diamond) at the end of each current peak.

\section{2. $\mathrm{Cr}(V I)$ trends}

Biological $\mathrm{Cr}(\mathrm{VI})$ reduction, either in the $\mathrm{POL}-0.3 \mathrm{~V}$ and $\mathrm{OC}$, outstanded the abiotic reduction. In the POL $-0.3 \mathrm{~V}$ system, a rapid decrease in the concentration of dissolved hexavalent chromium was observed (Figure 4). After 6 days from test set-up, the residual concentration in POL $-0.3 \mathrm{~V}$ was equal to $92.1 \pm 13.2 \mu \mathrm{g} \mathrm{L}^{-1}$, corresponding to a removal rate of about $151 \mu \mathrm{g} \mathrm{L}^{-1} \mathrm{day}^{-1}$. A slower removal rate, about $75 \mu \mathrm{g} \mathrm{L}^{-1}$ day $^{-1}$, approximately half the POL $-0.3 \mathrm{~V}$, was registered in the the OC test. However, the overall removal was relevant, with low residual $\mathrm{Cr}(\mathrm{VI})$ concentration at the end of the test of $24.6 \pm 7.7 \mu \mathrm{g} \mathrm{L}{ }^{-1}$.

In both the bioreduction tests, $\mathrm{POL}-0.3 \mathrm{~V}$ and $\mathrm{OC}, \mathrm{Cr}(\mathrm{VI})$ reduction rate was not influenced by a declining in the $\mathrm{Cr}(\mathrm{VI})$ concentration. We hypothesise that, in our biological tests, $\mathrm{Cr}(\mathrm{VI})$ could be used as a terminal electron acceptor $[44,45]$. The higher removal rate in the polarized system might be ascribed to a larger array of electron donors, with respect to the open circuit control. In addition to endogenous electron reserves, the electrode posed at $-0.3 \mathrm{~V}$ can act as a further electron source [46], that could have promoted chromium reduction. Additional biological mechanisms of chromium reduction, such as enzyme reduction (soluble or membrane-associated reductase) [21], intracellular detoxification mechanisms [45,47] and adsorption on the cell surface [48,49] may have occurred equally in both biological systems.

ABI-OC showed adsorption onto materials did not provide any significant contribution to the removal of $\mathrm{Cr}(\mathrm{VI})$, with an overall efficiency not exceeding $3 \%$ in the operational conditions of the test. 
In $\mathrm{ABI}-0.3 \mathrm{~V}$ about $35 \%$ removal was recorded over 12 days. Following an initial rapid decline, in the first 3 days, about $68.5 \mu \mathrm{g} \mathrm{L}^{-1}$ day $^{-1}, \mathrm{Cr}(\mathrm{VI})$ removal rate slowed down, leading in about a week to an asymptotic residual concentration of $728 \pm 35 \mu \mathrm{g} \mathrm{L} \mathrm{L}^{-1}$, corresponding to $31 \mu \mathrm{g} \mathrm{L}^{-1}$ day $^{-1}$ average removal rate. This purely electrochemical $\mathrm{Cr}(\mathrm{VI})$ reduction appears to be somehow limited by the operating conditions, neutral $\mathrm{pH}(7.4 \pm 0.1)$ and poised working electrode potential, as already pointed out, even at higher initial $\mathrm{Cr}(\mathrm{VI})$ concentrations, in previous experiences [50,51]. Moreover, as already reported in other studies, $\mathrm{Cr}(\mathrm{III})$ precipitation could passivate the electrode further limiting $\mathrm{Cr}(\mathrm{VI})$ reduction [14].

By comparing $\mathrm{Cr}(\mathrm{VI})$ removal rates in the different tests, it is possible to observe how, in our experimental conditions, biolelectrochemical reduction in POL $-0.3 \mathrm{~V}$, about $150 \mu \mathrm{g} \mathrm{L}-1 \mathrm{Cr}(\mathrm{VI})$, appears to be about $20 \%$ faster than the simple superimposition of purely electrochemical and bioreduction mechanisms ( $31.4 \mu \mathrm{g} \mathrm{L}{ }^{-1} \mathrm{day}^{-1}$ in $\mathrm{ABI}-0.3 \mathrm{~V}$ and $75 \mu \mathrm{g} \mathrm{L}{ }^{-1}$ in OC).

Due to the presence of an electroactive biofilm in this study, it was possible to observe more than $90 \%$ hexavalent chromium reduction at neutral $\mathrm{pH}$. Conversely, in previous studies, the electrochemical reduction of $\mathrm{Cr}(\mathrm{VI})$ was found to be strongly dependent on the $\mathrm{pH}$ of the cathodic solution $[13,15]$. Singhvi and Chhabra demonstrated low $\mathrm{pH}$ increases the reduction rate of $\mathrm{Cr}(\mathrm{VI})$ to $\mathrm{Cr}(\mathrm{III})$ and the concomitant production of electrical energy in abiotic cathodes, while Gangadharan and Nambi did not observe any reduction in a cathodic solution at $\mathrm{pH} 7$ [50,52].

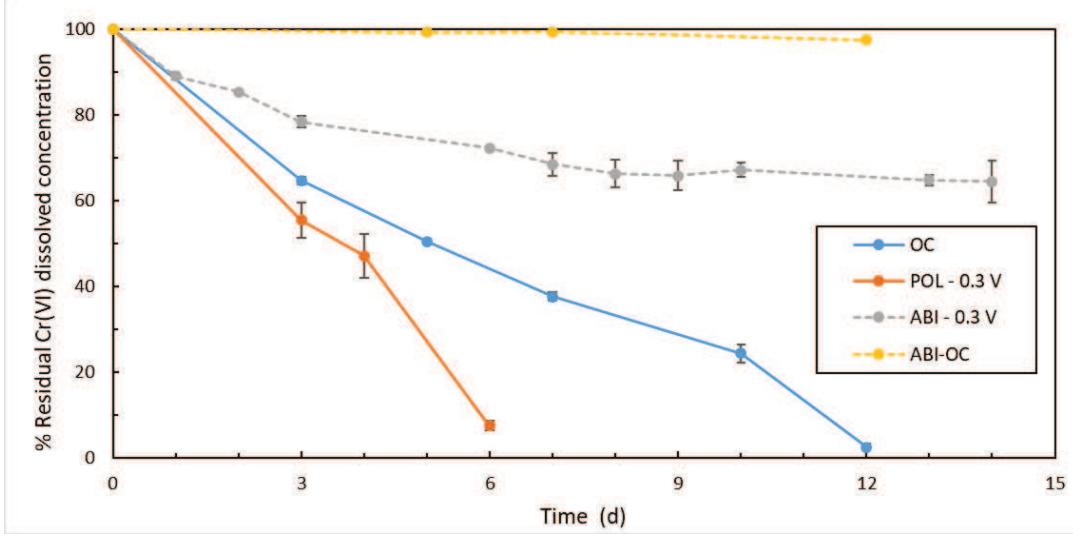

Figure 4. Reduction of $\mathrm{Cr}(\mathrm{VI})$ concentrations over time in ABI-OC (yellow dashed line), OC (blue solid line), POL $-0.3 \mathrm{~V}$ (orange solid line), $\mathrm{ABI}-0.3 \mathrm{~V}$ (pink dashed line).

\subsection{Microbial Communities}

From the four samples, a total of 98,719 amplicon reads were obtained. Rarefaction curves showed an appreciable representation of the real OTU richness for four samples ( $\mathrm{t} 0 \mathrm{Ph}$. II, OC, POL $-0.3 \mathrm{~V}$ and POL $-0.3 \mathrm{~V}$ electrode) (Figure S1). Whereas, the observed OTU richness is probably an underestimation of the real richness of samples t0 $\mathrm{Ph}$. I and OC graphite. To overcome this underestimation, the Chao1 index was calculated, in order to estimate the exact richness [53]. Data analysis shows that the diversity of the microbial communities decreased on the electrodes compared with the bulks. The decrease in diversity was shown by both a decrease in the Shannon and Chao1 indices from the bulks (Shannon: ranging from 4.33 for POL $-0.3 \mathrm{~V}$ to 4.43 for OC; Chao1: ranging from 333.23 for t0 $\mathrm{Ph}$. I to 635.19 for POL $-0.3 \mathrm{~V}$ ), compared to the electrodes (Shannon: 4.14 for OC graphite and 3.68 for POL $-0.3 \mathrm{~V}$ electrode; Chao1: 343.77 for OC graphite and 437.00 for POL -0.3 V electrode). These decreases in diversity likely resulted from the selection of electroactive microorganisms on the electrodes (Table S1). 
The results of the microbiological analyses showed an evolution bacterial community to begin from the inoculum ( $\mathrm{t} 0 \mathrm{Ph}$. I) to the inoculum of $\mathrm{POL}-0.3 \mathrm{~V}$ and $\mathrm{OC}$ ( $\mathrm{t} 0 \mathrm{Ph}$. II) (Figure 5). The microbial communities show an increase in the relative abundance of bacteria belonging to the Burkholderiales (from $<1.5$ to $25.5 \%$ ), Bacteroidales (from 3.1 to $11.7 \%$ ), Pseudomonadales (from $<1.5$ to $9.4 \%$ ) and Clostridiales (from 10.4 to $12.6 \%$ ) orders. The representatives of the Burkholderiales (Alcaligenaceae, Comamonadaceae), Bacteroidales (Porphyromonadaceae), Pseudomonadales (Pseudomonadaceae) orders have been previously described as bacteria able to perform electrochemical interactions with the anode [54-58]. Likewise, the presence of the families Porphyromonadaceae, Comamonadaceae and Pseudomonadaceae were described on the cathode [59] or in cathodic chambers [60].

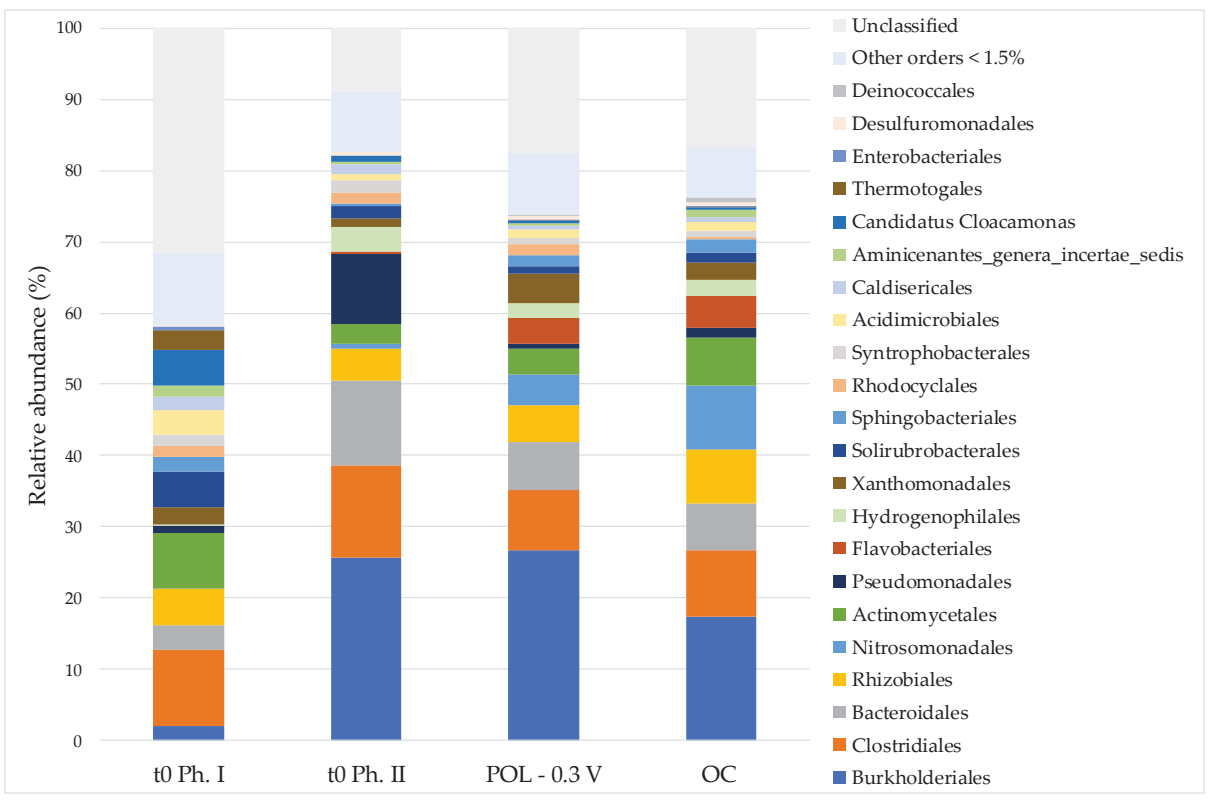

Figure 5. Planktonic bacterial communities structure at order level in the inoculum of MFC (t0 Ph. I), beginning of the second phase ( $\mathrm{t} 0 \mathrm{Ph}$. II), polarized system (POL $-0.3 \mathrm{~V}$ ) and open circuit (OC). "Other orders $<1.5 \%$ " indicated strains with abundance less than $1.5 \%$.

The addition of $\mathrm{Cr}(\mathrm{VI})$ and carbonates as the sole carbon source have influenced the structure of the bacterial community from the beginning of the second phase ( $\mathrm{t} 0 \mathrm{Ph}$. II). Compared to the inoculum, both in POL $-0.3 \mathrm{~V}$ and in OC systems, Pseudomonadales, Bacteroidales and Clostridiales reduced their relative abundances by about $80 \%, 50 \%$ and $30 \%$, respectively. Viceversa, in OC, an increase in the relative abundance of the Nitrosomonadales, from $<1.5 \%$ to $8.8 \%$, was observed. On the other hand, in POL $-0.3 \mathrm{~V}$ there was a slight increase in the orders Burkholderiales due to a net increase in the population of Comamonadaceae, from $2.8 \%$ in to $\mathrm{Ph}$. II to $10.1 \%$. In the same system also relative abundance of Xanthomonadales increased respect to the inoculum. Both the POL $-0.3 \mathrm{~V}$ and the OC showed relative abundance increase, compared to the inoculum of the bacteria belonging to the Flavobacteriales order, from $0.3 \%$ to $3.6 \%$, and $4.4 \%$, respectively.

The lack of organic electron donors, such as acetate, has influenced the structure of the suspended bacterial community, suggesting a possible advantage for autotrophic microorganisms (Nitrosomonadales and Flavobacteriales) able to use carbonates and ammonium in the mineral medium as carbon source and inorganic electron donor [61]. In the POL $-0.3 \mathrm{~V}$ solution, the presence of the polarized electrode may have favored bacteria belonging to Burkholderiales order (Comamonadaceae 
and Alcaligenaceae families), as already reported in other studies as components of the electroactive communities, enriched from anaerobic digester sludge and chromium tolerant—resistant/autotrophic microrganisms [62-64].

Furthermore, bacteria belonging to these two families have been observed in bioelectrochemical systems, both for the removal of inorganic compounds, such as $\mathrm{H}_{2} \mathrm{~S}$ and $\mathrm{NO}_{3}{ }^{-}$under autotrophic or mixotrophic conditions $[63,65]$, and for $\mathrm{Cr}(\mathrm{VI})$ bioreduction $[21,66]$.

The results of $16 \mathrm{~S}$ rRNA gene sequencing of the biofilms developed on the polarized electrode (POL $-0.3 \mathrm{~V}$ electrode) and on the graphite in the open circuit control (OC graphite) were compared, starting from the order level (Figure 6) and it was deepened on a genus level (Table 2). The Burkholderiales Order, observed in both the solutions of the inoculated systems (17.4\% in OC and $26.8 \%$ in POL $-0.3 \mathrm{~V}$ ) and in OC graphite $(22.1 \%)$, is present instead with a relative minor abundance on POL $-0.3 \mathrm{~V}$ electrode $(16.5 \%)$. On the polarized bioelectrode bacteria belonging to the orders Flavobacteriales ( $16.9 \%$ compared to $4.1 \%$ in OC graphite), Rhizobiales (13.7\% compared to $5 \%$ in OC graphite), and Deinococcales (4.9\% compared to $1.7 \%$ in OC graphite) were more abundant; instead the same were almost absent in the planktonic communities (Flavobacteriales $3.6-4.4 \%$, Rhizobiales $<1.5 \%$, Deinococcales $<1.5 \%$ ).

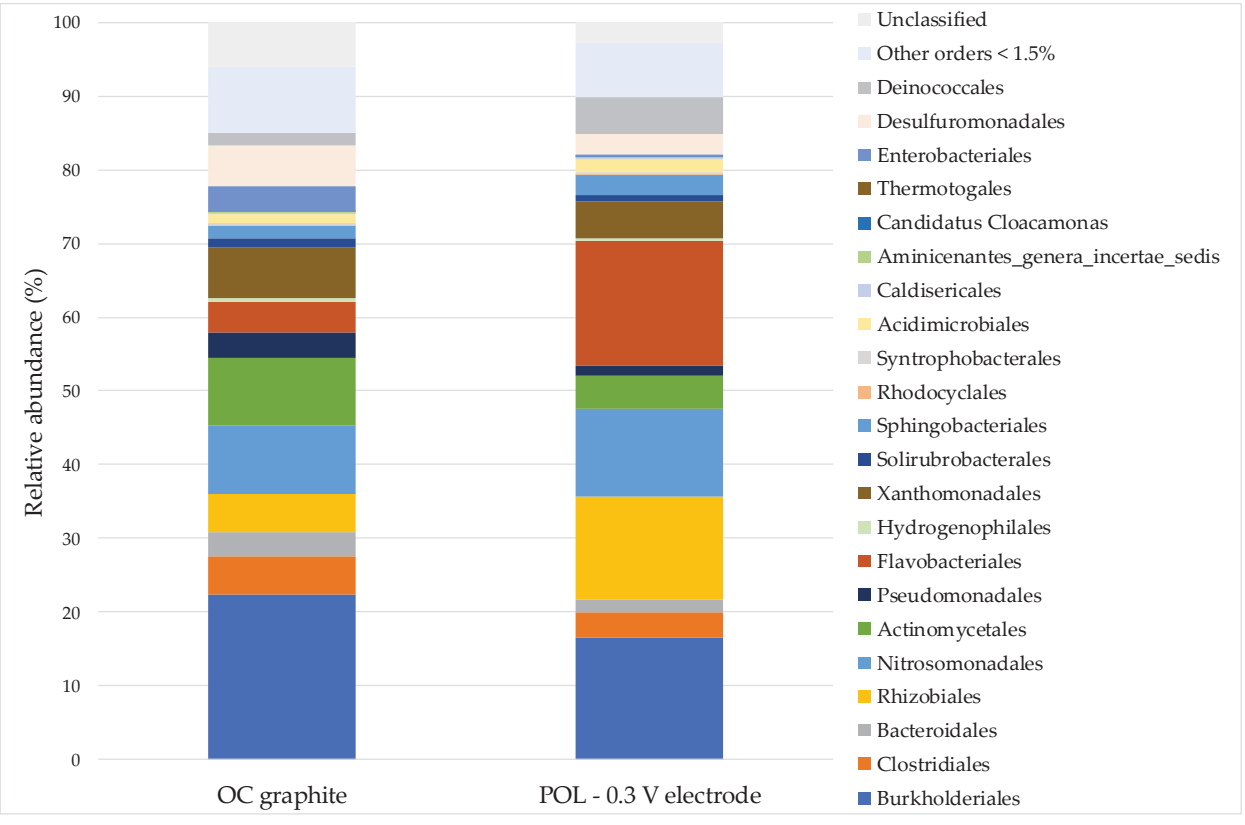

Figure 6. Bacterial community structures at order level of the biofilm developed on graphite of the open circuit system (OC graphite) and on polarized electrode (POL $-0.3 \mathrm{~V}$ electrode). "Other orders $<1.5 \% "$ indicated strains with abundance less than $1.5 \%$.

The only genus detected within the Flavobacteriales order was Moheibacter. Moheibacter was isolated in a cathodic biofilm in a BES for the degradation of oxytetracicline [67] and also in underground rocks, and in anaerobic environment [68]. Schauss and colleagues [69], isolated a novel Moheibacter sp. whit high content of quinone that could be involved in electron transfer to multi-heme c-type cytochromes that have a key role in External Electron Transfer (EET) to electrodes and minerals [12]. The sharp increase in relative abundances of this genus on the polarized bioelectrode, as well as in other electroactive biocathodic communities, as reported in the literature [70,71], may suggest this genus is involved in the transfer of electrons from an electrode. However, to date, there has been no research that has pointed out the Moheibacter is directly implicated in EET. The only genus that was detected 
within the Rhizobiales order was Nitrobacter. Bacteria that belong to the Nitrobacter genus are known for oxidizing nitrite to nitrate, and have been previously observed in autotrophic biocathodes for nitrate removal [72,73]. The whole Deinococcales order was constituted by Truepera genus. This genus has been previously described in electroactive cathodic communities also consisting of microorganisms belonging to the genera Moheibacter and Nitrosomonas [72,74]. Although, an ecological relationship has not yet been defined, the abundance of these genera on the polarized bioelectrode suggests they were at an advantage compared to open circuit system.

Table 2. Relative abundance at order and genus level of the biofilm developed on graphite of the open circuit system (OC graphite) and on polarized electrode (POL $-0.3 \mathrm{~V}$ electrode).

\begin{tabular}{|c|c|c|c|c|}
\hline \multirow{2}{*}{$\begin{array}{l}\text { Order } \\
\text { Burkholderiales }\end{array}$} & \multicolumn{2}{|c|}{ OC Graphite (\%) } & \multicolumn{2}{|c|}{ POL $-0.3 \mathrm{~V}$ Electrode $(\%)$} \\
\hline & 22.4 & & 16.5 & \\
\hline Advenella & & 14.7 & & 8.2 \\
\hline Cupriavidus & & 2.8 & & 1.6 \\
\hline Polaromonas & & 1.6 & & $<1.5$ \\
\hline Flavobacteriales & 4.2 & & 17.0 & \\
\hline Moheibacter & & 4.1 & & 16.7 \\
\hline Nitrosomonadales & 9.3 & & 11.9 & \\
\hline Nitrosomonas & & 9.1 & & 11.9 \\
\hline Rhizobiales & 5.2 & & 14.0 & \\
\hline Nitrobacter & & $<1.5$ & & 9.9 \\
\hline Actinomycetales & 9.2 & & 4.4 & \\
\hline Rhodococcus & & 5.0 & & 1.5 \\
\hline Xanthomonadales & 6.9 & & 5.0 & \\
\hline Stenotrophomonas & & 3.0 & & 3.1 \\
\hline Dyella & & 3.3 & & $<1.5$ \\
\hline Clostridiales & 5.1 & & 3.5 & \\
\hline Clostridium XI & & 1.8 & & 1.8 \\
\hline Desulfuromonadales & 5.4 & & 2.9 & \\
\hline Geobacter & & 4.2 & & 1.8 \\
\hline Deinococcales & 1.8 & & 4.9 & \\
\hline Truepera & & 1.8 & & 4.9 \\
\hline Bacteroidales & 3.2 & & 1.7 & \\
\hline Petrimonas & & 1.7 & & $<1.5$ \\
\hline Pseudomonadales & 3.3 & & 1.4 & \\
\hline Pseudomonas & & 3.1 & & $<1.5$ \\
\hline Sphingobacteriales & 1.6 & & 2.9 & \\
\hline Enterobacteriales & 3.5 & & $<1.5$ & \\
\hline Escherichia/Shigella & & 3.5 & & $<1.5$ \\
\hline Acidimicrobiales & $<1.5$ & & 1.8 & \\
\hline Other orders $<1.5 \%$ & 8.9 & & 7.5 & \\
\hline Others genera $<1.5 \%$ & & 24.4 & & 21.9 \\
\hline Unclassified order & 6.1 & & 2.7 & \\
\hline Unclassified genus & & 16.1 & & 16.7 \\
\hline
\end{tabular}

\section{Conclusions}

The acclimatization phase in the MFC allowed for the rapid development of the electroactive biofilm, which was able to couple organic substrate oxidation with bioenergy production. Furthermore, the development of an electroactive biofilm shortened the time for $\mathrm{Cr}(\mathrm{VI})$ reduction. The bioelectrode polarized at $-0.3 \mathrm{~V}$ (versus SHE) reduced dissolved $\mathrm{Cr}(\mathrm{VI})$ with larger efficiency (above $90 \%$ ) and/or less time than the controls. Bioelectrochemical reduction overcame both, purely electrochemical reduction, showing only $35 \% \mathrm{Cr}(\mathrm{VI})$ removal under neutral $\mathrm{pH}$, and bioreduction, characterized by high overall efficiency and a significantly slower rate. Furthermore, the bioelectrochemical reduction rate was $20 \%$ faster than the other mechanisms (biological and electrochemical reduction). 
Electroactive biofilm was proven to be essential for the removal of dissolved chromium. Community analyses suggest that Moheibacter, Nitrobacter and Truepera were selectively enriched in the biofilm of the polarized system. Bacteria belonging to the Flavobacteriales, Nitrosomonadales and Rhizobiales orders play a dominant role in electroactive communities enriched in POL $-0.3 \mathrm{~V}$. This work was done to demonstrate, on a laboratory scale, that the bioelectrochemical removal of $\mathrm{Cr}(\mathrm{VI})$ can occur, even in the absence of organic carbon. The results of this study corroborate the results of previous studies, that reported high efficiency in bioelectrochemical $\mathrm{Cr}(\mathrm{VI})$ removal polarized electrodes at $-0.3 \mathrm{~V}$. Although, bioelectrochemical $\mathrm{Cr}(\mathrm{VI})$ reduction requires further research, especially at the pilot scale with real contaminated groundwater, this approach can be considered the basis for a new and sustainable technology for groundwater remediation.

Supplementary Materials: The following are available online at http:/www.mdpi.com/2073-4441/12/2/466/s1 Figure S1: Rarefaction curves of bacterial communities based on OTUS, from the following reactors: to Ph. I, t0 Ph. II, POL -0.3 V electrode, POL - 0.3 V, OC graphite, OC; Table S1: Species richness and diversity estimates.

Author Contributions: Conceptualization, G.B., A.F.M. and E.S.; data curation, A.E.T. and A.F.; formal analysis, G.B., A.E.T., A.F., A.F.M. and E.S.; funding acquisition, S.S.; investigation, G.B., A.F.M. and E.S.; methodology, G.B., A.F.M. and E.S.; supervision, A.F. and S.S.; visualization, G.B., M.D., A.E.T., A.F.M. and E.S.; writing-original draft, G.B., A.E.T., A.F.M. and E.S.; writing-review and editing, G.B., M.D., A.E.T., A.F.M. and E.S. All authors have read and agree to the published version of the manuscript.

Funding: This research was funded by this work was supported by Fondazione Cariplo in the framework of the project BEvERAGE-BioElEctrochemical RemediAtion of Groundwater plumes (2015-0195).

Conflicts of Interest: The authors declare no conflict of interest.

\section{References}

1. Ayyappan, C.S. Microbial leaching of chromium from solidified waste forms-A kinetic study. J. Ecol. Eng. 2015, 16, 36-42. [CrossRef]

2. Tschersich, C.; Barouki, R.; Uhl, M.; Klánová, J.; Horvat, M.; Alimonti, A.; Sarigiannis, D.; Santonen, T.; Lebret, E.; Schoeters, G. Scoping Documents for 2018 Deliverable Report D 4.2-Input for Cd and Cr(VI); Tenical Report for HBM4EU H2020 Programme; 2018; Available online: https://www.hbm4eu.eu/deliverables/ (accessed on 7 February 2020).

3. Mohan, D.; Rajput, S.; Singh, V.K.; Steele, P.H.; Pittman, C.U. Modeling and evaluation of chromium remediation from water using low cost bio-char, a green adsorbent. J. Hazard. Mater. 2011, 188, 319-333. [CrossRef]

4. Song, Z.; Williams, C.J.; Edyvean, R.G.J. Sedimentation of tannery wastewater. Water Res. 2000, 34, $2171-2176$. [CrossRef]

5. Madhavi, V.; Vijay, A.; Reddy, B.; Reddy, K.G.; Madhavi, G.; Nagavenkata, T.; Prasad, K.V. An Overview on Research Trends in Remediation of Chromium. Res. J. Recent Sci. Res. 2013, 2, 71-83.

6. Peng, H.; Guo, J.; Li, B.; Liu, Z.; Tao, C. High-efficient recovery of chromium (VI) with lead sulfate. J. Taiwan Inst. Chem. Eng. 2018, 85, 149-154. [CrossRef]

7. Peng, H.; Leng, Y.; Cheng, Q.; Shang, Q.; Shu, J.; Guo, J. Efficient Removal of Hexavalent Chromium from Wastewater with Electro-Reduction. Processes 2019, 7, 41. [CrossRef]

8. Jobby, R.; Jha, P.; Yadav, A.K.; Desai, N. Biosorption and biotransformation of hexavalent chromium [Cr(VI)]: A comprehensive review. Chemosphere 2018, 207, 255-266. [CrossRef]

9. Daghio, M.; Aulenta, F.; Vaiopoulou, E.; Franzetti, A.; Arends, J.B.A.; Sherry, A.; Suárez-Suárez, A.; Head, I.M.; Bestetti, G.; Rabaey, K. Electrobioremediation of oil spills. Water Res. 2017, 114, 351-370. [CrossRef]

10. Logan, B.E.; Hamelers, B.; Rozendal, R.; Schröder, U.; Keller, J.; Freguia, S.; Aelterman, P.; Verstraete, W.; Rabaey, K. Microbial fuel cells: Methodology and technology. Environ. Sci. Technol. 2006, 40, 5181-5192. [CrossRef]

11. Rabaey, K.; Angenent, L.; Schroder, U.; Keller, J. Bioelectrochemical Systems: From Extracellular Electron Transfer to Biotechnological Application; IWA Publishing: London, UK, 2009; ISBN 9781843392330.

12. Shi, L.; Dong, H.; Reguera, G.; Beyenal, H.; Lu, A.; Liu, J.; Yu, H.-Q.Q.; Fredrickson, J.K. Extracellular Electron Transfer Mechanisms between Microorganisms and Minerals. Nat. Rev. Microbiol. 2016, 14, 651-662. [CrossRef] 
13. An, Z.; Zhang, H.; Wen, Q.; Chen, Z.; Du, M. Desalination combined with hexavalent chromium reduction in a microbial desalination cell. Desalination 2014, 354, 181-188. [CrossRef]

14. Li, Z.; Zhang, X.; Lei, L. Electricity production during the treatment of real electroplating wastewater containing Cr6+ using microbial fuel cell. Process Biochem. 2008, 43, 1352-1358. [CrossRef]

15. Wang, G.; Huang, L.; Zhang, Y. Cathodic reduction of hexavalent chromium [Cr(VI)] coupled with electricity generation in microbial fuel cells. Biotechnol. Lett. 2008, 30, 1959-1966. [CrossRef] [PubMed]

16. Zhang, B.; Feng, C.; Ni, J.; Zhang, J.; Huang, W. Simultaneous reduction of vanadium (V) and chromium (VI) with enhanced energy recovery based on microbial fuel cell technology. J. Power Sources 2012, 204, 34-39. [CrossRef]

17. Huang, L.; Chen, J.; Quan, X.; Yang, F. Enhancement of hexavalent chromium reduction and electricity production from a biocathode microbial fuel cell. Bioprocess Biosyst. Eng. 2010, 33, 937-945. [CrossRef]

18. Tandukar, M.; Huber, S.J.; Onodera, T.; Pavlostathis, S.G. Biological chromium(VI) reduction in the cathode of a microbial fuel cell. Environ. Sci. Technol. 2009, 43, 8159-8165. [CrossRef]

19. Huang, L.; Chai, X.; Quan, X.; Logan, B.E.; Chen, G. Reductive dechlorination and mineralization of pentachlorophenol in biocathode microbial fuel cells. Bioresour. Technol. 2012, 111, 167-174. [CrossRef]

20. Xafenias, N.; Zhang, Y.; Banks, C.J. Enhanced performance of hexavalent chromium reducing cathodes in the presence of Shewanella oneidensis MR-1 and lactate. Environ. Sci. Technol. 2013, 47, 4512-4520. [CrossRef]

21. Thatoi, H.; Das, S.; Mishra, J.; Rath, B.P.; Das, N. Bacterial chromate reductase, a potential enzyme for bioremediation of hexavalent chromium: A review. J. Environ. Manag. 2014, 146, 383-399. [CrossRef]

22. Lovley, D.R.; Phillips, E.J.P. Reduction of Chromate by Desulfovibrio-Vulgaris and Its c3 Cytochrome. Appl. Environ. Microbiol. 1994, 60, 726-728. [CrossRef]

23. Chung, J.; Nerenberg, R.; Rittmann, B.E. Bio-reduction of soluble chromate using a hydrogen-based membrane biofilm reactor. Water Res. 2006, 40, 1634-1642. [CrossRef] [PubMed]

24. Inglett, K.S.; Bae, H.S.; Aldrich, H.C.; Hatfield, K.; Ogram, A.V. Clostridium chromiireducens sp. nov., isolated from Cr(VI)-contaminated soil. Int. J. Syst. Evol. Microbiol. 2011, 61, 2626-2631. [CrossRef] [PubMed]

25. Mclean, J.; Beveridge, T.J. Chromate Reduction by a Pseudomonad Isolated from a Site Contaminated with Chromated Copper Arsenate. Appl. Environ. Microbiol. 2001, 67, 1076-1084. [CrossRef] [PubMed]

26. McLean, J.S.; Beveridge, T.J.; Phipps, D. Isolation and characterization of a chromium-reducing bacterium from a chromated copper arsenate-contaminated site. Environ. Microbiol. 2000, 2, 611-619. [CrossRef] [PubMed]

27. Malaviya, P.; Singh, A. Bioremediation of chromium solutions and chromium containing wastewaters. Crit. Rev. Microbiol. 2016, 42, 607-633. [CrossRef] [PubMed]

28. Wang, H.; Zhang, S.; Wang, J.; Song, Q.; Zhang, W.; He, Q.; Song, J.; Ma, F. Comparison of performance and microbial communities in a bioelectrochemical system for simultaneous denitrification and chromium removal: Effects of pH. Process Biochem. 2018, 73, 154-161. [CrossRef]

29. Xue, H.; Zhou, P.; Huang, L.; Quan, X.; Yuan, J. Cathodic Cr(VI) reduction by electrochemically active bacteria sensed by fluorescent probe. Sens. Actuators B Chem. 2017, 243, 303-310. [CrossRef]

30. Pous, N.; Balaguer, M.D.; Colprim, J.; Puig, S. Opportunities for groundwater microbial electro-remediation. Microb. Biotechnol. 2018, 11, 119-135. [CrossRef]

31. Williams, K.H.; Nevin, K.P.; Franks, A.; Englert, A.; Long, P.E.; Lovley, D.R. Electrode-based approach for monitoring in situ microbial activity during subsurface bioremediation. Environ. Sci. Technol. 2010, 44, 47-54. [CrossRef]

32. Huang, L.; Wang, Q.; Jiang, L.; Zhou, P.; Quan, X.; Logan, B.E. Adaptively Evolving Bacterial Communities for Complete and Selective Reduction of $\mathrm{Cr}(\mathrm{VI}), \mathrm{Cu}(\mathrm{II})$, and $\mathrm{Cd}(\mathrm{II})$ in Biocathode Bioelectrochemical Systems. Environ. Sci. Technol. 2015, 49, 9914-9924. [CrossRef]

33. Song, T.S.; Jin, Y.; Bao, J.; Kang, D.; Xie, J. Graphene/biofilm composites for enhancement of hexavalent chromium reduction and electricity production in a biocathode microbial fuel cell. J. Hazard. Mater. 2016, 317, 73-80. [CrossRef] [PubMed]

34. Wu, X.; Zhu, X.; Song, T.; Zhang, L.; Jia, H.; Wei, P. Effect of acclimatization on hexavalent chromium reduction in a biocathode microbial fuel cell. Bioresour. Technol. 2015, 180, 185-191. [CrossRef] [PubMed]

35. Kellner, K.; Posnicek, T.; Ettenauer, J.; Zuser, K.; Brandl, M. A new, low-cost potentiostat for environmental measurements with an easy-to-use PC interface. Procedia Eng. 2015, 120, 956-960. [CrossRef] 
36. Rowe, A.A.; Bonham, A.J.; White, R.J.; Zimmer, M.P.; Yadgar, R.J.; Hobza, T.M.; Honea, J.W.; Ben-Yaacov, I.; Plaxco, K.W. Cheapstat: An open-source, "do-it-yourself" potentiostat for analytical and educational applications. PLoS ONE 2011, 6, e23783. [CrossRef]

37. Eaton, A.D.; Franson, M.A.H. Standard Methods for the Examination of Water and Wastewater, 21st ed.; American Public Health Association, Ed.; American Public Health Association: Washington, DC, USA, 2005; ISBN 9780875530475.

38. Huber, J.A.; Welch, D.B.M.; Morrison, H.G.; Huse, S.M.; Neal, P.R.; Butterfield, D.A.; Sogin, M.L. Microbial population structures in the deep marine biosphere. Science 2007, 318, 97-101. [CrossRef]

39. Wang, Y.; Qian, P.Y. Conservative fragments in bacterial $16 \mathrm{~S}$ rRNA genes and primer design for $16 \mathrm{~S}$ ribosomal DNA amplicons in metagenomic studies. PLoS ONE 2009, 4, e7401. [CrossRef]

40. Palma, E.; Daghio, M.; Espinoza Tofalos, A.; Franzetti, A.; Cruz Viggi, C.; Fazi, S.; Petrangeli Papini, M.; Aulenta, F. Anaerobic electrogenic oxidation of toluene in a continuous-flow bioelectrochemical reactor: Process performance, microbial community analysis, and biodegradation pathways. Environ. Sci. Water Res. Technol. 2018, 4, 2136-2145. [CrossRef]

41. Wang, Q.; Garrity, G.M.; Tiedje, J.M.; Cole, J.R. Naïve Bayesian classifier for rapid assignment of rRNA sequences into the new bacterial taxonomy. Appl. Environ. Microbiol. 2007, 73, 5261-5267. [CrossRef]

42. Rismani-Yazdi, H.; Carver, S.M.; Christy, A.D.; Tuovinen, O.H. Cathodic limitations in microbial fuel cells: An overview. J. Power Sources 2008, 180, 683-694. [CrossRef]

43. Lu, L.; Ren, N.; Zhao, X.; Wang, H.; Wu, D.; Xing, D. Hydrogen production, methanogen inhibition and microbial community structures in psychrophilic single-chamber microbial electrolysis cells. Energy Environ. Sci. 2011, 1329-1336. [CrossRef]

44. Wang, Y.-T. Microbial reduction of chromate. In Environmental Microbe-Metal Interactions; American Society of Microbiology: Washington, DC, USA, 2000; pp. 225-235.

45. Viti, C.; Marchi, E.; Decorosi, F.; Giovannetti, L. Molecular mechanisms of $\mathrm{Cr}(\mathrm{VI})$ resistance in bacteria and fungi. FEMS Microbiol. Rev. 2014, 38, 633-659. [CrossRef] [PubMed]

46. Huang, L.; Regan, J.M.; Quan, X. Electron transfer mechanisms, new applications, and performance of biocathode microbial fuel cells. Bioresour. Technol. 2011, 102, 316-323. [CrossRef] [PubMed]

47. Focardi, S.; Pepi, M.; Focardi, S.E. Microbial Reduction of Hexavalent Chromium as a Mechanism of Detoxification and Possible Bioremediation Applications. Biodegrad. Life Sci. 2013, 12, 321-348.

48. Vendruscolo, F.; da Rocha Ferreira, G.L.; Antoniosi Filho, N.R. Biosorption of hexavalent chromium by microorganisms. Int. Biodeterior. Biodegrad. 2017, 119, 87-95. [CrossRef]

49. Qu, Y.; Zhang, X.; Xu, J.; Zhang, W.; Guo, Y. Removal of hexavalent chromium from wastewater using magnetotactic bacteria. Sep. Purif. Technol. 2014, 136, 10-17. [CrossRef]

50. Gangadharan, P.; Nambi, I.M. Hexavalent chromium reduction and energy recovery by using dual-chambered microbial fuel cell. Water Sci. Technol. 2015, 71, 353-358. [CrossRef]

51. Li, M.; Zhou, S.; Xu, Y.; Liu, Z.; Ma, F.; Zhi, L.; Zhou, X. Simultaneous Cr(VI) reduction and bioelectricity generation in a dual chamber microbial fuel cell. Chem. Eng. J. 2018, 334, 1621-1629. [CrossRef]

52. Singhvi, P.; Chhabra, M.; Singhvi, P.; Chhabra, M. Simultaneous Chromium Removal and Power Generation Using Algal Biomass in a Dual Chambered Salt Bridge Microbial Fuel Cell. J. Bioremediat. Biodegrad. 2013, 4, 190.

53. Chao, A. Estimating the Population Size for Capture-Recapture Data with Unequal Catchability. Biometrics 1987, 43, 783-791. [CrossRef]

54. Sotres, A.; Díaz-Marcos, J.; Guivernau, M.; Illa, J.; Magrí, A.; Prenafeta-Boldú, F.X.; Bonmatí, A.; Viñas, M. Microbial community dynamics in two-chambered microbial fuel cells: Effect of different ion exchange membranes. J. Chem. Technol. Biotechnol. 2015, 90, 1497-1506. [CrossRef]

55. Barbosa, S.G.; Peixoto, L.; Soares, O.S.G.P.; Pereira, M.F.R.; Heijne, A.T.; Kuntke, P.; Alves, M.M.; Pereira, M.A. Influence of carbon anode properties on performance and microbiome of Microbial Electrolysis Cells operated on urine. Electrochim. Acta 2018, 267, 122-132. [CrossRef]

56. Read, S.T.; Dutta, P.; Bond, P.L.; Keller, J.; Rabaey, K. Initial development and structure of biofilms on microbial fuel cell anodes. BMC Microbiol. 2010, 10, 98. [CrossRef] [PubMed]

57. Joicy, A.; Song, Y.-C.; Lee, C.-Y. Electroactive microorganisms enriched from activated sludge remove nitrogen in bioelectrochemical reactor. J. Environ. Manag. 2019, 233, 249-257. [CrossRef] [PubMed] 
58. Saratale, G.D.; Saratale, R.G.; Shahid, M.K.; Zhen, G.; Kumar, G.; Shin, H.S.; Choi, Y.G.; Kim, S.H. A comprehensive overview on electro-active biofilms, role of exo-electrogens and their microbial niches in microbial fuel cells (MFCs). Chemosphere 2017, 178, 534-547. [CrossRef] [PubMed]

59. Franzetti, A.; Daghio, M.; Parenti, P.; Truppi, T.; Bestetti, G.; Trasatti, S.P.; Cristiani, P. Monod Kinetics Degradation of Low concentration Residual Organics in Membraneless Microbial Fuel Cells. J. Electrochem. Soc. 2017, 164, H3091-H3096. [CrossRef]

60. Yun, H.; Liang, B.; Kong, D.; Wang, A. Improving biocathode community multifunctionality by polarity inversion for simultaneous bioelectroreduction processes in domestic wastewater. Chemosphere 2018, 194, 553-561. [CrossRef] [PubMed]

61. Herrmann, M.; Opitz, S.; Harzer, R.; Totsche, K.; Küsel, K. Attached and Suspended Denitrifier Communities in Pristine Limestone Aquifers Harbor High Fractions of Potential Autotrophs Oxidizing Reduced Iron and Sulfur Compounds. Microb. Ecol. 2017, 74, 264-277. [CrossRef]

62. Fernandez, N.; Sierra-Alvarez, R.; Amils, R.; Field, J.A.; Sanz, J.L. Compared microbiology of granular sludge under autotrophic, mixotrophic and heterotrophic denitrification conditions. Water Sci. Technol. 2009, 59, 1227-1236. [CrossRef]

63. Im, C.H.; Kim, C.; Song, Y.E.; Oh, S.E.; Jeon, B.H.; Kim, J.R. Electrochemically enhanced microbial CO conversion to volatile fatty acids using neutral red as an electron mediator. Chemosphere 2018, 191, 166-173. [CrossRef]

64. Paiva, M.C.; Ávila, M.P.; Reis, M.P.; Costa, P.S.; Nardi, R.M.D.; Nascimento, A.M.A. The microbiota and abundance of the class 1 integron-integrase gene in tropical sewage treatment plant influent and activated sludge. PLoS ONE 2015, 10, e0131532. [CrossRef]

65. Khanongnuch, R.; Di Capua, F.; Lakaniemi, A.-M.; Rene, E.R.; Lens, P.N.L. $\mathrm{H}_{2} \mathrm{~S}$ removal and microbial community composition in an anoxic biotrickling filter under autotrophic and mixotrophic conditions. J. Hazard. Mater. 2018, 367, 397-406. [CrossRef] [PubMed]

66. Morel, M.A.; Iriarte, A.; Jara, E.; Musto, H.; Castro-Sowinski, S. Revealing the biotechnological potential of Delftia sp. JD2 by a genomic approach. AIMS Bioeng. 2016, 3, 156-175. [CrossRef]

67. Chen, J.; Yang, Y.; Liu, Y.; Tang, M.; Wang, R.; Tian, Y.; Jia, C. Bacterial community shift and antibiotics resistant genes analysis in response to biodegradation of oxytetracycline in dual graphene modified bioelectrode microbial fuel cell. Bioresour. Technol. 2019, 276, 236-243. [CrossRef] [PubMed]

68. Mei, J.; Wu, Y.; Qian, F.; Chen, C.; Shen, Y.; Zhao, Y. Methane-Oxidizing Microorganism Properties in Landfills. Polish J. Environ. Stud. 2019, 28, 3809-3818. [CrossRef]

69. Schauss, T.; Busse, H.J.; Golke, J.; Kämpfer, P.; Glaeser, S.P. Moheibacter stercoris sp. Nov., isolated from an input sample of a biogas plant. Int. J. Syst. Evol. Microbiol. 2016, 66, 2585-2591. [CrossRef]

70. Liao, C.; Wu, J.; Zhou, L.; Li, T.; Du, Q.; An, J.; Li, N.; Wang, X. Optimal set of electrode potential enhances the toxicity response of biocathode to formaldehyde. Sci. Total Environ. 2018, 644, 1485-1492. [CrossRef]

71. Sun, J.; Xu, W.; Yang, P.; Li, N.; Yuan, Y.; Zhang, H.; Ning, X.; Zhang, Y.; Chang, K.; Peng, Y.; et al. Enhancing the performance of photo-bioelectrochemical fuel cell using graphene oxide/cobalt/polypyrrole composite modified photo-biocathode in the presence of antibiotic. Int. J. Hydrogen Energy 2018, 44, 1919-1929. [CrossRef]

72. Huang, L.; Wang, Q.; Quan, X.; Liu, Y.; Chen, G. Bioanodes/biocathodes formed at optimal potentials enhance subsequent pentachlorophenol degradation and power generation from microbial fuel cells. Bioelectrochemistry 2013, 94, 13-22. [CrossRef]

73. Xiao, Y.; Zheng, Y.; Wu, S.; Yang, Z.H.; Zhao, F. Bacterial Community Structure of Autotrophic Denitrification Biocathode by 454 Pyrosequencing of the 16S rRNA Gene. Microb. Ecol. 2015, 69, 492-499. [CrossRef]

74. Liao, C.; Wu, J.; Zhou, L.; Li, T.; An, J.; Huang, Z.; Li, N.; Wang, X. Repeated transfer enriches highly active electrotrophic microbial consortia on biocathodes in microbial fuel cells. Biosens. Bioelectron. 2018, 121, 118-124. [CrossRef]

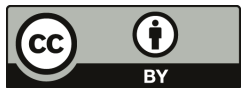

(C) 2020 by the authors. Licensee MDPI, Basel, Switzerland. This article is an open access article distributed under the terms and conditions of the Creative Commons Attribution (CC BY) license (http://creativecommons.org/licenses/by/4.0/). 

Article

\title{
Comparing the Adsorption Performance of Multiwalled Carbon Nanotubes Oxidized by Varying Degrees for Removal of Low Levels of Copper, Nickel and Chromium(VI) from Aqueous Solutions
}

Marko Šolić ${ }^{1}$, Snežana Maletić ${ }^{1, *}$, Marijana Kragulj Isakovski ${ }^{1}$, Jasmina Nikić ${ }^{1}$, Malcolm Watson ${ }^{1}$, Zoltan Kónya ${ }^{2,3}$ and Jelena Tričković ${ }^{1}$

1 Department of Chemistry, Biochemistry and Environmental Protection, Faculty of Sciences, University of Novi Sad, Trg Dositeja Obradovića 3, 21000 Novi Sad, Serbia; marko.solic@dh.uns.ac.rs (M.S.); marijana.kragulj@dh.uns.ac.rs (M.K.I.); jasmina.nikic@dh.uns.ac.rs (J.N.); malcolm.watson@dh.uns.ac.rs (M.W.); jelena.trickovic@dh.uns.ac.rs (J.T.)

2 Department of Applied and Environmental Chemistry, University of Szeged, Rerrich Béla tér 1, H-6720 Szeged, Hungary; konya@chem.u-szeged.hu

3 MTA-SZTE Reaction Kinetics and Surface Chemistry Research Group, Rerrich Béla tér 1, H-6720 Szeged, Hungary

* Correspondence: snezana.maletic@dh.uns.ac.rs; Tel.: +381-21-485-2727

Received: 31 January 2020; Accepted: 3 March 2020; Published: 6 March 2020

\begin{abstract}
Functionalized multiwalled carbon nanotubes (MWCNTs) have drawn wide attention in recent years as novel materials for the removal of heavy metals from the aquatic media. This paper investigates the effect that the functionalization (oxidation) process duration time ( $3 \mathrm{~h}$ or $6 \mathrm{~h}$ ) has on the ability of MWCNTs to treat water contaminated with low levels of $\mathrm{Cu}(\mathrm{II}), \mathrm{Ni}(\mathrm{II})$ and $\mathrm{Cr}(\mathrm{VI})$ (initial concentrations $0.5-5 \mathrm{mg} \mathrm{L}^{-1}$ ) and elucidates the adsorption mechanisms involved. Adsorbent characterization showed that the molar ratio of $\mathrm{C}$ and $\mathrm{O}$ in these materials was slightly lower for the oxMWCNT6h, due to the higher degree of oxidation, but the specific surface areas and mesopore volumes of these materials were very similar, suggesting that prolonging the functionalization duration had an insignificant effect on the physical characteristics of oxidized multiwalled carbon nanotubes (oxMWCNTs). Increasing the $\mathrm{Ph}$ of the solutions from $\mathrm{Ph} 2$ to $\mathrm{Ph} 8$ had a large positive impact on the removal of $\mathrm{Cu}(\mathrm{II})$ and $\mathrm{Ni}(\mathrm{II})$ by oxMWCNT, but reduced the adsorption of $\mathrm{Cr}(\mathrm{VI})$. However, the ionic strength of the solutions had far less pronounced effects. Coupled with the results of fitting the kinetics data to the Elowich and Weber-Morris models, we conclude that adsorption of $\mathrm{Cu}(\mathrm{II})$ and $\mathrm{Ni}(\mathrm{II})$ is largely driven by electrostatic interactions and surface complexation at the interface of the adsorbate/adsorbent system, whereas the slower adsorption of $\mathrm{Cr}(\mathrm{VI})$ on the oxMWCNTs investigated is controlled by an additional chemisorption step where $\mathrm{Cr}(\mathrm{VI})$ is reduced to $\mathrm{Cr}(\mathrm{III})$. Both oxMWCNT3h and oxMWCNT6h have high adsorption affinities for the heavy metals investigated, with adsorption capacities (expressed by the Freundlich coefficient $K_{F}$ ) ranging from 1.24 to $13.2\left(\mathrm{mg} \mathrm{g}^{-1}\right) /\left(\mathrm{mg} \mathrm{l}^{-1}\right)^{\mathrm{n}}$, highlighting the great potential such adsorbents have in the removal of heavy metals from aqueous solutions.
\end{abstract}

Keywords: adsorption; heavy metals; carbon nanotubes; adsorption mechanism

\section{Introduction}

Heavy metals, as naturally occurring elements, can originate from both natural and anthropogenic sources. However, the increasing release of these pollutants in more toxic and mobile forms has made anthropogenic sources a worldwide issue [1]. The main anthropogenic sources of heavy metals in the 
aquatic environment can be attributed to urbanization, industrialization (in particular the wastewater of modern chemical plants) and certain agricultural activities [1,2]. Metal processing and mining contribute to $48 \%$ of the total release of contaminants by the European industrial sector [3]. Heavy metals cannot undergo biodegradation processes and accumulate in the environment and living organisms at all levels of the food chain, making this group of pollutants even more noteworthy. A number of health problems may result from human exposure, intake and eventual buildup of non-essential (e.g., $\mathrm{Cr}(\mathrm{VI})$ and Ni) and even essential heavy metals (e.g., Cu) [2,4,5].

For this reason, the permissible concentrations of toxic elements in drinking water, surface waters and wastewaters before discharge to recipients, are set to very low levels. For example, the WHO provisional guideline values for $\mathrm{Cu}, \mathrm{Ni}$ and $\mathrm{Cr}$ are $2 \mathrm{mg} \mathrm{L}^{-1}, 0.07 \mathrm{mg} \mathrm{L}^{-1}$ and $0.05 \mathrm{mg} \mathrm{L}^{-1}$, respectively [6]. Emission levels for those metals in the most wastewater streams, according to the best available technologies, have been limited in the range of 0.01 to the $0.5 \mathrm{mg} \mathrm{L}^{-1}[7,8]$. These concentrations are low, and thus, further treatment in order to comply with legislation is a difficult task. Conventional techniques such as chemical precipitation, coagulation and flocculation etc., are not efficient and are not able to remove low concentrations of target pollutants to permissible levels [2,9]. Techniques such as membrane filtration and ion exchange work well at low concentrations and achieve high efficacies, but suffer from disadvantages such as high operational cost and operational problems, etc. [1,10].

Adsorption can be an economically sustainable and viable solution for the removal of heavy metals from aqueous solutions. Adsorption has many advantages, such as simple operation, low cost, good Ph tolerance, and large industrial processing capacity $[2,9,11,12]$. However, there is still a need to develop and study new adsorbents, as many of the commonly applied adsorbent materials (activated carbons, zeolites, clay minerals, solid by-products of industrial processes and biosorbents) do not show satisfactory performance for the removal of heavy metals present in low concentrations [10]. Nanomaterials and especially carbon nanotubes (CNT) stand out as particularly promising materials to meet the requirements outlined above $[4,10,11,13,14]$. In order to achieve the desired level of efficiency for heavy metal removal, CNT functionalization has been widely investigated in recent years. The functionalization of CNT has already led to the development of new adsorbents for aqueous heavy metal treatments with state-of-the-art performance [10]. Even so, many review papers have recognized gaps in the current knowledge, whereby the majority of studies conducted concern the adsorption of very high concentrations of the heavy metals investigated, or do not explore the effects of preparation conditions on the functionalized nanomaterials (such as oxidation process duration, etc.) or the combined effects of different parameters on the adsorption process, or do not investigate the potential mechanism and chemistry involved in the heavy metals removal $[1,4,10,11,13-16]$. Oxidation of CNT is one of the simplest and therefore most economically viable functionalization techniques [10]. Regarding the removal of heavy metals such as $\mathrm{Cu}(\mathrm{II}), \mathrm{Ni}(\mathrm{II})$ and $\mathrm{Cr}(\mathrm{VI})$ by CNT, the literature data is very limited, with papers which deal with just one level of CNT oxidation and which investigate adsorption at high concentration levels above $10 \mathrm{mg} \mathrm{L}^{-1}$ [17-23].

The aim of this paper was therefore to investigate how the duration of the oxidation process of multiwalled carbon nanotubes (oxMWCNT3h or oxMWCNT6h) effects their use for the treatment of water contaminated with low levels of $\mathrm{Cu}(\mathrm{II}), \mathrm{Ni}(\mathrm{II})$ and $\mathrm{Cr}(\mathrm{VI})$, and to give insight into the adsorption mechanism of these metals on the oxidized MWCNTs. In order to achieve this goal, the synthesized adsorbents have been extensively characterized and the adsorption process was characterized by examining the contact time, the heavy metals concentration, and the $\mathrm{Ph}$ and ionic strength of the solutions.

\section{Materials and Methods}

\subsection{Materials and Chemicals}

Oxidized multiwalled carbon nanotubes (oxMWCNTs) were synthesized (by chemical vapour deposition) at the University of Szeged, according to the method described elsewhere [24]. Functionalization of MWCNTs was also carried out at the aforementioned institution under varying 
conditions to provide two different adsorbents for this study, following this procedure: (Step 1) $10 \mathrm{~g}$ of pristine MWCNTs was mixed with $1 \mathrm{~L}$ of $\mathrm{cc}$. $\mathrm{HNO}_{3}$ for $1 \mathrm{~h}$ by means of magnetic stirring, (Step 2) the obtained suspension was oxidized under reflux for $3 \mathrm{~h}$ (oxMWCNT3h) or $6 \mathrm{~h}$ (oxMWCNT6h), then (Step 3) rinsed with eionized water until neutral Ph was obtained. The oxMWCNTs selected for this study were then used as received. Stock solutions of $\mathrm{Cu}$ (II) and $\mathrm{Ni}(\mathrm{II})\left(100 \mathrm{mg} \mathrm{L}^{-1}\right)$ were prepared by diluting the appropriate metal standard solutions $\left(1000 \mathrm{mg} \mathrm{L}^{-1}\right)$, while the $\mathrm{Cr}(\mathrm{VI})$ stock solution (100 mg L ${ }^{-1}$ ) was obtained by dissolving $\mathrm{K}_{2} \mathrm{Cr}_{2} \mathrm{O}_{7}$ in deionized water. The stock solutions were further diluted to the desired metals concentrations. All chemicals used in this research were analytical grade and were purchased from Merck Co. The experiments were performed using ultrapure deionized water (resistivity not less than $17.5 \mathrm{M} \Omega$ ).

\subsection{Adsorbents Characterisation}

The specific surface areas, pore sizes, pore volumes and pore-size distributions of the investigated adsorbents were determined from nitrogen adsorption/desorption isotherms at $77 \mathrm{~K}$, acquired by the AutosorbiQ Surface Area Analyzer (Quantachrome Instruments, USA). The specific surface areas were calculated using the multi-point Brunauer-Emmett-Teller (BET) method, while meso and micro pore volumes were obtained by the utilization of the desorption Barrett-Joyner-Halenda (BJH) isotherms and t-test method, respectively. Scanning electron microscopy (SEM) (TM3030, Hitachi High-Technologies, Japan) coupled with energy dispersive spectrometry (EDS) (Bruker Quantax 70 X-ray detector system, Bruker Nano, GmbH Germany) and transmission electron microscopy (TEM) (Philips CM10) were used to examine the materials morphological structures and surface elemental compositions. Identification of the functional groups present on the oxMWCNT3h and oxMWCNT6h was carried out by Fourier transform infrared (FTIR) spectrometry (Thermo-Nicolet Nexus 670 (USA) FTIR spectrometer), in the $4000-400 \mathrm{~cm}^{-1}$ range and in a diffuse reflection mode at a resolution of $4 \mathrm{~cm}^{-1}$. The points of zero charge ( $\mathrm{pHpzc}$ ) of the adsorbents were obtained by adjusting the $\mathrm{Ph}$ value of $0.1 \mathrm{M} \mathrm{NaNO}_{3}$ solutions in the range from 2 to 6 , followed by measuring the Ph change of the $\mathrm{NaNO}_{3} / \mathrm{oxMWCNTs}$ mixtures after $24 \mathrm{~h}$ of contact.

\subsection{Adsorption Experiments}

All adsorption studies were carried out in batch experiments conducted according to the following general procedure: (Step 1) $5 \mathrm{mg}$ of oxMWCNT3h or oxMWCNT6h was weighed into $40 \mathrm{Ml}$ glass vials, (Step 2) $30 \mathrm{Ml}$ of background solution $\left(\mathrm{NaNO}_{3}\right)$ was added to each vial, (Step 3) oxMWCNT3h/NaNO and oxMWCNT6h/ $\mathrm{NaNO}_{3}$ suspensions were subjected to $30 \mathrm{~min}$ of sonication (to enhance the dispersion of the adsorbents) (Ultrasons 1 litre bath), followed by stirring at $180 \mathrm{rpm}$ (to pre-equilibrate oxMWCNTs and $\mathrm{NaNO}_{3}$ ) for $24 \mathrm{~h}$, (Step 4) stock solutions of $\mathrm{Cu}(\mathrm{II}), \mathrm{Ni}(\mathrm{II})$ or $\mathrm{Cr}(\mathrm{VI})$ were spiked to achieve desired concentrations of selected heavy metals, (Step 5) the Ph of adsorption systems was adjusted by adding 0.1 and/or $0.01 \mathrm{M} \mathrm{NaOH}$ or $\mathrm{HNO}_{3}$, (Step 6) the adsorption systems were stirred for a certain period of time at $180 \mathrm{rpm}$ and constant temperature of $298 \mathrm{~K}$, (Step 7) the solid and liquid phases were separated by filtering the samples through $0.45 \mu \mathrm{m}$ cellulose acetate membrane filters, (Step 8) the residual $\mathrm{Cu}(\mathrm{II}), \mathrm{Ni}(\mathrm{II})$ or $\mathrm{Cr}(\mathrm{VI})$ concentrations were determined using ICP-MS technique (Agilent Technologies 7700 Series ICP-MS). Method detection limits for the metals investigated were as follows: $\mathrm{Cu}(\mathrm{II}): 0.001 \mathrm{mg} \mathrm{L}^{-1}, \mathrm{Ni}(\mathrm{II}): 0.001 \mathrm{mg} \mathrm{L}^{-1}$, and $\mathrm{Cr}(\mathrm{VI}): 0.001 \mathrm{mg} \mathrm{L}^{-1}$.

The following deviations from this general procedure were made in order to investigate a variety of operational parameters: (1) influence of contact time-adsorption systems were stirred for various durations, ranging from $5 \mathrm{~min}$ to $24 \mathrm{~h}$ for $\mathrm{Cu}(\mathrm{II})$ and $\mathrm{Ni}(\mathrm{II})$, and in the case of $\mathrm{Cr}(\mathrm{VI})$, from $5 \mathrm{~min}$ to $168 \mathrm{~h}$ (Step 6); (2) influence of initial metal concentration-initial $\mathrm{Cu}(\mathrm{II}), \mathrm{Ni}(\mathrm{II})$ or $\mathrm{Cr}(\mathrm{VI})$ concentrations were varied between 0.5 and $5 \mathrm{mg} \mathrm{L}^{-1}$ (Step 4); (3) influence of $\mathrm{Ph}$-initial sample $\mathrm{Ph}$ was adjusted to different values, ranging from 2 to 8 (Step 5); (4) influence of ionic strength-the $\mathrm{NaNO}_{3}$ concentration in the background solutions was varied between 0.1 and $1 \mathrm{M}$ (Step 2). Unless otherwise indicated, operational parameters were: (1) contact time-24 h (Cu(II) and $\mathrm{Ni}(\mathrm{II}))$ and $96 \mathrm{~h}(\mathrm{Cr}(\mathrm{VI}))$, (2) $1 \mathrm{mg} \mathrm{L}^{-1}$ 
initial metal concentration, (3) initial $\mathrm{Ph}=5(\mathrm{Cu}(\mathrm{II})$ and $\mathrm{Ni}(\mathrm{II}))$ and $\mathrm{Ph}=2.5(\mathrm{Cr}(\mathrm{VI}))$, (4) $0.1 \mathrm{M} \mathrm{NaNO}_{3}$ ionic strength. The decision to investigate the effect of $\mathrm{Ph}$ and ionic strength in this work was made on the basis of the importance that the scientific literature assigns to these parameters.

In order to establish that the observed removals of heavy metals were a consequence of their adsorption on oxMWCNT3h and oxMWCNT6h, and not the result of some other processes (e.g., adsorption on glass vials walls, precipitation, etc.), triplicate blank experiments without the addition of the adsorbents were performed, according to the procedures given above. The levels of $\mathrm{Cu}$ (II), $\mathrm{Ni}(\mathrm{II})$ or $\mathrm{Cr}(\mathrm{VI})$ detected in these runs were used in all calculations as initial adsorbate concentrations. Experimental uncertainty, including instrumental errors, were determined using triplicates of the batch experiments and control samples in each adsorption series, with relative standard deviations falling mostly within $\pm 5 \%$ of the reported values.

The adsorption capacities of oxMWCNT3h and oxMWCNT6h for the heavy metals investigated were calculated using mass balance Equation (1). Removal efficiencies of $\mathrm{Cu}(\mathrm{II}), \mathrm{Ni}(\mathrm{II})$ or $\mathrm{Cr}(\mathrm{VI})$ were determined by Equation (2).

$$
\begin{aligned}
q_{t}\left(\text { or } q_{e}\right) & =\frac{\left(C_{0}-C_{t}\left(\text { or } C_{e}\right)\right)}{m} V \\
R E_{t}\left(\text { or } R E_{e}\right) & =\frac{\left(C_{0}-C_{t}\left(\text { or } C_{e}\right)\right)}{C_{0}} \times 100
\end{aligned}
$$

where: $q_{t}$ and $q_{e}$ represent adsorption capacity per gram dry weight of the adsorbents at a specific time and at the state of equilibrium $\left(\mathrm{mg} \mathrm{g}^{-1}\right) ; C_{0}, C_{t}$ and $C_{e}$ are the initial, specific time and equilibrium adsorbate concentrations in the liquid phase $\left(\mathrm{mg} \mathrm{L}^{-1}\right) ; V$ is the volume of the liquid phase (L); $m$ is the dry weight of the adsorbent $(\mathrm{g}) ; R E_{t}$ and $R E_{e}$ are the specific time and equilibrium adsorbate removal efficiencies (\%).

\subsection{Adsorption Kinetics and Isotherms Modelling}

\subsubsection{Adsorption Kinetics}

In order to identify the adsorbate uptake rate, the rate-controlling step and to obtain insight into the possible mechanisms/reaction pathways of the investigated adsorption processes, four kinetic models (Lagergren pseudo-first order, pseudo-second order, Elovich and Weber-Morris (intra-particle diffusion)) were used to fit the experimental data.

The non-linear equations and parameters of the kinetic models tested, as well as information concerning their relationship to the potentially rate limiting adsorption steps, are provided in Table 1 .

\begin{tabular}{|c|c|c|}
\hline Model & Model Equation & Model Parameters \\
\hline Lagergren pseudo-first order (a) & $q_{t}=q_{e}\left(1-e^{-k_{1} t}\right)$ & $k_{1}$-Lagergren pseudo-first order rate constant $\left(\mathrm{h}^{-1}\right)$ \\
\hline Pseudo-second order (b) & $\begin{aligned} q_{t} & =\frac{q_{e}^{2} k_{2} t}{1+k_{2} t q_{e}} \\
h & =k_{2} q_{e}^{2}\end{aligned}$ & $\begin{array}{l}k_{2} \text {-pseudo-second order rate constant }\left(\mathrm{g} \mathrm{mg}^{-1} \mathrm{~h}^{-1}\right) \\
h \text {-initial adsorption rate }\left(\mathrm{mg} \mathrm{g}^{-1} \mathrm{~h}^{-1}\right)\end{array}$ \\
\hline Elovich ${ }^{(c)}$ & $q_{t}=\frac{1}{\beta} \ln (1+\alpha \beta t)$ & $\begin{array}{l}\alpha \text {-initial adsorption rate }\left(\mathrm{g} \mathrm{mg}^{-1} \mathrm{~h}^{-2}\right) \\
\beta \text { - extent of surface coverage and the activation energy } \\
\text { for chemisorption }\left(\mathrm{g} \mathrm{mg}^{-1}\right)\end{array}$ \\
\hline $\begin{array}{l}\text { Weber-Morris (intra-particle } \\
\text { diffusion) (d) }\end{array}$ & $q_{t}=k_{3} t^{0.5}$ & $k_{3}$-intra-particle diffusion rate constant $\left(\mathrm{mg} \mathrm{g} \min ^{0.5}\right)$ \\
\hline
\end{tabular}

Table 1. Adsorption kinetics models.

Note: Potential steps involved in heavy metal adsorption by porous adsorbents: (1) transport from bulk liquid phase to the external surface of the adsorbent; (2) passage through the liquid film attached to the solid surface; (3) interactions with the adsorbent surface (limiting step in reaction-based models ${ }^{(a)}$, (b) and (c); (4) diffusion into adsorbent internal sites (pores and interstitial channels) (limiting step in the diffusion-based ${ }^{(d)}$ model) [25]. 


\subsubsection{Adsorption Isotherms}

In order to obtain data concerning the maximum adsorption capacity of the adsorbents, as well as to get a better understanding of the adsorption mechanisms, the Freundlich, Langmuir and Dubinin-Radushkevic (D-R) isotherm models were used to analyze the experimental equilibrium data.

The non-linear mathematical expressions, parameters and the most significant assumptions of the three applied models, along with the equations for the separation factor (also called the equilibrium parameter) and adsorption activation energy, which are essential features of the Langmuir and D-R isotherms, are given in Table 2.

Table 2. Adsorption isotherm models.

\begin{tabular}{|c|c|c|}
\hline Model & Model Equation & Model Parameters \\
\hline Freundlich ${ }^{\text {(a) }}$ & $q_{e}=K_{F} C_{e}^{n}$ & $\begin{array}{l}K_{F} \text {-Freundlich constant indicating the adsorption } \\
\text { capacity }\left(\left(\mathrm{mg} \mathrm{g}^{-1}\right)\left(\mathrm{L} \mathrm{mg}^{-1}\right)^{1 / \mathrm{n})}\right. \\
n-\text { Freundlich exponent related to the energy } \\
\text { distribution of adsorption sites (adsorption intensity) } \\
\text { (dimensionless) }\end{array}$ \\
\hline \multirow[t]{2}{*}{ Langmuir $^{(b)}$} & $q_{e}=\frac{q_{m} K_{L} C_{e}}{1+K_{L} C_{e}}$ & $\begin{array}{l}q_{m}-\text { maximum adsorption capacity }\left(\mathrm{mg} \mathrm{g}^{-1}\right) \\
K_{L}-\text { Langmuir constant representing the energy of } \\
\text { adsorption process }\left(\mathrm{L} \mathrm{mg}^{-1}\right)\end{array}$ \\
\hline & $R_{L}=\frac{1}{1+K_{L} C_{0}}$ & $\begin{array}{l}R_{L} \text {-Langmuir separation factor associated with } \\
\text { adsorption favourability (dimensionless) }\end{array}$ \\
\hline \multirow[t]{2}{*}{$\mathrm{D}-\mathrm{R}^{(\mathrm{c})(*)}$} & $q_{e}=q_{d}{ }^{-K_{D} R T \ln \left(1+1 / C_{e}\right)}$ & $\begin{array}{l}q_{d} \text {-maximum adsorption capacity }\left(\mathrm{mg} \mathrm{g}^{-1}\right) \\
K_{D}-\mathrm{D}-\mathrm{R} \text { constant corresponding to the mean free } \\
\text { energy of adsorption }\left(\mathrm{mol} 2 \mathrm{~K}^{-1} \mathrm{~J}^{-2}\right)\end{array}$ \\
\hline & $E_{a}=\frac{1}{\sqrt{2 K_{D}}}$ & $E_{a}$ - activation energy $\left(\mathrm{kJ} \mathrm{mol}^{-1}\right)$ \\
\hline
\end{tabular}

(a) An empirical equation describing multilayer adsorption onto energy-heterogeneous surfaces with interactions between adsorbed species. The stronger binding sites are occupied first and the binding strength decreases as site occupation increases. ${ }^{(b)}$ A theoretical equation describing monolayer adsorption onto energy-homogenous surfaces with no lateral interaction and steric hindrance between the adsorbed molecules, even on adjacent sites. All binding sites are characterized by the same energy, which makes the binding strength identical throughout the adsorption sites are characterized by the same energy, which makes the binding strength identical throughout the adsorption
process. (c) A semi-empirical equation describing adsorption with Gaussian energy distribution onto heterogeneous surfaces. It is usually applied to differentiate between physical and chemical adsorption of metal ions [26]. $\left({ }^{*}\right) R$ is the universal gas constant $\left(8.314 \mathrm{~J} \mathrm{~mol}^{-1} \mathrm{~K}^{-1}\right)$.

\section{Results and Discussion}

\subsection{Adsorbents Characterization}

The TEM images of oxMWCNT3h and oxMWCNT6h are shown in Figure 1. The tubes are long and curved forming entangled oxMWCNTs networks. Note that the tubes have open ends as a result of the chemical functionalization (oxidation with cc. $\mathrm{HNO}_{3}$ ) [17]. The opening up of the tubes has led to defects on the sidewalls of the nanotubes and has shortened their length. The inner tube diameters of oxMWCNT3h and oxMWCNT6h, ranged from 7-12 and 9-18 nm respectively, while the outer tube diameters of these materials were 15-24 and 7-32 nm [27]. 


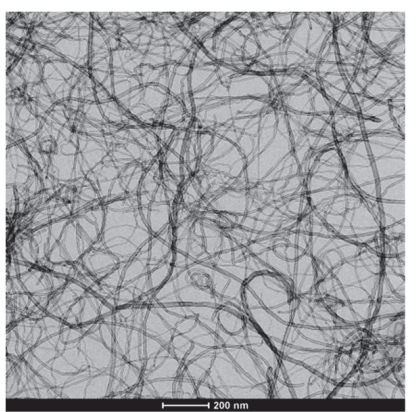

(a)

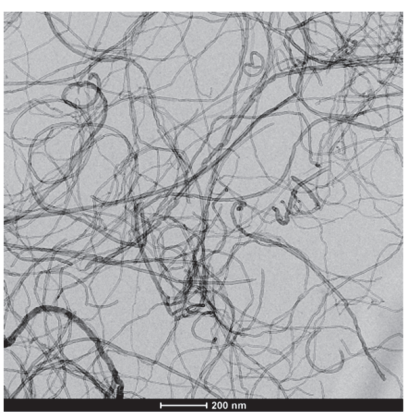

(b)

Figure 1. TEM images of: (a) oxMWCNT3h and (b) oxMWCNT6h.

Scanning electron microscopy was also used to investigate the surface morphology of oxMWCNT3h and oxMWCNT6h (Figure S1). It is evident that the surface of oxMWCNTs mainly consists of aggregated nanotubes. EDS analysis of oxMWCNT3h and oxMWCNT6h confirms that $\mathrm{C}$ and $\mathrm{O}$ are the dominant elements on the surface of these materials. The molar ratios of $\mathrm{C}$ and $\mathrm{O}$ in these materials were lower for oxMWCNT6h (11.32:1 compared to 9.32:1), as a consequence of the higher rate of oxidation. Traces of $\mathrm{N}$ originates from the $\mathrm{HNO}_{3}$ which was used for functionalization of oxMWCNTs (Table S1).

The FTIR spectra of oxMWCNT3h and oxMWCNT6h are presented in Figure 2. Both spectra exhibit broad peaks at $3420 \mathrm{~cm}^{-1}$ which can be assigned to $-\mathrm{OH}$ stretching vibration of carboxylic and phenolic groups (-COOH and -COH). Absorption peaks at 2973 and $2923 \mathrm{~cm}^{-1}$ relate to the asymmetric and symmetric stretching vibrations of $\mathrm{C}-\mathrm{H}$ originating from the surface of the tubes or from the sidewalls [20,28]. The peaks at 1630 and $1633 \mathrm{~cm}^{-1}$ can be attributed to bending vibration of $-\mathrm{OH}$ groups from physisorbed water molecules. The peaks at 1574, 1386, and $1396 \mathrm{~cm}^{-1}$, observed in FTIR spectra of oxMWCNT3h, are associated with asymmetric and symmetric vibration of -COO groups [17,28]. Absorption peaks at 1046, 1086, and $1163 \mathrm{~cm}^{-1}$ in FTIR spectra of oxMWCNT3hare are associated with deformation vibrations of the $-\mathrm{OH}$ in alcohol, phenolic and carboxyl groups [20,21,28]. Generally, these oxygen-containing functional groups provide numerous adsorption sites and thus increase the adsorption capacity of the MWCNTs for metal ions $[17,20]$.

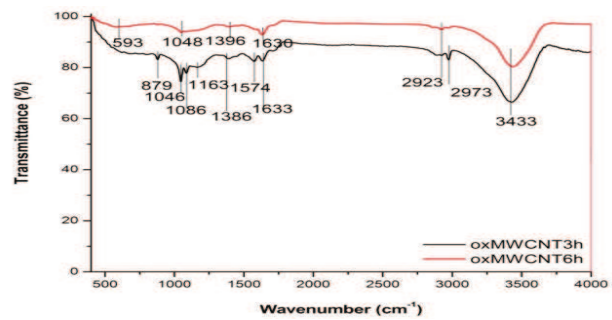

Figure 2. FTIR spectra of oxMWCNT3h and oxMWCNT6h.

The textural characteristics of oxMWCNT3h and oxMWCNT6h, including specific surface area, mesopore and micropore volumes and average pore size are shown in Table 3.

The specific surface areas of oxMWCNT3h and oxMWCNT6h, as well as the mesopore volume of these materials, were very similar, implying that the prolonged mixing time during functionalization has an insignificant effect on the physical characteristics of oxMWCNTs (Table 1). Moreover, the specific surface area of these materials is significantly higher than the specific surface area of MWCNTs which functionalized differently, using $\mathrm{H}_{2} \mathrm{O}_{2}$ and $\mathrm{HNO}_{3}$ (in a ratio of $\left.1: 3(\mathrm{v} / \mathrm{v})\right)\left(196 \mathrm{~m}^{2} \mathrm{~g}^{-1}\right)$ [17]. The point of zero charges of oxMWCNT3h and oxMWCNT6h are 3.2 and 3.4, respectively (Figure S2). 
Table 3. Textural properties of oxMWCNT3h and oxMWCNT6h.

\begin{tabular}{cccc}
\hline & & oxMWCNT3h & oxMWCNT6h \\
\hline Specific surface area & $\left(\mathrm{m}^{2} \mathrm{~g}^{-1}\right)$ & 277 & 273 \\
Mesopore volume $(2-50 \mathrm{~nm})$ & $\left(\mathrm{cm}^{3} \mathrm{~g}^{-1}\right)$ & 1.95 & 1.65 \\
Micropore volume $(<2 \mathrm{~nm})$ & $\left(\mathrm{cm}^{3} \mathrm{~g}^{-1}\right)$ & $8 \times 10^{-3}$ & $1 \times 10^{-3}$ \\
Average pore size & $(\mathrm{nm})$ & 14.2 & 12.2 \\
\hline
\end{tabular}

3.2. Influence of Contact Time and Investigation of Adsorption Kinetics

\subsubsection{Influence of Contact Time}

The influence of contact time on the removal of $\mathrm{Cu}(\mathrm{II}), \mathrm{Ni}(\mathrm{II})$ and $\mathrm{Cr}(\mathrm{VI})$ by oxMWCNT3h and oxMWCNT6h, presented as $q_{t}$ vs. $t$, is shown in Figure 3.
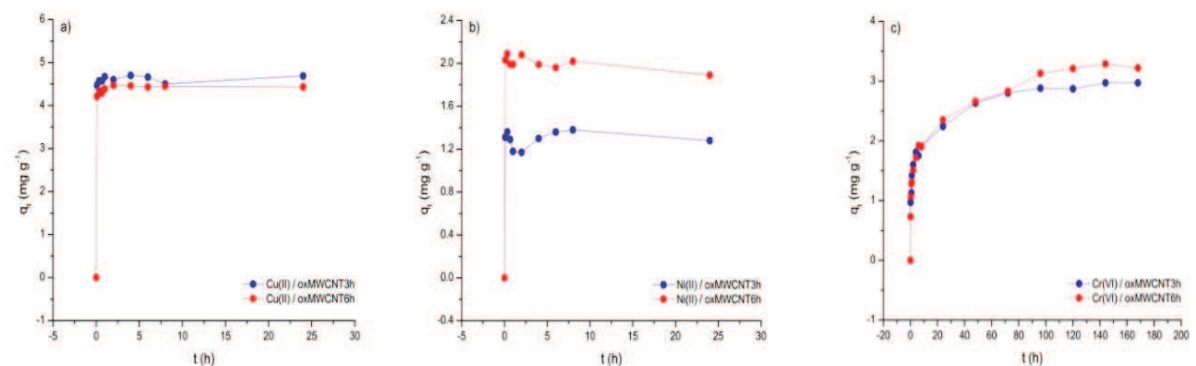

Figure 3. Adsorption of: (a) $\mathrm{Cu}(\mathrm{II}),(\mathbf{b}) \mathrm{Ni}(\mathrm{II})$ and (c) $\mathrm{Cr}(\mathrm{VI})$ on oxMWCNT3h and oxMWCNT6h as a function of contact time $\left(m=5 \mathrm{mg}, V=30 \mathrm{~mL}\left(0.1 \mathrm{M} \mathrm{NaNO}_{3}\right), \mathrm{C}_{0}=1 \mathrm{mg} \mathrm{L}^{-1}, \mathrm{pH}=5 \pm 0.1(\mathrm{Cu}\right.$ (II) and $\mathrm{Ni}(\mathrm{II}))$ and $2.5 \pm 0.1(\mathrm{Cr}(\mathrm{VI})), t=5 \mathrm{~min}-24 \mathrm{~h}(\mathrm{Cu}(\mathrm{II})$ and $\mathrm{Ni}(\mathrm{II}))$ and $5 \mathrm{~min}-168 \mathrm{~h}(\mathrm{Cr}(\mathrm{VI}))$, agitation speed $=180 \mathrm{rpm}, \mathrm{T}=298 \pm 2 \mathrm{~K}$ )

As can be seen in Figure 3, in the case of both investigated adsorbents, equilibrium for $\mathrm{Cu}(\mathrm{II})$ and $\mathrm{Ni}(\mathrm{II})$, was reached very quickly, in less than $20 \mathrm{~min}$, indicating that the adsorption of these metals is predominantly controlled by the interactions taking place on the adsorbate/adsorbent surface. Throughout the entire studied duration, $q_{t}$ (and $R E_{t}$ ) values remained very stable, averaging $4.60 \mathrm{mg}$ $\mathrm{g}^{-1}(85.1 \%), 4.39 \mathrm{mg} \mathrm{g}^{-1}(93.0 \%), 1.29 \mathrm{mg} \mathrm{g}^{-1}(25.2 \%)$ and $2.00 \mathrm{mg} \mathrm{g}^{-1}(39.5 \%)$ for $\mathrm{Cu}(\mathrm{II})$ and $\mathrm{Ni}(\mathrm{II})$, respectively. Unlike in the case of $\mathrm{Cu}(\mathrm{II})$, the difference in the affinity of the studied oxMWCNTs for $\mathrm{Ni}(\mathrm{II})$ proved evident already in this type of adsorption experiments. Similar results have been obtained by other authors $[23,25,29]$.

In contrast, the overall $\mathrm{Cr}(\mathrm{VI})$ adsorption rate for the two examined oxMWCNTs was much lower, with approximately $96 \mathrm{~h}$ required to reach equilibrium. Over the monitored period of time, the rate of $\mathrm{Cr}(\mathrm{VI})$ removal changed-during the first $8 \mathrm{~h}$ it was very high, and then slowly started to decline as the systems gradually approached a state of equilibrium. This behavior immediately suggests that $\mathrm{Cr}(\mathrm{VI})$ adsorption kinetics are controlled by more than one process of different physical origins (e.g., film diffusion, surface interactions and intra-particle diffusion), or that they are limited by the action of a single, but highly complex phenomenon (e.g., the presence of surface interactions or diffusion within pores of different dimensions) [30]. Clearly, the increased contact time was followed by an increase in $q_{t}$ (and $\left.R E_{t}\right)$ values, resulting in equilibrium averages $\left(q_{e}\right.$ and $\left.R E_{e}\right)$ of $2.92 \mathrm{mg} \mathrm{g}^{-1}(47.8 \%)$ and $3.21 \mathrm{mg}$ $\mathrm{g}^{-1}(58.5 \%)$ for oxMWCNT3h and oxMWCNT6h, respectively.

It is also important to note that the duration of the MWCNTs oxidation treatment did not affect the rate at which the equilibrium was reached in any of adsorption systems investigated (oxMWCNT3h $=$ oxMWCNT3h; $\mathrm{Cu}(\mathrm{II})=\mathrm{Ni}(\mathrm{II})>\mathrm{Cr}(\mathrm{VI}))$. Based on the results obtained by these experiments, in order to ensure the feasibility of subsequent experiments, the time given to reach equilibrium in the studies 
considering the influence of other selected operational parameters for $\mathrm{Cu}(\mathrm{II}) / \mathrm{Ni}(\mathrm{II})$ and $\mathrm{Cr}(\mathrm{VI})$ was set to be 24 and $96 \mathrm{~h}$.

\subsubsection{Adsorption Kinetics Modelling}

Due to very rapid achievement of equilibrium, it was not possible to properly fit the $\mathrm{Cu}$ (II) and $\mathrm{Ni}$ (II) kinetics data to the kinetics models investigated. Further investigation of adsorption kinetics, utilizing the Lagergren pseudo-first order, pseudo-second order, Elovich and intra-particle diffusion models, was therefore only conducted in the case of $\mathrm{Cr}(\mathrm{VI})$.

Based on the $R^{2}$ values obtained by non-linear regression of the selected functions (Figure $\left.4 a, b\right)$, the best fit model was chosen. The calculated parameters of the corresponding equations are listed in Table 4. All the experimental data are in very good compliance with the Elovich model $\left(R^{2}>0.97\right)$, which is generally valid for systems that are characterized by active chemical adsorption (without desorption of products), a process which includes the occurrence of valence forces, forming through sharing or exchanging of electrons between the adsorbate and the energetically heterogeneous surface of the adsorbent. The suitability of this model, additionally confirmed by the low $\chi^{2}$ values $(0.16$ and 0.14; $\chi^{2}$ determined by means of an $\chi^{2}$ distribution table), also suggests that the observed decrease in $\mathrm{Cr}(\mathrm{VI})$ adsorption rate overtime on both oxMWCNTs is mainly due to the presence of different, complex surface interactions, the most important of which, in this respect, probably relates to very slow $\mathrm{Cr}(\mathrm{VI}) /$ oxMWCNTs redox reactions (see Section 3.4.) [31-33]. When it comes to Elovich coefficients, it is noticeable that the $\beta$ values are similar for the two applied adsorbents, whereas the $\alpha$ is more than twice as high for oxMWCNT3h (supported by comparable behavior in the pseudo-second order $h$ values), therefore indicating a faster initial uptake for oxMWCNT3h.
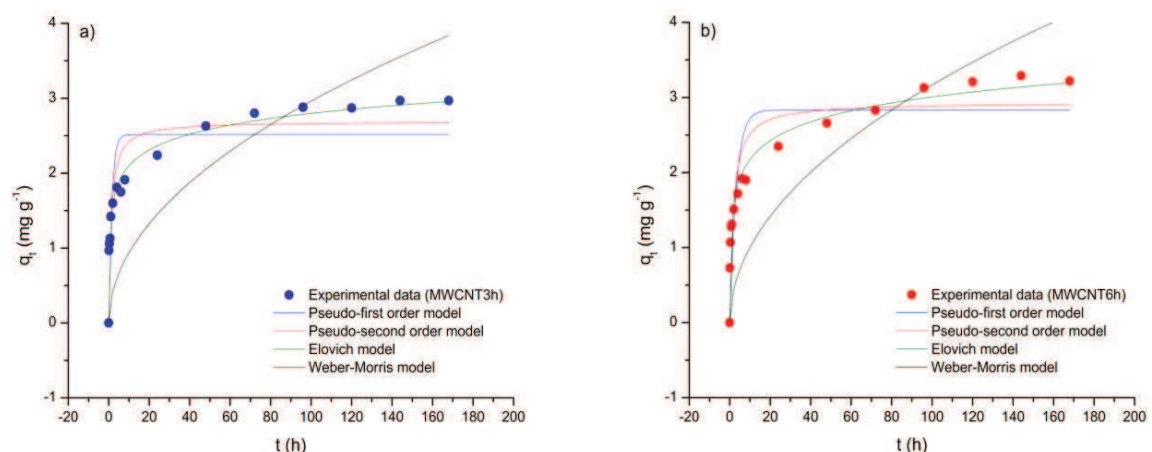

Figure 4. Non-linear regressions of kinetics data, obtained using Lagergren pseudo-first order, pseudo-second order, Elovich and intra-particle diffusion models for $\mathrm{Cr}(\mathrm{VI})$ adsorption on (a) oxMWCNT3h and (b) oxMWCNT6h.

It is important to note that in most of the scientific literature, the intra-particle diffusion model is linearly fitted [34]. According to this approach, intra-particle diffusion plays a significant role in controlling the kinetics only if $q_{t}$ vs. $t^{0.5}$ produces a straight line passing through the origin of the plot (a zero intercept). Put differently, the deviation from linearity indicates that the adsorption rate is limited by some other process or processes. Furthermore, many authors state that the occurrence of multilinearity in Weber-Morris plots confirms the involvement of intra-particle diffusion in investigated adsorption mechanism, but again, not it the context of the rate-limiting step [35]. 
Table 4. Parameters of Lagergren pseudo-first order, pseudo-second order, Elovich and intra-particle diffusion models for the adsorption of $\mathrm{Cr}(\mathrm{VI})$ on oxMWCNT3h and oxMWCNT6h.

\begin{tabular}{|c|c|c|c|}
\hline & & oxFMWCNT3h & oxFMWCNT6h \\
\hline \multirow{4}{*}{ Lagergren pseudo-first order } & $\mathrm{R}^{2}$ & 0.711 & 0.741 \\
\hline & $k_{1}\left(\mathrm{~h}^{-1}\right)$ & 0.697 & 0.322 \\
\hline & $x^{2}$ & 2.051 & 3.750 \\
\hline & $\mathrm{R}^{2}$ & 0.833 & 0.851 \\
\hline \multirow{4}{*}{ Pseudo-second order } & $\mathrm{R}^{2}$ & 0.833 & 0.851 \\
\hline & $k_{2}\left(\mathrm{~g} \mathrm{mg}^{-1} \mathrm{~h}^{-1}\right)$ & 0.329 & 0.204 \\
\hline & $h\left(\mathrm{~g} \mathrm{mg}^{-1} \mathrm{~h}^{-1}\right)$ & 2.384 & 1.756 \\
\hline & $x^{2}$ & 1.330 & 1.493 \\
\hline \multirow{4}{*}{ Elovich } & $\mathrm{R}^{2}$ & 0.981 & 0.984 \\
\hline & $\alpha\left(\mathrm{g} \mathrm{mg}^{-1} \mathrm{~h}^{-2}\right)$ & 30.600 & 14.562 \\
\hline & $\beta\left(\mathrm{mg} \mathrm{g}^{-1} \mathrm{~h}^{-1}\right)$ & 3.295 & 2.760 \\
\hline & $x^{2}$ & 0.160 & 0.142 \\
\hline \multirow{3}{*}{ Weber-Morris (non-linear) } & $\mathrm{R}_{1}^{2}$ & 0.066 & 0.342 \\
\hline & $k_{i}\left(\mathrm{mg} \mathrm{g}^{-1} \mathrm{~h}^{-0.5}\right)$ & 0.296 & 0.317 \\
\hline & $x^{2}$ & 6.889 & 6.216 \\
\hline \multirow{4}{*}{ Weber-Morris (linear) } & $\mathrm{R}_{1}^{2}$ & 0.902 & 0.926 \\
\hline & $k_{i}\left(\mathrm{mg} \mathrm{g}^{-1} \mathrm{~h}^{-0.5}\right)$ & 0.155 & 0.183 \\
\hline & $C_{i}\left(\mathrm{mg} \mathrm{g}^{-1}\right)$ & 1.270 & 1.195 \\
\hline & $x^{2}$ & 13.003 & 11.490 \\
\hline
\end{tabular}

The results obtained using this approach are shown in Figure 5a,b, with the corresponding parameters given in Table 4. As can be seen, both plots are multilinear (the red dashed lines) with the linear fit across the whole range of values yielding an intercept greater than zero (in Table 2 designated $\left.C_{i}\right)$. Therefore, as stated in the literature, it can be concluded that intra-particle diffusion, even if not the rate dominant factor, may be involved in the adsorption of $\mathrm{Cr}(\mathrm{VI})$ on oxMWCNT3h and oxMWCNT6h. Given the results shown in the Elowich and Weber-Morris models, these adsorption processes (in terms of rate and mechanism) are most likely controlled by complex surface interactions $[20,36,37]$.
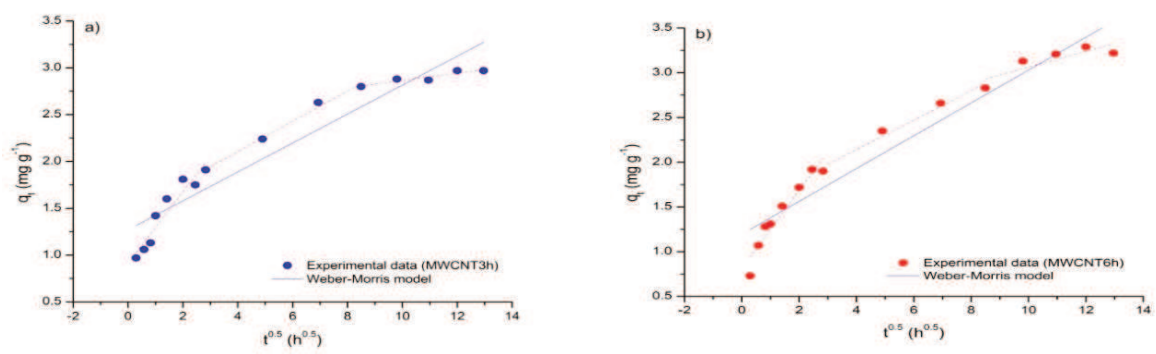

Figure 5. Linear regressions of experimental kinetics data, obtained using the intra-particle diffusion model for $\mathrm{Cr}(\mathrm{VI})$ adsorption on: (a) oxMWCNT3h and (b) oxMWCNT6h.

\subsection{Modelling the Adsorption Isotherms (Influence of Initial Metal Concentration)}

In order to describe the adsorption of $\mathrm{Cu}(\mathrm{II}), \mathrm{Ni}(\mathrm{II})$ and $\mathrm{Cr}(\mathrm{VI})$ on the oxMWCNTs investigated more precisely, the experimental data was analyzed using the Freundlich, Langmuir and D-R equations. The non-linear fitting curves resulting from these models are shown in Figure 6, while the parameters of these functions are given in Table 5 . 

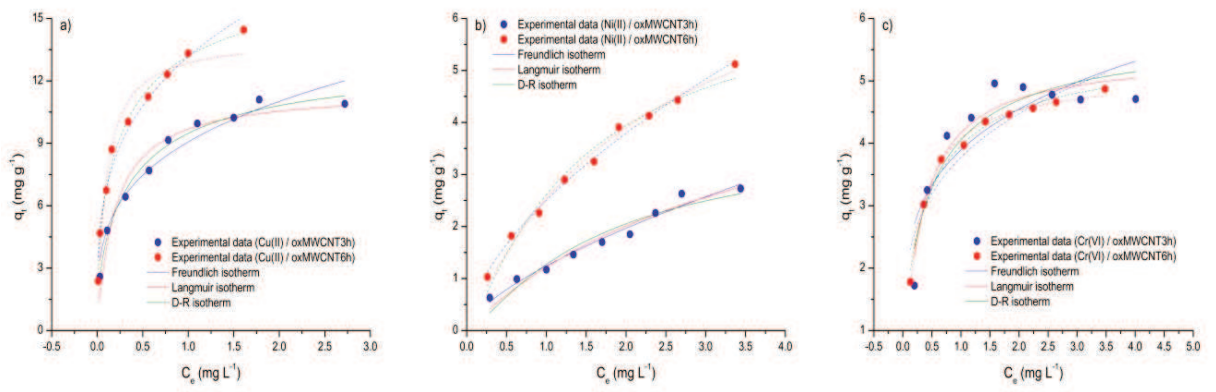

Figure 6. Non-linear regressions of experimental isotherms, obtained using Freundlcih, Langmuir and D-R models for: (a) Cu(II), (b) Ni(II) and (c) $\mathrm{Cr}$ (VI) adsorption on oxMWCNT3h and oxMWCNT6h $\left(m=5 \mathrm{mg}, V=30 \mathrm{~mL}\left(0.1 \mathrm{M} \mathrm{NaNO}_{3}\right), \mathrm{C}_{0}=0.5-5 \mathrm{mg} \mathrm{L}^{-1}, \mathrm{pH}=5 \pm 0.1(\mathrm{Cu}(\mathrm{II})\right.$ and $\mathrm{Ni}(\mathrm{II}))$ and $2.5 \pm 0.1$ $(\mathrm{Cr}(\mathrm{VI})), t=24 \mathrm{~h}(\mathrm{Cu}(\mathrm{II})$ and $\mathrm{Ni}(\mathrm{II}))$ and $96 \mathrm{~h}(\mathrm{Cr}(\mathrm{VI}))$, agitation speed $=180 \mathrm{rpm}, \mathrm{T}=298 \pm 2 \mathrm{~K})$.

Table 5. Parameters of Freundlich, Langmuir and D-R models for the adsorption of (a) Cu(II), (b) Ni(II) and (c) $\mathrm{Cr}(\mathrm{VI})$ on oxMWCNT3h and oxMWCNT6h.

\begin{tabular}{|c|c|c|c|c|c|c|c|}
\hline & & \multicolumn{3}{|c|}{ oxFMWCNT3h } & \multicolumn{3}{|c|}{ oxFMWCNT6h } \\
\hline & & $\mathrm{Cu}(\mathrm{II})$ & $\mathrm{Ni}(\mathrm{II})$ & $\mathrm{Cr}(\mathrm{VI})$ & $\mathrm{Cu}(\mathrm{II})$ & $\mathrm{Ni}(\mathrm{II})$ & $\mathrm{Cr}(\mathrm{VI})$ \\
\hline \multirow{5}{*}{ Freundlich } & $\mathrm{R}^{2}$ & 0.951 & 0.970 & 0.706 & 0.976 & 0.993 & 0.920 \\
\hline & $K_{F}(*)$ & 9.066 & 1.242 & 3.892 & 13.165 & 2.506 & 3.777 \\
\hline & $n$ & 0.281 & 0.662 & 0.225 & 0.286 & 0.598 & 0.244 \\
\hline & $x^{2}$ & 0.474 & 0.062 & 0.858 & 0.695 & 0.031 & 0.217 \\
\hline & $\mathrm{R}^{2}$ & 0.946 & 0.954 & 0.920 & 0.946 & 0.988 & 0.994 \\
\hline \multirow{4}{*}{ Langmuir } & $K_{L}\left(1 \mathrm{mg}^{-1}\right)$ & 5.129 & 0.273 & 3.331 & 10.459 & 0.428 & 3.996 \\
\hline & $q_{\max }\left(\mathrm{mg} \mathrm{g}^{-1}\right)$ & 11.567 & 5.691 & 5.422 & 14.086 & 8.455 & 5.100 \\
\hline & $R_{L}$ & $0.867-0.067$ & $0.927-0.516$ & $0.600-0.070$ & $0.905-0.056$ & $0.900-0.409$ & $0.658-0.067$ \\
\hline & $x^{2}$ & 0.735 & 0.145 & 0.209 & 1.124 & 0.075 & 0.010 \\
\hline \multirow{5}{*}{ D-R } & $\hat{\mathrm{R}}^{2}$ & 0.985 & 0.922 & 0.863 & 0.991 & 0.975 & 0.986 \\
\hline & $q_{d}\left(\mathrm{mg} \mathrm{g}^{-1}\right)$ & 13.017 & 4.014 & 5.764 & 17.238 & 7.035 & 5.509 \\
\hline & $K_{d}\left(\mathrm{~mol}^{2} \mathrm{~K}^{-1} \mathrm{~J}^{-2}\right)$ & $1.846 \times 10^{-4}$ & $6.683 \times 10^{-4}$ & $2.051 \times 10^{-4}$ & $1.555 \times 10^{-4}$ & $5.765 \times 10^{-4}$ & $1.920 \times 10^{-4}$ \\
\hline & $E_{a}\left(\mathrm{~kJ} \mathrm{~mol}^{-1}\right)$ & 52.050 & 27.353 & 49.376 & 56.702 & 29.450 & 51.027 \\
\hline & $x^{2}$ & 0.112 & 0.252 & 0.369 & 0.212 & 0.157 & 0.037 \\
\hline
\end{tabular}

High $R^{2}(>0.91)$ and low $\chi^{2}(<1.12)$ values were obtained for all isotherms. The exception is the Freundlich and D-R isotherms of $\mathrm{Cr}(\mathrm{VI})$ /oxMWCNT3h, but even here the relatively low $\mathrm{R}^{2}$ values (0.71 and 0.86$)$ have corresponding acceptable $\chi^{2}(0.86$ and 0.37$)$ values, suggesting that each of the three applied models is suitable for describing the adsorption of all the metals investigated on both oxMWCNT3h and oxMWCNT6h. The differences in the goodness of fit for Freundlich and Langmuir models are insignificant, so it is not possible to draw strong conclusions relating and number of adsorbate layers forming during the process.

Values of the Freundlich exponent $n$ are less than 1 in each case, suggesting that all the processes can be characterized as favorable, with the adsorption of $\mathrm{Cu}$ (II) and $\mathrm{Cr}(\mathrm{VI})$ being good $(0.1<n<0.5)$ and $\mathrm{Ni}$ (II) moderate $(0.5<n<1)(\mathrm{Cu}(\mathrm{II}) \sim \mathrm{Cr}(\mathrm{VI})>\mathrm{Ni}(\mathrm{II}))$. This observation can be further substantiated by the $R_{L}$ factors, which lie within the range 0 to 1 (adsorption is irreversible, favorable, linear or unfavorable, when $R_{L}=0,0<R_{L}<1, R_{L}=1, R_{L}>1$, respectively). The generally high and significantly different $K_{F}$ and $K_{L}$ values obtained indicate the presence of selective adsorbents which have high affinities for the adsorption of the metals investigated.

Depending on how it is expressed, the adsorption capacity of oxMWCNT3h and oxMWCNT6h towards the selected metals exhibits the following trend: $K_{F}$ (relative) $-\mathrm{Cu}(\mathrm{II})>\mathrm{Cr}(\mathrm{VI})>\mathrm{Ni}(\mathrm{II})$, $q_{m}-\mathrm{Cu}(\mathrm{II})>\mathrm{Ni}(\mathrm{II})>\mathrm{Cr}(\mathrm{VI}), q_{d}-\mathrm{Cu}(\mathrm{II})>\mathrm{Cr}(\mathrm{VI})>\mathrm{Ni}(\mathrm{II})($ oxMWCNT3h) and $\mathrm{Cu}(\mathrm{II})>\mathrm{Ni}(\mathrm{II})>\mathrm{Cr}(\mathrm{VI})$ (oxMWCNT6h). Furthermore, the $\mathrm{Cu}(\mathrm{II})$ and $\mathrm{Ni}(\mathrm{II})$ removals were more pronounced for oxMWCNT6h, while the $\mathrm{Cr}(\mathrm{VI})$ uptake was slightly higher in the case of oxMWCNT3h $\left(K_{F}, q_{m}\right.$, as well as $q_{d}$ for the 
adsorption of $\mathrm{Cr}(\mathrm{VI})$ on the applied adsorbents differs much less compared to the two other metals). These differences in the removal capacities of oxMWCNT3h and oxMWCNT6h (observed in the case of $\mathrm{Cu}(\mathrm{II})$ and $\mathrm{Ni}(\mathrm{II})$, and to a much lesser extent for $\mathrm{Cr}(\mathrm{VI})$ ) are most likely due to the influence of the functionalization process length on the surface properties of the nanotubes (e.g., an increase in the quantity of various oxygen-containing groups with longer functionalization time; see Table S1), making them more suitable for the uptake of the divalent metals studied. Of the trends mentioned above, the experimental observations ( $q_{e}$ values) are most consistent with the values obtained by the Freundlich isotherm, so the assumptions behind this model can potentially be considered the most relevant for this study (see Table 2) [37,38].

Adsorption energies $E_{a}$, calculated using the D-R model, are greater than $16 \mathrm{~kJ} \mathrm{~mol}^{-1}$, which implies that the formation of chemical bonds, as opposed to ion-exchange or non-specific physical interactions, dominantly controls all considered systems (adsorption is physical, ion-exchange or chemical type when $1 \mathrm{~kJ} \mathrm{~mol}^{-1}<E_{a}<8 \mathrm{~kJ} \mathrm{~mol}^{-1}, 8 \mathrm{~kJ} \mathrm{~mol}^{-1}<E_{a}<16 \mathrm{~kJ} \mathrm{~mol}^{-1}, E_{a}>16 \mathrm{~kJ} \mathrm{~mol}^{-1}$, respectively). This finding is consistent with the conclusions reached through non-linear modelling of the kinetics data [39].

A comprehensive overview of the capacity of other available adsorbents is given in the following papers $[5,40,41]$. As can be seen, oxMWCNT3h and oxMWCNT6h are, in most cases, characterized by a similar or lower adsorption capacity for $\mathrm{Cu}(\mathrm{II}), \mathrm{Ni}(\mathrm{II})$ and $\mathrm{Cr}(\mathrm{VI})$ compared to other materials. Considering the non-uniformity of the experimental conditions applied in different studies (e.g., $\mathrm{C}_{0}$ range, initial $\mathrm{pH}$ value, $\mathrm{m} / \mathrm{V}$ ratio, etc.), as well as the specificity of those under which this research was conducted (very low and narrow $C_{0}$ range and low $\mathrm{m} / \mathrm{V}$ ratio) it is clear that the direct comparison of, for example, the $q_{\max }$ values obtained herein with the results of other authors, though possible, provides an unrealistic picture when it comes to efficiency of investigated oxMWCNTs.

\subsection{Influence of $p H$}

The solution $\mathrm{pH}$ acidity is the one matrix property with the highest potential to affect the adsorption of heavy metals. The removal of $\mathrm{Cu}(\mathrm{II}), \mathrm{Ni}(\mathrm{II})$ and $\mathrm{Cr}(\mathrm{VI})$ by oxMWCNT3h and oxMWCNT6h, as a function of $\mathrm{pH}$, is illustrated in Figure 7.
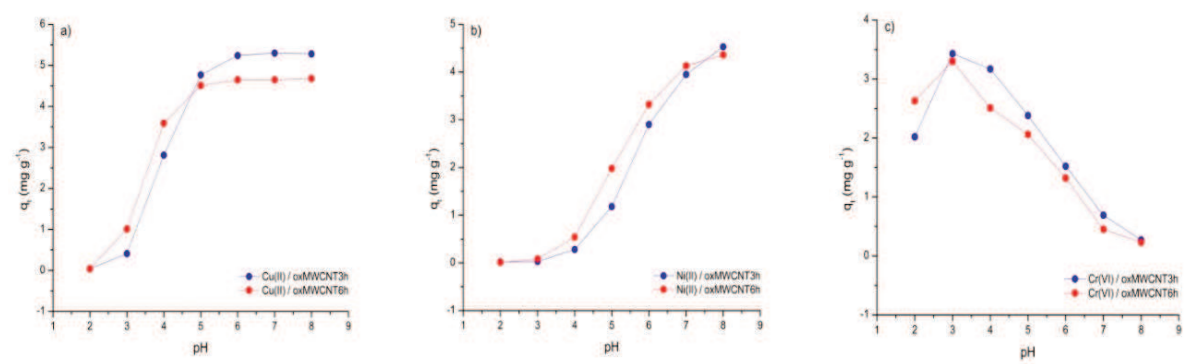

Figure 7. Adsorption of (a) $\mathrm{Cu}(\mathrm{II}),(\mathbf{b}) \mathrm{Ni}(\mathrm{II})$ and (c) $\mathrm{Cr}(\mathrm{VI})$ on oxMWCNT3h and oxMWCNT6h as a function of $\mathrm{pH}\left(m=5 \mathrm{mg}, V=30 \mathrm{~mL}\left(0.1 \mathrm{M} \mathrm{NaNO}_{3}\right), \mathrm{C}_{0}=1 \mathrm{mg} \mathrm{L}^{-1}, \mathrm{pH}=2-8 \pm 0.1, t=24 \mathrm{~h}(\mathrm{Cu}\right.$ (II) and $\mathrm{Ni}(\mathrm{II}))$ and $96 \mathrm{~h}(\mathrm{Cr}(\mathrm{VI}))$, agitation speed $=180 \mathrm{rpm}, \mathrm{T}=298 \pm 2 \mathrm{~K})$.

As can be seen, $\mathrm{pH}$ plays an important role in the behavior of all studied adsorption systems. More specifically, $\mathrm{Cu}(\mathrm{II})$ uptake $\left(q_{e}\right.$ and $R E_{e}$ ) sharply increases as initial $\mathrm{pH}$ goes from 2 to 6 and then, as the liquid phase becomes more basic, maintains a constant high level $\left(0.04\right.$ to $5.28 \mathrm{mg} \mathrm{g}^{-1}(0.70$ to $99.4 \%$ ) and 0.04 to $4.68 \mathrm{mg} \mathrm{g}^{-1}(0.92$ to $99.3 \%)$ ). oxMWCNTs capacity for $\mathrm{Ni}(\mathrm{II})$ rises throughout the entire $\mathrm{pH}$ range investigated ( 0.02 to $4.53 \mathrm{mg} \mathrm{g}^{-1}(0.40 \%$ to $82.2 \%)$, whereas the $\mathrm{Cr}(\mathrm{VI})$ systems demonstrated the best removals at $\mathrm{pH}=3(3.43(59.9 \%)$ and $3.30(64.1 \%))$.

The influence of $\mathrm{pH}$ on adsorption can be explained by considering the effect this parameter has on the surface properties of the oxMWCNTs and the hydrolysis capacity of the selected metals. Depending 
on the solution $\mathrm{pH}$, oxygen-containing functional groups (e.g., $-\mathrm{OH}$ and $-\mathrm{COOH}$ ), the presence of which was confirmed in the FTIR spectra, undergo protonation or deprotonation reactions, making the adsorbents net surface charge positive or negative depending upon where the solution $\mathrm{pH}$ lies in relation to the adsorbent pHpzc (Equations (3) and (4)).

$$
\begin{gathered}
\mathrm{Cx}-\mathrm{OH}+\mathrm{H}^{+} \leftrightarrow \mathrm{Cx}-\mathrm{OH}_{2}^{+} \\
\mathrm{Cx}-\mathrm{OH} \leftrightarrow \mathrm{C}_{\mathrm{x}}-\mathrm{O}^{-}+\mathrm{H}^{+}
\end{gathered}
$$

where: $\mathrm{Cx}-\mathrm{OH}, \mathrm{Cx}-\mathrm{OH}_{2}{ }^{+}$and $\mathrm{Cx}-\mathrm{O}^{-}$are neutral, protonated and deprotonated sites on the oxMWCNTs surfaces ( $\mathrm{Cx}$ is the adsorbent carbon surface, while $-\mathrm{OH}$ represents all the oxygen-containing functional groups).

Whether, and to what extent, certain heavy metals will interact with such adsorption centers, largely depends on the form/forms in which the metals are present in solution. Therefore, the Visual MINTEQ (version 3.1) software was used to predict the relative proportion of $\mathrm{Cu}(\mathrm{II}), \mathrm{Ni}(\mathrm{II})$ and $\mathrm{Cr}(\mathrm{VI})$ species present, with the results shown in Figure 8.
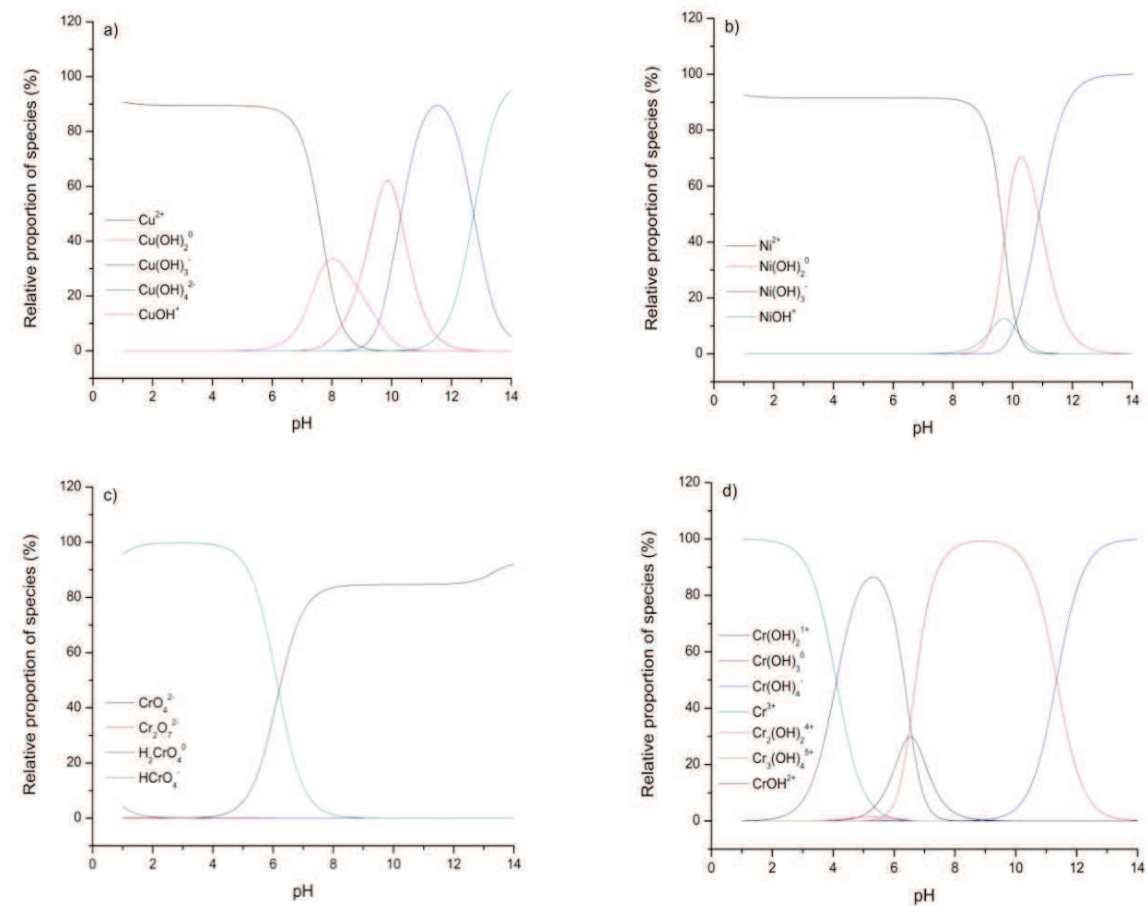

Figure 8. Relative proportion of: (a) $\mathrm{Cu}(\mathrm{II}),(\mathbf{b}) \mathrm{Ni}(\mathrm{II}),(\mathbf{c}) \mathrm{Cr}(\mathrm{VI})$ and (d) $\mathrm{Cr}$ (III) species as a function of $\mathrm{pH}\left(\mathrm{C}_{0}=1 \mathrm{mg} \mathrm{L}^{-1}\right.$, ionic strength $\left.=0.1 \mathrm{M} \mathrm{NaNO}_{3}, \mathrm{~T}=298 \mathrm{~K}\right)$.

According to the plots in Figure $8 \mathrm{a}, \mathrm{b}$, at different $\mathrm{pH}$ values $\mathrm{Cu}(\mathrm{II})$ and $\mathrm{Ni}(\mathrm{II})$ exists as $\mathrm{M}^{2+}$, $\mathrm{M}(\mathrm{OH})^{+}, \mathrm{M}(\mathrm{OH})_{2}{ }^{0}, \mathrm{M}(\mathrm{OH})_{3}{ }^{-}$and/or $\mathrm{M}(\mathrm{OH})_{4}{ }^{2-}(\mathrm{Cu}(\mathrm{II})$ only) (M stands for metal). Hence, the low removal of $\mathrm{Cu}(\mathrm{II})$ and $\mathrm{Ni}(\mathrm{II})$ in strongly acidic media $(\mathrm{pH}<4)$ can be partly attributed to the existence of competition between $\mathrm{H}^{+}$and $\mathrm{M}^{2+}$ aqua cations $\left(\left[\left(\mathrm{M}\left(\mathrm{H}_{2} \mathrm{O}_{6}\right)\right]^{2+}\right)\right.$, the dominant form of these metals under given conditions, for the same oxygen-containing groups. The uptake of highly mobile $\mathrm{H}^{+}$ions is clearly more preferential than $\mathrm{M}^{2+}$ complex uptake, so most of oxMWCNTs surface sites become occupied and also positively charged (Equation (3)). This therefore hinders the adsorption of $\mathrm{Cu}(\mathrm{II})$ 
and $\mathrm{Ni}(\mathrm{II})$ due to the unavailability of sites and electrostatic repulsion. In support of this, the pHpzc of the applied adsorbents was found to be very similar, $\sim 3.2$ and $\sim 3.4$, indicating that at low $\mathrm{pH}$ values oxMWCNT3h and oxMWCNT6h particles exhibit a net positive charge, which makes them incompatible to react with (adsorb) the divalent metals studied. The generally poor, but still evident removals of $\mathrm{Cu}(\mathrm{II})$ and $\mathrm{Ni}$ (II) in solutions of $\mathrm{pH}<4$ can be mainly attributed to their exchange with $\mathrm{H}^{+}$ ions present on the oxMWCNTs surface (Equation (5)).

$$
2 \mathrm{Cx}-\mathrm{OH}_{2}^{+}+\mathrm{M}^{2+} \leftrightarrow\left[(\mathrm{Cx}-\mathrm{OH})_{2} \mathrm{M}\right]^{+}+2 \mathrm{H}^{+}
$$

When the $\mathrm{pH}$ goes up $\left(\mathrm{H}^{+}\right.$concentration decreases), $\mathrm{H}^{+} / \mathrm{M}^{2+}$ competition gradually begins to decline and certain acidic functional groups become more dissociated (Equation (4)), thus changing the net surface charge to negative ( $\mathrm{pH}>\mathrm{pHpzc})$. In an environment like this, cationic metal ions, besides being electrostatically attracted by polarized, but not deprotonated centers (e.g., hydroxyl groups, pKa 9.5 to 13), easily form metal-ligand complexes with the now available, ionized nucleophilic sites, where the CNT oxygens act as electron-donating atoms (e.g., carboxyl (carboxylate) groups, pKa 1.7 to 4.7) (Equation (6) and only in the case of $\mathrm{Cu}(\mathrm{II})$ Equation (7)).

$$
\begin{gathered}
2 \mathrm{C}_{\mathrm{x}}-\mathrm{CO}^{-}+\mathrm{M}^{2+} \leftrightarrow\left[\left(\mathrm{C}_{\mathrm{x}}-\mathrm{CO}\right)_{2} \mathrm{M}\right]^{0} \\
\mathrm{C}_{\mathrm{x}}-\mathrm{CO}^{-}+\mathrm{M}(\mathrm{OH})^{+} \leftrightarrow\left[\mathrm{C}_{\mathrm{x}}-\mathrm{COM}(\mathrm{OH})\right]^{0}
\end{gathered}
$$

Note that beyond $\mathrm{pH} 7 \mathrm{Cu}$ (II) begins to precipitate as relatively weakly soluble $\mathrm{Cu}(\mathrm{OH})_{2}{ }^{0}$ due to the more intense hydrolyzation. In contrast, $\mathrm{Ni}(\mathrm{II})$ remains stable over the entire tested $\mathrm{pH}$ range. Therefore, the removal of $\mathrm{Cu}$ (II) in more alkaline ( $\mathrm{pH} 7$ to 8 ) surroundings results from the simultaneous action of adsorption $\left(\mathrm{Cu}^{2+}, \mathrm{Cu}(\mathrm{OH})^{+}\right)$and also chemical deposition $\left(\mathrm{Cu}(\mathrm{OH})_{2}{ }^{0}\right)[29,42,43]$.

The influence of $\mathrm{pH}$ on the extent of $\mathrm{Cr}(\mathrm{VI})$ uptake by oxMWCNT3h and oxMWCNT6h demonstrated an opposite effect to that described above. Namely, the capacity of oxMWCNTs for $\mathrm{Cr}(\mathrm{VI})$ at first increases, reaching a maximum at $\mathrm{pH}=3$, beyond which it begins to gradually decline. According to the speciation graph (Figure 8c), it is clear that in the highly acidic solutions $(\mathrm{pH}<4)$ the most stable form of $\mathrm{Cr}(\mathrm{VI})$ is $\mathrm{HCrO}_{4}{ }^{-}$. These negatively charged oxyanions are readily electrostatically attracted and very likely chemically bonded (conclusion made on the basis of D-R isotherm model $E_{a}$ values) to the oxMWCNTs surfaces (protonated and electrophilic centers), which are positive when $\mathrm{pH}<\mathrm{pHpzc}$, mainly asa consequence of the protonation of various weakly acidic and basic oxygen-containing functional groups (Equation (8)).

$$
\mathrm{C}_{\mathrm{x}}-\mathrm{OH}_{2}^{+}+\mathrm{HCrO}_{4}^{-} \leftrightarrow\left[\mathrm{C}_{\mathrm{x}}-\mathrm{OH}_{2} \mathrm{CrO}_{4}\right]^{-}+\mathrm{H}^{+}
$$

The removal of $\mathrm{Cr}(\mathrm{VI})$ at low $\mathrm{pH}$ values can also take place through the occurrence of another ("indirect") mechanism, involving a three-step process: 1) reduction of $\mathrm{HCrO}_{4}{ }^{-}$to $\mathrm{Cr}$ (III) by oxMWCNTs electron donors (various carboxyl and hydroxyl) groups. This reaction is maintained thanks to the high degree of $\mathrm{Cr}(\mathrm{VI})$ uptake at low $\mathrm{pH}$; and the slow kinetics of this reaction are most likely responsible for the low $\mathrm{Cr}(\mathrm{VI})$ adsorption rate (Equation (9)), 2) release of $\mathrm{Cr}(\mathrm{III})$ species back into solution, 3) capturing $\mathrm{Cr}(\mathrm{III})$ aqua cations (mainly $\mathrm{Cr}^{3+}$, speciation shown in Figure 8d) through the action of electrostatic attraction, chemisorption (deprotonated acidic sites) (Equation (10)) and ion exchange (protonated weakly acidic and basic sites) (Equation (11)). The $\mathrm{H}^{+} / \mathrm{Cr}$ (III) competition diminishes the effectiveness of this pathway, which is the reason why the total adsorption of $\mathrm{Cr}$ rises as $\mathrm{pH}$ goes up from $\mathrm{pH} 2$ to pH 3.

$$
\begin{gathered}
3 \mathrm{Cx}-\mathrm{OH}+\mathrm{HCrO}_{4}^{-}+4 \mathrm{H}^{+}+3 \mathrm{e}^{-} \leftrightarrow 3 \mathrm{Cx}-\mathrm{O}^{-}+\mathrm{Cr}^{3+}+4 \mathrm{H}_{2} \mathrm{O} \\
2 \mathrm{C}_{\mathrm{x}}-\mathrm{CO}^{-}+\mathrm{Cr}^{3+} \leftrightarrow\left[\left(\mathrm{C}_{\mathrm{x}}-\mathrm{CO}\right)_{2} \mathrm{Cr}^{+}\right. \\
2 \mathrm{C}_{\mathrm{x}}-\mathrm{OH}_{2}^{+}+\mathrm{Cr}^{3+} \leftrightarrow\left[\left(\mathrm{C}_{\mathrm{x}}-\mathrm{O}\right)_{2} \mathrm{Cr}\right]^{2+}+2 \mathrm{H}^{+}
\end{gathered}
$$


It was not possible to confirm the presence of this mechanism via determination of the oxidation state of $\mathrm{Cr}$ (in solution or on the surfaces of oxMWCNT3h and oxMWCNT6h) after the adsorption process. However, the kinetic parameters, as well as the results of other authors who examined similar materials, clearly indicate its presence is likely [30].

At $\mathrm{pH}$ values greater than 3 , deprotonation intensifies, the surface of the adsorbents becomes increasingly negative, and it becomes significantly more difficult for $\mathrm{HCrO}_{4}{ }^{-}$to adsorb, due to electrostatic repulsion, according to Equation (8). This phenomenon is particularly pronounced in the case of higher charge number $\mathrm{Cr}_{2} \mathrm{O}_{7}{ }^{2-}$ ions, the dominant form of $\mathrm{Cr}(\mathrm{VI})$ at $\mathrm{pH}>6$. Additionally, adsorption of oxyanions itself contributes to the negativity of oxMWCNTs surface, thus inhibiting the further removal of this metal. Finally, the existence of competition between excess $\mathrm{OH}^{-}$and $\mathrm{HCrO}_{4}{ }^{-} / \mathrm{Cr}_{2} \mathrm{O}_{7}{ }^{2-}$ for the same adsorption sites also has an adverse effect on the process studied [44].

\subsection{Influence of Ionic Strength}

The influence of the background electrolyte concentration on the degree of $\mathrm{Cu}(\mathrm{II}), \mathrm{Ni}(\mathrm{II})$ and $\mathrm{Cr}(\mathrm{VI})$ removal by oxMWCNT3h and oxMWCNT6h is illustrated in Figure 9. This is one of the potential controlling factors in any adsorption system.
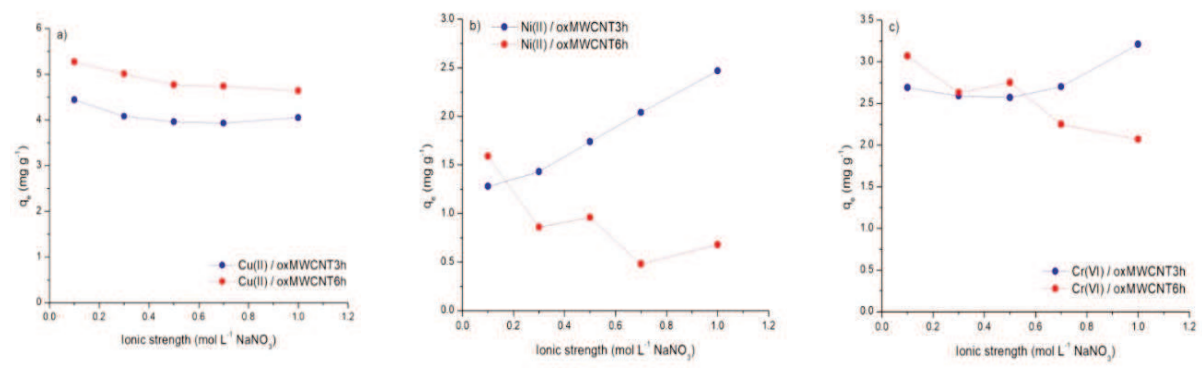

Figure 9. Adsorption of: (a) $\mathrm{Cu}(\mathrm{II}),(\mathbf{b}) \mathrm{Ni}(\mathrm{II})$ and (c) $\mathrm{Cr}(\mathrm{VI})$ on oxMWCNT3h and oxMWCNT6h as a function of ionic strength $\left(m=5 \mathrm{mg}, V=30 \mathrm{~mL}\left(0.1-1 \mathrm{M} \mathrm{NaNO}_{3}\right), C_{0}=1 \mathrm{mg} \mathrm{L}^{-1}, \mathrm{pH}=5 \pm 0.1\right.$ $(\mathrm{Cu}(\mathrm{II})$ and $\mathrm{Ni}(\mathrm{II}))$ and $2.5 \pm 0.1(\mathrm{Cr}(\mathrm{VI})), t=24 \mathrm{~h}(\mathrm{Cu}(\mathrm{II})$ and $\mathrm{Ni}(\mathrm{II}))$ and $96 \mathrm{~h}(\mathrm{Cr}(\mathrm{VI}))$, agitation speed $=$ $180 \mathrm{rpm}, \mathrm{T}=298 \pm 2 \mathrm{~K}$ ).

As can be seen, increasing the ionic strength from 0.1 to an extremely high level of $1 \mathrm{M} \mathrm{NaNO}_{3}$, has a slight effect on the adsorption systems investigated, although it is considerably less than the effect of changing the solution $\mathrm{pH}$. The observed variations in $q_{e}$ (and $R E_{e}$ ) values are not completely consistent, even in the same metal/different adsorbent cases, and are located within the following limits: $\mathrm{Cu}(\mathrm{II})-3.93$ to $4.44 \mathrm{mg} \mathrm{g}^{-1}$ (78.1\% to $88.8 \%$ ) and 4.64 to $5.27 \mathrm{mg} \mathrm{g}^{-1}$ (83.2\% to $\left.94.6 \%\right), \mathrm{Ni}(\mathrm{II})-1.28$ to $2.47 \mathrm{mg} \mathrm{g}^{-1}$ (25.4\% to $48.5 \%$ ) and 0.48 to $1.59 \mathrm{mg} \mathrm{g}^{-1}$ (8.5\% to $\left.28.1 \%\right), \mathrm{Cr}(\mathrm{VI})-2.57$ to $3.21 \mathrm{mg} \mathrm{g}^{-1}$ $(48.0 \%$ to $60.0 \%)$ and 2.07 to $3.07 \mathrm{mg} \mathrm{g}^{-1}(34.7 \%$ to $51.2 \%)$. From the data reported above, it is clear that the greatest impact, be it positive or negative, depends on whether oxMWCNT3h or oxMWCNT6h is the adsorbent, in the case of adsorption of $\mathrm{Ni}(\mathrm{II})$.

Generally, when a solid charged surface is brought into contact with the liquid ionic medium, two layers of opposite polarity appear at the common boundary (interface) among the adjacent phases. Since the thickness of this electric double layer, as well as the interface potential, is determined by the background electrolyte concentration, the dominant types of interactions which take place on the related adsorbate/adsorbent exterior can be predicted.

According to the triple-layer (surface complexation) model, the uptake of $\mathrm{Cu}(\mathrm{II}), \mathrm{Ni}(\mathrm{II})$ and $\mathrm{Cr}(\mathrm{VI})$ associated with the oxMWCNTs surface, can occur in two different ways. The first of these involves the formation of inner-sphere complexes, that is partially or completely dehydrated metal ions directly and chemically specifically attached to adsorbent active sites. Such coordinatively bound species are 
located in the so-called o-plane. The second one, designated as outer-sphere complexation, is realized through the occurrence of electrostatic attraction between fully solvated metal ions, placed in the $\beta$ plane on a favorably charged surface. Bearing in mind that the outer-sphere ion-pairs are set in the same region as background electrolyte counterions, it is expected for them to be more susceptible to ionic strength variations than strongly adsorbed o-plane complexes [45].

Considering all of the above, the large increase in $\mathrm{Na}^{+} / \mathrm{NO}_{3}{ }^{-}$concentration required to cause only narrow changes in $q_{e}$ values, when taken into account together with the conclusions on the high $\mathrm{pH}$-dependence of $\mathrm{Cu}(\mathrm{II}), \mathrm{Ni}(\mathrm{II})$ and $\mathrm{Cr}(\mathrm{VI})$ adsorption, clearly indicate that the inner-sphere surface complexation (chemisorption) can be designated as the dominant process in the removal of these heavy metals from solution. Outer-sphere complexes can therefore be ruled out, which means the role of background ions competition must be excluded from the explanation of the slight reduction in metals uptake at high $\mathrm{Na}^{+} / \mathrm{NO}_{3}{ }^{-}$concentrations. Instead, this reduction is explained as follows: 1) a high ionic strength environment lowers the repulsive electrostatic energy of oxMWCNTs, which results in solid particles agglomeration (destabilization) and therefore a decrease in the number of available active sites; 2 ) introduction of $\mathrm{Na}^{+} / \mathrm{NO}_{3}{ }^{-}$decreases the activity coefficients of $\mathrm{Cu}(\mathrm{II}), \mathrm{Ni}(\mathrm{II})$ and $\mathrm{Cr}(\mathrm{VI})$ ions, thus retarding their transfer to the adsorbent's surface. The positive influence of ionic strength, evident only when it comes to the $\mathrm{Ni}(\mathrm{II})$ /oxMWCNT3h system, may be attributed to diminishing of some repulsive electrostatic interactions, possibly as a consequence of developing the screening effect. This finding cannot be considered very reliable, especially due to the fact that $\mathrm{Ni}$ (II) behaves completely differently in the presence of oxMWCNT6h, which according to the characterization results, is fairly similar to oxMWCNT3h. The observations derived from these experiments do agree with and further confirm those made in the previous sections $[19,30,46,47]$.

\section{Conclusions}

Taking into account all the results obtained, the following conclusions can be drawn:

The $\mathrm{Cu}(\mathrm{II})$ and $\mathrm{Ni}$ (II) adsorption systems reach a state of equilibrium very quickly, in less than $20 \mathrm{~min}$. This indicates that the removal of these metals is mainly determined by the interactions occurring at the adsorbate/adsorbent surface. The $\mathrm{Cr}(\mathrm{VI})$ uptake rate, divided into two stages, is much slower, with $96 \mathrm{~h}$ required to achieve equilibrium. The duration of the MWCNTs oxidation treatment does not influence the kinetics of these adsorption processes (oxMWCNT3h $=$ oxMWCNT3h; $\mathrm{Cu}(\mathrm{II})=$ $\mathrm{Ni}(\mathrm{II})>\mathrm{Cr}(\mathrm{VI}))$.

The $\mathrm{Cr}(\mathrm{VI})$ adsorption kinetics are well described by the non-linear Elovich equation, which is valid for mechanisms dominated by chemisorption. According to the linearization of Weber-Morris plots, intra-particle diffusion may be involved, but is not a rate determining factor in $\mathrm{Cr}(\mathrm{VI})$ removal by oxMWCNT3h and oxMWCNT6h. Instead, the overall rate and mechanism of adsorption in this systems are controlled by complex surface interactions, the most important of which, in this respect, relates to very slow $\mathrm{Cr}(\mathrm{VI}) / \mathrm{oxMWCNTs}$ redox reactions.

The Freundlich, Langmuir and D-R isotherms are all in good compliance with the corresponding experimental data. Values of $n, R_{L}$ and $E_{a}$ indicate that the $\mathrm{Cu}(\mathrm{II}), \mathrm{Ni}(\mathrm{II})$ and $\mathrm{Cr}(\mathrm{VI})$ adsorption on the applied MWCNTs is favorable and chemically specific. The capacity of oxMWCNT3h and oxMWCNT6h for these metals expressed as $K_{F}$, the parameter most consistent with the non-fitted observations, follows the order: $\mathrm{Cu}(\mathrm{II})>\mathrm{Cr}(\mathrm{VI})>\mathrm{Ni}(\mathrm{II})(\mathrm{Cu}(\mathrm{II})$ and $\mathrm{Ni}$ (II): oxMWCNT6h $>$ oxMWCNT3h, $\mathrm{Cr}(\mathrm{VI})$ : oxMWCNT3h $\geq$ oxMWCNT6h).

All the studied systems are strongly influenced by the solution $\mathrm{pH}$. Specifically, $\mathrm{Cu}(\mathrm{II})$ uptake increases as the initial $\mathrm{pH}$ increases from 2 to $6, \mathrm{Ni}$ (II) removal rises throughout the entire $\mathrm{pH}$ range investigated, while $\mathrm{Cr}(\mathrm{VI})$ is best adsorbed at $\mathrm{pH}=3$. Ionic strength has a far less pronounced effect on the behavior of the adsorption processes investigated. These findings further confirm that the most important factor in the complicated mechanism of $\mathrm{Cu}(\mathrm{II}), \mathrm{Ni}(\mathrm{II})$ and $\mathrm{Cr}(\mathrm{VI})$ adsorption on oxMWCNT3h and oxMWCNT6h is inner-sphere surface complexation (chemisorption) involving the coordination of metal ions with oxygen-containing functional groups. 
Supplementary Materials: The following are available online at http://www.mdpi.com/2073-4441/12/3/723/s1, Figure S1: SEM images of: (a) oxMWCNT3h and (b) oxMWCNT6h., Figure S2: Points of zero charge of: (a) oxMWCNT3h and (b) oxMWCNT6h. Table S1: EDS analysis of oxMWCNT3h and oxMWCNT6h.

Author Contributions: Conceptualization, S.M. and M.Š.; methodology, S.M., M.Š. and M.K.I.; software, M.W.; validation, S.M., M.W. and M.K.I.; formal analysis, J.N.; investigation; resources, J.T. and Z.K.; data curation, M.Š.; writing—original draft preparation, M.Š.; writing—review and editing, S.M.; visualization, M.Š.; supervision, S.M.; project administration, J.T.; funding acquisition, J.T. All authors have read and agreed to the published version of the manuscript.

Funding: This research was funded by the Ministry of Education, Science and Technological Development of the Republic of Serbia (Project No. 451-03-68/2020-14/ 200125)

Acknowledgments: The authors gratefully acknowledge the support of the Ministry of Education, Science and Technological Development of the Republic of Serbia (Project No. 451-03-68/2020-14/ 200125).

Conflicts of Interest: The authors declare no conflict of interest.

\section{References}

1. Vareda, J.P.; Valente, A.J.M.; Durães, L. Assessment of heavy metal pollution from anthropogenic activities and remediation strategies: A review. J. Environ. Manag. 2019, 246, 101-118. [CrossRef] [PubMed]

2. Vardhan, K.H.; Kumar, P.S.; Panda, R.C. A review on heavy metal pollution, toxicity and remedial measures: Current trends and future perspectives. J. Mol. Liq. 2019, 290, 111197. [CrossRef]

3. Panagos, P.; Van Liedekerke, M.; Yigini, Y.; Montanarella, L. Contaminated Sites in Europe: Review of the Current Situation Based on Data Collected through a European Network. Ecol. Indic. 2013, 24, 439-450. [CrossRef]

4. Kumari, P.; Alam, M.; Siddiqi, W.A. Usage of nanoparticles as adsorbents for waste water treatment: An emerging trend. Sustain. Mater. Technol. 2019, 22, e00128. [CrossRef]

5. Yadav, V.B.; Gadi, R.; Kalra, S. Clay based nanocomposites for removal of heavy metals from water: A review. J. Environ. Manag. 2019, 232, 803-817. [CrossRef]

6. WHO. Guidelines for Drinking-Water Quality, 4th ed.; WHO: Geneva, Switzerland, 2012.

7. EU. European Commission Implementing Decision (EU) 2017/1442 of 31 July 2017 establishing best available techniques (BAT) conclusions, under Directive 2010/75/EU of the European Parliament and of the Council, for large combustion plants. Off. J. Eur. Union 2017. Available online: http://www.legislation.gov.uk/eudn/ 2017/1442 (accessed on 5 March 2020).

8. EU. European Commission Implementing Decision (EU) 2016/1032 of 13 June 2016 establishing best available techniques (BAT) conclusions, under Directive 2010/75/EU of the European Parliament and of the Council, for the non-ferrous metals industries. Off. J. Eur. Union 2016, 32-106. Available online: http://www.legislation.gov.uk/eudn/2016/1032 (accessed on 5 March 2020).

9. Nasir, A.M.; Goh, P.S.; Abdullah, M.S.; Ng, B.C.; Ismail, A.F. Adsorptive nanocomposite membranes for heavy metal remediation: Recent progresses and challenges. Chemosphere 2019, 232, 96-112. [CrossRef]

10. Xu, J.; Cao, Z.; Zhang, Y.; Yuan, Z.; Lou, Z.; Xu, X.; Wang, X. A review of functionalized carbon nanotubes and graphene for heavy metal adsorption from water: Preparation, application, and mechanism. Chemosphere 2018, 195, 351-364. [CrossRef]

11. Joseph, L.; Jun, B.-M.; Flora, J.R.V.; Park, C.M.; Yoon, Y. Removal of heavy metals from water sources in the developing world using low-cost materials: A review. Chemosphere 2019, 229, 142-159. [CrossRef]

12. Wang, L.; Wang, Y.; Ma, F.; Tankpa, V.; Bai, S.; Guo, X.; Wang, X. Mechanisms and reutilization of modified biochar used for removal of heavy metals from wastewater: A review. Sci. Total Environ. 2019, 668, 1298-1309. [CrossRef]

13. Fiyadh, S.S.; AlSaadi, M.A.; Jaafar, W.Z.; AlOmar, M.K.; Fayaed, S.S.; Mohd, N.S.; Hin, L.S.; El-Shafie, A. Review on heavy metal adsorption processes by carbon nanotubes. J. Clean. Prod. 2019, 230, 783-793. [CrossRef]

14. Gupta, N.K.; Choudhary, B.C.; Gupta, A.; Achary, S.N.; Sengupta, A. Graphene-based adsorbents for the separation of f-metals from waste solutions: A review. J. Mol. Liq. 2019, 289, 111121. [CrossRef] 
15. Joseph, L.; Jun, B.-M.; Jang, M.; Park, C.M.; Muñoz-Senmache, J.C.; Hernández-Maldonado, A.J.; Heyden, A.; Yu, M.; Yoon, Y. Removal of contaminants of emerging concern by metal-organic framework nanoadsorbents: A review. Chem. Eng. J. 2019, 369, 928-946. [CrossRef]

16. Almeida, J.C.; Cardoso, C.E.D.; Tavares, D.S.; Freitas, R.; Trindade, T.; Vale, C.; Pereira, E. Chromium removal from contaminated waters using nanomaterials-A review. TrAC Trends Anal. Chem. 2019, 118, 277-291. [CrossRef]

17. Farghali, A.A.; Abdel Tawab, H.A.; Abdel Moaty, S.A.; Khaled, R. Functionalization of acidified multi-walled carbon nanotubes for removal of heavy metals in aqueous solutions. J. Nanostruct. Chem. 2017, 7, 101-111. [CrossRef]

18. Mobasherpour, I.; Salahi, E.; Ebrahimi, M. Removal of divalent nickel cations from aqueous solution by multi-walled carbon nano tubes: Equilibrium and kinetic processes. Res. Chem. Intermed. 2012, 38, 2205-2222. [CrossRef]

19. Ge, Y.; Li, Z.; Xiao, D.; Xiong, P.; Ye, N. Sulfonated multi-walled carbon nanotubes for the removal of copper (II) from aqueous solutions. J. Ind. Eng. Chem. 2014, 20, 1765-1771. [CrossRef]

20. Abdel-Ghani, N.T.; El-Chaghaby, G.A.; Helal, F.S. Individual and competitive adsorption of phenol and nickel onto multiwalled carbon nanotubes. J. Adv. Res. 2015, 6, 405-415. [CrossRef]

21. Zhao, X.H.; Jiao, F.P.; Yu, J.G.; Xi, Y.; Jiang, X.Y.; Chen, X.Q. Removal of Cu(II) from aqueous solutions by tartaric acid modified multi-walled carbon nanotubes. Colloids Surfaces A Physicochem. Eng. Asp. 2015, 476, 35-41. [CrossRef]

22. Kandah, M.I.; Meunier, J.L. Removal of nickel ions from water by multi-walled carbon nanotubes. J. Hazard. Mater. 2007, 146, 283-288. [CrossRef]

23. Kosa, S.A.; Al-Zhrani, G.; Abdel Salam, M. Removal of heavy metals from aqueous solutions by multi-walled carbon nanotubes modified with 8-hydroxyquinoline. Chem. Eng. J. 2012, 181-182, 159-168. [CrossRef]

24. Kanyó, T.; Kónya, Z.; Kukovecz, Á.; Berger, F.; Dékány, I.; Kiricsi, I. Quantitative characterization of hydrophilic-hydrophobic properties of MWNTs surfaces. Langmuir 2004, 20, 1656-1661. [CrossRef]

25. Abdel Salam, M.; Al-Zhrani, G.; Kosa, S.A. Removal of heavy metal ions from aqueous solution by multi-walled carbon nanotubes modified with 8-hydroxyquinoline: Kinetic study. J. Ind. Eng. Chem. 2014, 20, 572-580. [CrossRef]

26. Ayawei, N.; Ebelegi, A.N.; Wankasi, D. Modelling and Interpretation of Adsorption Isotherms. J. Chem. 2017, 2017, 3039817. [CrossRef]

27. Kragulj, M.; Tričković, J.; Dalmacija, B.; Kukovecz, Á.; Kónya, Z.; Molnar, J.; Rončević, S. Molecular interactions between organic compounds and functionally modified multiwalled carbon nanotubes. Chem. Eng. J. 2013, 225, 144-152. [CrossRef]

28. Wang, S.; Sun, H.; Ang, H.M.; Tadé, M.O. Adsorptive remediation of environmental pollutants using novel graphene-based nanomaterials. Chem. Eng. J. 2013, 226, 336-347. [CrossRef]

29. Yang, S.; Li, J.; Shao, D.; Hu, J.; Wang, X. Adsorption of $\mathrm{Ni}(\mathrm{II})$ on oxidized multi-walled carbon nanotubes: Effect of contact time, $\mathrm{pH}$, foreign ions and PAA. J. Hazard. Mater. 2009, 166, 109-116. [CrossRef] [PubMed]

30. Hu, J.; Chen, C.; Zhu, X.; Wang, X. Removal of chromium from aqueous solution by using oxidized multiwalled carbon nanotubes. J. Hazard. Mater. 2009, 162, 1542-1550. [CrossRef]

31. Gholipour, M.; Hashemipour, H. Evaluation of multi-walled carbon nanotubes performance in adsorption and desorption of hexavalent chromium. Chem. Ind. Chem. Eng. Q. 2012, 18, 509-523. [CrossRef]

32. Can, M. Studies of the kinetics for rhodium adsorption onto gallic acid derived polymer: The application of nonlinear regression analysis. Acta Phys. Pol. A 2015, 127, 1308-1310. [CrossRef]

33. Lee, C.; Kim, S. Cr(VI) Adsorption to Magnetic Iron Oxide Nanoparticle-Multi-Walled Carbon Nanotube Adsorbents. Water Environ. Res. 2016, 88, 2111-2120. [CrossRef]

34. Tran, H.N.; You, S.J.; Hosseini-Bandegharaei, A.; Chao, H.P. Mistakes and inconsistencies regarding adsorption of contaminants from aqueous solutions: A critical review. Water Res. 2017, 120, 88-116. [CrossRef] [PubMed]

35. Jung, C.; Heo, J.; Han, J.; Her, N.; Lee, S.J.; Oh, J.; Ryu, J.; Yoon, Y. Hexavalent chromium removal by various adsorbents: Powdered activated carbon, chitosan, and single/multi-walled carbon nanotubes. Sep. Purif. Technol. 2013, 106, 63-71. [CrossRef]

36. Tofighy, M.A.; Mohammadi, T. Adsorption of divalent heavy metal ions from water using carbon nanotube sheets. J. Hazard. Mater. 2011, 185, 140-147. [CrossRef] [PubMed] 
37. Zhang, X.; Huang, Q.; Liu, M.; Tian, J.; Zeng, G.; Li, Z.; Wang, K.; Zhang, Q.; Wan, Q.; Deng, F.; et al. Preparation of amine functionalized carbon nanotubes via a bioinspired strategy and their application in $\mathrm{Cu}^{2+}$ removal. Appl. Surf. Sci. 2015, 343, 19-27. [CrossRef]

38. Labied, R.; Benturki, O.; Eddine Hamitouche, A.Y.; Donnot, A. Adsorption of hexavalent chromium by activated carbon obtained from a waste lignocellulosic material (Ziziphus jujuba cores): Kinetic, equilibrium, and thermodynamic study. Adsorpt. Sci. Technol. 2018, 36, 1066-1099. [CrossRef]

39. Yu, F.; Wu, Y.; Ma, J.; Zhang, C. Adsorption of lead on multi-walled carbon nanotubes with different outer diameters and oxygen contents: Kinetics, isotherms and thermodynamics. J. Environ. Sci. (China) 2013, 25, 195-203. [CrossRef]

40. Burakov, A.E.; Galunin, E.V.; Burakova, I.V.; Kucherova, A.E.; Agarwal, S.; Tkachev, A.G.; Gupta, V.K. Adsorption of heavy metals on conventional and nanostructured materials for wastewater treatment purposes: A review. Ecotoxicol. Environ. Saf. 2018, 148, 702-712. [CrossRef]

41. Sarma, G.K.; Sen Gupta, S.; Bhattacharyya, K.G. Nanomaterials as versatile adsorbents for heavy metal ions in water: A review. Environ. Sci. Pollut. Res. 2019, 26, 6245-6278. [CrossRef]

42. Sun, X.; Liu, X.; Yang, B.; Xu, L.; Yu, S. Functionalized chrysotile nanotubes with mercapto groups and their $\mathrm{Pb}(\mathrm{II})$ and $\mathrm{Cd}$ (II) adsorption properties in aqueous solution. J. Mol. Liq. 2015, 208, 347-355. [CrossRef]

43. Xiao, D.L.; Li, H.; He, H.; Lin, R.; Zuo, P.L. Adsorption performance of carboxylated multi-wall carbon nanotube-Fe3O4 magnetic hybrids for $\mathrm{Cu}(\mathrm{II})$ in water. Xinxing Tan Cailiao/New Carbon Mater. 2014, 29, 15-25. [CrossRef]

44. Di Natale, F.; Lancia, A.; Molino, A.; Musmarra, D. Removal of chromium ions form aqueous solutions by adsorption on activated carbon and char. J. Hazard. Mater. 2007, 145, 381-390. [CrossRef] [PubMed]

45. Sheng, G.; Li, J.; Shao, D.; Hu, J.; Chen, C.; Chen, Y.; Wang, X. Adsorption of copper(II) on multiwalled carbon nanotubes in the absence and presence of humic or fulvic acids. J. Hazard. Mater. 2010, 178, 333-340. [CrossRef] [PubMed]

46. Chen, C.; Hu, J.; Shao, D.; Li, J.; Wang, X. Adsorption behavior of multiwall carbon nanotube/iron oxide magnetic composites for $\mathrm{Ni}(\mathrm{II})$ and $\mathrm{Sr}(\mathrm{II})$. J. Hazard. Mater. 2009, 164, 923-928. [CrossRef] [PubMed]

47. López-Ramón, V.; Moreno-Castilla, C.; Rivera-Utrilla, J.; Radovic, L.R. Ionic strength effects in aqueous phase adsorption of metal ions on activated carbons. Carbon N. Y. 2003, 41, 2020-2022. [CrossRef] 


\title{
Arsenic Removal from Water by Green Synthesized Magnetic Nanoparticles
}

\author{
Jasmina Nikić, Aleksandra Tubić *, Malcolm Watson, Snežana Maletić, Marko Šolić, \\ Tatjana Majkić and Jasmina Agbaba \\ Department of Chemistry, Biochemistry and Environmental Protection, Faculty of Sciences, University of Novi \\ Sad, Trg Dositeja Obradovića 3, 21000 Novi Sad, Serbia; jasmina.nikic@dh.uns.ac.rs (J.N.); \\ malcolm.watson@dh.uns.ac.rs (M.W.); snezana.maletic@dh.uns.ac.rs (S.M.); marko.solic@dh.uns.ac.rs (M.̌̌.); \\ tatjana.majkic@dh.uns.ac.rs (T.M.); jasmina.agbaba@dh.uns.ac.rs (J.A.) \\ * Correspondence: aleksandra.tubic@dh.uns.ac.rs
}

Received: 30 September 2019; Accepted: 25 November 2019; Published: 28 November 2019

\begin{abstract}
Magnetite nanoparticles were synthesized by a simple and ecofriendly method using onion peel (MNp-OP) and corn silk extract (MNp-CS), in order to develop new low-cost adsorbents for arsenic removal from groundwater. As a point of comparison, magnetite nanoparticles were also synthesized with a conventional chemical process (MNp-CO). The antioxidant potential of onion peel and corn silk extracts was determined using ferric reducing antioxidant power (FRAP) and free radical (DPPH) scavenging assays, including the total phenolics, flavonoids and tannins contents. The synthesized magnetite nanoparticles were characterised using different techniques (Scanning electron microscope/Energy dispersive spectroscopy (SEM/EDS), X-ray diffraction (XRD), Fourier-transform infrared spectroscopy (FTIR) and Brunauer-Emmett-Teller (BET) surface area analyzer). The adsorption capacity of MNp-OP and MNp-CS and the arsenic removal mechanism of these novel adsorbents was investigated through kinetic and equilibrium experiments and their corresponding mathematical models. Characterisation of MNp-OP and MNp-CS shows high BET specific surface areas of $243 \mathrm{~m}^{2} / \mathrm{g}$ and $261 \mathrm{~m}^{2} / \mathrm{g}$, respectively. XRD and FTIR analysis confirmed the formation and presence of magnetite nanoparticles. The arsenic adsorption mechanism on $\mathrm{MNp}-\mathrm{OP}, \mathrm{MNp}-\mathrm{CS}$ and $\mathrm{MNp}-\mathrm{CO}$ involves chemisorption, intraparticle and external diffusion. Maximal adsorption capacities of MNp-OP, MNp-CS and MNp-CO were 1.86, 2.79, and $1.30 \mathrm{mg} / \mathrm{g}$ respectively. The green synthesis applied using onion peel and corn silk extracts was cost effective and environmentally friendly, and results in adsorbents with a high capacity for arsenic and magnetic properties, making them a very promising alternative approach in the treatment of arsenic contaminated groundwater.
\end{abstract}

Keywords: magnetite nanoparticles; onion peel; corn silk; arsenic; adsorption; groundwater

\section{Introduction}

The presence of arsenic in groundwater, either from anthropogenic or natural sources, is a serious problem in many different parts of the world. Millions of people, mostly in rural and developing countries, are exposed to high levels of arsenic via the intake of arsenic rich groundwater [1]. The main concerns related to arsenic in groundwater are its high toxicity and carcinogenicity, since long-term exposure to arsenic has been associated with cancer (skin, lungs, urinary tract, kidneys and liver) and other various noncancerous diseases [2]. In order to minimize and reduce the adverse health effects, the World Health Organization (WHO) recommends a maximum allowable concentration (MAC) for arsenic in drinking water of $10 \mu \mathrm{g} / \mathrm{L}[3]$.

Various technologies have been employed for arsenic removal from groundwater including coagulation, membrane separation, ion exchange and adsorption [4]. Among these techniques, 
adsorption offers many advantages including simple and stable operation, easy handling of waste, absence of added reagents, compact facilities, and generally lower operation costs [5-8].

Many synthetic and natural adsorbents have been developed and applied for arsenic removal, however in recent years, iron nanoparticles (INPs) have been the most interesting novel materials, due to their unique physicochemical properties (small particle size, high surface area, high magnetism, low toxicity) and their strong affinity for arsenic species [9-12]. INPs can be classified into three major groups namely:

(1) iron oxide nanoparticles (IONs) (i.e., magnetite; $\mathrm{Fe}_{3} \mathrm{O}_{4}$, hematite: $\alpha-\mathrm{Fe}_{2} \mathrm{O}_{3}$, maghemite; $\gamma$ - $\mathrm{Fe}_{2} \mathrm{O}_{3}$ ),

(2) iron oxide hydroxide $(\mathrm{FeOOH})$ nanoparticles and

(3) zero-valent iron (ZVI) nanoparticles.

Among the iron oxide nanoparticles, magnetite $\left(\mathrm{Fe}_{3} \mathrm{O}_{4}\right)$ and maghemite $\left(\gamma-\mathrm{Fe}_{2} \mathrm{O}_{3}\right)$ nanoparticles, have attracted a lot of attention for applications with arsenic contaminated waters [13-16]. Their ease of fabrication and high adsorption capacities for arsenic and super-paramagnetic properties allow for their easy separation from water, make them popular candidates for remediation of arsenic contaminated groundwaters.

Different methods have been reported for the synthesis of magnetic nanoparticles such as sol-gel process [16], electrical wire explosion (EWE) [13], hydrothermal synthesis [17], coprecipitation [18], etc. These methods require toxic solvents, high energy consumption and/or generate hazardous by-products. In contrast to these chemical and physical methods, the green synthesis of nanoparticles has been proposed as a cost-effective environmentally friendly and promising approach [19]. Biogenic or green synthesis of magnetic nanoparticles includes the use of plants, algae, and different microorganisms (yeast, fungi, diatoms, and bacteria), with plant-mediated synthesis of magnetite nanoparticles being the most investigated. Different parts of plants can be applied for the synthesis of magnetic nanoparticles; however, most researchers apply various leaf extracts [20-25]. In general, the extracts obtained from plants contain a variety of phytochemicals (polyphenolics, flavonoid, tannins etc.) and various types of proteins, enzymes, polysaccharides and alcoholic compounds which can act as natural sources for reducing and capping agents in a one-pot synthesis reaction. Such an approach eliminates multistep synthesis practice problems and the costs of chemical reagents. Moreover, the use of plant residues from non-food sources (which would otherwise be waste materials) as a feedstock for green synthesis reactions reduces production costs and further contributes to sustainability.

To date, there is no literature relating to the green synthesis of magnetite nanoparticles using extracts obtained from onion peel and corn silk, or their application on arsenic remediation.

Onion (Allium cepa L.) is one of the most frequently consumed vegetables, and its production increases every day due to increasing consumer demand. Simultaneously, huge amounts of waste are produced from different parts of the onion, which affect the environment in various ways. Hence, proper use as well as disposal of this waste is important from an environmental aspect [26]. The concentrations of total phenols, flavonoids, flavonols and other antioxidants are higher in the onion peel than in the edible portion of the onion [27-30]. This waste therefore has great promise as a natural reductant in the one-pot synthesis of magnetic nanoparticles.

Corn silk, the female flower stigma of maize (Zea mays L.), is a yellow silky strand found on the top of corn fruit. Corn silk is a by-product obtained from corn production such as food, processed food and animal feed, and is discarded as waste together with other parts of corn such as the cob and husk [31]. Like onion peel, corn silk contains various components, including protein, vitamins, carbohydrates, $\mathrm{Ca}, \mathrm{K}, \mathrm{Mg}$, sitosterol, stigmasterol, alkaloids, saponins, tannins and flavonoids (maysin, methoxymaysin, apimaysin, and luteolin derivatives). Moreover, it is a good source of polyphenol compounds, which are strong antioxidants $[32,33]$. Corn silk is used in traditional medicine to treat many diseases [34,35], but despite its medicinal properties, it is still not used in the pharmaceutical industry and is treated as a waste material. 
Thus, in this study magnetite nanoparticles were synthesized for the first time in a one-step process using extract obtained from onion shell (Mag-OS) and corn silk (Mag-CS). These novel adsorbents were characterized by different techniques (SEM/EDS, XRD, FTIR, BET) and further applied for arsenic removal from groundwater. In order to compare efficiency of the green synthesis, as well arsenic adsorption capacities, magnetic nanoparticles were also synthesized by conventional chemical coprecipitation method (MNp-CO), the most common fabrication pathway for this material.

\section{Materials and Methods}

\subsection{Green Synthesis of Magnetic Nanoparticles}

\subsubsection{Preparation of Onion Peel and Corn Silk Extracts}

Onion peels (OP) and corn silk (CS) were collected from locally grown produce (Dutch yellow onions and NS 6010 Hybrid corn, both from NS Seme, Novi Sad). The collected materials were washed several times with distilled water to remove impurities, dried at ambient temperature, then cut into small pieces. Ten $\mathrm{g}$ of CS/OP were weighed and transferred to a $500 \mathrm{~mL}$ beaker, to which $300 \mathrm{~mL}$ of distilled water was added. The beaker was then placed in a shaker bath at $30^{\circ} \mathrm{C}$ for $1 \mathrm{~h}$. After shaking, the solution was filtered with a Büchner Vacuum Filtration Funnel and the filtrate was used for magnetite nanoparticles production.

\subsubsection{Preparation of Magnetite Nanoparticles}

The magnetic nanoparticles were synthesized by green precipitation method without addition of a chemical reducing agent. In green synthesis, the plant extracts act as chemical reducing agents while sodium acetate acts as an electrostatic stabilizing agent for the produced $\mathrm{Fe}_{3} \mathrm{O}_{4}$ nanoparticles [36]. In the reaction procedure, $2.16 \mathrm{~g}$ of $\mathrm{FeCl}_{3} \cdot 6 \mathrm{H}_{2} \mathrm{O}$ and $6.56 \mathrm{~g}$ of sodium acetate was dissolved in $40 \mathrm{~mL}$ of corn silk/onion peel extract. The suspension was placed under vigorous stirring for $1 \mathrm{~h}$ at $80^{\circ} \mathrm{C}$, and the resulting precipitate centrifuged and washed several times with distilled water. The obtained magnetic nanoparticles were dried in an oven at $105^{\circ} \mathrm{C}$. The synthesized magnetic nanoparticles were denoted as $\mathrm{MNp}-\mathrm{CS}$ and $\mathrm{MNp}-\mathrm{OP}$.

\subsection{Synthesis of Magnetic Nanoparticles by Coprecipitation Methods}

In order to compare the efficiency of the green synthesis method and the adsorption capacity of the green nanoparticles obtained (MNp-CS and $\mathrm{MNp}-\mathrm{OP}$ ), magnetic nanoparticles were also synthesized via the chemical coprecipitation method using $\mathrm{Fe}^{3+}$ and $\mathrm{Fe}^{2+}$ salts at a molar ratio of 2:1. 2.50 g of $\mathrm{FeCl}_{3} \cdot 6 \mathrm{H}_{2} \mathrm{O}$ and $1.21 \mathrm{~g} \mathrm{FeSO}_{4} \cdot 7 \mathrm{H}_{2} \mathrm{O}$ were dissolved in $40 \mathrm{~mL}$ of deionized water in a $200 \mathrm{~mL}$ glass beaker. Two $\mathrm{M} \mathrm{NaOH}$ solution was added dropwise until the mixture reached $\mathrm{pH} 9$ and a black precipitate developed. The synthesized $\mathrm{MNp}-\mathrm{CO}$ were then separated from the suspension by external magnet and washed repeatedly with deionised water until a supernatant of neutral $\mathrm{pH}$ was obtained.

\subsection{Characteristion of Plant Extracts}

Total phenolics in the plant extract were determined by Folin-Ciocalteu reagent (FC), as previously described [37]. The total phenol content (TPC) was expressed as mg of gallic acid equivalents (GAE) per $g$ dry weight $(\mathrm{dw})$ of extracts. The tannin content was determined using insoluble polyvinyl polypirrolidone, which binds the tannins. The total tannin content (TTC) was expressed as mg of catechin equivalents (CE) per g dry weight $(\mathrm{dw})$ of extracts. The total content of flavonoids (TFC) was determined by using the aluminium chloride colorimetric method as previously described. The total content of flavonoids was expressed as mg of quercetin equivalents $(\mathrm{QE})$ per $\mathrm{g}$ dry weight $(\mathrm{dw})$ of extracts. The antioxidant potential of plant extracts was determined using tests related to free radical $\left(\mathrm{DPPH}^{\bullet}\right)$ scavenging. 
Reducing power was measured by Ferric Reducing Antioxidant Power (FRAP) assay according to the previously described procedure [38]. Reducing power were expressed as mmol of trolox equivalents (TE) per g dry weight (dw) of extracts.

\subsection{Characterisation of Magnetite Nanoparticles}

The specific surface area of the magnetic nanoparticles was measured by nitrogen adsorption using the Brunauer-Emmett-Teller (BET) method with a Autosorb TMiQ surface area analyzer (Quantachrome, Boynton Beach, FL, USA). Mesopore and micropore volumes were determined using the Barett-Joyner-Halender (BJH) method using desorption isotherm, and $t$-test method, respectively. The surface morphology, microstructure and elemental composition of the magnetic nanoparticles were examined using scanning electron microscopy combined with energy dispersive X-ray spectroscopy (SEM-EDX) (Hitachi TM3030, Japan). X-ray diffraction (XRD) patterns were obtained on Philips PW automated X-ray powder diffractometer (USA). Fourier transform infrared (FTIR) spectra of magnetic nanoparticles were recorded by infrared spectrophotometer (FTIR Nexus 670, Thermonicolet, USA). The point of zero charge $\left(\mathrm{pH}_{\mathrm{pzc}}\right)$ of the magnetic nanoparticles was determined according to the method described by Zhang et al. [39]

\subsection{Adsorption Experiments}

Adsorption experiments were conducted with groundwater samples taken from Višnjićevo (a settlement located in the Autonomous Province of Vojvodina, Serbia). The characteristics of the groundwater are given in Table 1. Measurement uncertainties are expressed as the standard deviations of 10 separate measurements. For the kinetics experiments, $20 \mathrm{~mL}$ water samples were added to $40 \mathrm{~mL}$ glass bottles containing $10 \mathrm{mg}$ of synthesized magnetic nanoparticles (MNp-CS, MNp-OP and $\mathrm{MNp}-\mathrm{CO})$. The suspensions were shaken on an orbital shaker $\left(180 \mathrm{rpm}, 22^{\circ} \mathrm{C}\right)$ for certain periods of time $(1,2,4,6,9,12,18,24 \mathrm{~h})$ and afterwards the supernatants were separated from the adsorbents using an external magnet. Residual arsenic concentrations in the samples were analyzed by inductively coupled plasma mass spectrometry (ICP-MS) as explained below. Equilibrium experiments were conducted with different sorbent doses $(0.01-0.1 \mathrm{~g})$ in the same manner as the kinetic experiments.

Table 1. Characteristics of the investigated groundwater.

\begin{tabular}{cc}
\hline Parameter & Value $\pm \mathbf{s d}^{\mathbf{a}}$ \\
\hline $\mathrm{pH}$ & $8.05 \pm 0.15$ \\
Conductivity $(\mu \mathrm{s} / \mathrm{cm})$ & $669 \pm 14.3$ \\
Alkalinity $\left(\mathrm{mmol}^{\mathrm{a}}\right)$ & $6.93 \pm 0.37$ \\
Hardness $\left(\mathrm{mg} \mathrm{CaCO}_{3} / \mathrm{L}\right)$ & $133 \pm 48.3$ \\
Total arsenic $(\mu \mathrm{g} / \mathrm{L})$ & $126 \pm 8.97$ \\
Arsenic $(\mathrm{III})$ & $98 \pm 12$ \\
Arsenic $(\mathrm{V})$ & $18 \pm 2.5$ \\
Fe $(\mu \mathrm{g} / \mathrm{L})$ & $20.2 \pm 25.8$ \\
TOC $\left(\mathrm{mgC}^{\mathrm{L}}\right)$ & $2.40 \pm 0.71$ \\
DOC $\left(\mathrm{mgC}^{\mathrm{L}}\right)$ & $2.12 \pm 0.51$ \\
Phosphate $\left(\mathrm{mgPO}_{4} / \mathrm{L}\right)$ & $1.33 \pm 0.05$ \\
Chloride $\left(\mathrm{mgCl}_{\mathrm{L}}\right)$ & $17.7 \pm 1.36$ \\
Ammonium $\left(\mathrm{mgN}^{\mathrm{L}} \mathrm{L}\right)$ & $0.15 \pm 0.10$ \\
Sulfate $\left(\mathrm{mgSO}_{4} / \mathrm{L}\right)$ & $20.3 \pm 12.2$ \\
\hline
\end{tabular}

${ }^{\text {a }}$ sd-standard deviation, based on 10 measurements.

The amount of arsenic adsorbed by a unit mass of adsorbent was calculated using the following equation:

$$
q_{e}=\frac{\left(C_{0}-C_{e}\right) V}{m}
$$


where $C_{0}$ and $C_{e}$ are the initial and equilibrium concentrations in solution $(\mathrm{mg} / \mathrm{L}) . V$ is the volume of solutions ( $\mathrm{L}$ ) and $\mathrm{m}$ the mass of sorbent applied during the experiment $(\mathrm{g})$.

Different kinetic models (pseudo-first order, pseudo-second order model, Elovich, Weber-Morris and Boyd model) [40] were used to fit the kinetic experimental data while the Langmuir, Freundlich, Dubinin-Radushkevich and Tempkin isotherm [41] were applied for modelling equilibrium experimental data. The parameters of these models were determined by nonlinear fitting of the data using Origin 8.0 software (OriginLab Corporation, Northampton, MA, USA).

\subsection{Analytical Methods}

$\mathrm{pH}$ measurements were carried out using an InoLab pH/ION 735 instrument (WTW, Austria). Total arsenic concentrations were analyzed by ICPMS (7700 Series, Agilent Technologies, Tokyo, Japan) and arsenic speciation analyses were carried out on the same system coupled with high performance liquid chromatography (1260 Infinity, Agilent Technologies, Germany) [42,43]. Water alkalinity (pand m-alkalinity) was measured by titration with a standard solution of $\mathrm{HCl}$ according to Standard Methods [44]. The concentration of orthophosphate was determined according to the official Serbian translation of a method published by the International Organization for Standardization (SRPS EN ISO 6878: 2008) [45]. Concentration of chloride and ammonium was determined according to methods SRPS ISO 9297/1:2007 and SRPS ISO 5664:1992, respectively [46,47]. Dissolved organic carbon (DOC) in groundwater was analysed after filtration through a $0.45 \mu \mathrm{m}$ membrane filter on an LiquiTOCII (Elementar, Germany), using Pt catalysed combustion at $850{ }^{\circ} \mathrm{C}$ to oxidize the carbon, in accordance with standard method SPRS ISO 8245:2007 [48].

\section{Results and Discussion}

\subsection{Characterization of Magnetic Nanoparticles}

The addition of $\mathrm{FeCl}_{3}$ to the $\mathrm{OP}$ and $\mathrm{CS}$ extracts initiated the formation of magnetite nanoparticles $\mathrm{MNp}-\mathrm{OP}$ and MNp-CS. The surface morphology, as well as the qualitative and semiquantitative composition of the surface of these nanoparticles, was investigated by SEM/EDS analysis, as shown in Figure 1. The magnetite nanoparticles (MNp-CO) synthesized for the sake of comparison by conventional coprecipitation method is also shown.

It can be seen that the surfaces of all three materials are rough and contain a large number of particles that are irregular in shape and size. A large number of aggregated particles on the surface of these materials could be attributed to nanostructures and magnetic properties, which contribute a tendency for agglomeration and aggregation.

EDS analysis of MNp-OP showed iron and oxygen weights of $57.1 \%$ and $40.3 \%$, respectively. Similarly, MNp-CS contained $55.6 \% \mathrm{Fe}$ and $40.9 \% \mathrm{O}$. Trace amounts of $\mathrm{Cl}$ and $\mathrm{C}$ were found on the surface of both materials $(<2 \%)$. As with MNp-OP and MNp-CS, EDS analysis of MNp-CO showed a molar ratio of $\mathrm{Fe}: \mathrm{O}$ of $41.7 \%$ to $43.2 \%$. In general, the presence of $\mathrm{Fe}$ and $\mathrm{O}$ peaks in the surface of these materials confirms the formation of iron oxide. The presence of carbon can be attributed either to polyphenols or other phytochemical compounds or $\mathrm{CO}_{2}$ from air. The traces of $\mathrm{Cl}$ come from the $\mathrm{FeCl}_{3}$ precursor.

The phase identification and crystalline structures of the nanoparticles was characterized by X-ray powder diffraction. The X-ray diffraction patterns of MNp-OP, MNp-CS and MNp-CO are presented in Figure 2. 

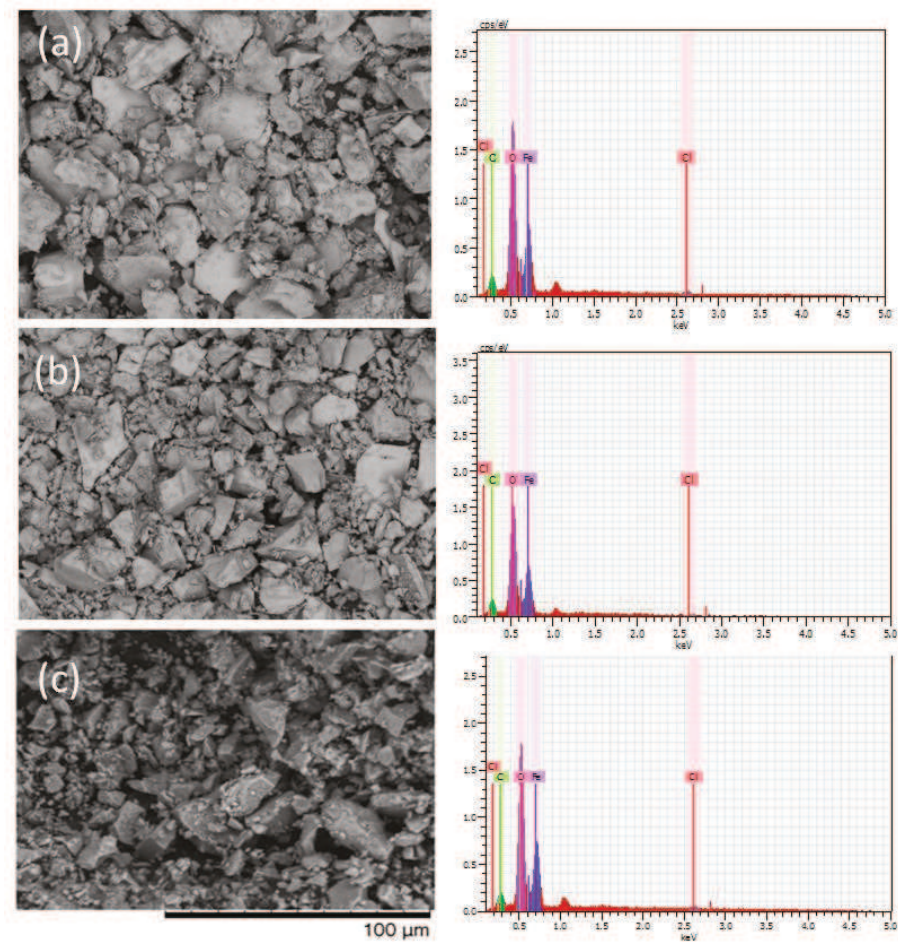

Figure 1. Scanning electron microscope (SEM) and energy-dispersive spectroscopy (EDS) images of (a) $\mathrm{MNp}-\mathrm{OP}(\mathbf{b}) \mathrm{MNp}-\mathrm{CS}$ (c) MNp-CO.

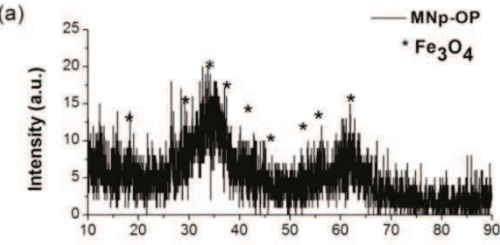

(b)
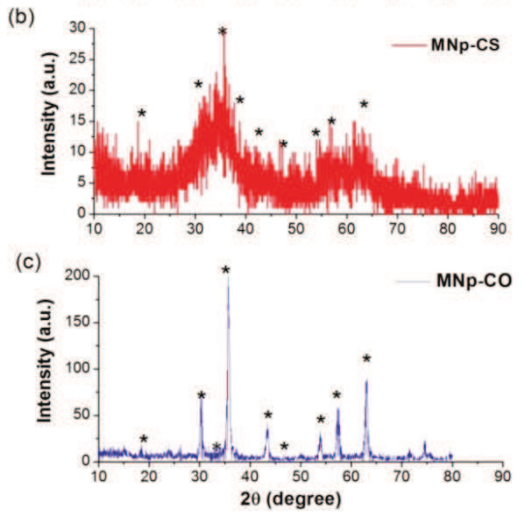

Figure 2. X-ray diffraction (XRD) patterns of (a) MNp-OP (b) MNp-CS and (c) MNp-CS. 
XRD patterns show that all diffraction peaks at $2 \theta=18.7,30.4,35.5,37.7,43.8,47.3,54.2,56.8$ and 62.5, show good matches with crystal planes of magnetite at (111), (220), (311), (222), (400), (331), (422), (511) and (440). Additionally, it may be noted that the peaks in XRD patterns of these materials were broad with low intensity, indicating nanosized particles [25,36,49]. The average particle sizes of the synthesized $\mathrm{MNp}-\mathrm{OP}, \mathrm{MNp}-\mathrm{CS}$ and $\mathrm{MNp}-\mathrm{CO}$, which were calculated using the Debye-Scherrer equation [50] were found to be $26 \mathrm{~nm}, 28 \mathrm{~nm}$ and $12 \mathrm{~nm}$, respectively. Thus, the XRD patterns indicate that the magnetic nanoparticles were successfully synthesized using the green method.

The magnetic nanoparticles were also analyzed by FTIR spectroscopy. The corresponding FTIR spectra of MNp-OP, MNp-CS and MNp-CO are presented in Figure 3.

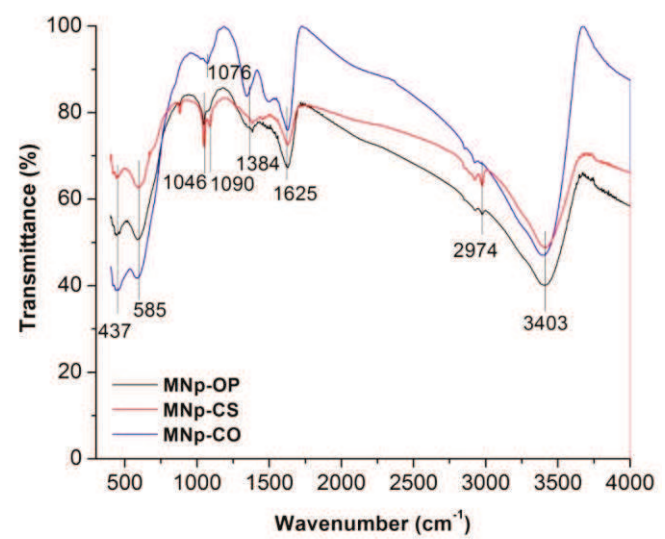

Figure 3. Fourier-transform infrared spectroscopy (FTIR) spectra of MNp-OP, MNp-CS and MNp-CO.

All spectra exhibited broad and strong bands at $3420 \mathrm{~cm}^{-1}$ and $1630 \mathrm{~cm}^{-1}$, attributable to O-H stretching and $\mathrm{O}-\mathrm{H}$ bending vibration from physisorbed water molecules [51]. The band at $2974 \mathrm{~cm}^{-1}$ is attributed to the $\mathrm{C}-\mathrm{H}$ stretching vibration of hydrocarbon chains. The peaks at 1046, 1076 and 1090 $\mathrm{cm}^{-1}$ correspond to the bending vibration of the hydroxyl groups $(\mathrm{Fe}-\mathrm{OH})$, which are responsible for the formation of inner sphere surface complexes [52]. Absorption peaks at $585 \mathrm{~cm}^{-1}$ and $437 \mathrm{~cm}^{-1}$ are characteristic peaks for magnetite confirming that green synthesis as a chemical synthesis can produce $\mathrm{Fe}_{3} \mathrm{O}_{4}$ nanoparticles [25,36,49].

The textural characteristics of the synthesized magnetic nanoparticles, including specific surface area, mesopore and micropore volumes and average pore size of the synthesized sorbents, obtained by BET, BJH and model $t$-tests, are shown in Table 2.

Table 2. Characteristics of MNp-OP, MNp-CS and MNp-CO.

\begin{tabular}{|c|c|c|c|c|}
\hline Adsorbents & $\begin{array}{c}\text { Specific Surface } \\
\text { Area }\left(\mathrm{m}^{2} / \mathrm{g}\right)\end{array}$ & $\begin{array}{l}\text { Mesopore Volume } \\
\left(\mathrm{cm}^{3} / \mathrm{g}\right)\end{array}$ & $\begin{array}{c}\text { Micropore } \\
\text { Volume }\left(\mathrm{cm}^{3} / \mathrm{g}\right)\end{array}$ & $\begin{array}{l}\text { Average Pore Size } \\
(\mathrm{nm})\end{array}$ \\
\hline MNp-OP & 243 & 0.067 & 0.038 & 1.42 \\
\hline MNp-CS & 261 & 0.066 & 0.042 & 1.29 \\
\hline $\mathrm{MNp}-\mathrm{CO}$ & 72.1 & 0.155 & 0 & 10.5 \\
\hline
\end{tabular}

BET analysis show that the specific surface area of magnetic nanoparticles synthesized via the green method, MNp-OP and MNp-CS, have much larger specific surfaces than MNp-CO and other structurally similar adsorbents, such as magnetite nanoparticles synthesized with plantain peel extract $\left(11.31 \mathrm{~m}^{2} / \mathrm{g}\right)$ [36], commercially available magnetite and maghemite nanoparticles (40 and $39 \mathrm{~m}^{2} / \mathrm{g}$, respectively), magnetite nanoparticles synthesized via electrical wire explosion (EWE) $\left(12 \mathrm{~m}^{2} / \mathrm{g}\right)$ [13], etc. The mesopore volume of MNp-CO obtained by BJH method was higher than for green synthesized 
magnetic nanoparticles. However, in comparison with $\mathrm{MNp}-\mathrm{CO}$, the $t$-test method shows that $\mathrm{MNp}$-OP and MNp-CS also contain micropores ( 0.038 and $0.042 \mathrm{~cm}^{3} / \mathrm{g}$, respectively) and pore size less than 2 $\mathrm{nm}$, which means that according to the International Union of Pure and Applied Chemistry (IUPAC) classification, these materials may be considered as microporous adsorbents (pore diameter less than 2 $\mathrm{nm}$ ) [53]. The magnetite nanoparticles synthesized via conventional precipitation method, $\mathrm{MNp}-\mathrm{CO}$, do not have micropores, and its pore size was $10.5 \mathrm{~nm}$, implying a mesoporous structure of this material (pore diameter in the range 2 to $50 \mathrm{~nm}$ ).

The points of zero charge of MNp-OP, $\mathrm{MNp}-\mathrm{CS}$ and $\mathrm{MNp}-\mathrm{CO}$ are $\mathrm{pH}_{\mathrm{pzc}}=5.63, \mathrm{pH}_{\mathrm{pzc}}=6.75$ and $\mathrm{pH}_{\mathrm{pzc}}=6.18$, respectively (Figure 4). It is well known that at $\mathrm{pH}$ values less than $\mathrm{pH}_{\mathrm{pzc}}$, the surface of the sorbent is positively charged, which favours the sorption of negatively charged arsenic anions. In contrast, at $\mathrm{pH}$ values higher than $\mathrm{pH}_{\mathrm{pzc}}$, the surface of the sorbent is negatively charged, leading to electrostatic repulsions between the surface of the sorbent and the arsenic anion. Since the speciation of arsenic in the investigated groundwater shows that dominant form of arsenic (Table 1 ) was $\mathrm{As}(\mathrm{III})$, which exists in neutral form $\left(\mathrm{as}_{3} \mathrm{AsO}_{3}\right)$ at the $\mathrm{pH}$ of the groundwater $(\mathrm{pH}=8.05 \pm 0.15)$, the contribution of electrostatic interactions during adsorption of $\mathrm{As}(\mathrm{III})$ on the synthesized materials will be insignificant.
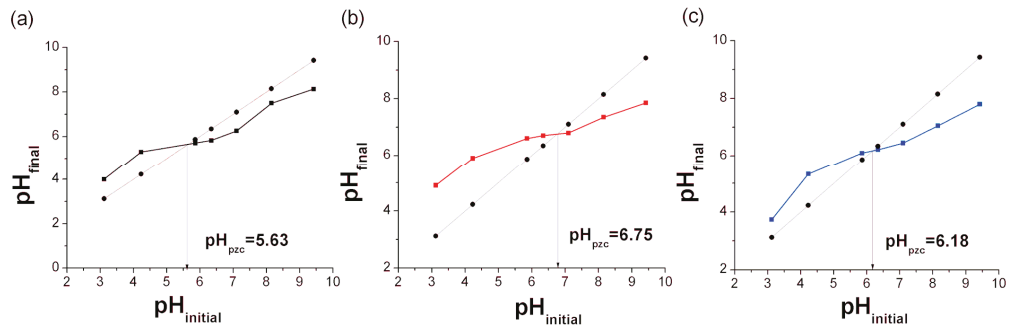

Figure 4. Points of zero charge of the synthesized (a) MNp-OP (b) MNp-CS and (c) MNp-CO.

\subsection{Formation of $M N p-O P$ and $M N p-C S$}

The antioxidant capacity of the plant extract is essential for synthesis of the magnetic nanoparticles and is usually in good correlation with phenols contents including flavonoids and tannins [54]. Their concentrations in the onion peel and corn silk extracts were therefore quantified. The results obtained from these tests are given in Table 3.

Table 3. Total phenols, flavonoids and tannins contents of onion peel and corn silk extracts.

\begin{tabular}{cccccc}
\hline & $\begin{array}{c}\text { Total Phenols } \\
(\mathbf{m g ~ G A E} / \mathbf{g ~ d w})\end{array}$ & $\begin{array}{c}\text { Total Flavonoids } \\
(\mathbf{m g ~ Q E} / \mathbf{g ~ d w})\end{array}$ & $\begin{array}{c}\text { Total Tannins } \\
(\mathbf{m g ~ C E} / \mathbf{g ~ d w})\end{array}$ & $\begin{array}{c}\text { DPPH・IC }_{\mathbf{5 0}} \\
(\boldsymbol{\mu g} / \mathbf{m L})\end{array}$ & $\begin{array}{c}\text { FRAP } \\
(\mathbf{m g} \text { TE/g dw) }\end{array}$ \\
\hline Onion peel extract & $155 \pm 4.8$ & $19.9 \pm 1.8$ & $133 \pm 9.5$ & $8.82 \pm 0.87$ & $2.17 \pm 0.17$ \\
Corn silk extract & $756 \pm 56.3$ & $205 \pm 7.1$ & $532 \pm 16$ & $2.93 \pm 0.21$ & $6.44 \pm 0.32$ \\
\hline
\end{tabular}

The corn silk extract has higher phenols, flavonoids and tannins contents than the onion peel extracts. Furthermore, the antioxidant capacity of corn silk extract obtained as DPPH${ }^{\bullet}$ scavenging and reduction potentials were higher than the onion peel extract, confirming the close relation between the content of phytochemical compounds and the extract's antioxidant properties [55]. Lee et al. [27] investigated different conditions for the extraction of phenolic compounds including flavonoids from onion peel and observed that total phenols and total flavonoids contents for onion peel extracts produced by hot water $\left(80^{\circ} \mathrm{C}\right.$ for $3 \mathrm{~h}$ ) was $120.60 \pm 6.05 \mathrm{GAE} / \mathrm{g}$ dry weight of extract and $54.50 \pm 5.21$ $\mathrm{mg} \mathrm{QE} / \mathrm{g}$ dry weight. The total phenols and flavonoids contents in corn silk extract in our study were also found to be comparable with corn silk extracts reported by other researchers [56,57]. It is possible that the mild extract conditions applied in this work $\left(30^{\circ} \mathrm{C}\right.$ for $\left.1 \mathrm{~h}\right)$, which were chosen for their 
significantly lower energy cost, resulted in fewer losses of phenolic compounds due to oxidation [58]. In general, however, the phytochemical content of plants is greatly affected by plant variety, maturity, growing conditions, cultivar areas and harvest times, so it is also possible the relatively high phenol contents in this work are the results of natural variation [35,59].

The characterisation results presented above demonstrate that the addition of $\mathrm{FeCl}_{3}$ to the onion peel or corn silk extracts cause the reduction of $\mathrm{Fe}^{3+}$ and subsequent formation of $\mathrm{Fe}_{3} \mathrm{O}_{4}$ nanoparticles. As can be seen from extract characterization (Table 3), onion shell and corn silk extract contained different phytochemical compounds with high antioxidant activities. In the synthesis of MNp-OP (suggested mechanism shown in Figure 5), we assume that the flavonoid querecetin, the major flavonoid in the onion peel extract, plays a critical role. Initially, carbonyl and hydroxyl groups (3-hydroxo-4-ketopresent) in these molecules chelate with $\mathrm{Fe}^{3+}$ to form ferric complex [60]. This metal chelation also has pro-oxidant properties (via electron or H-atom donation), whereas the transfer of an electron to $\mathrm{Fe}^{3+}$ resulting in formation of $\mathrm{Fe}^{2+}$ where quinones are suggested as flavonoid oxidation products [60]. Finally, $\mathrm{Fe}^{2+}$ and excess $\mathrm{Fe}^{3+}$ form black precipitate of $\mathrm{Fe}_{3} \mathrm{O}_{4}$ nanoparticles. Like onion peel, corn silk extract is also rich in phenolic compounds which are capable of reducing $\mathrm{Fe}^{3+}$ [61].

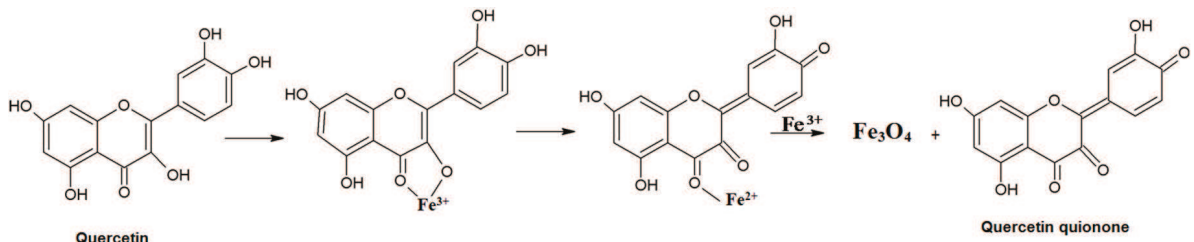

Figure 5. Schematic illustration of preparation of magnetic nanoparticles (MNp-OP) obtained from onion peel extract.

The results above demonstrate that onion peel and corn silk can both be used to produce magnetic nanoparticles, thus representing a significant added value to materials currently disposed of as a non-usable wastes.

\subsection{Arsenic Adsorption Kinetics}

Kinetic adsorption experiments and their corresponding mathematical models were used to investigate the adsorption rate and mechanism of arsenic removal on the synthesized magnetic nanoparticles. The changes in the adsorption of the synthesized nanoparticles $\left(q_{t}\right)$ of arsenic during time $t$, are presented in Figure 6.

(a)

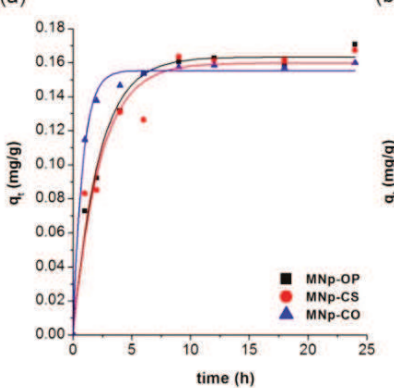

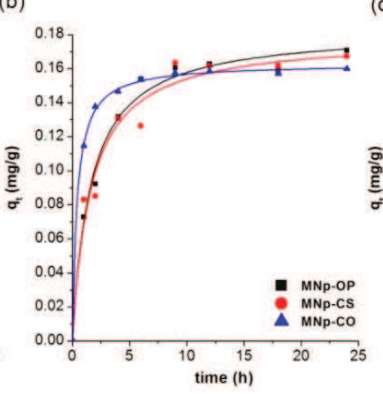

(c)

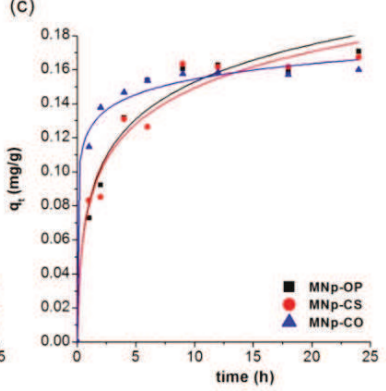

Figure 6. (a) Pseudo-first order (b) pseudo-second order and (c) Elovich model for adsorption of As on $\mathrm{MNp}-\mathrm{OP}, \mathrm{MNp}-\mathrm{CS}$ and MNp-CO. 
As can be seen from Figure 6, the adsorption process is time dependent and can be divided into two steps. During the first $4 \mathrm{~h}$, adsorption of arsenic was fast and over this period, arsenic removal was $55-61 \%$, depending on the applied magnetic nanoparticles. In subsequent slower steps, the adsorption of arsenic decreased and reached equilibrium after $9 \mathrm{~h}$ in the case of MNp-OP and MNp-CS. In the case of arsenic adsorption on $\mathrm{MNp}-\mathrm{CO}$, a contact time of $6 \mathrm{~h}$ was sufficient to reach equilibrium.

The adsorption behaviour of arsenic on the synthesized materials can be explained by the basic mechanisms of sorption and the hydrodynamics of the system. Namely, at the beginning of the process, the number of sorption sites and the concentration of arsenic in the solution are maximum, so the driving force of the sorption process is also at a maximum. In addition, mixing provides the energy necessary to transport the arsenic through the liquid film to the active sites on the sorbent. Consequently, sorption is promoted by these three facts: the presence of a large number of active sites, a large driving force and less resistance to mass transfer caused by mixing [62]. Over time, due to the accumulation of arsenic on the sorbent surface and the resulting decrease in the concentration gradient, the rate of arsenic sorption decreases, eventually reaching a state of equilibrium.

In addition, since the equilibrium time in all investigated cases was relatively slow (in the order of hours), this suggests that specific adsorption (which involves the formation of inner surface complexes) of arsenic occurs on these materials. Unlike specific adsorption, adsorption that is achieved only by electrostatic interactions is usually very fast (in the order of seconds) [63].

To obtain more in-depth information about the mechanism of arsenic adsorption onto the synthesized magnetic nanoparticles, the kinetic data was fitted to pseudo-first-order, pseudo-second-order, and Elovich kinetic models [40]. The parameters of these models are presented in Table 4.

Table 4. Kinetic parameters for arsenic adsorption on MNp-OP, MNp-CS and MNp-CO.

\begin{tabular}{ccccc}
\hline & & MNp-OP & MNp-CS & MNp-CO \\
\hline \multirow{3}{*}{ Pseudo-first order } & $\mathrm{k}_{1}(1 / \mathrm{h})$ & 0.459 & 0.443 & 1.26 \\
& $\mathrm{q}_{\mathrm{e}}(\mathrm{mg} / \mathrm{g})$ & 0.164 & 0.159 & 0.155 \\
& $\mathrm{R}^{2}$ & 0.9867 & 0.9371 & 0.9925 \\
\hline \multirow{5}{*}{ Pseudo-second order } & $\mathrm{k}_{2}(\mathrm{~g} / \mathrm{mg} \mathrm{h})$ & 3.43 & 3.49 & 15.2 \\
& $\mathrm{q}_{\mathrm{e}}(\mathrm{mg} / \mathrm{g})$ & 0.183 & 0.179 & 0.163 \\
& $\mathrm{q}_{\text {eexp }}(\mathrm{mg} / \mathrm{g})$ & 0.170 & 0.173 & 0.177 \\
& $\mathrm{~h}(\mathrm{mg} / \mathrm{g} \mathrm{h})$ & 0.115 & 0.112 & 0.403 \\
& $\mathrm{R}^{2}$ & 0.9871 & 0.9632 & 0.9990 \\
\hline \multirow{2}{*}{ Elovich } & $\alpha(\mathrm{mg} / \mathrm{g} \mathrm{h})$ & 0.377 & 0.382 & 180 \\
& $\beta(\mathrm{mg} / \mathrm{g})$ & 31.3 & 32.3 & 76.6 \\
& $\mathrm{R}^{2}$ & 0.9592 & 0.9607 & 0.9868 \\
\hline
\end{tabular}

Based on the coefficients of determination $\left(R^{2}\right)$, all applied models show good fit with the experimental data. However, the highest values of $R^{2}$ were observed for the pseudo-second-order kinetic model in all cases (Table 4), implying that adsorption process may be controlled by chemisorption [8]. The theoretical $\mathrm{q}_{\mathrm{e}}$ values calculated from the pseudo-second order model were very close to the experimental $\mathrm{q}_{\mathrm{e}}$ values confirming the good agreement with the model. The initial sorption rate, $\mathrm{h}$, in all cases was higher in comparison to the rate constant $k_{2}$, indicating that the rate of adsorption was much faster at the beginning of the process and decreased with time.

In a solid-liquid sorption process, which include porous adsorbents, transfer of adsorbate often takes place over four steps: bulk diffusion, film diffusion (which includes transfer of adsorbate from the bulk liquid phase to the adsorbent's external surface through a hydrodynamic boundary layer or film), intraparticle diffusion (which involves diffusion of adsorbate into the pores of the adsorbent, along pore-wall surfaces, or both), and sorption of sorbate molecules onto active sites distributed within the sorbent particles [64]. The first and last steps are usually very fast and they do not have a 
Water 2019, 11, 2520

determinant role in governing sorption rates. Consequently, the adsorption rate might be controlled by external diffusion, inner diffusion or both.

Since the pseudo-first, the pseudo-second order and Elovich kinetic models cannot identify the influence of diffusion on sorption, the intraparticle diffusion model proposed by Weber and Morris, and the external diffusion model, were also used to fit the experimental data (Table 5, Figures 7 and 8).

Table 5. Intraparticle and external diffusion parameters for arsenic adsorption on $\mathrm{MNp}-\mathrm{OP}, \mathrm{MNp}-\mathrm{CS}$ and $\mathrm{MNp}-\mathrm{CO}$.

\begin{tabular}{ccccc}
\hline Diffusion Model & Parameters & MNp-OP & MNp-CS & MNp-CO \\
\hline & $\mathrm{k}_{\mathrm{i}}\left(\mathrm{mg} / \mathrm{g} \mathrm{h}^{0.5}\right)$ & 0.0576 & 0.0407 & 0.0954 \\
& $\mathrm{C}_{\mathrm{i}}$ & 0.0139 & 0.0376 & 0.0250 \\
Weber-Morris model & $\mathrm{R}^{2}$ & 0.9630 & 0.8844 & 0.8364 \\
& $\mathrm{k}_{\mathrm{i}}\left(\mathrm{mg} / \mathrm{g} \mathrm{h}^{0.5}\right)$ & 0.00510 & 0.00188 & 0.150 \\
& $\mathrm{Ci}$ & 0.143 & 0.156 & 0.00195 \\
& $\mathrm{R}^{2}$ & 0.5454 & 0.0319 & 0.4932 \\
\hline \multirow{2}{*}{ Boyd model } & Intercept & 0.240 & 0.254 & 0.482 \\
& $\mathrm{R}^{2}$ & 0.9822 & 0.9288 & 0.9942 \\
\hline
\end{tabular}

(a)

(b)

(c)
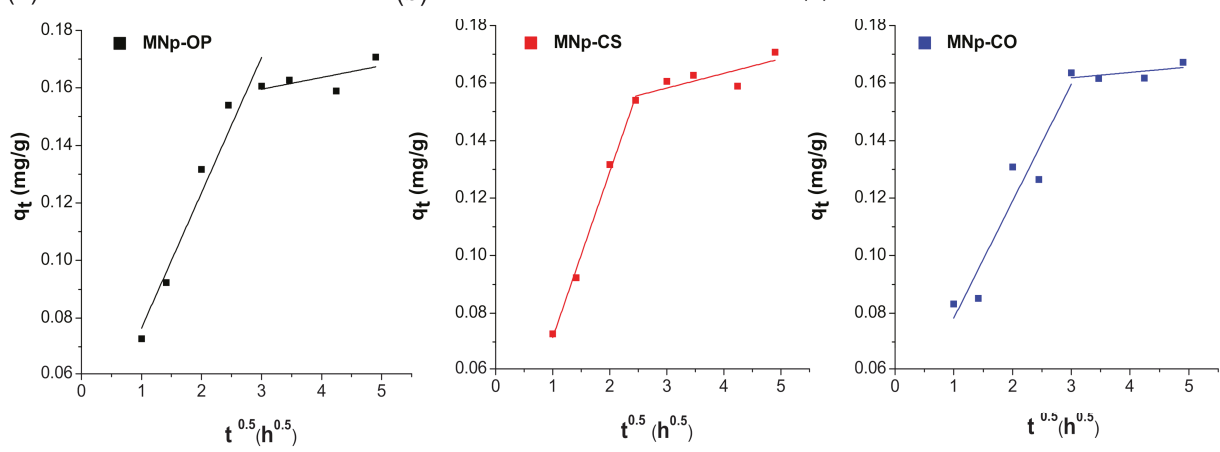

Figure 7. Weber-Morris model for arsenic adsorption on (a) MNp-OP (b) MNp-CS and (c) MNp-CO. Initial As concentration $120 \mu \mathrm{g} / \mathrm{L}$; adsorbent dose $0.5 \mathrm{~g} / \mathrm{L} ; \mathrm{pH} 8.2$.

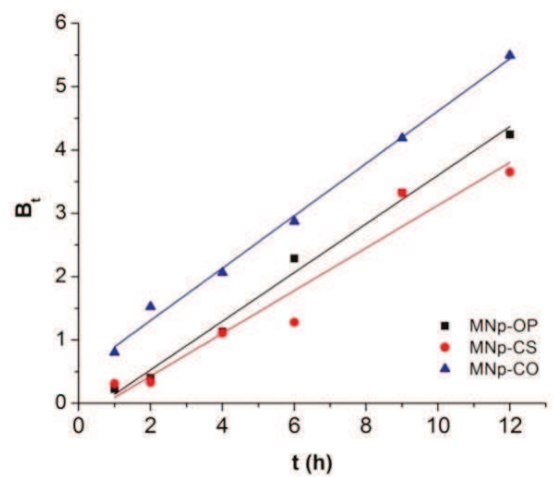

Figure 8. Boyd model for arsenic adsorption on MNp-OP, MNp-CS and MNp-CO. Initial As concentration $120 \mu \mathrm{g} / \mathrm{L}$; adsorbent dose $0.5 \mathrm{~g} / \mathrm{L}$; $\mathrm{pH}$ 8.2. 
According to the Weber-Morris model, if the plot of $\mathrm{q}_{\mathrm{t}} \mathrm{vs} . \mathrm{t}^{0.5}$ is linear and passes through the origin, adsorption is entirely governed by intraparticle diffusion. In contrast, if the plot is multilinear, it indicates that the adsorption is a multi-stage process controlled by various limiting factors at different steps of the process [8].

As can be seen from Figure 7 all the plots present multi-linearity, imply that intraparticle diffusion was involved in the adsorption process, but not the only rate-controlling step. Moreover, all plots give an intercept $C$ (Table 4 ) which means that external film mass transfer or boundary layer control also exists.

The contribution of boundary layer or film diffusion is often confirmed using the Boyd model [65]. According to this model, if the plot Bt vs. $t$, is a straight line passing through the origin, then intraparticle diffusion is the rate controlling step. Otherwise film diffusion determines the process.

From Figure 8, it is observed that all plots $t$ are linear, but the curves do not pass through the origin and have an intercept, suggesting that arsenic sorption on MNp-OP, MNp-CS and MNp-CO was mainly governed by external mass transfer (film diffusion) [66].

In order to make a distinction between kinetic and diffusion control, a very general guideline can be used: if equilibrium is achieved within $3 \mathrm{~h}$, the process is usually kinetic controlled and above $24 \mathrm{~h}$, it is diffusion-controlled [67]. Thus, taking into account that the equilibrium time of arsenic adsorption on MNp-OP, MNp-CS and MNp-CO was $6 \mathrm{~h}$ and $9 \mathrm{~h}$, respectively, the good correlation of the experimental data with the pseudo-second order model, and the results obtained by the diffusion model, we suggest that adsorption mechanism on $\mathrm{MNp}-\mathrm{OP}$, MNp-CS and $\mathrm{MNp}-\mathrm{CO}$ is a complex process involving chemical interaction (surface adsorption), external and intraparticle diffusion.

\subsection{Arsenic Adsorption Isotherms}

Adsorption isotherms are fundamental in describing the interactive behaviour between adsorbate and adsorbent. The adsorption isotherm yields certain constant values, which express the surface properties and affinity of the adsorbent which play an important role in the design of an adsorption system. Different adsorption isotherms have been developed, however in this study, the non-linear form of Langmuir, Freundlich, Temkin and Dubinin-Radushkevich isotherms [41] were used to model the experimental equilibrium data (Figure 9, Table 6).

a)

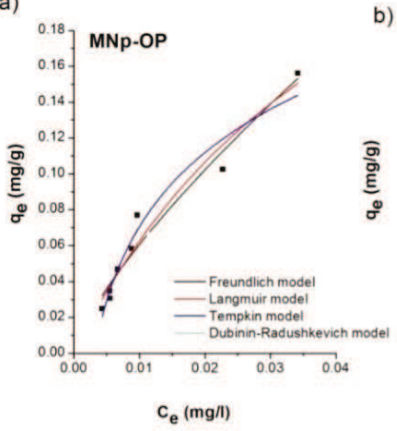

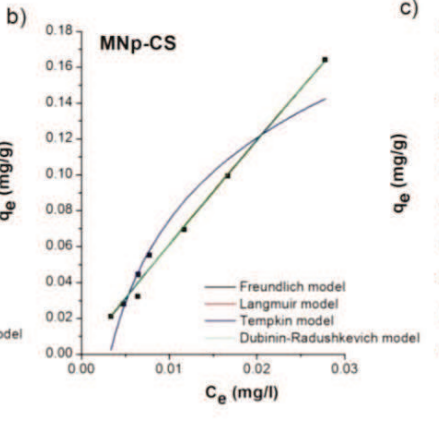

c)

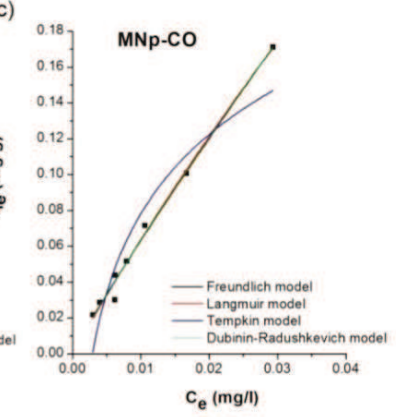

Figure 9. Adsorption isotherms of arsenic on (a) MNp-OP (b) MNp-CS and (c) MNp-CO. $\left(\mathrm{C}_{0}(\mathrm{As})=\right.$ $120 \mu \mathrm{g} / \mathrm{L}$; sorbent dose $0.5-5 \mathrm{~g} / \mathrm{L} ; \mathrm{pH}=8.1$. 
Table 6. Parameters of Freundlich, Langmuir, Temkin and Dubinin-Radushkevich sorption isotherm models for $\mathrm{As}(\mathrm{III})$ and $\mathrm{As}(\mathrm{V})$ sorption on MNp-OP, MNp-CS and MNp-CO.

\begin{tabular}{cccc}
\hline & MNp-OP & MNp-CS & MNp-CO \\
\hline Freundlich model & & & \\
$\mathrm{K}_{\mathrm{F}}(\mathrm{mg} / \mathrm{g}) /(\mathrm{mg} / \mathrm{L})^{\mathrm{n}}$ & 4.97 & 5.22 & 4.49 \\
$\mathrm{n}$ & 0.756 & 0.966 & 0.925 \\
$\mathrm{R}^{2}$ & 0.9620 & 0.9899 & 0.9901 \\
\hline Langmuir model & & & \\
$\mathrm{q}_{\max }(\mathrm{mg} / \mathrm{g})$ & 1.86 & 2.79 & 1.30 \\
$\mathrm{~K}_{\mathrm{L}}(\mathrm{L} / \mathrm{g})$ & 8.21 & 2.24 & 5.15 \\
$\mathrm{R}_{\mathrm{L}}$ & 0.9524 & 0.782 & 0.610 \\
$\mathrm{R}^{2}$ & 0.9594 & 0.9880 & 0.9881 \\
\hline Dubinin-Radushkevich model & & & \\
$\mathrm{q}_{\mathrm{d}}(\mathrm{mg} / \mathrm{g})$ & 4.45 & 5.64 & 4.84 \\
$\mathrm{k}_{\mathrm{ads}}\left(\mathrm{mol}{ }^{2} / \mathrm{kJ}{ }^{2}\right)$ & 0.000671 & 0.000397 & 0.000381 \\
$\mathrm{E}_{\left(\mathrm{kJ} / \mathrm{mol}^{2}\right)}$ & 27.3 & 35.5 & 36.2 \\
$\mathrm{R}^{2}$ & 0.9473 & 0.9878 & 0.9496 \\
Tempkin model $_{\mathrm{b}_{\mathrm{T}}\left(\mathrm{kJ} / \mathrm{mol}^{2}\right)}$ & & \\
$\mathrm{A}_{\mathrm{T}}(\mathrm{L} / \mathrm{g})$ & 41.2 & 37.1 & 38.6 \\
$\mathrm{R}^{2}$ & 325 & 309 & 341 \\
\hline
\end{tabular}

The results of the isotherm modelling, based on the coefficient of determination $\left(R^{2}\right)$, revealed that all applied models show good agreement with the experimental data (Table 6). However, the Freundlich model provided slightly better fit for As adsorption on MNp-OP, MNp-CS and MNp-CO (coefficients of determination, $R^{2}$, were $0.9620,0.9899$ and 0.9901 , respectively), suggesting that multilayer (heterogeneous) adsorption was the preferred removal mechanism $[51,68]$. This is supported by the SEM images, which showed that the surface of these materials was nonuniform with different particle shapes and sizes.

The Freundlich constant $\mathrm{K}_{\mathrm{f}}$ of MNp-CS and MNp-OP was higher than for MNp-CO, implying that the green synthesized adsorbents can be competitive in terms of adsorption affinity with magnetic nanoparticles produced via chemical precipitation method. The parameter, $1 / \mathrm{n}$ as a measure of adsorption intensity or adsorbent surface heterogeneity, in all cases was less than 1 , indicating that adsorption of As on synthesized magnetic nanoparticles is favourable and chemical in nature [68].

The maximum adsorption capacity obtained from the Langmuir model $\left(\mathrm{q}_{\max }\right)$ of the MNp-CS and MNp-OP was higher than MNp-CO. This trend was in accordance with the $\mathrm{K}_{\mathrm{F}}$ values obtained by the Freundlich model. The Langmuir equilibrium constant which reflects the affinity between adsorbent and the adsorbate, $\mathrm{K}_{\mathrm{L}}(\mathrm{L} / \mathrm{g})$, was 8.21, 2.24 and $5.15 \mathrm{~L} / \mathrm{g}$, for MNp-OP, MNp-CS and MNp-CO, respectively, suggesting strong binding of arsenic onto the magnetite nanoparticles. Separation factors $\left(R_{L}\right)$, essential characteristics of the Langmuir model, were in all cases below 1 , which means that adsorption of arsenic on synthesized magnetic nanoparticles was favourable [69]. This was consistent with the Freundlich constants $1 / \mathrm{n}$ measure of sorption intensity, which also ranged between zero and one.

In the case of the Dubinin-Radushkevich model, $\mathrm{R}^{2}$ values were in the order of MNp-CS > $\mathrm{MNp}-\mathrm{CO}>\mathrm{MNp}-\mathrm{OP}$. The theoretical sorption capacity $\left(\mathrm{q}_{\mathrm{d}}\right)$ obtained from this model was the highest for $\mathrm{MNp}$-CS and the lowest for $\mathrm{MNp}-\mathrm{CO}$, which could be attributed to its higher specific surface area (Table 2). The free energy of adsorption (E) for MNp-OP, MNp-CS and MNp-CO, were $27.3 \mathrm{~kJ} / \mathrm{mol}$, $35.5 \mathrm{~kJ} / \mathrm{mol}$ and $36.2 \mathrm{~kJ} / \mathrm{mol}$, respectively, implying that chemisorption may be the preferred sorption mechanism of As on the magnetic nanoparticles. Namely, when the value of $\mathrm{E}$ is less than $20 \mathrm{~kJ} / \mathrm{mol}$, the adsorption process is called physisorption, if it is between $20-40 \mathrm{~kJ} / \mathrm{mol}$ the process is known as ionic exchange, and when $\mathrm{E}$ is larger than $40 \mathrm{~kJ} / \mathrm{mol}$ it is a chemisorption process [70]. 
The correlation coefficients for the Tempkin isotherm were low in comparison with other applied models $\left(R^{2}=0.8825-0.9252\right)$. Temkin constants, $b_{T}$, which represent the heat of adsorption, were in the range $37.1-41.2 \mathrm{~kJ} / \mathrm{mol}$, indicating the exothermic nature of the adsorption process. The value of $\mathrm{b}_{\mathrm{T}}>8 \mathrm{~kJ} / \mathrm{mol}$ implied that the interaction between arsenic and synthesized magnetic nanoparticles was fairly strong and was not easily reversible (chemisorption) [71] which is in agreement with the results of the Dubinin-Radushkevich model. The binding constants of magnetic nanoparticles, $\mathrm{A}_{\mathrm{T}}$ $(\mathrm{L} / \mathrm{g})$, synthesized via green method, was higher than $\mathrm{MNp}-\mathrm{CO}$, confirming their higher adsorption capacity as predicted by the Langmuir isotherm.

Note that these experiments were all carried out in real groundwater, which is naturally contaminated with arsenic. It is therefore not possible to directly compare for example the $q_{\max }$ values obtained herein with the results of other authors, as a large number of other factors can significantly affect the efficacy of adsorption processes, especially the initial arsenic concentration and the species of arsenic present, the $\mathrm{pH}$ of the water and the presence of other anions. For example, phosphate is well known to compete with arsenic in adsorption processes [18] and has a concentration 11 times higher than the arsenic concentration in this groundwater (Table 1). Furthermore, although the arsenic content of the real groundwater investigated is an order of magnitude higher than recommended, it is still an order of magnitude lower than many of the studies carried out in synthetic matrices, where the very high initial arsenic concentrations often result in correspondingly high $q_{\max }$ values $[16,18,51]$. The range of values ( 1.3 to $2.8 \mathrm{mg} / \mathrm{g}$ ) obtained in this work compare very favourably with those from our previous work, in which Fe-Mn modified granular activated carbon was investigated with the same groundwater $\left(q_{\max }=0.5 \mathrm{mg} / \mathrm{g}\right)$ [72], making these the most effective sorbents we have investigated to date.

Finally, in order to evaluate the stability of synthesized nanoparticles, after the adsorption experiments, the residual iron concentrations in the treated samples were determined (Table 7).

Table 7. Residual Fe concentration in groundwater samples after arsenic adsorption on MNp-OP, $\mathrm{MNp}-\mathrm{CS}$ and MNp-CO.

\begin{tabular}{ccccccccc}
\hline Sorbent Dose $(\mathrm{g} / \mathrm{L})$ & $\mathbf{0 . 5}$ & $\mathbf{1 . 0}$ & $\mathbf{1 . 5}$ & $\mathbf{2 . 0}$ & $\mathbf{2 . 5}$ & $\mathbf{3 . 5}$ & $\mathbf{4 . 0}$ & $\mathbf{5 . 0}$ \\
\hline & \multicolumn{7}{c}{ Residual Fe $(\mathrm{mg} / \mathrm{L})$} \\
\hline MNp-OP & 0.036 & 0.045 & 0.062 & 0.068 & 0.079 & 0.116 & 0.120 & 0.171 \\
MNp-CS & 0.045 & 0.065 & 0.089 & 0.078 & 0.092 & 0.134 & 0.154 & 0.168 \\
MNp-CO & 0.035 & 0.052 & 0.065 & 0.084 & 0.086 & 0.120 & 0.133 & 0.154 \\
\hline
\end{tabular}

The residual iron concentrations increased with the applied sorbent dose. For high sorbent doses $(>2.5 \mathrm{~g} / \mathrm{L})$, the maximum allowable concentration (MAC) for iron in drinking water of $0.1 \mathrm{mg} / \mathrm{L}$ was exceeded. However, the MAC for arsenic was satisfied at much lower sorbent doses where residual iron concentrations were below the permissible level, suggesting that these adsorbents can be applied safety.

\section{Conclusions}

Novel magnetic nanoparticles (MNp-OP and MNp-CS) were successfully prepared via a green synthesis approach, using environmentally sound waste materials, onion peel and corn silk extract. The presence and formation of magnetic nanoparticles was confirmed by XRD and FTIR analysis while the high specific surface area and pore volume of these materials suggested they would have good performance for the removal of arsenic from groundwater. In terms of adsorption capacity, the green synthesized magnetic nanoparticles were shown to be highly competitive and effective alternatives to magnetic nanoparticles synthesized by the most common chemical precipitation method (MNp-CO). Adsorption kinetics of arsenic on MNp-OP, MNp-CS, MNp-CO were best described by the pseudo-second-order model, suggesting a chemisorption mechanism, while the Weber-Morris and Boyd model showed that external and intraparticle diffusion contributed to the overall adsorption process. The magnetic properties of these green synthesized adsorbents, which allows for their easy 
separation from water and which thus eliminates more complex and expensive separation techniques (filtration and centrifugation methods), along with their high potential for arsenic removal from groundwater, makes these materials very promising candidates for water treatment.

Author Contributions: Conceptualization, A.T. and J.A.; Investigation, J.N., M.W., M.Š. and T.M.; Methodology, J.N. and S.M.; Project administration, J.A.; Supervision, J.A.; Visualization, J.N.; Writing—original draft, J.N. and S.M.; Writing-review \& editing, A.T. and M.W.

Funding: This research was funded by the Ministry of Education, Science and Technological Development of the Republic of Serbia (Project No. TR37004 and III43005).

Acknowledgments: The authors gratefully acknowledge the support of the Ministry of Education, Science and Technological Development of the Republic of Serbia.

Conflicts of Interest: The authors declare no conflicts of interest.

\section{References}

1. Shankar, S.; Shanker, U.; Shikha. Arsenic Contamination of Groundwater: A Review of Sources, Prevalence, Health Risks, and Strategies for Mitigation. Sci. World J. 2014, 2014, 304524. [CrossRef] [PubMed]

2. Abdul, M.K.S.; Jayasingheb, S.S.; Chandanaa, E.P.S.; Jayasumanac, C.; Mangala, P.; De Silva, C.S. Arsenic and human health effects: A review. Environ. Toxicol. Pharmacol. 2015, 40, 828-846. [CrossRef] [PubMed]

3. World Health Organisation (WHO). Guidelines Drinking-Water Quality, 4th ed.; WHO: Geneva, Switzerland, 2011.

4. Nicomel, N.N.; Leus, K.; Folens, K.; De Voort, P.V.; Laing, G.D. Technologies for Arsenic Removal from Water: Current Status and Future Perspectives. Int. J. Environ. Res. Public Health 2016, 13, 62. [CrossRef] [PubMed]

5. Pathan, S.; Bose, S. Arsenic Removal Using "Green" Renewable Feedstock-Based Hydrogels: Current and Future Perspectives. ACS Omega 2018, 3, 5910-5917. [CrossRef]

6. Mukherjeea, D.; Ghosha, S.; Majumdar, S.; Annapurnaa, K. Green synthesis of $\alpha-\mathrm{Fe}_{2} \mathrm{O}_{3}$ nanoparticles for arsenic(V) remediation with a novel aspect for sludge management. J. Environ. Chem. Eng. 2016, 4, 639-650.

7. Poguberović, S.; Krčmar, D.; Maletić, S.; Kónya, Z.; Tomašević Pilipović, D.; Kerkez, Đ.; Rončević, S. Removal of $\mathrm{As}(\mathrm{III})$ and $\mathrm{Cr}(\mathrm{VI})$ from aqueous solutions using "green" zero-valent iron nanoparticles produced by oak, mulberry and cherryleaf extracts. Removal of As(III) and Cr(VI) from aqueous solutions using "green" zero-valent iron nanoparticles produced by oak, mulberry and cherryleaf extracts. Ecol. Eng. 2016, 90, 42-49.

8. Medina-Ramirez, A.; Gamero-Melo, P.; Ruiz-Camacho, B.; Minchaca-Mojica, J.I.; Romero-Toledo, R.; Gamero-Vega, K.Y. Adsorption of Aqueous As(III) in Presence of Coexisting Ions by a Green Fe-Modified W Zeolite. Water 2019, 11, 281. [CrossRef]

9. Asere, T.G.; Stevens, C.V.; Laing, G.D. Use of (modified) natural adsorbents for arsenic remediation: A review. Sci. Total Environ. 2019, 676, 706-720. [CrossRef]

10. Habuda-Stanić, M.; Nujić, M. Arsenic removal by nanoparticles: A review. Environ. Sci. Pollut. Res. 2015, 22, 8094-8123. [CrossRef]

11. Siddiqui, S.I.; Chaudhry, S.A. Arsenic removal from water using nano-composites: A review. Curr. Environ. Eng. 2017, 4, 81-102. [CrossRef]

12. Wong, W.W.; Wong, H.Y.; Borhan, A.; Badruzzaman, M.; Goh, H.H.; Zaman, M. Recent advances in exploitation of nanomaterial for arsenic removal from water: A review. Nanotechnology 2017, 28, 1-31. [CrossRef] [PubMed]

13. Song, K.; Kim, W.; Suh, C.Y.; Shin, D.; Ko, K.S.; Ha, K. Magnetic iron oxide nanoparticles prepared by electrical wire explosion for arsenic removal. Powder Technol. 2013, 246, 572-574. [CrossRef]

14. Lunge, S.; Singh, S.; Sinha, A. Magnetic iron oxide $\left(\mathrm{Fe}_{3} \mathrm{O}_{4}\right)$ nanoparticles from tea waste for arsenic removal. J. Magn. Magn. Mater. 2014, 356, 21-31. [CrossRef]

15. Roya, P.K.; Choudhury, M.R.; Ali, M.A. As (III) and As (V) Adsorption on Magnetite Nanoparticles: Adsorption Isotherms, Effect of $\mathrm{pH}$ and phosphate, and Adsorption Kinetics. Int. J. Chem. Environ. Eng. 2013, 4, 55-63.

16. Tuutijärvi, T.; Lu, J.; Sillanpää, M.; Chen, G. As(V) adsorption on maghemite nanoparticles. J. Hazard. Mater. 2009, 166, 1415-1420. [CrossRef] 
17. Haw, C.Y.; Mohamed, F.; Chia, C.H.; Radiman, S.; Zakaria, S.; Huang, N.M.; Lim, H.N. Hydrothermal synthesis of magnetite nanoparticles as MRI contrast agents. J. Ceram. Int. 2010, 36, 1417-1422. [CrossRef]

18. Lin, S.; Lu, D.; Liu, Z. Removal of arsenic contaminants with magnetic- $\mathrm{Fe}_{2} \mathrm{O}_{3}$ nanoparticles. Chem. Eng. J. 2012, 211, 46-52. [CrossRef]

19. Ebrahiminezhad, A.; Zare-Hoseinabadi, A.; Sarmah, A.K.; Taghizadeh, S.; Ghasemi, Y.; Berenjian, A. Plant-Mediated Synthesis and Applications of Iron Nanoparticles. Mol. Biotechnol. 2018, 60, $154-168$. [CrossRef]

20. Latha, N.; Gowri, M. Bio synthesis and characterization of $\mathrm{Fe}_{3} \mathrm{O}_{4}$ nanoparticles using Caricaya Papaya leaves extract. Synthesis 2014, 3, 1551-1556.

21. Martínez-Cabanas, M.; López-García, M.; Barriada, J.L.; Herrero, R.; de Vicente, M.E.S. Green synthesis of iron oxide nanoparticles. Development of magnetic hybrid materials for efficient As (V) removal. Chem. Eng. J. 2016, 301, 83-91. [CrossRef]

22. Awwad, A.M.; Salem, N.M. A green and facile approach for synthesis of magnetite nanoparticles. J. Nanosci. Nanotechnol. 2012, 2, 208-213. [CrossRef]

23. Kumar, B.; Smita, K.; Cumbal, L.; Debut, A. Biogenic synthesis of iron oxide nanoparticles for 2-arylbenzimidazole fabrication. J. Saudi Chem. Soc. 2014, 18, 364-369. [CrossRef]

24. Maheswari, K.C.; Sreenivasula Reddy, P. Green Synthesis of Magnetite Nanoparticles through Leaf Extract of Azadirachta indica. J. Nanosci. Technol. 2016, 2, 189-191.

25. Venkateswarlu, S.; Yoon, M. Rapid removal of cadmium ions using green synthesized $\mathrm{Fe}_{3} \mathrm{O}_{4}$ nanoparticles capped with diethyl-4-(4 amino-5-mercapto-4H-1,2,4-triazol-3-yl) phenyl phosphonate. RSC Adv. 2015, 5, 65444-65453. [CrossRef]

26. Sharma, K.; Mahato, N.; Nile, S.H.; Lee, E.T.; Lee, Y.R.; Mahato, N.; Nile, S.H.; Lee, E.T.; Lee, Y.R. Economical and environmentally-friendly approaches for usage of onion (Allium cepa L.) waste. Food Funct. 2016, 7, 3354-3369. [CrossRef] [PubMed]

27. Lee, K.A.; Kim, K.T.; Kim, H.J.; Chung, M.S.; Chang, P.S.; Park, H.; Paik, H.D. Antioxidant Activities of Onion (Allium cepa L.) Peel Extracts Produced by Ethanol, Hot Water, and Subcritical Water Extraction. Food Sci. Biotechnol. 2014, 23, 615-621. [CrossRef]

28. Bonaccorsi, P.; Caristi, C.; Gargiulli, C.; Leuzzi, U. Flavonol glucosides in Allium species: A comparative study by means of HPLC-DAD-ESI-MS-MS. Food Chem. 2008, 107, 1668-1673. [CrossRef]

29. Benítez, V.; Mollá, E.; Martín-Cabrejas, M.A.; López-Andréu, J.F.; Downes, K.; Terry, L.A.; Esteban, R.M. Study of bioactive compound content in different onion sections. Plant Foods Hum. Nutr. 2011, 66, 48-57. [CrossRef]

30. Ifesan, B.O.T. Chemical Composition of Onion Peel (Allium cepa) and its Ability to Serve as a Preservative in Cooked Beef. Int. J. Sci. Res. Methodol. 2017, 7, 25-34.

31. Aukkanita, N.; Kemngoena, T.; Ponharna, N. Utilization of Corn Silk in Low Fat Meatballs and Its Characteristics. Procedia-Soc. Behav. Sci. 2015, 197, 1403-1410. [CrossRef]

32. Nurhanan, A.R.; Rosli, W.I.W.; Mohsin, S.S.J. Total polyphenol content and Free radical scavenging activity of Cornsilk (Zea mays hairs). Sains Malays. 2012, 41, 1217-1221.

33. Nurhanan, A.R.; Rosli, W.I.W. Nutritional compositions and antioxidative capacity of the silk obtained from immature and mature corn. J. King Saud Univ. Sci. 2014, 26, 119-127.

34. Fatima, A.; Agrawal, P.; Singh, P.P. Herbal option for diabetes: An overview. Asian Pac. J. Trop. Biomed. 2012, 2, S536-S544. [CrossRef]

35. Sarepoua, E.; Tangwongchai, R.; Suriharn, B.; Kamol, L. Influence of variety and harvest maturity on phytochemical content corn silk. Food Chem. 2015, 169, 424-429. [CrossRef] [PubMed]

36. Venkateswarlu, S.; Subba Rao, Y.; Balaji, T.; Prathima, B.; Jyothi, N.V.V. Biogenic synthesis of $\mathrm{Fe}_{3} \mathrm{O}_{4}$ magnetic nanoparticles using plantain peel extract. Mater. Lett. 2013, 100, 241-244. [CrossRef]

37. Beara, I.N.; Lesjak, M.M.; Jovin, E.D.; Balog, K.J.; Anačkov, G.T.; Orčić, D.Z.; Mimica-Dukić, N.M. Plantain (Plantago L.) species as novel sources of flavonoid antioxidants. J. Agric. Food Chem. 2009, 57, 9268-9273. [CrossRef] [PubMed]

38. Beara, I.N.; Torović, L.D.; Pintać, D.; Majkić, T.M.; Orčić, D.Z.; Mimica-Dukić, N.M.; Lesjak, M.M. Polyphenolic profile, antioxidant and neuroprotective potency of grape juices and wines from Fruška Gora region (Serbia). Int. J. Food Prop. 2018, 20, S2552-S2568. [CrossRef] 
39. Zhang, G.; Liu, H.; Qu, J.; Jefferson, W. Arsenate uptake and arsenite simultaneous sorption and oxidation by Fe-Mn binary oxides: Influence of Mn/Fe ratio. $\mathrm{pH}$. $\mathrm{Ca}^{2+}$ and humic acid. J. Colloid. Interface Sci. 2012, 366, 141-146. [CrossRef]

40. Largitte, L.; Pasquier, R. A review of the kinetics adsorption models and their application to the adsorption of lead by an activated carbon. Chem. Eng. Res. Des. 2016, 109, 495-504. [CrossRef]

41. Foo, K.Y.; Hameed, B.H. Insights into the modeling of adsorption isotherm systems. Chem. Eng. J. 2010, 156, 2-10. [CrossRef]

42. USEPA. Method 200.8: Determination of Trace Elements in Waters and Wastes by Inductively Coupled Plasma-Mass Spectrometry; Revision 5.4; USEPA: Cincinnati, OH, USA, 1994.

43. Arsenic Speciation in Urine Becomes Routine Using Agilent HPLC with 7500 Series ICP-MS; 5989-8399EN; Agilent Technologies: Santa Clara, CA, USA, 2008.

44. AWWA-APHA-WEF. Standard Methods for the Examination of Water and Wastewater, 20th ed.; American Public Health Association/American Water Works Association/Water Environment Federation: Washington, DC, USA, 2012.

45. Water Quality_Determination of Phosphorus_Ammonium Molybdate Spectrometric Method; SRPS EN ISO 6878:2008; Institute for Standardization of Serbia: Belgrade, Serbia, 2008.

46. Water Quality—Determination of Chloride—Silver Nitrate Titration with Chromate Indicator (Mors Method); SRPS ISO 9297/1:2007; Institute for Standardization of Serbia: Belgrade, Serbia, 2007.

47. Water Quality—Determination of Ammonium—Distillation and Titration Method; SRPS ISO 5664:1992; Institute for Standardization of Serbia: Belgrade, Serbia, 1992.

48. Guidelines for Determination of Total Organic Carbon (TOC) and Dissolved Organic Carbon (DOC) in Water; SRPS ISO 8245:2007; Institute for Standardization of Serbia: Belgrade Serbia, 2007.

49. Mahdavi, M.; Namvar, F.; Ahmad, B.; Rosfarizan, M. Green Biosynthesis and Characterization of Magnetic Iron Oxide $\left(\mathrm{Fe}_{3} \mathrm{O}_{4}\right)$ Nanoparticles Using Seaweed (Sargassum muticum) Aqueous Extract. Molecules 2013, 18, 5954-5964. [CrossRef] [PubMed]

50. Scherrer, P. Bestimmung der Grosse und der Inneren Struktur von Kolloidteilchen Mittels Rontgenstrahlen, Nachrichten von der Gesellschaft der Wissenschaften, Gottingen. Math.-Phys. Kl. 1918, 2, 98-100.

51. Wen, Z.; Dai, C.; Zhu, Y.; Zhang, Y. Synthesis of ordered mesoporous iron manganese bimetal oxides for arsenic removal from aqueous solutions. RSC Adv. 2015, 5, 4058-4068. [CrossRef]

52. Kong, S.; Wang, Y.; Zhan, H.; Yuan, S.; Yu, M.; Liu, M. Adsorption/Oxidation of Arsenic in Groundwater by Nanoscale Fe-Mn Binary Oxides Loaded on Zeolite. Water Environ. Res. 2014, 86, 147-155. [CrossRef] [PubMed]

53. Sing, K.S.W.; Evertt, D.H.; Haul, R.A.W.; Moscou, L.R.A.; Pierotti, J.; Rouquerol, T.; Siemieniewska, T. Reporting Physisorption Data for Gas/Solid Systems with Special Reference to the Determination of Surface Area and Porosity. Pure Appl. Chem. 1985, 57, 603-619. [CrossRef]

54. Ignat, I.; Volf, I.; Popa, V.I. A critical review of methods for characterisation of polyphenolic compounds in fruits and vegetables. Food Chem. 2011, 126, 1821-3185. [CrossRef]

55. Machado, S.; Pinto, S.L.; Grosso, J.P.; Nouws, H.P.A.; Albergaria, J.T.; Delerue-Matos, C. Green production of zero-valent iron nanoparticles using tree leaf extracts. Sci. Total Environ. 2013, 445-446, 1-8. [CrossRef]

56. Nurhanan, A.R.; WR, W.I. Evaluation of polyphenol content and antioxidant activities of some selected organic and aqueous extracts of cornsilk (Zea mays hairs). J. Med Bioeng. 2012, 1, 48-51.

57. Irawaty, W.; Ayucitra, A.; Indraswati, N. Radical scavenging activity of various extracts and varieties of corn silk. ARPN J. Eng. Appl. Sci. 2018, 13, 10-16.

58. Viera, V.B.; Piovesan, N.; Rodrigues, J.B.; Mello, R.O.; Prestes, R.C.; Santos, R.C.V.; Vaucher, R.A.; Hautrive, T.P.; Kubota, E.H. Extraction of phenolic compounds and evaluation of the antioxidant and antimicrobial capacity of red onion skin (Allium cepa L.). Int. Food Res. J. 2017, 24, 990-999.

59. El Amrani, F.B.; Perello, L.; Real, J.A.; Gonzalez-Alvarez, M.; Alzuet, G.; Borras, J.; Garcia-Granda, S.; Montejo-Bernardo, J. Oxidative DNA cleavage induced by an iron(III) flavonoid complex: Synthesis, crystal structure and characterization of chlorobis (flavonolato)(methanol) iron(III) complex. J. Inorg. Biochem. 2006, 100, 1208-1218. [CrossRef] [PubMed]

60. Xu, G.R.; In, M.Y.; Yuan, Y.; Joon Lee, J.; Kim, S. In situ Spectroelectrochemical Study of Quercetin Oxidation and Complexation with Metal Ions in Acidic Solutions. Bull. Korean Chem. Soc. 2007, 28, 889-892. 
61. Ebrahimzadeh, M.A.; Pourmorad, F.; Bekhradnia, A.R. Iron chelating activity, phenol and flavonoid content of some medicinal plants from Iran. Afr. J. Biotechnol. 2008, 7, 3188-3192.

62. Mondal, P.; Mohanty, B.; Majumder, C.B. Removal of Arsenic from Simulated Groundwater by GAC-Fe: A Modeling Approach. AIChE J. 2009, 55, 1860-1871. [CrossRef]

63. Zhang, G.; Liu, H.; Liu, R.; Qu, J. Adsorption behavior and mechanism of arsenate at Fe-Mn binary oxide/water interface. J. Hazard. Mater. 2009, 168, 820-825. [CrossRef]

64. Tran, H.N.; You, S.J.; Bandegharaei, A.H.; Chao, H.P. Mistakes and inconsistencies regarding adsorption of contaminants from aqueous solutions: A critical review. Water Res. 2017, 120, 88-116. [CrossRef]

65. Boyd, G.E.; Schubert, J.; Adamson, A.W. The exchange adsorption of ions from aqueous solutions by organic zeolites. Ion-exchange equilibria. J. Am. Chem. Soc. 1947, 69, 2818-2829. [CrossRef]

66. Kajjumba, S.W.; Emik, S.; Öngen, A.; Özcan, H.K.; Aydın, S. Modelling of Adsorption Kinetic Processes-Errors, Theory and Application. In Advanced Sorption Process Applications; Edebali, S., Ed.; IntechOpen: Rijeka, Croatia, 2018.

67. Ho, Y.S.; Ng, J.C.Y.; McKay, G. Kinetics of pollutant sorption by biosorbents: Review. Sep. Purif. Method 2000, 29, 189-232. [CrossRef]

68. Niazi, N.K.; Bibi, I.; Shahid, M.; Ok, Y.S.; Burton, E.D.; Wang, H.; Shaheen, S.M.; Rinklebe, J.; Lüttge, A. Arsenic removal by perilla leaf biochar in aqueous solutions and groundwater: An integrated spectroscopic and microscopic examination. Environ. Pollut. 2018, 232, 31-41. [CrossRef]

69. Mudzielwana, R.; Gitari, M.W.; Ndungu, P. Uptake of As(V) from Groundwater Using Fe-Mn Oxides Modified Kaolin Clay: Physicochemical Characterization and Adsorption Data Modeling. Water 2019, 11, 1245. [CrossRef]

70. Monárrez-Corderoa, B.E.; Amézaga-Madrida, P.; Leyva-Porrasa, C.C.; Pizá-Ruiza, P.; Miki-Yoshidaa, M. Study of the Adsorption of Arsenic (III and V) by Magnetite Nanoparticles Synthesized via AACVD. Mater. Res. 2016, 19, 1-10.

71. Shafique, U.; Ijaz, A.; Salman, M.; Zaman, W.; Jamil, N.; Rehman, R.; Javaid, A. Removal of arsenic from water using pine leaves. J. Taiwan Inst. Chem. Eng. 2012, 43, 256-263. [CrossRef]

72. Nikić, J.; Agbaba, J.; Watson, M.A.; Tubić, A.; Šolić, M.; Maletić, S.; Dalmacija, B. Arsenic adsorption on Fe-Mn modified granular activated carbon (GAC-FeMn): Batch and fixed-bed column studies. J. Environ. Sci. Health Part A 2019, 54, 168-178. [CrossRef] [PubMed]

(C) 2019 by the authors. Licensee MDPI, Basel, Switzerland. This article is an open access article distributed under the terms and conditions of the Creative Commons Attribution (CC BY) license (http://creativecommons.org/licenses/by/4.0/). 
Article

\title{
Phosphate Induced Arsenic Mobilization as a Potentially Effective In-Situ Remediation Technique-Preliminary Column Tests
}

\author{
Martin V. Maier ${ }^{1, *}$, Yvonne Wolter ${ }^{1}$, Daniel Zentler ${ }^{1}$, Christian Scholz ${ }^{1}$, Charlotte N. Stirn ${ }^{2}$ and \\ Margot Isenbeck-Schröter ${ }^{1}$ \\ 1 Institute of Earth Sciences, Ruprecht-Karls-University Heidelberg, 69120 Heidelberg, Germany \\ 2 Institute of Geography, Ruprecht-Karls-University Heidelberg, 69120 Heidelberg, Germany \\ * Correspondence: martin.maier@geow.uni-heidelberg.de; Tel.: +49-6221-546-004
}

Received: 28 September 2019; Accepted: 5 November 2019; Published: 12 November 2019

\begin{abstract}
Arsenic (As) contamination of groundwater is commonly remediated by pump and treat. However, this technique is difficult to apply or maintain efficiently because the mobility of arsenic varies depending on the geochemical aquifer conditions. Arsenic interacting with the sediment can cause strong retardation, which is counteracted by ions competing for sedimentary sorption sites like silica, bicarbonate and phosphate. Phosphate competes most effectively with arsenic for sorption sites due to its chemical similarity. To accelerate an ongoing but ineffective pump and treat remediation, we examined the competitive effect of increasing phosphate doses on contaminated aquifer material of different depths and thus under distinct geochemical conditions. In the columns with phosphate addition, significant amounts of arsenic were released rapidly under oxic and anoxic conditions. In all tests, the grade of leaching was higher under anoxic conditions than under oxic conditions. As(III) was the dominant species, in particular during the first release peaks and the anoxic tests. Higher amounts of phosphate did not trigger the arsenic release further and led to a shift of arsenic species. We suggest that the competitive surface complexation is the major process of arsenic release especially when higher amounts of phosphate are used. Commonly arsenic release is described at iron reducing conditions. In contrast, we observed that a change in prevailing redox potential towards manganese reducing conditions in the oxic tests and iron reducing conditions in the anoxic column took place later and thus independently of arsenic release. The reduction of $\mathrm{As}(\mathrm{V})$ to $\mathrm{As}(\mathrm{III})$ under both redox conditions is presumed to be an effect of microbial detoxification. A loss of sulphate in all columns with phosphate indicates an increased microbial activity, which might play a significant role in the process of arsenic release. Preliminary tests with sediment material from a contaminated site showed that phosphate additions did not change the $\mathrm{pH}$ value significantly. Therefore, a release of other metals is not likely. Our results indicate that in-situ application of phosphate amendments to arsenic-contaminated sites could accelerate and enhance arsenic mobility to improve the efficiency of pump and treat remediation without negative side effects. The novelty of this approach is the use of only small amounts of phosphate in order to stimulate microbial activity in addition to surface complexation. Therefore, this method might become an innovative and cost-effective remediation for arsenic contaminated sites.
\end{abstract}

Keywords: arsenic; phosphate; competitive surface complexes; release; mobility; remediation

\section{Introduction}

Remediating arsenic (As) contamination is challenging and generally pump and treat technology is applied. For this method, water is extracted from the contaminated aquifer and treated on-site to reduce the contamination from the source area and to avoid the contaminant from spreading. Iron(II) 
sulphate and iron(II) chloride are commonly used as reactants to treat the extracted water (e.g., [1,2]). The effectiveness of this approach is often limited due to the geochemistry of the remediation site. In addition, a continuous input of energy is required. If the treatment is inefficient or even terminated because of decreasing efficiency, the contaminant remains.

Aquifer properties like redox conditions and mineral composition are the main factors controlling arsenic reactions and thus mobility, which can differ considerably from site to site [3,4]. Under neutral conditions there are two redox species of inorganic arsenic-Arsenite $\left(\mathrm{H}_{3} \mathrm{AsO}_{3}\right)$, where arsenic is in the trivalent oxidation state $\mathrm{As}(\mathrm{III})$ and Arsenate $\left(\mathrm{HAsO}_{4}{ }^{2-}\right.$ and $\left.\mathrm{H}_{2} \mathrm{AsO}_{4}{ }^{-}\right)$in the pentavalent oxidation state $\mathrm{As}(\mathrm{V})$. Under oxic conditions $\mathrm{As}(\mathrm{V})$ is the dominant redox state. $\mathrm{As}(\mathrm{V})$ is less mobile than $\mathrm{As}(\mathrm{III})$ because it forms complexes on mineral surfaces, especially on hydroxides and oxides of iron(III) [5-7] as well as on calcite [8]. Under iron reducing conditions arsenic is released from those surfaces into groundwater and remains mobile after subsequent reduction to $\mathrm{As}(\mathrm{III})[4,9,10]$. In contrast to this, arsenic precipitates as sulphide or forms sulphide complexes if sulphate-reducing conditions prevail and sulphate is available [11,12].

Instead of water extraction, more recent remediation strategies aim to mobilize or immobilize arsenic within the aquifer [13]. In remediation practice, different amendments are used in-situ to decrease arsenic mobility by creating a suitable redox milieu for the sorption of arsenic on iron minerals or the precipitation of iron sulphide minerals [14-20]. However, through immobilization, the contaminant remains in the subsoil and a remobilization cannot be ruled out. A different approach is to increase arsenic mobility by implementing iron reducing conditions in combination with a hydraulic barrier (e.g., pump and treat) to remove the contaminant [21,22]. Artificially implemented iron reducing conditions (e.g., with lactate) are difficult to maintain stable during the entire remediation process and undesired impacts on the aquifer's geochemistry, such as heavy metal release, are a possible side effect.

Phosphate is an opponent substance for arsenate in building up strong surface complexes on iron(hydr-)oxides [23-25]. In pH neutral conditions, the affinity of phosphate to form surface complexes on iron minerals like goethite and gibbsite phases is higher than the one of $\mathrm{As}(\mathrm{V})[26,27]$. Recent studies indicate similar processes with calcite, although the sorption of arsenic on calcite is less favoured than onto iron minerals [28]. It may become a relevant reaction when the proportion of iron minerals in the aquifer sediment is low or if hydrogen carbonate dominates. The reaction kinetics are discussed controversially. Some studies assume an incorporation of arsenic into calcite [29], while others show that arsenic is bound in surface complexation $[8,30]$. Results of both studies agree that predominantly the $\mathrm{As}(\mathrm{V})$-species interacts with calcite, which can be replaced by phosphate.

Arsenic release from sediment by phosphate addition has been topic to research since the early 70 s and recent studies show that the high complexity of the process limits the predictability for field application [31-33]. One study found that high phosphate dosages up to $300 \mathrm{mM}$ to sediment samples under oxic conditions led to arsenic release rates of $80 \%$ [33]. Neither longer reaction nor repeated treatment could significantly increase the arsenic leaching. A different study demonstrated that pulse injections of phosphate could increase the total desorption of arsenic up to 94\% [34]. Even low phosphate amendments of $6 \mathrm{mM}$ could rapidly desorb more than $35 \%$ of the total arsenic from the sediment and continuing amendments led to up to $65 \%$ desorption [35].

The novelty of the approach presented here is an increase of arsenic mobility without changing the aquifer's geochemistry for future field application [36,37]. Phosphate is known to compete with arsenate for sedimentary sorption sites but so far there is no information about the effect of different amounts of phosphate on the mobility of arsenic under different redox conditions. In order to investigate the driving processes, we conducted column tests with amendment of varying phosphate concentrations under oxic and anoxic conditions and closely monitored arsenic species distribution in the sediment and the column outflow. In contrast to previous studies [34,35], low phosphate concentrations were used to identify the relevant mechanisms underlying arsenic mobility and speciation. This preliminary laboratory study is the basis for further research to develop an innovative and more efficient remediation field method. 


\section{Materials and Methods}

\subsection{Aquifer Material, Groundwater Sampling and Analysis}

The aquifer sediment material was collected during previous investigations at the contaminated site in Lampertheim, Germany [36]. Sediments were gathered through percussion drilling with polyethylene-lined probes $(\mathrm{d}=100 \mathrm{~mm} ; \mathrm{l}=1 \mathrm{~m})$ to the aquifer basis $(30 \mathrm{~m}$ b.g.l.). The liners were sealed immediately after recovery to avoid changes of the predominant redox milieu in the aquifer. The cores were opened lengthwise under argon atmosphere for sediment profile description and sampling for geochemical analyses. The cores were covered with plastic wrap and stored at $-18^{\circ} \mathrm{C}$. For the column tests, these cores were defrosted and prepared under argon atmosphere. Sediments from the partially water-saturated ( 5 to $6 \mathrm{~m}$ ) and completely water-saturated (11 to $12 \mathrm{~m}$ ) depths of the aquifer were used to ensure they contain the redox-adapted microfauna.

Sedimentary characteristics like grain size, moisture content, smell and colour were determined according to standard regulations (ISO 14688). For the analytical procedures and the column preparation the sediment was homogenized under argon atmosphere. Analytical procedures were performed in replicate to ensure reproducibility. Chemicals used were of per analysis (p.a.) quality. Aqua regia extractions were done once before and once after the column tests and with the sediment standard BAM U112a. Therefore, $1 \mathrm{~g}$ of moist sample was mixed with $3 \mathrm{~mL}$ of nitric acid $\left(65 \% \mathrm{HNO}_{3}\right.$ p.a., J.T. Baker) and $9 \mathrm{~mL}$ of hydrochloric acid $(37 \% \mathrm{HCl}$ p.a., J.T. Baker), covered with watch glasses and simmered for about $3 \mathrm{~h}$ at about $130^{\circ} \mathrm{C}$ (method modified after ISO11466:1995). After cooling, the samples were filled up to $50 \mathrm{~mL}$ with distilled water, filtered through a pleated paper filter and stored at $4{ }^{\circ} \mathrm{C}$ until measurement.

In order to distinguish how the different arsenic species are bound to the sediment surfaces, fractionated elutions_-based on the method by Reference [38] — were made before and after the column tests. Under argon atmosphere $3.5 \mathrm{~g}$ of moist sediment was weighed into four vessels respectively. Distilled water $(40 \mathrm{~mL})$ was added to two of the samples and $40 \mathrm{~mL}$ of $1 \mathrm{M}$ sodium dihydrogen phosphate $\left(\mathrm{NaH}_{2} \mathrm{PO}_{4} \cdot \mathrm{H}_{2} \mathrm{O}\right.$ p.a., Grüssing) to the other two. The closed samples were stirred for $24 \mathrm{~h}$ on a shaking table, centrifuged ( $5 \mathrm{~min}$ at $4000 \mathrm{rpm}$ ) and then filtrated through $0.45 \mu \mathrm{m}$ membrane filters. The samples were acidified with $6 \mathrm{M}$ hydrochloric acid to $\mathrm{pH} 1$ and stored at $4{ }^{\circ} \mathrm{C}$ until measurement.

Stratified groundwater samples from the study site were taken based on the regulations of ISO 5667-11:2009 with a Grundfos MP1 (Grundfos GmbH, Erkrath, Germany) and a packer system after 30 min of pumping. Temperature (SenTix ${ }^{\circledR}$ 940, WTW, Weilheim, Germany), oxygen (CellOx ${ }^{\circledR} 325$, WTW, Weilheim, Germany), electrical conductivity (Tetracon ${ }^{\circledR}$ 925, WTW, Weilheim, Germany), pH value (SenTix ${ }^{\circledR}$ 940, WTW, Weilheim, Germany) and redox potential (SenTix ${ }^{\circledR}$ ORP-T 900, WTW, Weilheim, Germany), were measured in a flow cell with a WTW Multiline (Multi 3420, WTW, Weilheim, Germany). Results are presented in Table A1. Samples for cations, anions and carbon species were filtered with $0.45 \mu \mathrm{m}$ syringe membrane filters and cation samples stabilized with $\mathrm{HNO}_{3}$, arsenic samples with $6 \mathrm{M} \mathrm{HCl}$ (p.a. Fluka) to $\mathrm{pH} 1$.

Water cation samples (groundwater and column outflow) and the extractions/elutions from the sediment samples were measured with an ICP-OES (VISTA-MPX CCD Simultaneous, Varian/Agilent, Mulgrave, Australia) for $\mathrm{As}, \mathrm{Fe}, \mathrm{Mn}, \mathrm{Ca}, \mathrm{Mg}, \mathrm{K}$ and $\mathrm{Na}$ after standard-procedures and calibrated with element standards (Ultra Scientific), the ICP multi-element standard solution IV (Merck) and validated with two reference materials (SPW-SW2 and TMDA-51.3). The calculated error of the measurement was between 1 and $15 \%$. Arsenic species were measured with a flow-injection hybrid generating system (FI-HG) coupled to the ICP-OES according to Reference [39]. Species were determined in two measurement steps as described in [40] and with a subsequent iterative calculation of arsenic. Water anion samples were analysed with ion chromatography (Dionex DX-120, ThermoFisher Scientific, Sunnyvale, $\mathrm{CA}, \mathrm{USA}$ ) for $\mathrm{Cl}, \mathrm{Br}, \mathrm{NO}_{3}, \mathrm{SO}_{4}$ and $\mathrm{F}$ with an $\mathrm{AS} 9 \mathrm{HC}$ column and standard calibration for the measured elements (Merck). Total carbon (TC) and inorganic carbon (IC) of the groundwater were measured with a TOC- $\mathrm{V}_{\mathrm{CPH}}$ (Shimadzu, Kyoto, Japan), from which the total organic carbon (TOC) 
content was calculated. A total inorganic carbon standard (Ultra Scientific) was used for calibration. Phosphate concentrations from the column outflow were determined with the molybdenum blue method and measured at $880 \mathrm{~nm}$ with a photometer (Specord 50, Analytik Jena, Jena, Germany). Total carbon of sediment samples was determined with a sulphur/carbon analyser (Leco SC 144DR, San Joseph, MI, USA). Measurement limits, used reference materials and standard deviations are given in Table 2.

The geochemical conditions in the columns were deduced from hydrogeochemical water composition with respect to redox-sensitive and $\mathrm{pH}$-sensitive parameters like iron, manganese and bicarbonate (Table A1). Because the aquifer material at the study site is carbonate-dominated, the system is sufficiently buffered and measurements of $\mathrm{pH}$ values at the column outflow were hence omitted. Redox conditions can be inferred more accurately from the prevailing geochemistry than from redox measurements. Overall measurement quality and methodological errors were evaluated through calibrations and standards, which are presented in Table 2. Ion balance calculations after [41] were within acceptable limits (10\% deviation) for the samples without phosphate addition.

\subsection{Column Tests}

All columns were designed identically with exception of the column diameters. The columns were filled under argon atmosphere with the sandy aquifer material from the contaminated site. For the oxic columns, sediments of 5 to $6 \mathrm{~m}$ depth were used, which was within the groundwater fluctuation zone and represents oxic to suboxic conditions. For the anoxic columns, sediments from below the groundwater table in 11 to $12 \mathrm{~m}$ depth were taken, representing anoxic conditions (Table 3). Glass wool at both ends of the columns allowed an even flow inside the columns. Top and bottom were sealed airtight with a screw top containing an outlet pipe. The columns were oriented vertically and connected to a peristaltic pump (Minipuls 2, Gilson, Middleton, WI, USA) to obtain a constant upward oriented flow (Figure 1). Through sodium bromide tracer tests the hydrodynamic properties were determined in each column after the leaching tests. Therefore, a $20 \mathrm{mg} / \mathrm{L}$ concentration of tracer was added continuously to the test water for $44 \mathrm{~h}$. Samples were taken every $30 \mathrm{~min}$ and measured with IC (Dionex DX-120, ThermoFischer Scientific, Sunnyvale, CA, USA) and a WTW multiline (bromide probe Br 500 and electrical conductivity, both WTW, Weilheim, Germany) respectively. The hydrodynamic dispersivities and effective porosities were calculated from breakthrough curves for each column using a one-dimensional analytical solution of the transport equation after Kinzelbach (1987), which was implemented in an Excel worksheet model [42,43].

Chemical analyses of the groundwater at the research site showed predominantly earth alkaline to alkaline water with high contents of hydrogen carbonate. For the column tests replicated groundwater with a composition according to the groundwater in the corresponding depth of the aquifer was prepared every four days and the ingredients (Table 4) were dissolved by carbon dioxide addition with a soda machine. For the anoxic columns, the process-water was degassed with argon for four days before application in order to remove oxygen.

The flow discharge varied from 180 to $220 \mathrm{~mL} /$ day respectively, depending on the column diameter. Flow rates were adapted correspondingly to 1 and 1.2 pore volumes (PV) per day to ensure comparable flushing of both columns. Accordingly, the effective porosity of the column fillings was 25 to $30 \%$ as calculated from the tracer test.

The experimental conditions of each column are shown in Table 5. All tests were initially run with replicated groundwater without phosphate for eight pore volumes. The anoxic columns were operated strictly anoxic in an argon-filled glove box. Tests with phosphate amendment were done in duplicate (columns 2, 3 and 5, 6, results of duplicates shown in Figures 3 and 4) to consider random errors. Reference columns (column 1 and 4) were run without phosphate amendments.

The timing of phosphate increments depended on the observed arsenic release. Deviations from the scheduled values were caused by phosphate precipitation in the storage vessels. Influent 
and effluent water was sampled daily to determine the actual concentration of the reactant and to calculate balances.

A fraction collector was used for sampling of columns 1,2, 4 and 5 and a collective daily sample was taken for columns 3 and 6 . The applied analytical methods and sample preparation are listed in Table 6 and described in Section 2.1.

\section{Results}

\subsection{Oxic Tests}

In the oxic tests without phosphate addition, (column 1, Figure 1a) the initial concentration of arsenic was about $300 \mu \mathrm{g} / \mathrm{L}$ and decreased quickly to level off at approximately $50 \mu \mathrm{g} / \mathrm{L}$. At the beginning of the test, As(III) was the dominating species. After 20 PV the shares of As(V) gradually increased while $\mathrm{As}(\mathrm{III})$ decreased. By the end of the experiment (PV 44), $\mathrm{As}(\mathrm{V})$ was the only remaining species. In total $0.67 \mathrm{mg}$ of arsenic was released from the column.

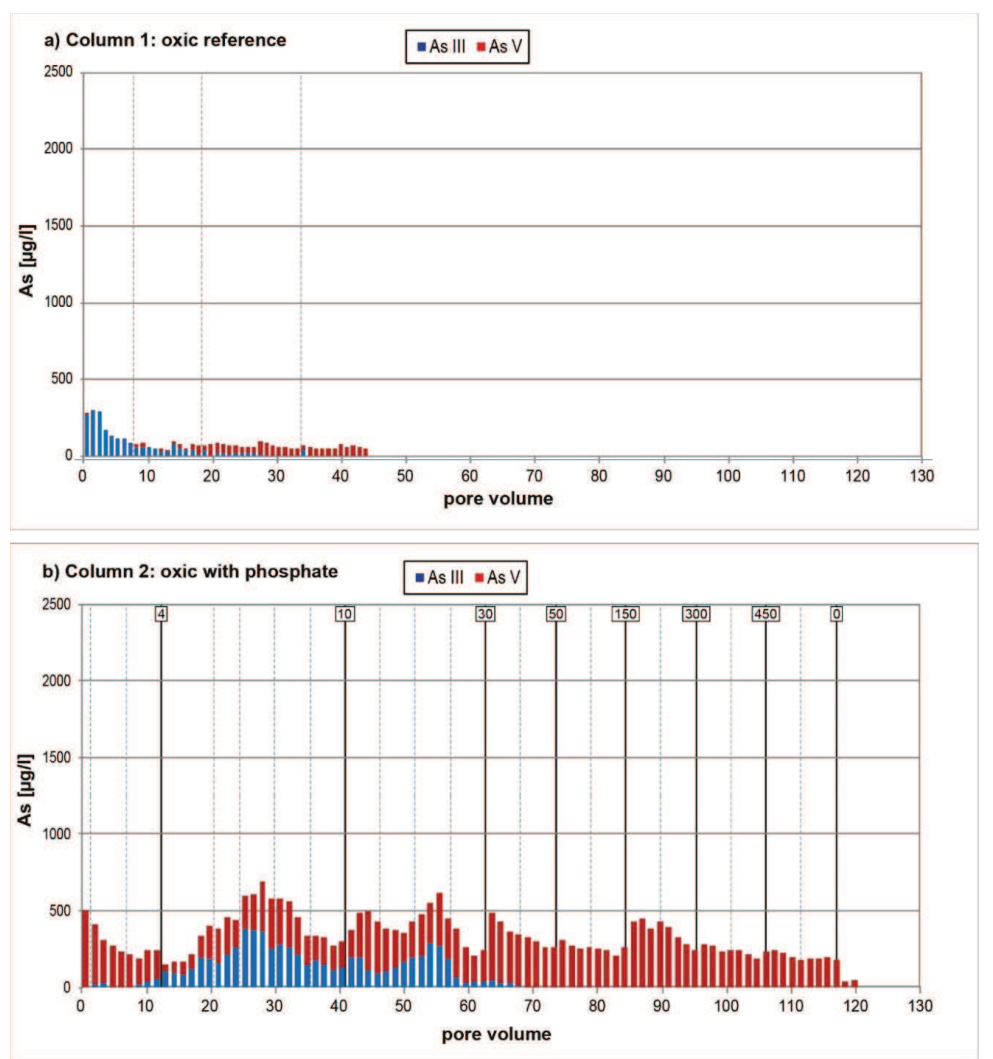

Figure 1. Arsenic release during the oxic column test, (a) column 1 without phosphate addition and (b) column 2 with phosphate addition (duplicate column 3 in Figure 2c). Vertical lines indicate refilling of replicated groundwater and the scheduled phosphate concentration $(\mathrm{mg} / \mathrm{L})$.

In the oxic tests with phosphate amendments (columns 2 and 3) concentrations of around $500 \mu \mathrm{g} / \mathrm{L}$ arsenic were desorbed at the beginning, which was predominantly As(V) (Figures $1 \mathrm{~b}$ and 2c) and declined to about $300 \mu \mathrm{g} / \mathrm{L}$ at the end of the test. The first addition of phosphate (4 mg/L) led to a rapid release with concentrations up to $690 \mu \mathrm{g} / \mathrm{L}$ and $820 \mu \mathrm{g} / \mathrm{L}$ arsenic respectively, more than $50 \%$ 
As(III). With every phosphate amendment of increased concentration, a peak in arsenic release was observed, independently of the amended phosphate concentration. After $50 \mathrm{PV}$ As(V) became the dominant species and remained the only species until the end of the test. In columns 2 and 3 the arsenic concentration of the outflow decreased to $35 \mu \mathrm{g} / \mathrm{L}$ by the end of the experiment. In total $4.69 \mathrm{mg}$ and $4.37 \mathrm{mg}$ arsenic were released from columns 2 and 3 respectively (Table 1).

Table 1. Arsenic contents in $\mathrm{mg}$ in aqua regia extractions of the sediment before and after the column tests in comparison with the cumulative release measured from the column outflow.

\begin{tabular}{|c|c|c|c|c|c|c|}
\hline Column Test & 1 & 2 & 3 & 4 & 5 & 6 \\
\hline Cumulative outflow release (mg) & $0.67 *$ & 4.69 & 4.37 & 3.20 & 11.4 & 13.1 \\
\hline Sedimentary As before test (mg) & & \multicolumn{2}{|c|}{$17 \pm 5$} & & \multicolumn{2}{|c|}{$25 \pm 0.8$} \\
\hline Sedimentary As after test (mg) & & $12.1 \pm 2.8$ & $11.4 \pm 3.8$ & & $15.5 \pm 3.3$ & $12.9 \pm 2.6$ \\
\hline Sedimentary mass losses (mg) & & $4.9 \pm 7.8$ & $5.6 \pm 8.8$ & & $9.5 \pm 4.1$ & $12.1 \pm 3.4$ \\
\hline
\end{tabular}

Aqua regia extractions before and after the column test show a sedimentary loss of arsenic similar to the cumulative release during the test, which corresponds to a total arsenic decrease of $26.5 \%$. Accordingly, the arsenic release of columns 2 and 3 with phosphate amendment was six times higher than in the reference column 1 without phosphate addition. Of the added phosphate, 93 to $97 \%$ could be retrieved in total from the column outflow.

In the oxic column, the first arsenic release peak is observed together with high manganese concentrations. Nitrate was not detectable, iron and sulphate remain low (Figures 3 and 2) and manganese returns to low levels after $55 \mathrm{PV}$, while arsenic release is continuously observed in accordance with phosphate amendments (Figure 2).

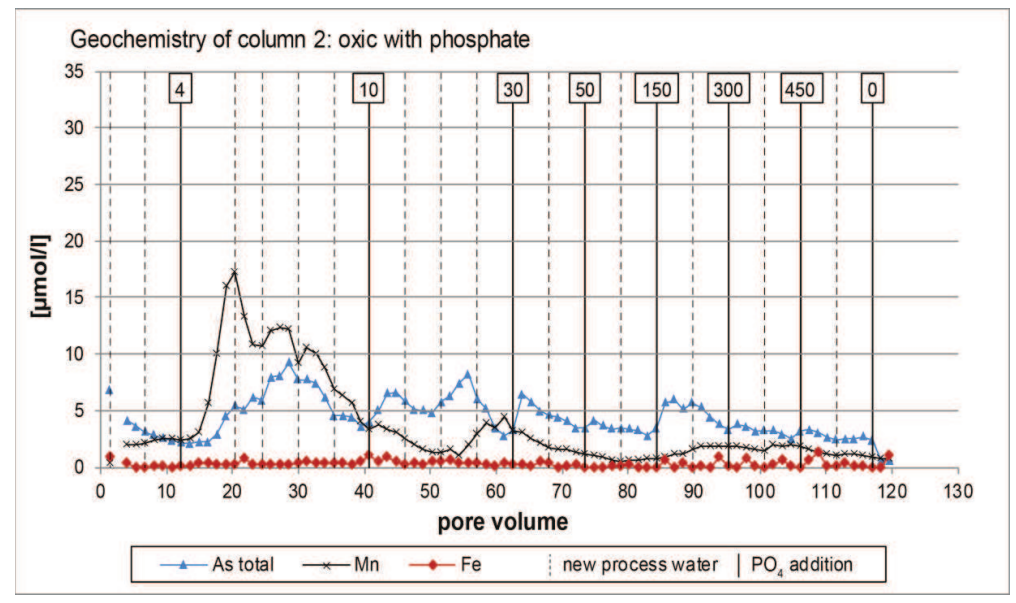

Figure 2. Release of arsenic, manganese and iron in the oxic column 2. Arsenic release is independent from geochemical milieu conditions, although it is temporarily accompanied with elevated manganese.

\subsection{Anoxic Tests}

In the anoxic column without phosphate addition (column 4, Figure 3a) the initial concentration of arsenic in the outflow was around $200 \mu \mathrm{g} / \mathrm{L}$ and increased to about $300 \mu \mathrm{g} / \mathrm{L}$ during the test. After $10 \mathrm{PV}$ the species distribution shifted from predominantly $\mathrm{As}(\mathrm{V})$ in the beginning to almost exclusively As(III), which remained the main species until the end of the test. A total of $3.20 \mathrm{mg}$ arsenic was released from the column. 

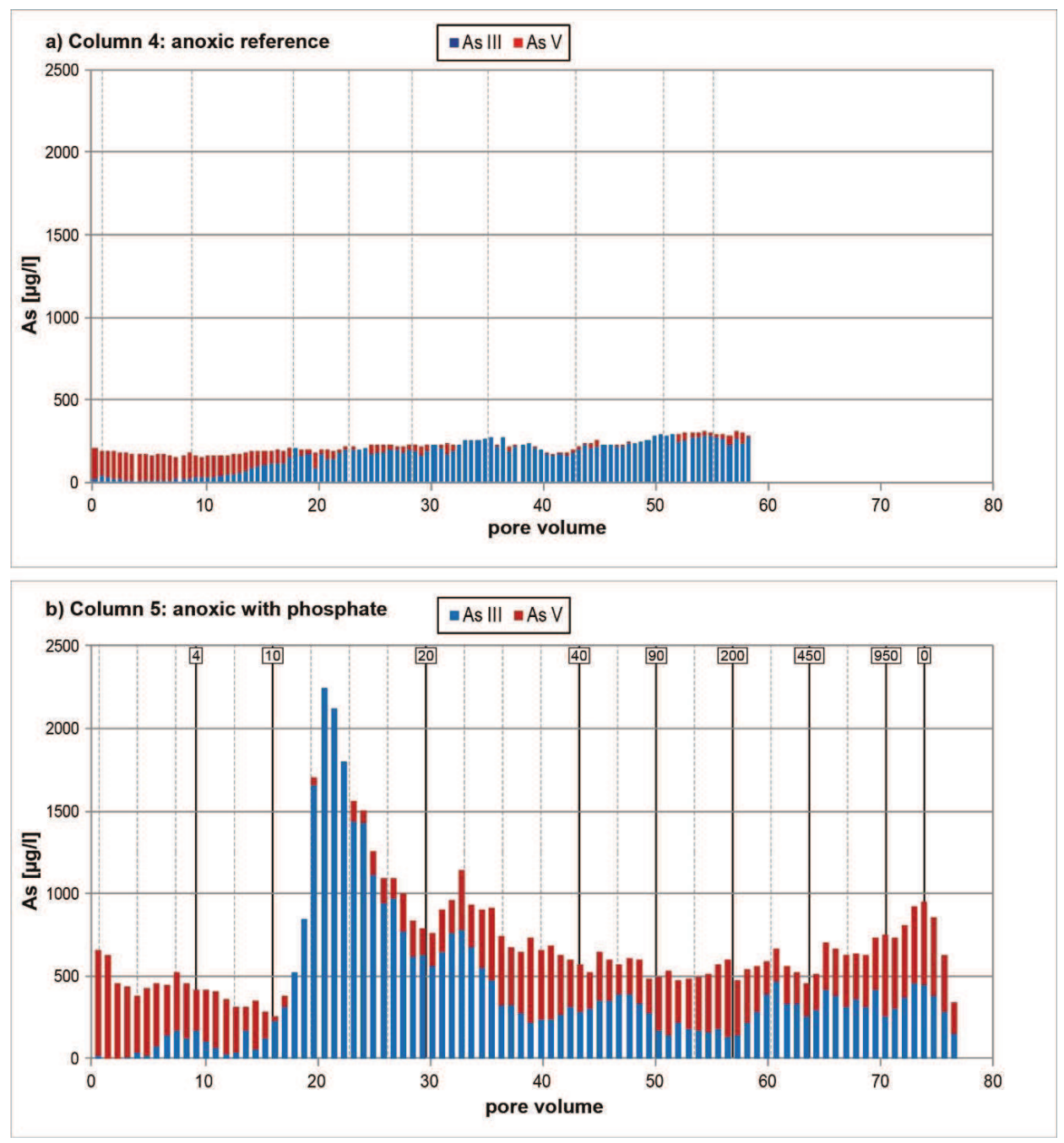

Figure 3. Arsenic release during the anoxic column tests, (a) column 4 without phosphate addition and (b) column 5 with phosphate addition. Vertical lines indicate refilling of replicated groundwater and the scheduled phosphate concentration $(\mathrm{mg} / \mathrm{L})$.

Both anoxic columns 5 and 6 (Figures $3 \mathrm{~b}$ and $4 \mathrm{c}$ ) at the beginning show an arsenic release of around $600 \mu \mathrm{g} / \mathrm{L}$, which is predominantly $\mathrm{As}(\mathrm{V})$. About $10 \mathrm{PV}$ after the addition of $10 \mathrm{mg} / \mathrm{L}$ phosphate, the arsenic release increased significantly up to $2251 \mu \mathrm{g} / \mathrm{L}$ and decreased again immediately. Every increase in added phosphate concentration was followed by an arsenic release peak. The amplitudes of the following peaks were lower than the first mobilization peak, even with very high phosphate dosages. According to the release balances, most of the extractable arsenic was mobilized during the first two peaks.

The species distribution in both anoxic columns with phosphate amendment shows a similar pattern. Differences are caused by heterogeneities of the sediment like variations in arsenic concentrations and organic compounds. With the onset of the first peak the species distribution changed from initially predominantly $\mathrm{As}(\mathrm{V})$ towards almost exclusively $\mathrm{As}(\mathrm{III})$. In column 5 the shares 
of $\mathrm{As}(\mathrm{V})$ increased again after $30 \mathrm{PV}$ and from $42 \mathrm{PV}$ until at the end the distribution of both species stayed equal. In contrast, As(III) remains the dominating species in column 6 after the first release peak. The high release concentrations of arsenic correlated with high shares of As(III) in both anoxic columns.

Total arsenic amounts of $11.4 \mathrm{mg}$ (column 5) and $13.1 \mathrm{mg}$ (column 6) were released during the anoxic tests (Table 1). According to a sediment concentration of $25 \mathrm{mg} / \mathrm{kg}$ (aqua regia extraction) before the test, $44-52 \%$ of the total arsenic content was released from the columns, which was validated by the aqua regia extractions after the column tests.

Through the phosphate amendment the arsenic release could be accelerated significantly and enhanced by four times on average in comparison to the reference. $85 \%$ of the amended phosphate was retrieved at the column outflow.

In the anoxic columns (5 and 6) the onset of iron reducing conditions were observed after 30 PV and thus after the main arsenic peak (Figures 4 and 4). Strongly iron reducing conditions with high iron concentrations in the outflowing water did not correlate with high arsenic concentrations. Sulphate concentrations showed no change with time but from the added sulphate in the process water up to $7.72 \%$ was consumed in the column (Table 7). The constant $\mathrm{HCO}_{3}$ concentrations in the column outflow indicate stable $\mathrm{pH}$ values as detected in preliminary studies (Figure 5). Manganese increased slightly throughout the test after phosphate amendments.

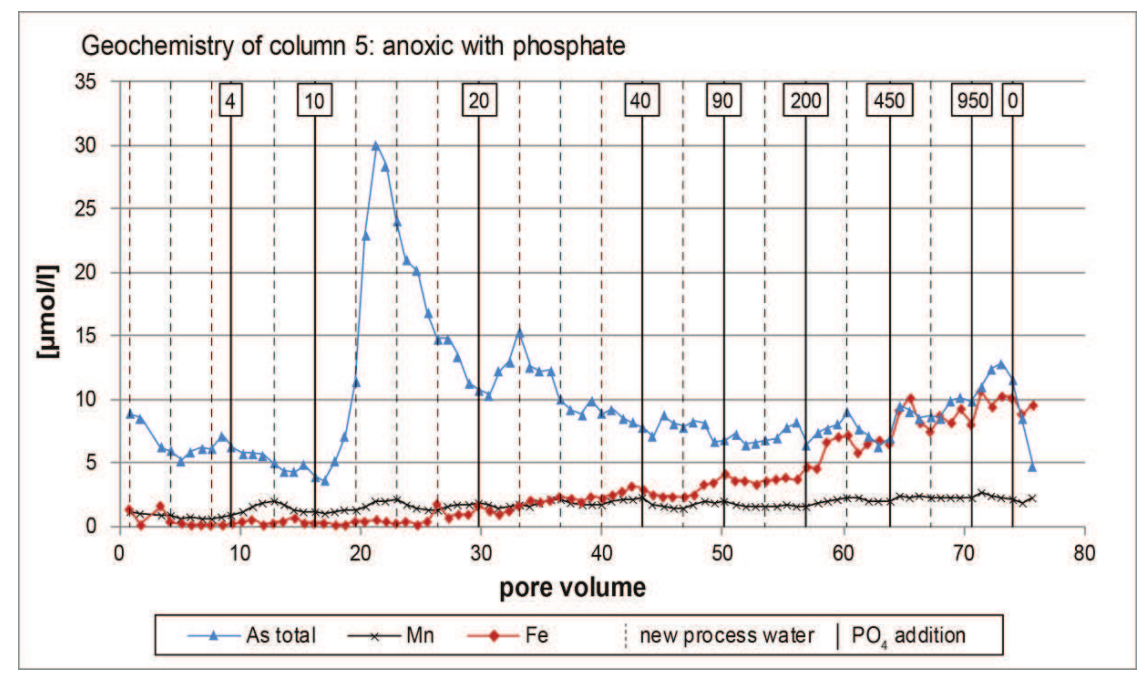

Figure 4. Release of arsenic, manganese and iron in the anoxic column 5. Manganese increases steadily while iron remains low and increases right after the high arsenic release peak.

\section{Discussion}

In all columns with phosphate amendment a significant release of arsenic was observed from the beginning during low phosphate amendment concentrations. Even smaller amounts of phosphate than used in other studies (0.04 mM instead of $6 \mathrm{mM}$ ) led to a comparable amount of arsenic release [35]. Phosphate concentrations measured from the column outflow demonstrate that most of the added phosphate was neither adsorbed or precipitated in the columns nor consumed by microorganisms.

As expected the total arsenic release rates were higher and faster under anoxic conditions. However, in comparison to the reference the release rates in columns 2 and 3 with phosphate were significantly increased under oxic conditions. Consequently, the addition of phosphate increased microbial processes, which consumed oxygen and nitrate, temporarily causing manganese-reducing conditions. This observed manganese release occurred simultaneously with a small peak of arsenic. Groundwater composition does not indicate a further development of suboxic conditions after the 
manganese peak but rather a return to more oxic conditions with low iron, low manganese and predominantly As(V). In the anoxic columns with phosphate (columns 5 and 6), the released arsenic contains high shares of both arsenic species compared to the reference (column 4). This shows that phosphate amendment significantly increased the normal arsenic desorption process under anoxic conditions. High mobility of $\mathrm{As}(\mathrm{V})$ can be attributed to competitive surface complexation with phosphate under both applied conditions, while the pattern of arsenic species might be attributed to microbial processes. The increased arsenic release is independent of the prevailing redox conditions and no significant effect on the $\mathrm{pH}$ value was observed (Figure 5).

Accelerated microbial activity in the columns with phosphate addition is indicated by the loss of sulphate (Table 7) and the increased iron and manganese in the column outflow. In both reference columns without phosphate, the sulphate concentration remained stable and no significant amounts of iron or manganese were released (Figure 6).

At a neutral $\mathrm{pH}$ value, the release of other metals besides arsenic is not probable. Before the field application of this approach at other sites without high carbonate buffering the possibility of heavy metal release should be tested. The aquifer material of the study area contained no other metals besides arsenic, thus the effect of phosphate amendments on other metals could not be considered.

Variations between the cumulative outflow and the sedimentary mass balances are caused by the different methodological approaches and the standard deviation of sedimentary arsenic measurements (Table 2). In the column outflows with phosphate amendment the arsenic release is 3.5 to 4.5 times higher under oxic and anoxic conditions. Compared to the phosphate extractable fractions in Table 2, a total of $36 \%$ (oxic) to $65 \%$ (anoxic) arsenic was released, most of it already with low additions of phosphate. The significant shift of arsenic species under anoxic conditions from As(V) to As(III) in the column outflow indicates enhanced microbial arsenic reduction in the column, as in the phosphate elution most of the extractable and thus surface bound arsenic was As(V).

Table 2. Arsenic species distribution in the sediment elutions and the release measured from the column outflow.

\begin{tabular}{lcccccc}
\hline \multirow{2}{*}{ Column } & \multicolumn{2}{c}{$\begin{array}{c}\text { Water Extractable } \\
\text { Arsenic (mg) }\end{array}$} & $\begin{array}{c}\text { Phosphate (1 M) Extractable } \\
\text { Arsenic (mg) }\end{array}$ & \multicolumn{2}{c}{$\begin{array}{c}\text { Arsenic Released from } \\
\text { Column (mg) }\end{array}$} \\
\cline { 2 - 7 } & As(III) & As(V) & As(III) & As(V) & As(III) & As(V) \\
\hline $\mathbf{2 ~ ( o x i c ) ~}$ & 0.13 & 1.24 & 1.19 & 11.9 & 1.13 & 3.58 \\
\hline $\mathbf{5}$ (anoxic) & 0.20 & 2.24 & 1.48 & 16.3 & 6.78 & 4.60 \\
\hline
\end{tabular}

The first phosphate amendments with low concentrations (10 mg/L) triggered a strong As(III) release. After this first peak, As(V) shares increased with respect to redox conditions. These findings indicate that a complex interplay of microbial processes and surface complexation govern the distribution of arsenic species depending on the availability of phosphate (Figure 5).

Preliminary tests indicated that under all described conditions a supersaturated phosphate concentration is necessary to start the release process [36]. The column tests in this study show that rapid release already starts at relatively low phosphate concentrations of $4 \mathrm{mg} / \mathrm{L}(0.04 \mathrm{mM})$ and continues when concentrations are increased during time. The wide range of phosphate amendment concentrations used in the other published studies illustrate that processes not only rely on the concentration of phosphate but are also strongly linked to the geochemistry of the sediment matrix, the water composition and microbial activity. 


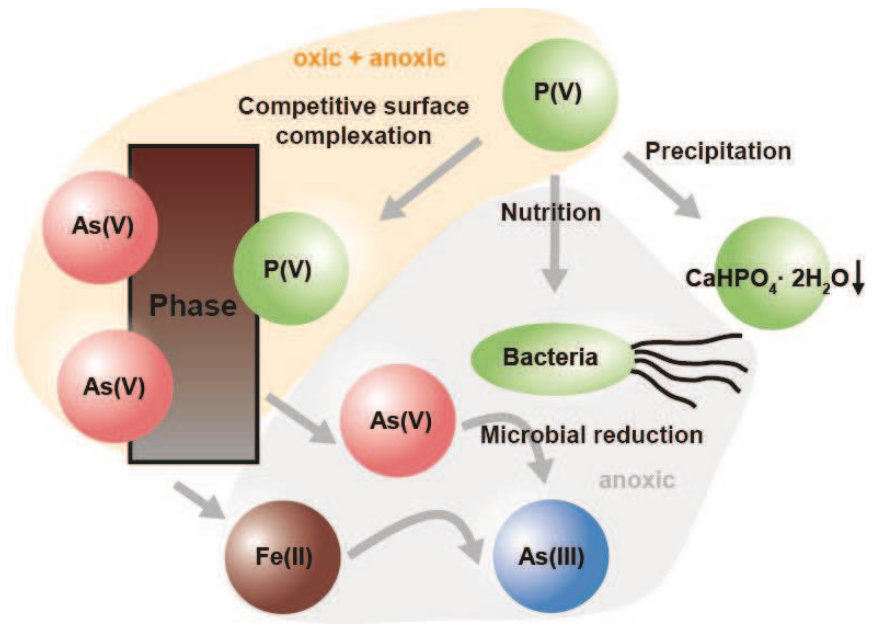

Figure 5. Schematic sketch of dominating processes supported by the results of this study: arsenic release by competitive surface complexation on iron and calcite minerals (phase), reduction of $\mathrm{As}(\mathrm{V})$ to $\mathrm{As}(\mathrm{III})$ by $\mathrm{Fe}(\mathrm{II})$ or arsenic-reducing bacteria and phosphate precipitation mainly as brushit $\left(\mathrm{CaHPO}_{4} \cdot 2 \mathrm{H}_{2} \mathrm{O}\right)$.

During the oxic tests, iron and manganese were not observed in significant concentrations in the column output, whereas nitrate reduction could be detected, which indicates that microbial activity in the columns leads to suboxic conditions. The temporal shift towards As(III) in the oxic tests with phosphate amendment might be artefacts of anoxic conditions in the sediment used for the columns or the fraction of $\mathrm{As}(\mathrm{III})$ on the sediment matrix (Table 2) but are more likely the effects of microbial processes fuelled by phosphate addition. Also, the high shares of As(III) in the anoxic tests were not linked to significant increases of manganese or iron. This is quite surprising considering the current standard of knowledge that microbial arsenic reduction prevails under iron-reducing conditions.

The observed rapid reduction of $\mathrm{As}(\mathrm{V})$ to $\mathrm{As}(\mathrm{III})$ after the $10 \mathrm{mg} / \mathrm{L}$ phosphate amendment could be explained by the stimulation of arsenic-reducing microorganisms by phosphate, which is likely the limiting factor for biological activity in the observed case. Macur et al. (2004) support the hypothesis that microorganisms are capable to oxidize and to reduce arsenic coexist in natural sediments [44]. Both tests indicate that the microorganisms were present in the sediment and just needed a time of incubation to grow in population. Campbell et al. (2006) subdivided two pathways of microbial $\mathrm{As}(\mathrm{V})$ reduction, the respiratory pathway and the detoxification [45]. Under anoxic conditions, the respiratory pathway was the dominating process. According to scientific consensus the As(V) reduction to As(III) by microbial respiration processes comes along with reducing conditions. For example, Huang et al. (2011) and Dhar et al. (2011) identified a microbe that mediated $\mathrm{As}(\mathrm{V})$ reduction under iron reducing conditions $[46,47]$. They agree with Zhang et al. (2009) that microbial desorption and iron reduction occur independently [48].

During our oxic and anoxic tests the $\mathrm{As}(\mathrm{V})$ release and subsequent reduction to $\mathrm{As}(\mathrm{III})$ was found independently from iron reducing conditions, which could be explained with the competitive surface complexation by phosphate from iron or carbonate surfaces. Another reason could be the dissolution of arsenic-bearing carbonates [28,30]. We suggest that the arsenic reduction of $\mathrm{As}(\mathrm{V})$ to $\mathrm{As}(\mathrm{III})$ is mainly due to microbial detoxification and is thus decoupled from the redox condition. The increased availability of phosphate leads to accelerated microbial activity combined with the uptake of $\mathrm{As}(\mathrm{V})$ in competition with phosphate and the release of As(III) species after the detoxification process.

In addition, Slaugther et al. (2012) demonstrated that arsenate reduction is suppressed at phosphate concentrations $>0.5 \mathrm{mM}$ and even inhibited at high $\mathrm{P} / \mathrm{As}$ ratios [49]. This observation gives 
a reasonable explanation for the decrease of these microbial detoxification processes with increasing phosphate amendments and a shift of arsenic species from dominantly As(III) to As(V) during the experiments. Further research will be necessary to understand the ongoing microbial processes.

\section{Conclusions}

The presented column tests clearly show that even low concentrations of phosphate amendment cause competitive exchange and can enhance biological processes, while higher phosphate dosages suppress microbial activity. Results also indicate that during low amendments of phosphate the microbial reduction of $\mathrm{As}(\mathrm{V})$ occurs very fast and is decoupled from manganese or iron reduction.

Enhanced in-situ arsenic remediation with phosphate bears great potential to accelerate the remediation process considerably. It is suitable for oxic and anoxic redox conditions, as it has no strong effects onto the prevailing redox milieu. Side effects such as mobility of heavy metals were not investigated in this study but have to be considered when applying the method at other places.

Additionally, transport velocities in field applications might be slower due to lower effective porosity of diagenetically compressed sediments in comparison with the manually compacted sediments in the columns. Furthermore, like in all in-situ remediation approaches, the heterogeneities in the sediment profile can change the effect and efficiency of the remediation, which could not be evaluated from the homogenized column material in this study.

Regarding the high phosphate amendment in total, the shares of phosphate consumed during the release processes are very low. Before field application, reactions with excess phosphate have to be considered. In the carbonate-rich aquatic environment of this study, the phosphate is precipitated with calcium, forming mainly white crystalline brushit $\mathrm{CaHPO}_{4} \cdot 2 \mathrm{H}_{2} \mathrm{O}$ (Figures 5 and 5 ) and shares of hydroxyl apatite $\mathrm{Ca}_{5}\left(\mathrm{PO}_{4}\right)_{3}(\mathrm{OH})$.

In carbonate-dominated systems, co-reactions of phosphate need to be compensated by a higher dosage. An economical application of phosphate is aspired for economic and ecologic reasons. Therefore, an optimal injection technique should be used in order to minimize phosphate amendments for efficient implementation in the remediation practice. Only in the anoxic columns significant amounts of phosphate remained in the sediment matrix after test termination. Future investigations should consider the phosphate precipitation and a potential field application [50].

In order to understand all occurring processes in the aquifer, larger scale studies in the field and geochemical modelling on the phosphate-induced arsenic release should be obtained in the framework of future project cooperation.

Author Contributions: Conceptualization, methodology, formal analysis, investigation, project administration, M.V.M.; methodology, validation and formal analysis, C.S.; supervision: M.I.-S.; writing —original draft preparation and visualization, Y.W. and D.Z.; writing—review, C.N.S.; writing—review and editing, M.V.M. and M.I.-S.

Funding: This work was funded by HIM ASG, Biebesheim and the regional council of Darmstadt (RP Darmstadt). We acknowledge financial support by Deutsche Forschungsgemeinschaft within the funding programme Open Access Publishing, by the Baden-Württemberg Ministry of Science, Research and the Arts and by Ruprecht-Karls-Universität Heidelberg.

Acknowledgments: The authors like to thank all colleagues from the University of Heidelberg, who contributed to the studies with laboratory works and scientific input. We also thank CDM Smith for technical and the Hessian Agency for Nature Conservation, Environment and Geology (HNLUG) for consultant support. Thank you to Amanda Wendt and Susanne Braun for language corrections and the reviewers for the helpful remarks and feedback.

Conflicts of Interest: The authors declare no conflict of interest. The funders had no role in the design of the study; in the collection, analyses or interpretation of data; in the writing of the manuscript or in the decision to publish the results. 
Appendix A

Table A1. Groundwater composition at the study site.

\begin{tabular}{|c|c|c|c|c|c|c|c|c|c|c|c|}
\hline \multicolumn{12}{|c|}{ Field Parameters } \\
\hline \multirow[t]{2}{*}{ Sample ID } & Sampling Depth & \multicolumn{2}{|c|}{ Temperature } & \multicolumn{2}{|c|}{ Electrical Conductivity } & \multicolumn{2}{|c|}{$\mathrm{pH}$ Value } & \multicolumn{2}{|c|}{ Acid Capacity } & ORP & Dissolved Oxygen \\
\hline & (m bgs) & \multicolumn{2}{|c|}{$\left({ }^{\circ} \mathrm{C}\right)$} & \multicolumn{2}{|c|}{$(\mu \mathrm{S} / \mathrm{cm})$} & \multicolumn{2}{|c|}{$(-)$} & \multicolumn{2}{|c|}{ (mmol) } & $(\mathrm{mV})$ & \\
\hline GWM 29/1 & 7.80 & \multirow{2}{*}{\multicolumn{2}{|c|}{13.3}} & \multicolumn{2}{|c|}{795} & \multicolumn{2}{|c|}{7.34} & \multicolumn{2}{|c|}{4.6} & 149 & 1.1 \\
\hline GWM 29/2 & 15.50 & & & \multirow{2}{*}{\multicolumn{2}{|c|}{$\begin{array}{l}617 \\
646\end{array}$}} & \multirow{2}{*}{\multicolumn{2}{|c|}{$\begin{array}{l}7.42 \\
7.39\end{array}$}} & \multicolumn{2}{|c|}{4.1} & 49 & 0.2 \\
\hline GWM 29/3 & 22.50 & \multicolumn{2}{|c|}{13.1} & & & & & & & 117 & 0.8 \\
\hline \multicolumn{12}{|c|}{ Major cations } \\
\hline \multirow[t]{2}{*}{ Sample ID } & Sampling Depth & \multicolumn{2}{|c|}{$\mathrm{Fe}$} & Mn & As & As III & As $\mathrm{V}$ & $\mathrm{Ca}$ & $\mathrm{K}$ & $\mathrm{Mg}$ & $\mathrm{Na}$ \\
\hline & (m bgs) & \multicolumn{2}{|c|}{$(\mathrm{mg} / \mathrm{L})$} & $(\mu \mathrm{g} / \mathrm{L})$ & $(\mu \mathrm{g} / \mathrm{L})$ & $(\mu \mathrm{g} / \mathrm{L})$ & $(\mu \mathrm{g} / \mathrm{L})$ & $(\mathrm{mg} / \mathrm{L})$ & $(\mathrm{mg} / \mathrm{L})$ & $(\mathrm{mg} / \mathrm{L})$ & $(\mathrm{mg} / \mathrm{L})$ \\
\hline GWM 29/1 & 7.80 & \multicolumn{2}{|c|}{2.24} & 407 & 667 & 19.0 & 648 & 154 & 9.46 & 9.74 & 18.9 \\
\hline GWM 29/2 & 15.50 & \multirow{2}{*}{\multicolumn{2}{|c|}{$\begin{array}{l}1.41 \\
1.21\end{array}$}} & 462 & 322 & 68.1 & 254 & 120 & 6.29 & 8.51 & 12.1 \\
\hline GWM 29/3 & 22.50 & & & 480 & 230 & 26.9 & 203 & 129 & 7.21 & 9.02 & 14.4 \\
\hline \multicolumn{12}{|c|}{ Heavy metals } \\
\hline \multirow[t]{2}{*}{ Sample ID } & Sampling Depth & $\mathrm{Al}$ & $\mathrm{Cd}$ & Co & $\mathrm{Cr}$ & \multicolumn{2}{|c|}{$\mathrm{Cu}$} & $\mathrm{Ni}$ & $\mathrm{Pb}$ & $\mathrm{Sr}$ & $\mathrm{Zn}$ \\
\hline & (m bgs) & $(\mu \mathrm{g} / \mathrm{L})$ & $(\mu \mathrm{g} / \mathrm{L})$ & $(\mu \mathrm{g} / \mathrm{L})$ & $(\mu \mathrm{g} / \mathrm{L})$ & \multicolumn{2}{|c|}{$(\mu \mathrm{g} / \mathrm{L})$} & $(\mu \mathrm{g} / \mathrm{L})$ & $(\mu \mathrm{g} / \mathrm{L})$ & $(\mu \mathrm{g} / \mathrm{L})$ & $(\mu \mathrm{g} / \mathrm{L})$ \\
\hline GWM 29/1 & 7.80 & $<50$ & $<5$ & $<5$ & $<5$ & & & $<5$ & $<10$ & 244 & 60 \\
\hline GWM 29/2 & 15.50 & $<50$ & $<5$ & $<5$ & $<5$ & & & $<5$ & $<10$ & 258 & 29.6 \\
\hline GWM 29/3 & 22.50 & $<50$ & $<5$ & $<5$ & $<5$ & & & $<5$ & $<10$ & 260 & 33.5 \\
\hline & & & & & nions & & & & & & \\
\hline Sample ID & Sampling Depth & $\mathrm{NO}_{3}$ & & $\mathrm{SO}_{4}$ & $\mathrm{PO}_{4}$ & & & $\mathrm{Cl}$ & & & $\mathrm{Br}$ \\
\hline & (m bgs) & $(\mathrm{mg} / \mathrm{L})$ & & $(\mathrm{mg} / \mathrm{L})$ & $(\mathrm{mg} / \mathrm{L})$ & $(\mathrm{m}$ & & $(\mathrm{mg} / \mathrm{L})$ & & & $\mathrm{mg} / \mathrm{L})$ \\
\hline GWM 29/1 & 7.80 & 5.4 & & 171 & $<1$ & & & 20.5 & & & 0.08 \\
\hline GWM 29/2 & 15.50 & 1.1 & & 106 & $<1$ & & & 14.9 & & & $<0.01$ \\
\hline GWM 29/3 & 22.50 & 1.2 & & 126 & $<1$ & & & 16.4 & & & 0.04 \\
\hline & & & & & arbon & & & & & & \\
\hline Sample ID & Sampling Depth & $\mathrm{HCO}_{3}^{-}$ & & TC & TIC & & & & TOC & & \\
\hline & (m bgs) & $(\mathrm{mg} / \mathrm{L})$ & & $(\mathrm{mg} / \mathrm{L})$ & $(\mathrm{mg} / \mathrm{L})$ & & & & $(\mathrm{mg} / \mathrm{L})$ & & \\
\hline GWM 29/1 & 7.80 & 270 & & 58.9 & 53 & & & & 5.87 & & \\
\hline GWM 29/2 & 15.50 & 225 & & 49.7 & 44.2 & & & & 5.51 & & \\
\hline GWM 29/3 & 22.50 & 247 & & 52.3 & 48.5 & & & & 3.75 & & \\
\hline GWM 29/3 & 22.50 & 247 & & 52.3 & 48.5 & & & & 3.75 & & \\
\hline
\end{tabular}


Table 2. Overview of the used measurements methods, ranges and quality control.

\begin{tabular}{cccc}
\hline Method & $\begin{array}{c}\text { Limit of } \\
\text { Determination (As) }\end{array}$ & Reference Material & Standard Deviation \\
\hline ICP-OES (water) & $50 \mu \mathrm{g} / \mathrm{L}$ & SPW-SW2 & $1-15 \%$ \\
HG-ICP-OES (As(III)) & $2.50 \mu \mathrm{g} / \mathrm{L}$ & $\begin{array}{c}\text { TMDA } 51.3 \\
\text { replication of } \\
\text { measurement }\end{array}$ & $1-8 \%$ \\
$\begin{array}{c}\text { ICP-OES (aqua } \\
\text { regia/elutions) }\end{array}$ & $2.50 \mathrm{mg} / \mathrm{kg}$ & BAM U112a, Blank & $2.83-5.35 \%$ \\
Photometer (phosphate) & $0.53 \mathrm{mg} / \mathrm{L}$ & & $6.02 \%$ \\
\hline
\end{tabular}

Table 3. Geochemical characteristics of the aquifer material from the liner (GWM 29) used for the columns, results from aqua regia extractions (n.n. = below detection).

\begin{tabular}{|c|c|c|c|c|c|c|c|c|c|}
\hline Sample & Depth & $\begin{array}{l}\text { As } \\
\text { Total }\end{array}$ & $\mathrm{Ca}$ & Mn & $\mathrm{Fe}$ & $\mathrm{CaCO}_{3}$ & Carbonate & C Total & $\begin{array}{c}\mathrm{C}_{\text {org }} \\
\text { (calc.) }\end{array}$ \\
\hline & (m bgs) & (mg/kg) & $(\%)$ & $(\mathrm{mg} / \mathrm{kg})$ & $(\%)$ & $(\%)$ & (as \%C) & $(\%)$ & $(\%)$ \\
\hline $29-1+2$ & $1-2$ & 35.2 & 0.56 & 151 & 0.63 & n.n. & n.n. & n.n. & n.n. \\
\hline $29-3$ & 3 & 12.5 & 1.82 & 105 & 0.45 & 4.30 & 0.52 & 0.64 & 0.12 \\
\hline $29-5$ & 5 & 60.5 & 0.72 & 28 & 0.20 & 2.15 & 0.28 & 0.23 & 0 \\
\hline $29-7$ & 7 & 25.8 & 1.86 & 56.2 & 0.27 & 6.46 & 0.78 & 0.96 & 0.18 \\
\hline $29-9$ & 9 & 28.9 & 3.30 & 68.2 & 0.29 & 7.94 & 0.95 & 1.15 & 0.20 \\
\hline $29-11$ & 11 & 33.6 & 2.95 & 85 & 0.41 & 12.2 & 1.47 & 1.36 & 0 \\
\hline $29-13$ & 13 & 22.2 & 2.17 & 59.7 & 0.30 & 7.27 & 0.87 & 0.70 & 0 \\
\hline $29-15$ & 15 & 25.4 & 2.87 & 66.2 & 0.31 & 6.13 & 0.74 & 0.77 & 0.03 \\
\hline
\end{tabular}

Table 4. Composition of the replicated groundwater used for the column tests based on the water composition at the contaminated site.

\begin{tabular}{llll}
\hline Ion & Concentration $(\mathrm{mg} / \mathrm{L})$ & Added as & Source and Quality \\
\hline $\mathrm{Ca}^{2+}$ & 128 & $\mathrm{CaSO}_{4}{ }^{2-} \cdot \mathrm{H}_{2} \mathrm{O}$ and $\mathrm{CaCO}_{3}$ & MERCK/Grüssing (p.a) \\
$\mathrm{Mg}^{2+}$ & 8 & $\mathrm{MgCl}_{2}{ }^{2-} \cdot 6 \mathrm{H}_{2} \mathrm{O}$ & AppliChem (p.a) \\
$\mathrm{Na}^{+}$ & 10 & $\mathrm{NaHCO}_{3}$ & Grüssing (p.a) \\
$\mathrm{K}^{+}$ & 5 & $\mathrm{KHCO}_{3}$ & Theoretikum (p.a) \\
$\mathrm{NO}_{3}{ }^{-}$ & $5 *$ & $\mathrm{NaNO}_{3}$ & Grüssing (p.a) \\
$\mathrm{SO}_{4}{ }^{2-}$ & 120 & $\mathrm{CaSO}_{4}{ }^{2+}$ & MERCK (p.a) \\
$\mathrm{Cl}^{-}$ & 23 & $\mathrm{MgCl}_{2}{ }^{2-} \cdot 6 \mathrm{H}_{2} \mathrm{O}$ & AppliChem (p.a) \\
\hline
\end{tabular}

Table 5. Column geometry, redox conditions and phosphate application.

\begin{tabular}{cccccc}
\hline Column & Diameter $(\mathbf{m})$ & Length $(\mathbf{m})$ & $\begin{array}{c}\text { Redox } \\
\text { Condition }\end{array}$ & $\begin{array}{c}\text { Discharge } \\
\text { (L/day) }\end{array}$ & $\begin{array}{c}\text { Phosphate } \\
\text { Application }\end{array}$ \\
\hline 1 & 0.005 & 0.3 & Oxic & 0.18 & none \\
2 & 0.004 & 0.3 & Oxic & 0.22 & via bypass into \\
3 & 0.004 & 0.3 & Oxic & 0.22 & columns entry \\
\hline 4 & 0.005 & 0.3 & Anoxic & 0.18 & none \\
5 & 0.005 & 0.3 & Anoxic & 0.18 & added to process water \\
6 & 0.005 & 0.3 & Anoxic & 0.18 & after degassing \\
\hline
\end{tabular}


Table 6. Considered parameters, applied sample preparation and analytical methods.

\begin{tabular}{|c|c|c|c|}
\hline \multicolumn{4}{|l|}{ Sediment Samples } \\
\hline Aqua regia extraction & $\begin{array}{l}\text { As (tot) and } \\
\text { cations }\end{array}$ & $\begin{array}{l}1 \mathrm{~g} \text { sample with } 3 \mathrm{~mL} 65 \%, \mathrm{HNO}_{3} \\
\text { and } 9 \mathrm{~mL} 37 \% \mathrm{HCl} \text {, filled up to } \\
50 \mathrm{~mL} \text { and filtered through } \\
\text { folded filter }\end{array}$ & \multirow[t]{3}{*}{$\begin{array}{l}\text { (HG)-ICP-OES (VISTA-MPX } \\
\text { CCD Simultaneous; Varian) }\end{array}$} \\
\hline Water elution & $\begin{array}{l}\text { As (III) and As } \\
\text { (tot) }\end{array}$ & $\begin{array}{l}3.5 \text { g sample add. } 40 \mathrm{~mL} \text { distilled } \\
\text { water, filtered by } 0.45 \mu \mathrm{m} \text { and } \\
\text { stabilized at pH } 1 \text { with } 6 \mathrm{M} \mathrm{HCl}\end{array}$ & \\
\hline Phosphate elution & $\begin{array}{l}\text { As (III) and As } \\
\text { (tot) }\end{array}$ & $\begin{array}{l}3.5 \mathrm{~g} \text { sample add. } 40 \mathrm{~mL} 1 \mathrm{M} \\
\mathrm{NaH}_{2} \mathrm{PO}_{4} \text {, filtered by } 0.45 \mu \mathrm{m} \text { and } \\
\text { stabilized at pH } 1 \text { with } 6 \mathrm{M} \mathrm{HCl}\end{array}$ & \\
\hline Solid sample & TC & & SC-Analyzer (SC 144R; Leco) \\
\hline \multicolumn{4}{|l|}{ Water Samples } \\
\hline \multirow{4}{*}{$\begin{array}{l}\text { Inflow solution and } \\
\text { column outflow }\end{array}$} & $\begin{array}{l}\text { As (III), As (tot) } \\
\text { and cations }\end{array}$ & stabilized at $\mathrm{pH} 1$ with $6 \mathrm{M} \mathrm{HCl}$ & $\begin{array}{l}\text { (HG)-ICP-OES (VISTA-MPX } \\
\text { CCD Simultaneous; Varian) }\end{array}$ \\
\hline & Anions & & $\begin{array}{l}\text { IC (Dionex DX-120; } \\
\text { ThermoFisher Scientific) }\end{array}$ \\
\hline & TIC/TC & & $\begin{array}{l}\text { TOC (TOC-VCSN; } \\
\text { Shimadzu) }\end{array}$ \\
\hline & Phosphate & Molybdenum-blue method & $\begin{array}{l}\text { UV-VIS Spectrophotometer; } \\
\text { (Specord 50; Analytik Jena) }\end{array}$ \\
\hline Tracer test & Bromide & & $\begin{array}{l}\text { Ion selective electrode } \\
\text { (Br 500; WTW); IC } \\
\text { (Dionex DX-120; } \\
\text { ThermoFisher Scientific) }\end{array}$ \\
\hline
\end{tabular}

Table 7. Sulphate balancing from the inflowing (replicated water) and outflowing water.

\begin{tabular}{|c|c|c|c|c|c|}
\hline & \multirow[b]{3}{*}{ Column } & \multicolumn{3}{|c|}{ Average $\mathrm{SO}_{4}(\mathrm{mg} / \mathrm{L})$} & \multirow{3}{*}{$\begin{array}{c}\text { Deviation } \\
\mathrm{SO}_{4}(\%)\end{array}$} \\
\hline & & \multicolumn{2}{|c|}{ Replicated Water } & \multirow{2}{*}{$\begin{array}{l}\text { Column } \\
\text { Outflow }\end{array}$} & \\
\hline & & Planned & Measured * & & \\
\hline 1 & reference oxic & \multirow{6}{*}{120} & 125 & 129 & 3.25 \\
\hline 2 & oxic $+\mathrm{PO}_{4}$ & & \multirow{2}{*}{120} & 111 & -7.72 \\
\hline 3 & oxic $+\mathrm{PO}_{4}$ & & & 115 & -4.71 \\
\hline 4 & reference anoxic & & 120 & 121 & 0.17 \\
\hline 5 & anoxic $+\mathrm{PO}_{4}$ & & \multirow{2}{*}{121} & 113 & -6.89 \\
\hline 6 & anoxic $+\mathrm{PO}_{4}$ & & & 114 & -6.51 \\
\hline
\end{tabular}




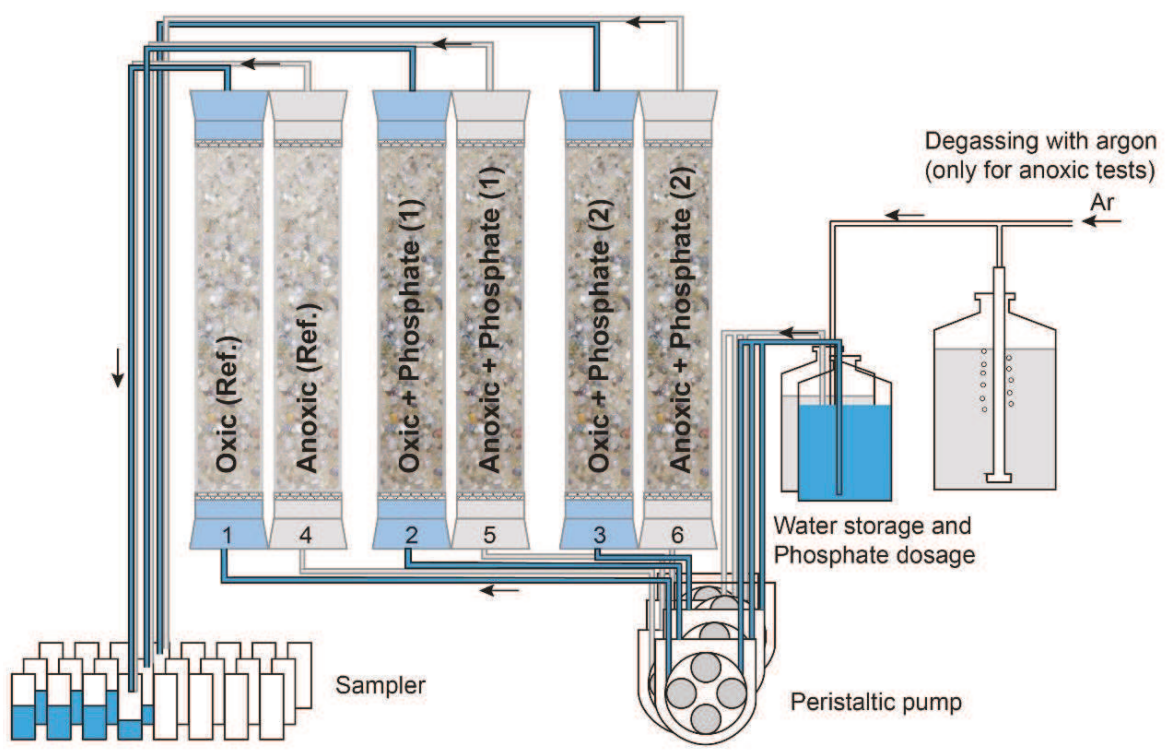

Figure 1. Setup of the column tests. Columns filled with contaminated sediment are percolated from bottom to top by replicated groundwater, to which phosphate is dosed stepwise. For the anoxic tests, the water was degassed with argon before percolation and the whole system was run in an argon floated glove box (modified after [51]). 

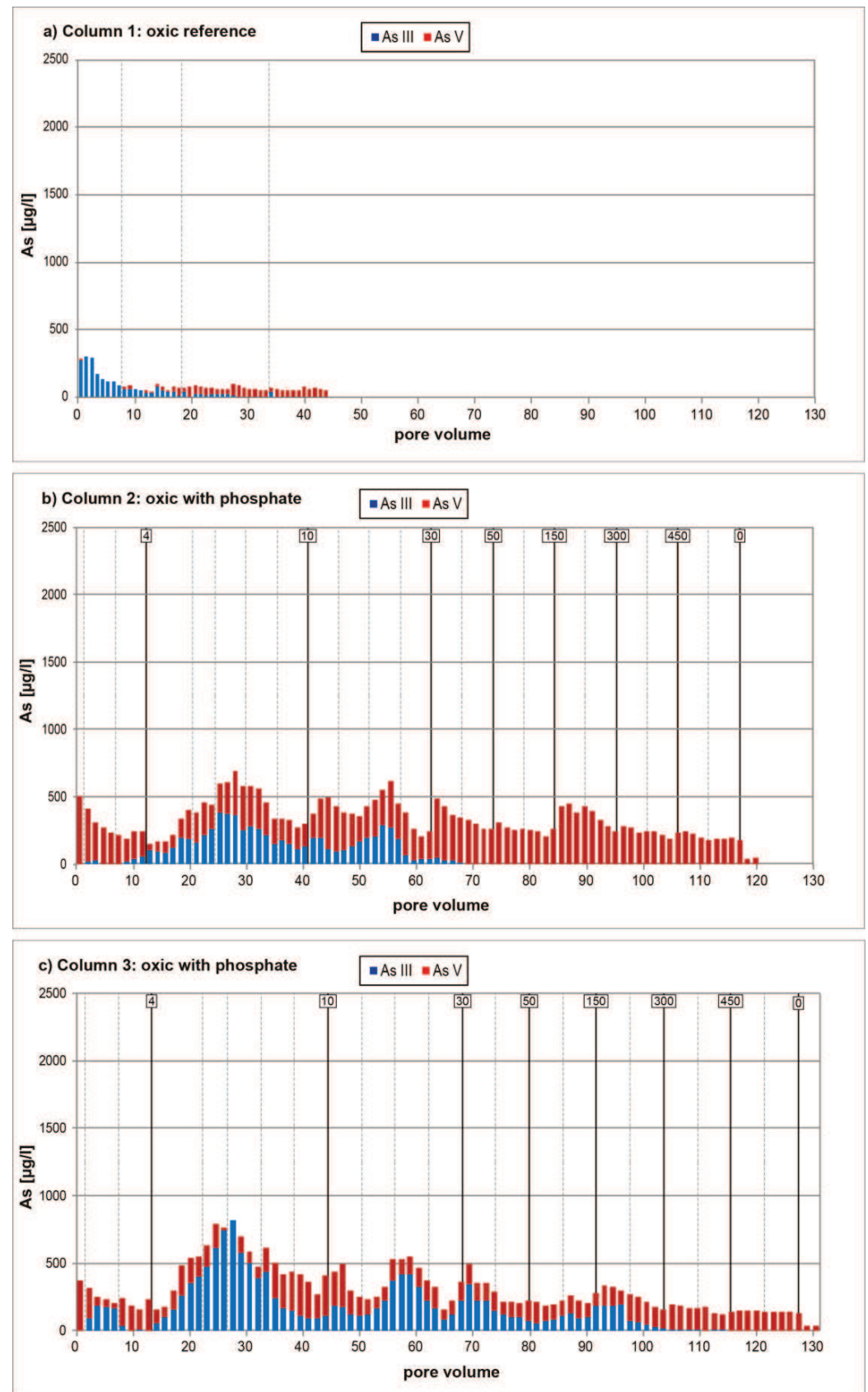

Figure 2. Arsenic release during the oxic column tests, (a) column 1 without phosphate addition and $(\mathbf{b})+(\mathbf{c})$ with phosphate addition in column 2 and 3 . Vertical lines indicate refilling of replicated groundwater and the numbers next to them the scheduled phosphate concentration $(\mathrm{mg} / \mathrm{L})$. 
Water 2019, 11, 2364
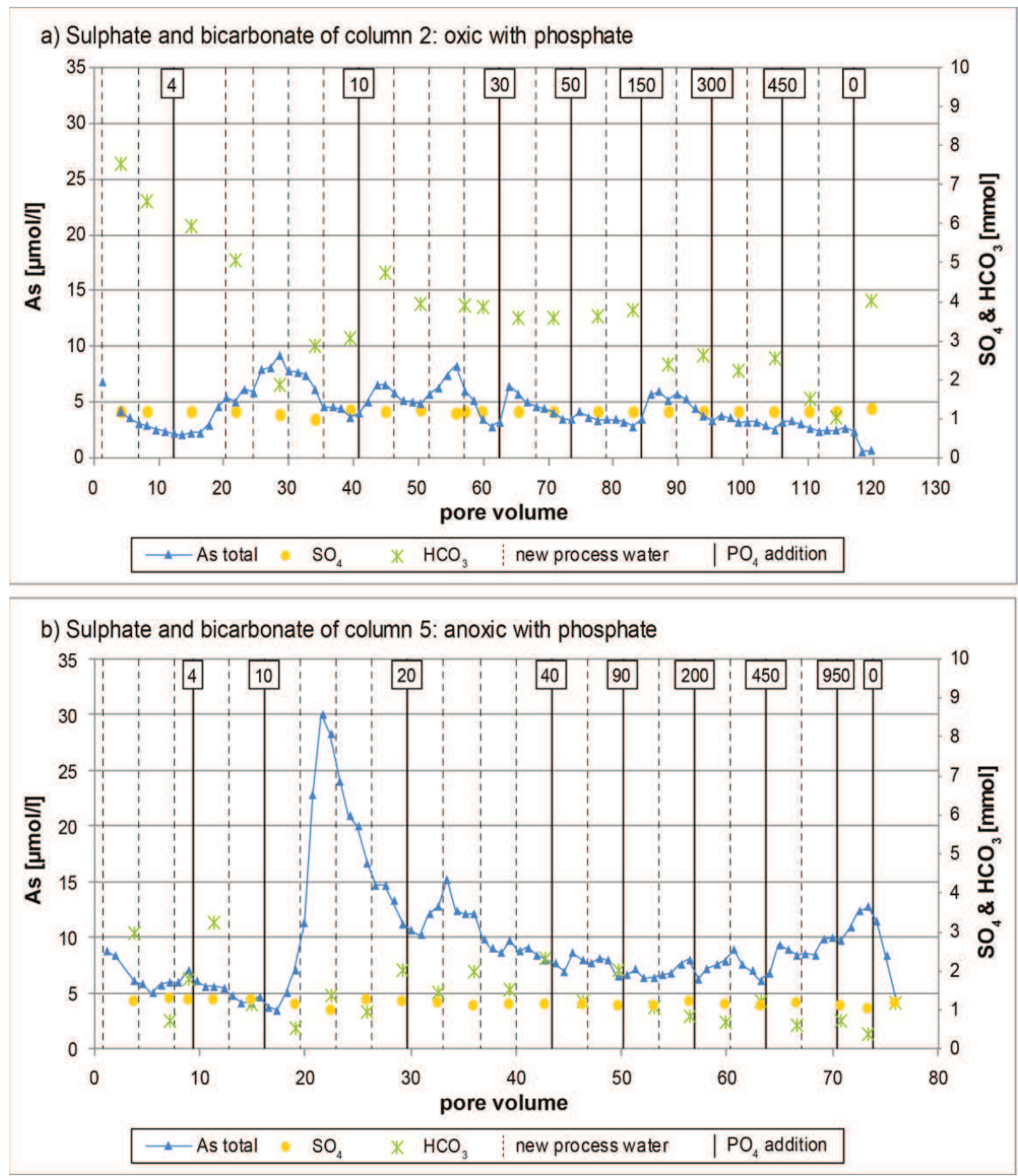

Figure 3. Sulphate $\left(\mathrm{SO}_{4}\right)$ and bicarbonate $\left(\mathrm{HCO}_{3}\right)$ concentrations (right axis) in comparison with arsenic (left axis) in (a) oxic column 2 and (b) anoxic column 5. 

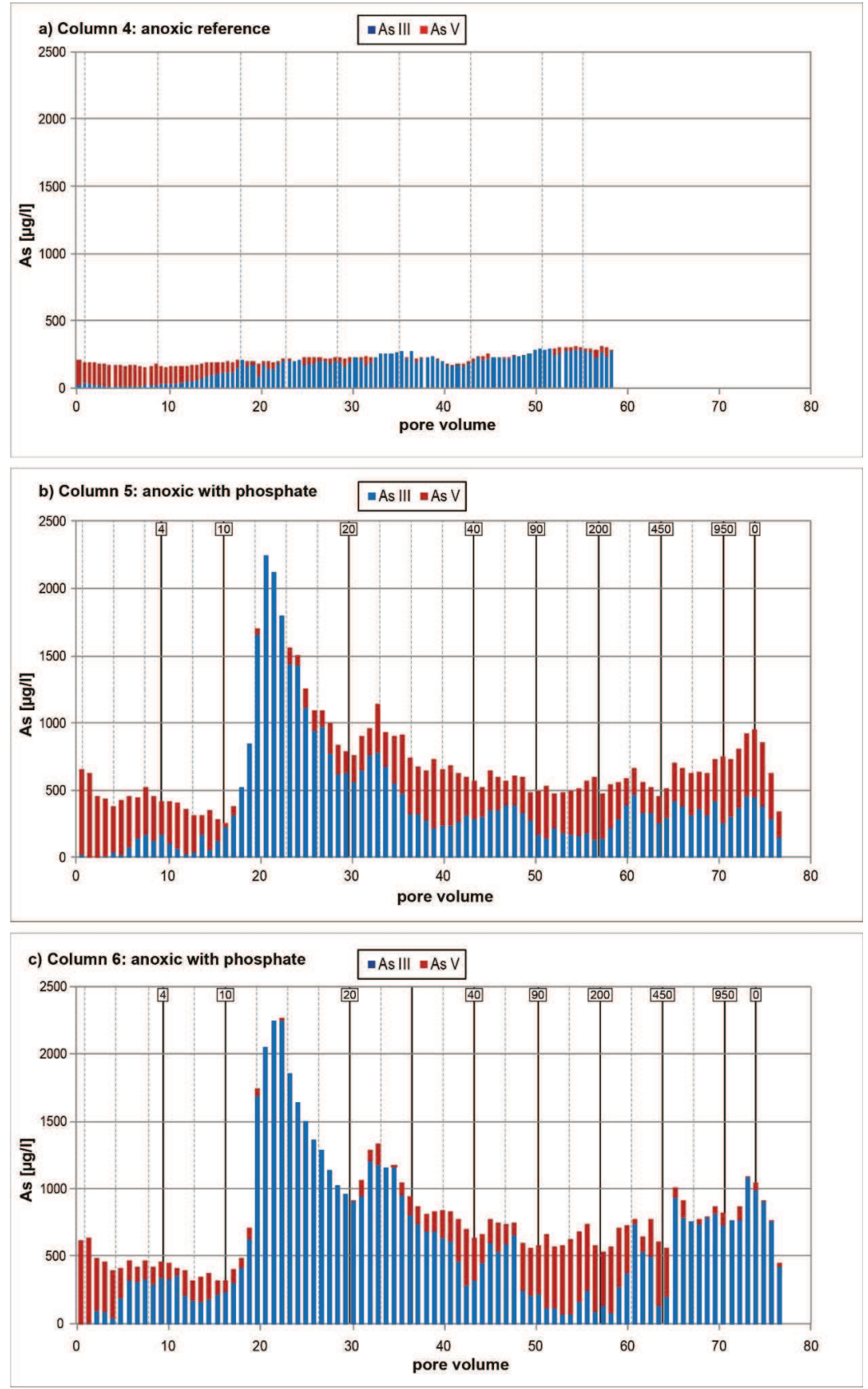

Figure 4. Arsenic release during the anoxic column tests, (a) column 4 without phosphate addition and $(\mathbf{b})+(\mathbf{c})$ column 5 and 6 with phosphate addition. Vertical lines indicate refilling of replicated groundwater, the attached numbers the amended phosphate concentrations $(\mathrm{mg} / \mathrm{L})$ at the time of solution preparation. 

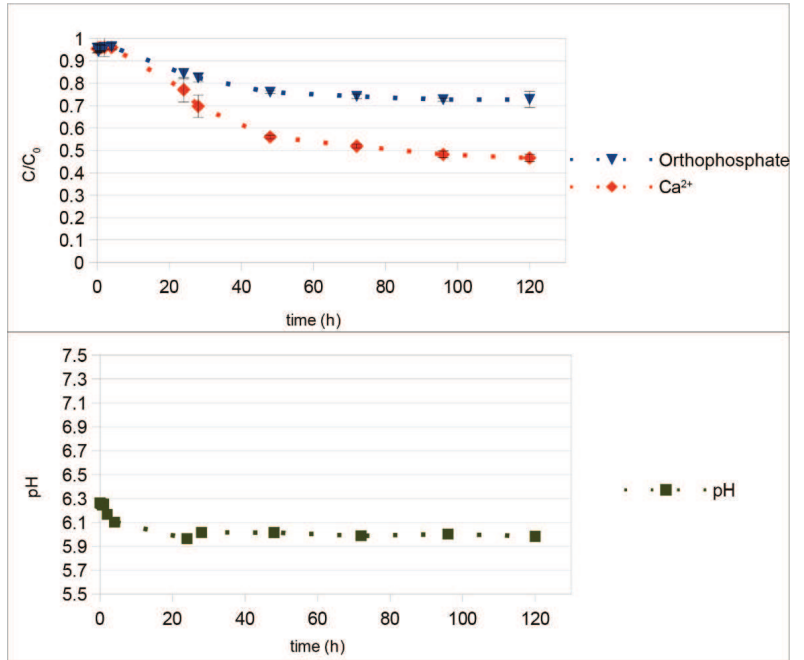

Figure 5. Bottom: Results from a batch experiment with groundwater from the study site verify that even very high phosphate amendments of $10 \mathrm{mmol} / \mathrm{L}$ only result in a small change in $\mathrm{pH}$ value from $\mathrm{pH}$ 6.3 to 6 without any further decline. Top: Change in concentration $\left(c / c_{0}\right)$ of calcium and orthophosphate over $120 \mathrm{~h}$ show the precipitation of brushit [52].
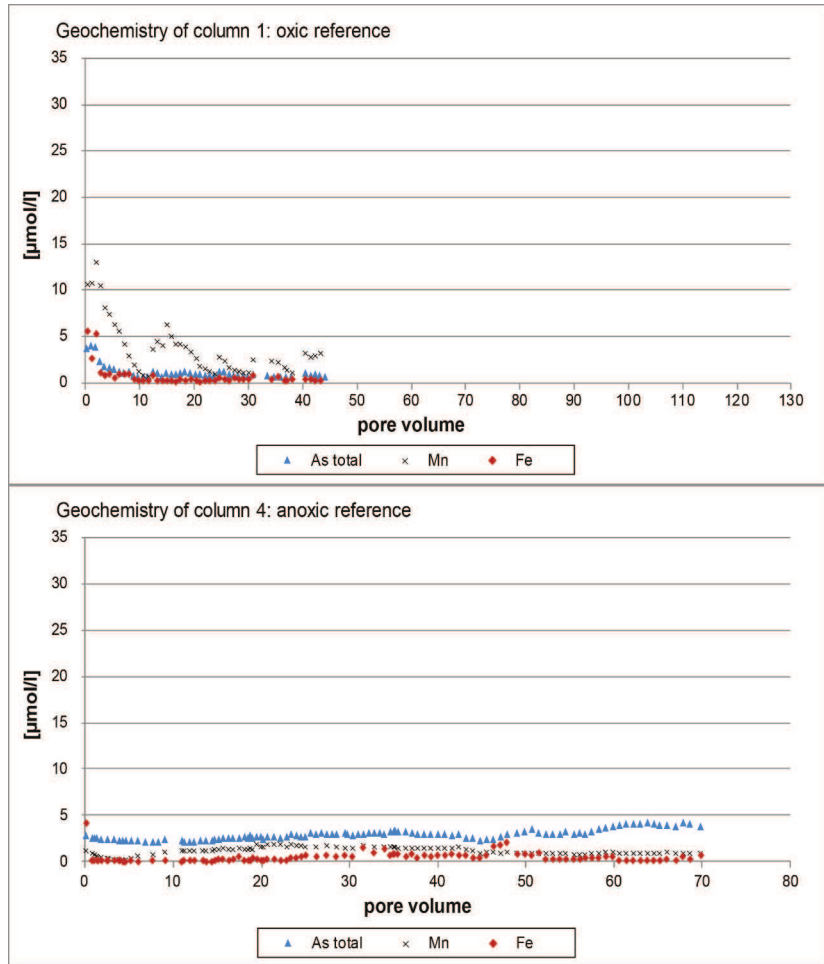

Figure 6. Release of arsenic, manganese and iron in the oxic reference column 1 (top) and the anoxic reference column 4 (bottom). 


\section{References}

1. Eljamal, O.; Sasaki, K.; Tsuruyama, S.; Hirajima, T. Kinetic Model of Arsenic Sorption onto Zero-Valent Iron (ZVI). Water Qual. Expo. Health 2011, 2, 125-132. [CrossRef]

2. Bissen, M.; Frimmel, F.H. Arsenic-A Review. Part II: Oxidation of Arsenic and its Removal in Water Treatment. Acta Hydrochim. Hydrobiol. 2003, 31, 97-107. [CrossRef]

3. Kuhlmeier, P.D. Sorption and desorption of arsenic from sandy soils: Column studies. J. Soil Contam. 1997, 6, 21-36. [CrossRef]

4. Smedley, P.L.; Kinniburgh, D.G. A review of the source, behaviour and distribution of arsenic in natural waters. Appl. Geochem. 2002, 17, 517-568. [CrossRef]

5. Guo, H.; Stüben, D.; Berner, Z.; Yu, Q. Characteristics of arsenic adsorption from aqueous solution: Effect of arsenic species and natural adsorbents. Appl. Geochem. 2009, 24, 657-663. [CrossRef]

6. Bowell, R.J. Sorption of arsenic by iron oxides and oxyhydroxides in soils. Appl. Geochem. 1994, 9, $279-286$. [CrossRef]

7. Dzombak, D.A.; Morel, F.M.M. Surface Complexation Modeling: Hydrous Ferric Oxide; Wiley-Interscience: New York, NY, USA, 1990.

8. Sø, H.U.; Postma, D.; Jakobsen, R.; Larsen, F. Sorption of phosphate onto calcite; results from batch experiments and surface complexation modeling. Geochim. Cosmochim. Acta 2011, 75, 2911-2923. [CrossRef]

9. Biswas, A.; Majumder, S.; Neidhardt, H.; Halder, D.; Bhowmick, S.; Mukherjee-Goswami, A.; Kundu, A.; Saha, D.; Berner, Z.; Chatterjee, D. Groundwater chemistry and redox processes: Depth dependent arsenic release mechanism. Appl. Geochem. 2011, 26, 516-525. [CrossRef]

10. Saunders, J.A.; Lee, M.-K.; Shamsudduha, M.; Dhakal, P.; Uddin, A.; Chowdury, M.T.; Ahmed, K.M. Geochemistry and mineralogy of arsenic in (natural) anaerobic groundwaters. Appl. Geochem. 2008, 23, 3205-3214. [CrossRef]

11. Rochette, E.A.; Bostick, B.C.; Li, G.; Fendorf, S. Kinetics of Arsenate Reduction by Dissolved Sulfide. Environ. Sci. Technol. 2000, 34, 4714-4720. [CrossRef]

12. Bostick, B.C.; Fendorf, S. Arsenite sorption on troilite $(\mathrm{FeS})$ and pyrite $\left(\mathrm{FeS}_{2}\right)$. Geochim. Cosmochim. Acta 2003, 67, 909-921. [CrossRef]

13. Bundschuh, J.; Hollander, H.; Lena, M. In-Situ Remediation of Arsenic-Contaminated Sites, 1st ed.; Bundschuh, J., Hollander, H., Lena, M., Eds.; CRC Press, Taylor \& Francis Group: London, UK, 2014.

14. Matthess, G. In Situ Treatment of Arsenic Contaminated Groundwater. In Studies in Environmental Science; Elsevier: Amsterdam, The Netherlands, 1981; Volume 17, pp. 291-296. [CrossRef]

15. Rott, U.; Friedle, M. Eco-friendly and cost-efficient removal of arsenic, iron and manganese by means of subterranean ground-water treatment. Water Supply 2000, 18, 632-636.

16. Kim, M.-J.; Nriagu, J. Oxidation of arsenite in groundwater using ozone and oxygen. Sci. Total Environ. 2000, 247, 71-79. [CrossRef]

17. Krüger, T.; Holländer, H.M.; Stummeyer, J.; Harazim, B.; Boochs, P.-W.; Billib, M. In-situ immobilization of arsenic in the subsurface on an anthropogenic contaminated site. In In-Situ Remediation of Arsenic-Contaminated Sites; Bundschuh, J., Holländer, H.M., Ma, L.Q., Eds.; CRC Press, Taylor \& Francis Group: London, UK, 2014.

18. Luong, V.T.; Cañas Kurz, E.E.; Hellriegel, U.; Luu, T.L.; Hoinkis, J.; Bundschuh, J. Iron-based subsurface arsenic removal technologies by aeration: A review of the current state and future prospects. Water Res. 2018, 133, 110-122. [CrossRef] [PubMed]

19. Onstott, T.C.; Chan, E.; Polizzotto, M.L.; Lanzon, J.; DeFlaun, M.F. Precipitation of arsenic under sulfate reducing conditions and subsequent leaching under aerobic conditions. Appl. Geochem. 2011, 26, $269-285$. [CrossRef]

20. Gemeinhardt, C.; Müller, S.; Weigand, H.; Marb, C. Chemical immobilisation of arsenic in contaminated soils using iron(II)sulphate-advantages and pitfalls. Water Air Soil Pollut. Focus 2006, 6, 281-297. [CrossRef]

21. Köber, R.; Daus, B.; Ebert, M.; Mattusch, J.; Welter, E.; Dahmke, A. Compost-Based Permeable Reactive Barriers for the Source Treatment of Arsenic Contaminations in Aquifers: Column Studies and Solid-Phase Investigations. Environ. Sci. Technol. 2005, 39, 7650-7655. [CrossRef] [PubMed]

22. Klaas, N.; Braun, J.; Mackenberg, S. Wissenschaftlicher Bericht Nr. 2007/06 (VEG 23) Entwicklung Eines Immobilisierungsverfahrens für Schwermetalle unter Nutzung des Geogenen Sulfatgehaltes im Grundwasser; VEGAS: Stuttgart, Germany, 2007. 
23. Zeng, H.; Fisher, B.; Giammar, D.E. Individual and Competitive Adsorption of Arsenate and Phosphate to a High-Surface-Area Iron Oxide-Based Sorbent. Environ. Sci. Technol. 2008, 42, 147-152. [CrossRef] [PubMed]

24. Kent, D.B. The influence of groundwater chemistry on arsenic concentrations and speciation in a quartz sand and gravel aquifer. Geochem. Trans. 2004, 5, 1-12. [CrossRef]

25. Hongshao, Z.; Stanforth, R. Competitive Adsorption of Phosphate and Arsenate on Goethite. Environ. Sci. Technol. 2001, 35, 4753-4757. [CrossRef] [PubMed]

26. Luengo, C.; Brigante, M.; Avena, M. Adsorption kinetics of phosphate and arsenate on goethite. A comparative study. J. Colloid Interface Sci. 2007, 311, 354-360. [CrossRef] [PubMed]

27. Manning, B.A.; Goldberg, S. Modeling Competitive Adsorption of Arsenate with Phosphate and Molybdate on Oxide Minerals. Soil Sci. Soc. Am. J. 1996, 60, 121-131. [CrossRef]

28. Bardelli, F.; Benvenuti, M.; Costagliola, P.; Di Benedetto, F.; Lattanzi, P.; Meneghini, C.; Romanelli, M.; Valenzano, L. Arsenic uptake by natural calcite: An XAS study. Geochim. Cosmochim. Acta 2011, 75, 3011-3023. [CrossRef]

29. Yokoyama, Y.; Tanaka, K.; Takahashi, Y. Differences in the immobilization of arsenite and arsenate by calcite. Geochim. Cosmochim. Acta 2012, 91, 202-219. [CrossRef]

30. Sø, H.U.; Postma, D.; Jakobsen, R.; Larsen, F. Sorption and desorption of arsenate and arsenite on calcite. Geochim. Cosmochim. Acta 2008, 72, 5871-5884. [CrossRef]

31. Pigna, M.; Krishnamurti, G.S.R.; Violante, A. Kinetics of Arsenate Sorption-Desorption from Metal Oxides. Soil Sci. Soc. Am. J. 2006, 70, 2017-2027. [CrossRef]

32. Alam, M.G.; Tokunaga, S.; Maekawa, T. Extraction of arsenic in a synthetic arsenic-contaminated soil using phosphate. Chemosphere 2001, 43, 1035-1041. [CrossRef]

33. Woolson, E.A.; Axley, J.H.; Kearney, P.C. The Chemistry and Phytotoxicity of Arsenic in Soils: II. Effects of Time and Phosphorus. Soil Sci. Soc. Am. J. 1973, 37, 254-259. [CrossRef]

34. Wovkulich, K.; Mailloux, B.J.; Lacko, A.; Keimowitz, A.R.; Stute, M.; Simpson, H.J.; Chillrud, S.N. Chemical treatments for mobilizing arsenic from contaminated aquifer solids to accelerate remediation. Appl. Geochem. 2010, 25, 1500-1509. [CrossRef] [PubMed]

35. O'Reilly, S.E.; Strawn, D.G.; Sparks, D.L. Residence Time Effects on Arsenate Adsorption/Desorption Mechanisms on Goethite. Soil Sci. Soc. Am. J. 2001, 65, 67. [CrossRef]

36. Maier, M. Untersuchungen zum Reaktiven Transport von Arsen im Grundwasserleiter: Prozessstudie und Entwicklung Einer Neuartigen Sanierungsmethode an Einem Altstandort in Hessen; Ruprecht-Karls-Universität Heidelberg: Heidelberg, Germany, 2014. [CrossRef]

37. Maier, M.V. Insitu-Mobilisierung von Arsen im Grundwasser. In Handbuch Altlastensanierung und Flächenmanagement (HdA); Franziskus, V., Altenbockum, M., Gerhold, T., Eds.; Hütig Jehle Rehm Verlag: Heidelberg, Germany, 2016; ISBN 978-3-8073-2397-8.

38. Keon, N.E.; Swartz, C.H.; Brabander, D.J.; Harvey, C.; Hemond, H.F. Validation of an arsenic sequential extraction method for evaluating mobility in sediments. Environ. Sci. Technol. 2001, 35, 2778-2784. [CrossRef] [PubMed]

39. Rüde, T.R. Beiträge zur Geochemie des Arsens; Puchelt, H., Ed.; Karlsruher Geochemische Hefte: Karlsruhe, Germany, 1996; Volume 10.

40. Höhn, R.; Isenbeck-Schröter, M.; Kent, D.B.; Davis, J.A.; Jakobsen, R.; Jann, S.; Niedan, V.; Scholz, C.; Stadler, S.; Tretner, A. Tracer test with As(V) under variable redox conditions controlling arsenic transport in the presence of elevated ferrous iron concentrations. J. Contam. Hydrol. 2006, 88, 36-54. [CrossRef] [PubMed]

41. Appelo, C.A.J.; Postma, D. Geochemistry, Groundwater and Pollution, 2nd ed.; CRC Press, Taylor \& Francis Group: Boca Raton, FL, USA; London, UK; New York, NY, USA, 2005.

42. Kinzelbach, W. Numerische Methoden zur Modellierung des Transports von Schadstoffen im Grundwasser; 2. Aufl.; Oldenbourg: München, Germany; Wien, Austria, 1987.

43. Isenbeck-Schröter, M. Transportverhalten von Schwermetallkationen und Oxoanionen-Laborversuche in Säulen und ihre Modellierung; Berichte Nr. 67; Fachbereich Geowissenschaften: Bremen, Germany, 1995.

44. Macur, R.E.; Jackson, C.R.; Botero, L.M.; Mcdermott, T.R.; Inskeep, W.P. Bacterial Populations Associated with the Oxidation and Reduction of Arsenic in an Unsaturated Soil. Environ. Sci. Technol. 2004, 38, $104-111$. [CrossRef] [PubMed] 
45. Campbell, K.M.; Malasarn, D.; Saltikov, C.W.; Newman, D.K.; Hering, J.G. Simultaneous Microbial Reduction of Iron(III) and Arsenic(V) in Suspensions of Hydrous Ferric Oxide. Environ. Sci. Technol. 2006, 40, 5950-5955. [CrossRef] [PubMed]

46. Huang, J.-H.; Voegelin, A.; Pombo, S.A.; Lazzaro, A.; Zeyer, J.; Kretzschmar, R. Influence of Arsenate Adsorption to Ferrihydrite, Goethite, and Boehmite on the Kinetics of Arsenate Reduction by Shewanella putrefaciens strain CN-32. Environ. Sci. Technol. 2011, 45, 7701-7709. [CrossRef] [PubMed]

47. Dhar, R.K.; Zheng, Y.; Saltikov, C.W.; Radloff, K.A.; Mailloux, B.J.; Ahmed, K.M.; van Geen, A. Microbes Enhance Mobility of Arsenic in Pleistocene Aquifer Sand from Bangladesh. Environ. Sci. Technol. 2011, 45, 2648-2654. [CrossRef] [PubMed]

48. Zhang, X.; Jia, Y.; Wang, S.; Pan, R.; Zhang, X. Bacterial reduction and release of adsorbed arsenate on Fe(III)-, Al- and coprecipitated Fe(III)/Al-hydroxides. J. Environ. Sci. 2012, 24, 440-448. [CrossRef]

49. Slaughter, D.C.; Macur, R.E.; Inskeep, W.P. Inhibition of microbial arsenate reduction by phosphate. Microbiol. Res. 2012, 167, 151-156. [CrossRef] [PubMed]

50. Maier, M.V.; Isenbeck-Schröter, M.; Klose, L.B.; Ritter, S.M.; Scholz, C. In situ-mobilization of arsenic in groundwater-an innovative remediation approach? Procedia Earth Planet. Sci. 2017, 17, 452-455. [CrossRef]

51. Tretner, A. Sorptions- und Redoxprozesse von Arsen an Oxidischen Oberflächen-Experimentelle Untersuchungen; Ruprecht-Karls-Universität Heidelberg: Heidelberg, Germany, 2002. [CrossRef]

52. Burger, J. Untersuchungen zur Fällungskinetik von Calciumphosphaten Batchversuche mit Grundwasser; Ruprecht-Karls-University Heidelberg: Heidelberg, Germany, 2014.

(C) 2019 by the authors. Licensee MDPI, Basel, Switzerland. This article is an open access article distributed under the terms and conditions of the Creative Commons Attribution (CC BY) license (http://creativecommons.org/licenses/by/4.0/). 
Article

\title{
Significance of Chlorinated Phenols Adsorption on Plastics and Bioplastics during Water Treatment
}

\author{
Aleksandra Tubić, Maja Lončarski *, Snežana Maletić, Jelena Molnar Jazić, Malcolm Watson, \\ Jelena Tričković and Jasmina Agbaba \\ Department of Chemistry, Biochemistry and Environmental Protection, Faculty of Sciences, \\ University of Novi Sad, Trg Dositeja Obradovića 3, 21000 Novi Sad, Serbia; aleksandra.tubic@dh.uns.ac.rs (A.T.); \\ snezana.maletic@dh.uns.ac.rs (S.M.); jelena.molnar@dh.uns.ac.rs (J.M.J.); malcolm.watson@dh.uns.ac.rs (M.W.); \\ jelena.trickovic@dh.uns.ac.rs (J.T.); jasmina.agbaba@dh.uns.ac.rs (J.A.) \\ * Correspondence: maja.loncarski@dh.uns.ac.rs; Tel.: +381-21-485-2798
}

Received: 2 October 2019; Accepted: 7 November 2019; Published: 10 November 2019

\begin{abstract}
Microplastics and chlorinated phenols (CPs) are pollutants found ubiquitously in freshwater systems. Meanwhile, bioplastics are attracting much attention as alternatives to conventional plastics, but there is little data about their effect on the behaviour of pollutants. This work therefore investigates the sorption of four CPs (4-chlorophenol-4-CP, 2,4-dichlorophenol-2,4-DCP, 2,4,6-trichlorophenol-2,4,6-TCP and pentachlorophenol-PCP) on three different plastics (polyethylene (PEg), polypropylene (PP) and polylactic acid (PLA)) using kinetics and isotherm studies. All experiments were carried out in a synthetic water matrix and in spiked Danube river water. In all cases, adsorption kinetics fitted well with the pseudo-second order rate model. Adsorption proceeded through two linear phases, corresponding to transport from the bulk solution to the external surfaces and then into the interior pores of the sorbents. Maximum adsorption capacities calculated with the Langmuir isotherm indicated that whereas adsorption of 4-CP was not significantly affected by the type of plastic present, the adsorption of 2,4-DCP, 2,4,6-TCP and PCP varied greatly, with polypropylene showing the greatest affinity for CPs adsorption. The differences observed between the adsorption behaviour of CPs in the synthetic and natural water matrices suggest further investigation is required into how the different fractions of natural organic matter impact interactions between CPs and plastics.
\end{abstract}

Keywords: microplastic; bioplastic; chlorinated phenols; sorption; kinetics; matrix effect

\section{Introduction}

It is well established that water environments have been contaminated by various pollutants, including chlorinated phenols and plastics [1-4].

Chlorophenols are ubiquitous contaminants in the environment originating from various anthropogenic activities such are chemical, textile and pharmaceutical activities [1,5]. Chlorophenols include widely applied pesticides and their degradation products. Thus, pentachlorophenol is a herbicide and insecticide used in various industries [5] and 2,4-dichlorophenol and 2,4,6-trichlorophenol are transformation products of the pesticide Triclosan [2]. Chlorophenols can also be present in drinking water due to the reaction between organic matter left in treated water and chlorine during the process of disinfection [2,5]. Furthermore, it has been confirmed that chlorophenols can be formed during disinfection, which raises particular concerns [2,6]. The European Union (EU) and United States Environmental Protection Agency (USEPA) [7-9] have therefore defined certain chlorinated phenols as priority contaminants, including 4-chlorophenol (4-CP), 2,4-dichlorophenol (2,4-DCP), 2,4,6-trichlorophenol (2,4,6-TCP) and pentachlorophenol (PCP). 
It has been determined that rivers are the most at risk of all water bodies, where chlorophenols have been detected at concentrations in the range of 2-2000 $\mu \mathrm{g} / \mathrm{L}$ [5]. Additionally, since rivers are highly connected to groundwaters, especialy by bank filtration, the presence of chlorinated phenols can pose a significant issue for drinking water treatment, not only in surface drinking water sources, but also in shallow groundwaters.

In addition to broad data indicating the adverse effects of organic pollutants to water environments and human health, in recent years plastic contamination has also attracted a lot of attention in the scientific community $[3,4,10,11]$. The presence of microplastics in freshwater systems is, in most cases, the consequence of inadequate communal and industrial waste management, as well as the discharge of both treated and untreated wastewater. This is becoming a major issue not only because of their direct influence on water biota, but also because many surface waters are actually drinking water sources. Polyethylene (PE) and polypropylene (PP) have been reported to represent more than $90 \%$ of the microplastics detected in drinking water sources and surface waters [4]. Recent studies have highlighted that these plastics are also frequently used as construction materials in drinking water treatment facilities, which can contribute further to the presence of these microplastics in drinking water [12]. Matsuzawa et al. (2010) [13] reported that some types of biodegradable polymers can adsorb certain hydrophobic organic compounds, including chlorinated phenols. Bioplastics have attracted much attention as alternatives of conventional plastics. Nowadays, following new EU legislation banning plastics for single use consumption, it is of special interest to investigate whether biodegradable plastics as well as petrochemical plastics can adsorb organic pollutants.

Data relating to the influence of microplastics (MP) on the marine environment and their toxicological effects on marine organisms have been thoroughly assessed. On the other hand, data on the influence of microplastics on inland water bodies and especially on drinking water sources are still very limited $[4,12]$. Consequently, the interactions of MPs with other pollutants that can be found in water sources, such as chlorinated phenols, are not yet fully understood. Novotna et al. (2019) [4] even suggest that some drinking water treatment plants will have to deal with microplastics as a "new" polluting agent.

The goal of this research is therefore to increase understanding of the challenges priority substances and MPs pose to groundwater treatment, by evaluating how chlorinated phenols are adsorbed both on PE and PP, the most abundant microplastics in drinking waters, and to compare these plastics with bioplastics.

\section{Materials and Methods}

\subsection{Materials}

In this study, granulated materials were used as sorbents. Two kinds of microplastic (MP) particles, polyethylene standard (PEg) and polypropylene (PP), and one bioplastic (polylactic acid, PLA), all manufactured by Sigma-Aldrich, were used. The basic physico-chemical properties of PEg of the investigated MPs and bioplastic PLA are given in Table 1.

Table 1. Physico-chemical properties of the investigated polymers.

\begin{tabular}{ccccccc}
\hline Compound & $\begin{array}{c}\text { Particle size } \\
(\mathbf{m m})\end{array}$ & $\begin{array}{c}\text { Density } \\
\left(\mathrm{g} / \mathrm{cm}^{3}\right)\end{array}$ & $\begin{array}{c}\text { Crystal- } \\
\text { linity } \\
(\%)\end{array}$ & $\begin{array}{c}\text { Melting } \\
\text { Temp. } \\
\left({ }^{\circ} \mathbf{C}\right)\end{array}$ & $\begin{array}{c}\text { Glass Transition } \\
\text { Temp. } \\
\left({ }^{\circ} \mathbf{C}\right)\end{array}$ & Reference \\
\hline PEg & $3.0^{*}$ & $0.918^{*}$ & 44.0 & 114 & -120 & {$[14]$} \\
\hline PP & $3.0^{*}$ & $0.9^{*}$ & 38.0 & 165 & -18 & {$[15,16]$} \\
\hline PLA & $3.0^{*}$ & $1.24^{*}$ & 20.9 & $173-178$ & $60-65$ & {$[17,18]$} \\
\hline
\end{tabular}

Polyethylene (PEg), polypropylene (PP), polylactic acid (PLA)*Provided by the supplier. 
Four chlorinated phenols (purchased from Pestanal ${ }^{\circledR}$ Sigma-Aldrich), 4-chlorophenol (4-CP), 2,4-dichlorophenol (2,4-DCP), 2,4,6-trichlorophenol (2,4,6-TCP) and pentachlorophenol (PCP) were investigated in this work. The physico-chemical properties of the CPs are presented in Table 2.

Table 2. Physico-chemical properties of the investigated chlorophenols.

\begin{tabular}{cccccc}
\hline Compound & $\mathbf{M W}$ & $\log \boldsymbol{K}_{\text {ow }}{ }^{\mathbf{a}}$ & $\mathbf{V}_{\boldsymbol{i}}{ }^{\mathbf{a}}$ & $\mathbf{S}_{\mathbf{w}}{ }^{\mathbf{a}}$ & $\mathrm{p} \boldsymbol{K}_{\boldsymbol{a}}{ }^{\mathbf{a}}$ \\
\hline 4-CP & 129 & 2.40 & 1.02 & 27,100 & 9.41 \\
2,4-DCP & 163 & 3.06 & 1.14 & 4500 & 7.90 \\
2,4,6-TCP & 197 & 3.69 & 1.26 & 800 & 6.40 \\
PCP & 266 & 5.12 & 1.39 & 14 & 4.80
\end{tabular}

Pentachlorophenol (PCP). MW, molecular weight (g/mol); $K_{o w}$, octanol-water partition coefficient; $V_{i}$, McGowan volume in units of $\left(\mathrm{cm}^{3} / \mathrm{mol}\right) / 100 ; S_{w}$, water solubility $(\mathrm{mg} / \mathrm{L}) ; \mathrm{p} K_{a}$ dissociation constant. ${ }^{\text {a }}$ Kragulj et al. (2013).

These CPs differ in hydrophobicity (octanol-water partition coefficient, $\log K_{o w}$ ), water solubility $\left(\mathrm{S}_{w}\right)$ and acid dissociation constants $\left(\mathrm{p} K_{a}\right)$.

Hexane and methanol were purchased from J.T.Baker (for organic residue analysis), acetic anhydride and hydrogen peroxide from Sigma-Aldrich. Analytical grade reagents, anhydrous calcium chloride $\left(\mathrm{CaCl}_{2}\right)$, sodium hydrogen carbonate $\left(\mathrm{NaHCO}_{3}\right)$, and magnesium sulphate heptahydrate $\left(\mathrm{MgSO}_{4} \cdot 7 \mathrm{H}_{2} \mathrm{O}\right)$, were also purchased from Sigma-Aldrich.

Sorption experiments were run using a batch equilibrium method. Adsorption kinetics and isotherms were investigated in two matrices. One matrix was synthetic water containing three salts $\left(\mathrm{CaCl}_{2}, \mathrm{NaHCO}_{3}\right.$ and $\left.\mathrm{MgSO}_{4} \cdot 7 \mathrm{H}_{2} \mathrm{O}\right)$, and the other was Danube river water, since it is polluted with plastics [19] and connected to groundwater drinking water sources obtained by riverbank filtration. The $\mathrm{pH}$ of the synthetic matrix was $7.23 \pm 0.06$ and thus did not require further adjustment to be comparable with the Danube river water $(\mathrm{pH} 7.45 \pm 0.07)$. The characteristics of the investigated matrices are given in Table 3.

Table 3. Characteristics of the synthetic water and Danube river water.

\begin{tabular}{ccc}
\hline Parameter & Synthetic Water & Danube River Water \\
\hline $\mathrm{pH}$ & $7.23 \pm 0.06$ & $7.45 \pm 0.07$ \\
Electro conductivity $25^{\circ} \mathrm{C}(\mu \mathrm{S} / \mathrm{cm})$ & $226 \pm 23$ & $333 \pm 7.0$ \\
Dissolved organic carbon $(\mathrm{mg} / \mathrm{L})$ & $<0.5$ & $2.84 \pm 0.12$ \\
Chloride concentration $(\mathrm{mg} / \mathrm{L})$ & $52.1 \pm 3.59$ & $44.0 \pm 1.52$ \\
Sulphate concentration $(\mathrm{mg} / \mathrm{L})$ & $21.2 \pm 4.89$ & $25.5 \pm 3.18$ \\
Hydrogen carbonate concentration $(\mathrm{mg} / \mathrm{L})$ & $134 \pm 6$ & $218 \pm 43$ \\
\hline
\end{tabular}

\subsection{Sorption Experiments}

All kinetics experiments were conducted in $30 \mathrm{~mL}$ glass vials at room temperature $\left(25^{\circ} \mathrm{C}\right) \mathrm{using}$ $20 \mathrm{mg}$ of investigated adsorbents, which were added to the synthetic matrix or freshwater. Stock solutions of all investigated CPs $(1000 \mu \mathrm{g} / \mathrm{mL})$ were prepared in $\mathrm{MeOH}$ (J.T. Baker, for organic residue analysis). The initial concentration of CPs in the experiments was $100 \mu \mathrm{g} / \mathrm{L}$. The vials were sealed and placed on a digital shaker at a speed of $150 \mathrm{rpm}$ (IKA ${ }^{\circledR}$ Orbital shaker KS 501 Digital). All experiments were performed in triplicate. Samples were collected at specified time intervals $(2,4,6,12,24,48,72$ and $96 \mathrm{~h}$ ) and filtered through a $0.45 \mu \mathrm{m}$ membrane filter. Filtered samples were prepared for gas chromatographic analysis. The obtained experimental data were fitted with three kinetic models: the pseudo-first order, pseudo-second order and Weber-Morris models.

Adsorption isotherm experiments were carried out at CP concentrations in the range of $0-100 \mu \mathrm{g} / \mathrm{L}$ $(1,25,50,75,100 \mu \mathrm{g} / \mathrm{L})$. All experiments were carried out at the $\mathrm{pH}$ of Danube river water $(\mathrm{pH}=7.45 \pm 0.07)$. After being continuously agitated for $48 \mathrm{~h}$ (equilibrium time), samples were collected to quantify the equilibrium concentrations of CPs in the aqueous phase. The Freundlich 
and Langmuir adsorption models (see Li et al. (2018) for the formulae applied) were used to fit the adsorption isotherm data [20].

\subsection{Analytical Procedure, Quality Assurance and Quality Control}

Determination of the selected chlorinated phenols in water was performed using gas chromatography with mass spectrometry (Agilent Technologies, 7890A GC System/5975C VL MSD) after derivatization and liquid-liquid extraction with hexane. Blank and control experiments were performed with the sorption experiments. Blank tests, containing the same amounts of water matrix and solid particles as the samples, but without the addition of chlorinated phenols, were carried out using conditions similar to those described previously, and no target compounds were found. Control tests were carried out in $20 \mathrm{~mL}$ of water matrix containing the same gradient of $\mathrm{CP}$ concentrations as the samples, but without solid particles, in order to evaluate the loss of $\mathrm{CP}$ resulting from additional removal processes, such as volatilization and/or sorption to the walls of the glass bottles. The method detection limits (MDLs) of the applied analytical methods ranged from 0.11 to $0.53 \mu \mathrm{g} / \mathrm{L}$. The correlation coefficient for the chlorinated phenols calibration curve was higher than 0.99. All the reported concentrations of $\mathrm{CP}$ were corrected with the recovery efficiency and internal standards.

\section{Results}

\subsection{Sorption Kinetics}

The results of the sorption kinetics of chlorinated phenols on the PEg, PP and PLA particles in the synthetic matrix (PEg-S, PP-S, PLA-S) and Danube river water (PEg-D, PP-D, PLA-D) are shown in Figure 1. The adsorption of CPs onto plastics reached equilibrium after $48 \mathrm{~h}$ for all the sorbate-sorbent combinations investigated. PP exhibited the highest uptake for the compounds (2,4-DCP, 2,4,6-TCP and $\mathrm{PCP}$ ) with higher hydrophobicity ( $\mathrm{pKow}>2.50$ ), and $\mathrm{pKa}$ values near or lower than $\mathrm{pH}$ of the water matrices.

The uptake of chlorinated phenols by the two kinds of microplastics and bioplastic PLA increases with time until sorption equilibrium is achieved after $48 \mathrm{~h}$ (Figure 1). These results are in the range of the usually reported periods for gaining sorption equilibrium of the organic compounds on various types of MPs [10,21]. PP adsorbs the highest amount of 2,4-DCP, 2,4,6-TCP and PCP (from 126-144 $\mu \mathrm{g} / \mathrm{g}$ ), while $4-\mathrm{CP}$ is best adsorbed on PLA $(85-101 \mu \mathrm{g} / \mathrm{g})$. Matrix effects are evident in the behaviour of all the MPs, and are the most pronounced for PEg, which adsorbed the lowest amounts of all the CPs in the synthetic matrix (up to $65.9 \mu \mathrm{g} / \mathrm{g}$ for 4-CP, $104 \mu \mathrm{g} / \mathrm{g}$ for 2,4-DCP, $99.5 \mu \mathrm{g} / \mathrm{g}$ for 2,4,6-TCP and $53.7 \mu \mathrm{g} / \mathrm{g}$ for PCP), while the amounts adsorbed in the Danube river water were much higher (up to $77.7 \mu \mathrm{g} / \mathrm{g}$ for $4-\mathrm{CP}, 134 \mu \mathrm{g} / \mathrm{g}$ for 2,4-DCP, $116 \mu \mathrm{g} / \mathrm{g}$ for 2,4,6-TCP and $88.0 \mu \mathrm{g} / \mathrm{g}$ for PCP). The same trend, but with much lower differences between the amounts of $\mathrm{CPs}$ adsorbed from the synthetic and Danube river water matrices, can be observed for PLA. The lowest matrix effect was observed for PP.

The kinetics data were fit to the pseudo-first order and pseudo-second order kinetic models. Correlation coefficients $\left(\mathrm{R}^{2}\right)$ for the first-order kinetics models were in the range of 0.10 for sorption of PCP on PLA to 0.95 for sorption of 2,4,6-TCP on PP_D, and in general were very low, suggesting that the pseudo-first-order model is not a good fit for the experimental data. In contrast, $\mathrm{R}^{2}$ values for the pseudo-second order model were very high (see Figure 2). The $R^{2}$ values were greater than 0.99 for the sorption of 2,4-DCP, 2,4,6-TCP and PCP on all three materials. Slightly lower $\mathrm{R}^{2}$ values were obtained for $4-\mathrm{CP}$, but the values are still high, ranging from 0.9460 to 0.9890 . The calculated $\mathrm{q}_{e}, \mathrm{k}_{2}$, and $\mathrm{R}^{2}$ values for the pseudo-second order model are listed in Table 4 . The qe values obtained agree well with the experimentally measured $\mathrm{q}_{\mathrm{e}}$ values. Based on these results, the pseudo-second order equation can successfully be used to describe the sorption process of the four investigated chlorinated phenols onto PEg, PP and PLA particles, from the beginning of the sorption process to the equilibrium stage. This means that chlorinated phenols can be adsorbed to different binding sites on the investigated MPs and PLA [11]. 


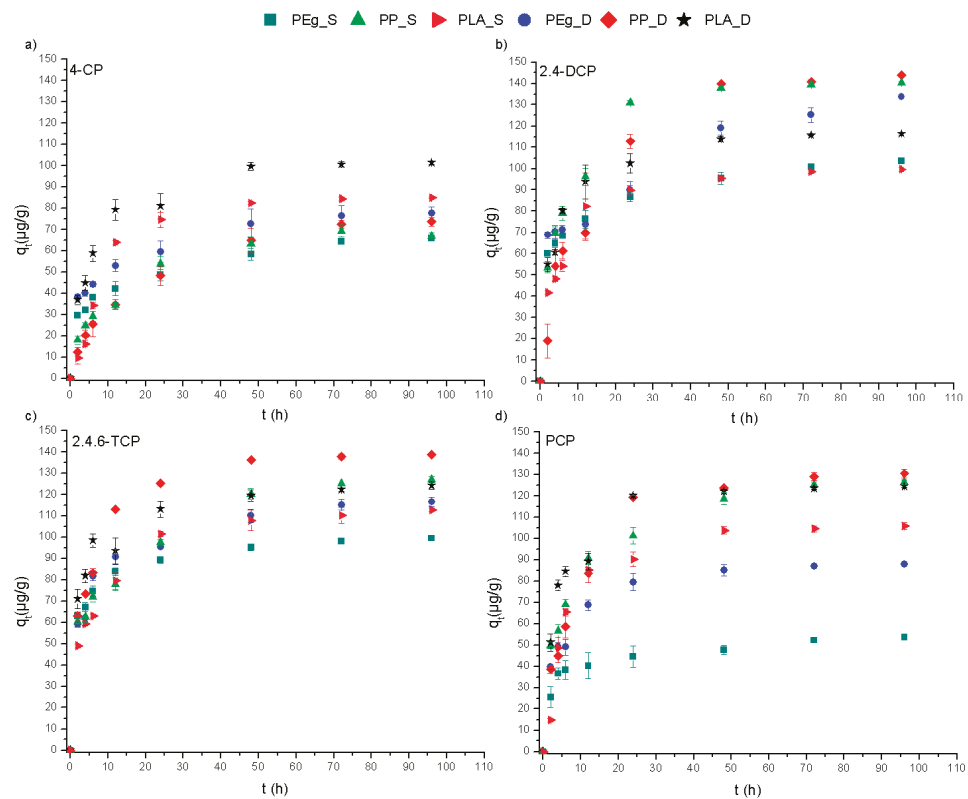

Figure 1. Experimental data ( $n=3$, mean value \pm SD) of (a) 4-CP; (b) 2,4-DCP; (c) 2,4,6-TCP and (d) PCP on PEg, PP and PLA particles in the synthetic matrix (PEg_S, PP_S and PLA_S) and Danube river water (PEg_D, PP_D and PLA_D).

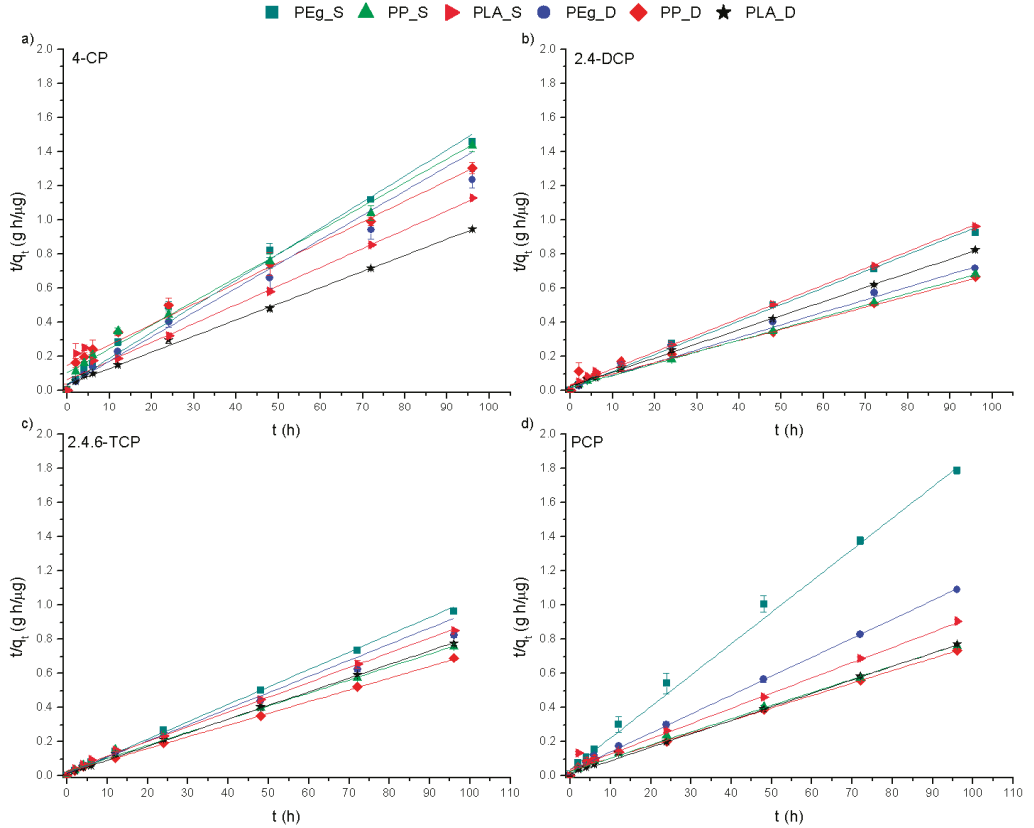

Figure 2. Plots for the sorption kinetics, based on the pseudo-second order model, of (a) 4- CP; (b) 2,4-DCP; (c) 2,4,6-TCP and (d) PCP on PEg, PP and PLA particles in the synthetic matrix (PEg_S, PP_S and PLA_S) and Danube river water (PEg_D, PP_D and PLA_D) $(n=3$, mean value \pm SD). 
Table 4. Parameters calculated with pseudo-second order kinetic models for the sorption of chlorinated phenols onto PEg, PP and PLA particles in synthetic and Danube river water.

\begin{tabular}{|c|c|c|c|c|c|}
\hline Compounds & Solid Phase & $\mathrm{k}_{2}\left(\mathrm{~h}^{-1}\right)$ & $\mathbf{R}^{2}$ & $\mathrm{q}_{\mathrm{e}}$ (Theoretical) & $\mathrm{q}_{\mathrm{e}}$ (Experimental) \\
\hline \multirow{6}{*}{$4-\mathrm{CP}$} & PEg_S & 0.0063 & 0.9890 & 65.85 & 65.49 \\
\hline & PEg_D & 0.0065 & 0.9460 & 77.69 & 70.22 \\
\hline & PP_S & 0.0018 & 0.9749 & 66.85 & 71.84 \\
\hline & PP_D & 0.0010 & 0.9815 & 73.62 & 83.13 \\
\hline & PLĀ_S & 0.0019 & 0.9939 & 85.02 & 90.83 \\
\hline & PLA_D & 0.0025 & 0.9981 & 101.4 & 105.6 \\
\hline \multirow{6}{*}{ 2,4-DCP } & PEg_S & 0.0059 & 0.9912 & 103.7 & 102.2 \\
\hline & PEg_D & 0.0032 & 0.9925 & 133.8 & 135.3 \\
\hline & PP_S & 0.0022 & 0.9978 & 140.4 & 145.8 \\
\hline & PP_D & 0.0012 & 0.9915 & 143.8 & 153.8 \\
\hline & PLA_S & 0.0031 & 0.9977 & 99.62 & 101.8 \\
\hline & PLA_D & 0.0026 & 0.9993 & 116.4 & 120.6 \\
\hline \multirow{6}{*}{ 2,4,6-ТCP } & PEg_S & 0.0085 & 0.9973 & 99.56 & 98.14 \\
\hline & PEg_D & 0.0056 & 0.9930 & 116.5 & 105.8 \\
\hline & PP_S & 0.0022 & 0.9974 & 126.9 & 130.7 \\
\hline & PP_D & 0.0020 & 0.9991 & 138.9 & 145.6 \\
\hline & PLA_S & 0.0026 & 0.9937 & 112.9 & 115.6 \\
\hline & PLA_D & 0.0046 & 0.9992 & 124.1 & 125.2 \\
\hline \multirow{6}{*}{ PCP } & PEg_S & 0.0087 & 0.9990 & 53.68 & 54.38 \\
\hline & PEg_D & 0.0041 & 0.9985 & 88.05 & 90.09 \\
\hline & PP_S & 0.0021 & 0.9952 & 126.3 & 129.9 \\
\hline & PP_D & 0.0017 & 0.9935 & 130.5 & 136.8 \\
\hline & PLA_S & 0.0020 & 0.9789 & 105.9 & 112.1 \\
\hline & PLA_D & 0.0060 & 0.9988 & 124.5 & 126.7 \\
\hline
\end{tabular}

Differences were observed between the most hydrophilic 4-CP and the most hydrophobic PCP on PEg, PP and PLA, with adsorptions ranging from 65.9 to $101 \mu \mathrm{g} / \mathrm{g}$ to 53.7 to $126 \mu \mathrm{g} / \mathrm{g}$, respectively.

The plots obtained using the Weber-Morris intraparticle diffusion model (shown in Figure 3) imply that the sorption of all four chlorophenols on PEg, PP and PLA proceeds through two linear phases, corresponding to the transport of the sorbate from the bulk solution to the external surfaces and then into the interior pores of the sorbent $[10,22]$. For most combinations of CPs and MPs/bioplastics, adsorption at the beginning is fast for the first five hours. After that period, a slower adsorption process is observed. The slowest adsorption rate was observed for all four CPs on PEg in both water matrices. The linear plots obtained by the Weber-Morris model do not pass through the origin for the sorption of all four chlorinated phenols on all three materials, which indicates that surface sorption could be the rate-controlling step [11]. 

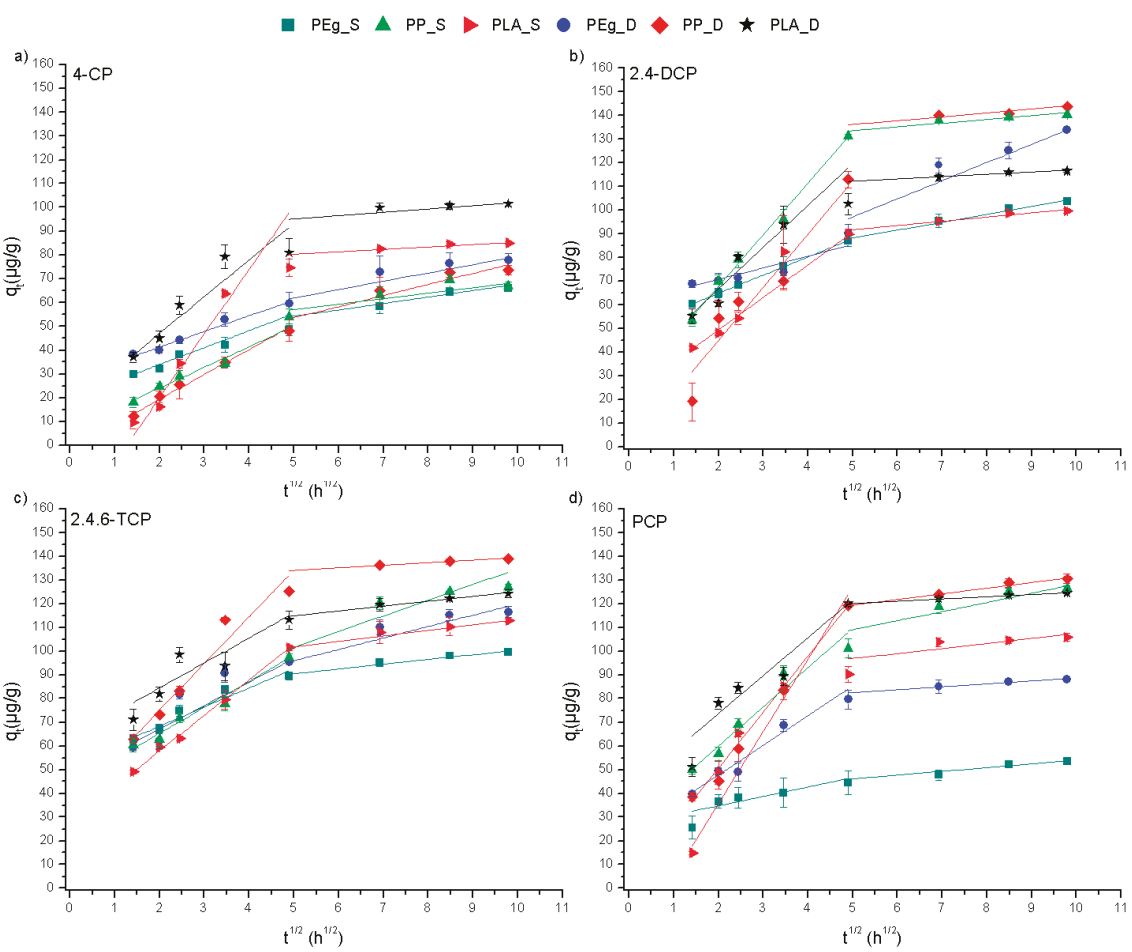

Figure 3. Plots for the sorption kinetics, based on the Weber-Morris model, of (a) 4- CP; (b) 2,4-DCP; (c) 2,4,6-TCP and (d) PCP on PEg, PP and PLA particles in the synthetic matrix (PEg_S, PP_S and PLA_S) and Danube river water (PEg_D, PP_D and PLA_D) $(n=3$, mean value \pm SD).

\subsection{Adsorption Isotherms}

In order to investigate the sorption mechanism of the chlorinated phenols on microplastics and bioplastics in the two matrices investigated, the Freundlich and Langmuir models were applied. These are the two most commonly applied models for describing the mechanism of interactions between sorbents and sorbates. The Freundlich model is applicable to both monolayer and multilayer sorption and assumes that the sorption process takes place on the heterogeneous surface of a sorbent [10,23]. The application of the Langmuir model can show whether the sorbate makes a monolayer coverage on homogenous sorbent surfaces [1,10]. Figure 4 presents the adsorption isotherms of chlorinated phenols on PEg, PP and PLA in the synthetic and Danube river water matrices. The values of the Freundlich and Langmuir model parameters are listed in Table 5. 
Water 2019, 11, 2358
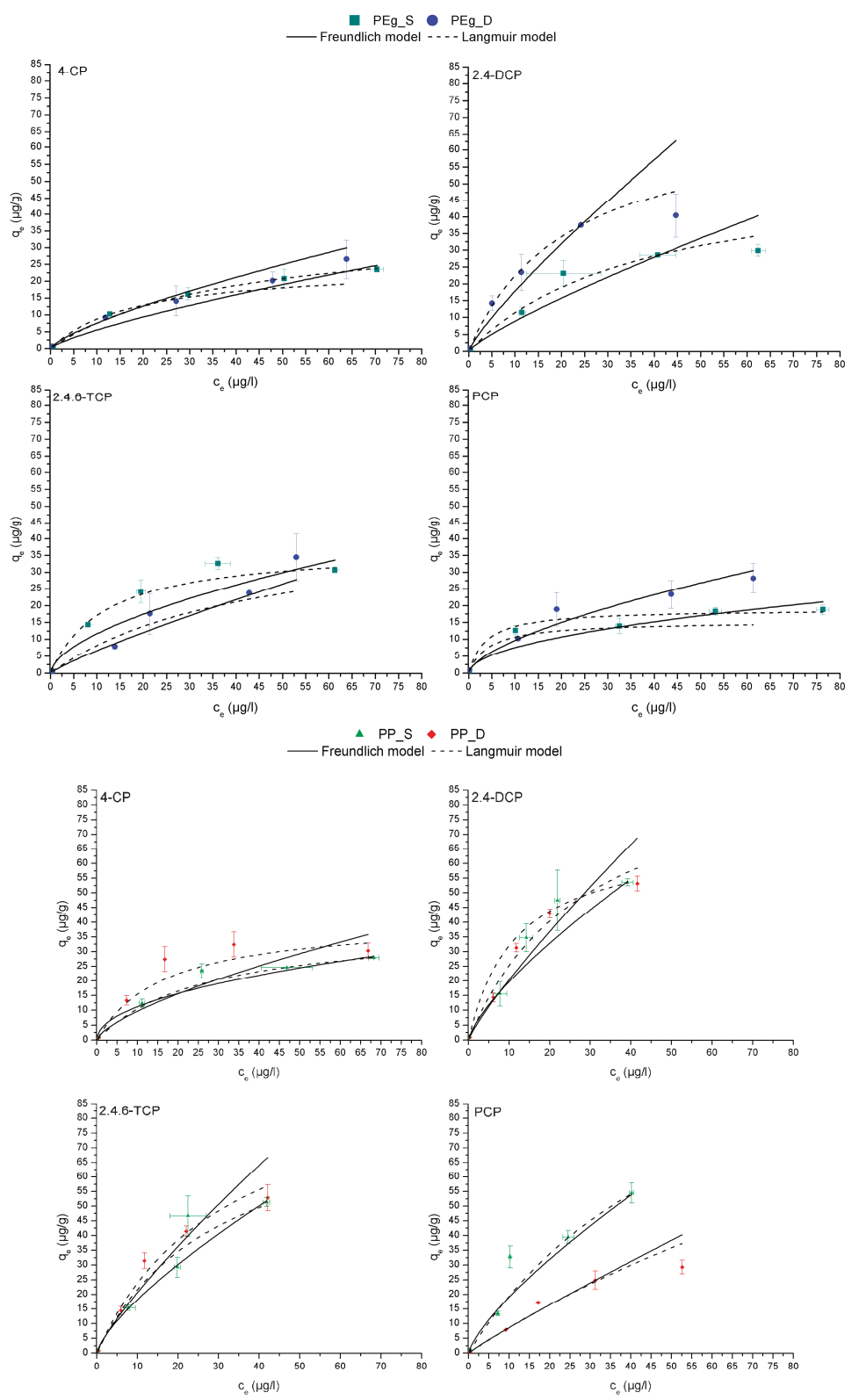

Figure 4. Cont. 


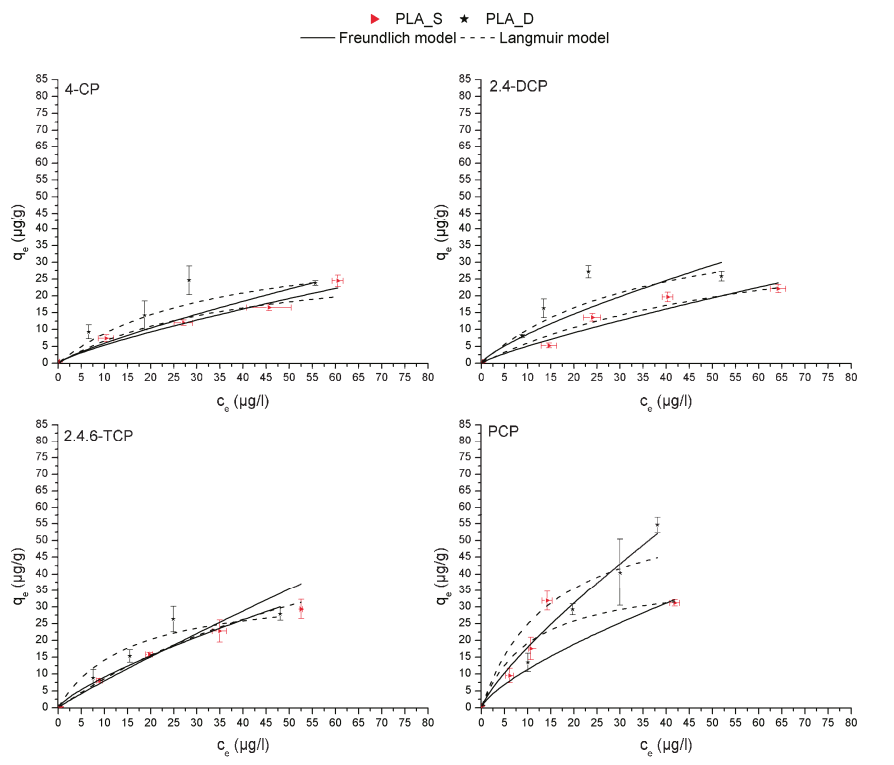

(c)

Figure 4. Sorption isotherms of 4-CP, 2,4-DCP, 2,4,6-TCP and PCP on (a) PEg, (b) PP and (c) PLA particles obtained for the synthetic matrix (PEg_S, PP_S and PLA_S) and Danube river water (PEg_D, PP_D and PLA_D) $(n=3$, mean value \pm SD).

Table 5. Values of the Freundlich and Langmuir model parameters for the sorption of 4-CP, 2,4-DCP, 2,4,6-TCP and PCP on PEg, PP and PLA.

\begin{tabular}{|c|c|c|c|c|c|c|c|}
\hline \multirow{2}{*}{ Compounds } & \multirow{2}{*}{ Adsorbents } & \multicolumn{3}{|c|}{ Freundlich model } & \multicolumn{3}{|c|}{ Langmuir model } \\
\hline & & $\mathbf{R}^{2}$ & $n$ & $K_{F}(\mu g / g) /(\mu g / L)^{n}$ & $\mathbf{R}^{2}$ & $\mathrm{q}_{\max }(\mu \mathrm{g} / \mathrm{g})$ & $K_{L}(1 / \mu g)$ \\
\hline \multirow{6}{*}{ 4-CP } & PEg_S & 0.9478 & 0.77 & 0.92 & 0.9892 & 37.03 & 0.0255 \\
\hline & PEg_D & 0.9816 & 0.74 & 1.36 & 0.9825 & 24.55 & 0.0551 \\
\hline & PP_S & 0.9974 & 0.48 & 3.69 & 0.9984 & 39.17 & 0.0365 \\
\hline & PP_D & 0.8292 & 0.69 & 1.98 & 0.9687 & 41.15 & 0.0599 \\
\hline & PLA_S & 0.9869 & 0.80 & 0.85 & 0.9762 & 32.74 & 0.0252 \\
\hline & PLA_D & 0.9835 & 0.82 & 0.91 & 0.9938 & 38.40 & 0.0298 \\
\hline \multirow{6}{*}{ 2,4-DCP } & PEg_S & 0.9949 & 0.83 & 1.33 & 0.9989 & 55.60 & 0.0258 \\
\hline & PEg_D & 0.9998 & 0.84 & 2.58 & 0.9998 & 71.36 & 0.0457 \\
\hline & PP_S & 0.9970 & 0.74 & 3.63 & 0.9945 & 68.98 & 0.0869 \\
\hline & PP_D & 0.9347 & 0.85 & 2.86 & 0.9884 & 100.2 & 0.0338 \\
\hline & PLA_S & 0.9585 & 0.83 & 0.74 & 0.9423 & 45.48 & 0.0152 \\
\hline & PLA_D & 0.9268 & 0.76 & 1.52 & 0.9392 & 46.35 & 0.0275 \\
\hline \multirow{6}{*}{ 2,4,6-TCP } & PEg_S & 0.9397 & 0.59 & 3.02 & 0.9390 & 37.47 & 0.0839 \\
\hline & PEg_D & 0.9897 & 0.86 & 0.90 & 0.9919 & 44.95 & 0.0222 \\
\hline & PP_S & 0.9960 & 0.73 & 3.37 & 0.9631 & 87.13 & 0.0330 \\
\hline & PP_D & 0.9599 & 0.82 & 3.14 & 0.9911 & 100.1 & 0.0313 \\
\hline & PLĀ_S & 0.9703 & 0.93 & 0.95 & 0.9881 & 82.23 & 0.0118 \\
\hline & PLA_D & 0.9668 & 0.76 & 1.59 & 0.9796 & 35.59 & 0.0662 \\
\hline \multirow{6}{*}{ РCP } & PEg_S & 0.9521 & 0.51 & 2.32 & 0.9913 & 18.93 & 0.2681 \\
\hline & PEg_D & 0.9958 & 0.63 & 2.24 & 0.9349 & 15.32 & 0.2261 \\
\hline & PP_S & 0.9708 & 0.75 & 3.39 & 0.9438 & 135.2 & 0.0167 \\
\hline & PP_D & 0.9884 & 0.93 & 1.02 & 0.9898 & 168.2 & 0.0054 \\
\hline & PLA_S & 0.9531 & 0.73 & 2.15 & 0.9817 & 62.74 & 0.0940 \\
\hline & PLA_D & 0.9925 & 0.80 & 2.88 & 0.9246 & 39.54 & 0.0658 \\
\hline
\end{tabular}


The correlation coefficients for the Freundlich and Langmuir models are, respectively, $\mathrm{R}^{2}=0.8292-0.9998$ and $\mathrm{R}^{2}=0.9246-0.9998$ for all four CPs on all of the polymers. Significant differences between these two models were not observed.

In the Freundlich isotherm, the parameter $n$ is an indicator of sorption linearity, with larger deviations from $n=1$ indicating greater nonlinearity. All the isotherms obtained are nonlinear ( $n$ values ranging from 0.48 to 0.93 ), suggesting heterogenic binding sites on the surface of the sorbents (Table 5). In general, greater nonlinearity was observed in the synthetic matrix than in the Danube river water, demonstrating the influence of this matrix on the sorption process.

In the case of the Langmuir model, it is assumed that sorption of the sorbate molecule occurs at a specific site on the sorbent, with no further sorption occurring at the same site [10,23]. The $\mathrm{q}_{\max }$ are in the ranges $24.55-41.15 \mu \mathrm{g} / \mathrm{g}, 46.35-100.2 \mu \mathrm{g} / \mathrm{g}, 35.59-100.1 \mu \mathrm{g} / \mathrm{g}$ and 15.3-168.2 $\mu \mathrm{g} / \mathrm{g}$ for 4-CP, 2,4-DCP, 2,4,6-TCP and PCP on PEg, PP and PLA, respectively. These differences confirm that the structure of the compound has a significant impact on its interactions with the plastic surfaces. PP showed a considerably higher sorption affinity for CPs than PLA and PEg, which confirms that sorption is dependent on the sorbent properties. The difference between the three sorbents investigated is most pronounced regarding PCP sorption. The highest amounts of PCP ( $\left.\mathrm{q}_{\max }=135.2-168.2 \mu \mathrm{g} / \mathrm{g}\right)$ are adsorbed on PP, following 2,4,6-TCP, 2,4-DCP and 4-CP. The lowest $\mathrm{q}_{\max }$ values were obtained for the sorption of PCP on PEg $\left(\mathrm{q}_{\max }=15.32-18.93 \mu \mathrm{g} / \mathrm{g}\right)$. In general, all the CPs had lower sorption affinities for $\mathrm{PEg}$ than either of the other two plastics investigated. Matrix influences on $\mathrm{q}_{\max }$ can also be observed, with higher values generally observed for PEg and PP in Danube river water compared to the synthetic matrix. The adsorption capacity of PLA towards CPs in Danube river water had similar values $(35.52-46.35 \mu \mathrm{g} / \mathrm{g})$, and these are similar or lower than in the synthetic matrix.

\section{Discussion}

Plastic debris is now found throughout the environment, and may serve as a carrier for organic pollutants, influencing not just their transport through various environments, but potentially also influencing how they express their toxicity towards aquatic organisms and humans [3]. Bioplastics are also becoming more broadly applied in everyday life, increasing their discharge to the environment. Understanding the interactions between various plastics and organic pollutants is therefore extremely important $[10,11,21,24]$.

The adsorption kinetics and isotherm data presented above demonstrate significant variations in the degree to which microplastics interact with chlorinated phenols in neutral $\mathrm{pH}$ aqueous environments. The different polarities of the phenols studied, as demonstrated by their various $\mathrm{pKa}$ values, mean that under the conditions investigated some of these compounds are partially present in disassociated forms, rather than as neutral species $[11,13]$. The different plastics have differing monomeric compositions, with the linear aliphatic PE, and the slightly branched aliphatic PP and PLA which is an aliphatic polyester. They are therefore likely to undergo different interactions with non-hydrophobic compounds such as phenols, as suggested by other authors $[10,25]$. The obtained results indicate that the structure of microplastic is significant for sorption processes when the available surfaces of the polymers are similar, which is in accordance with the finding of other authors [24,25]. PP showed the highest sorption capacity towards all four CPs, followed by PLA and PEg, suggesting that nonlinear polymers exhibit a higher potential to adsorb and transport ionisable compounds through the environment. One can assume that the hydrophobic character of these compounds is responsible for the majority of interactions between CPs and PP, because with increases in compound hydrophobicity, in both water matrices increases in the adsorption capacity were observed. The poor sorption of ionised PCP and 2,4,6-TCP observed on PEg are probably explained by electrostatic repulsion (Table 5). The best sorption on this plastic was observed for 2,4-DCP, which is hydrophobic and non-ionised under the prevailing $\mathrm{pH}$ conditions of the experiment. The adsorption capacity of $\mathrm{PE}$ towards 4-CP is similar to $2,4,6-\mathrm{TCP}$, indicating that the slightly hydrophilic nature of this compound and its non-ionised structure 
both influence the sorption. In the synthetic matrix, the capacity of PLA to adsorb the hydrophobic ionised molecules of 2,4,6-TCP and PCP is two times higher than for the non-ionised 4-CP and 2,4-DCP.

The presence of other water constituents in the Danube river water, especially the natural organic matter (NOM), was expected to potentially interfere with the adsorption of the CPs by competing for adsorption sites on the surface of the plastics. However, the reverse trend was observed, whereby the $\mathrm{q}_{\max }$ of CPs in the presence of PEg, PP and PLA was generally greater or similar in the experiments carried out with Danube river water, in comparison to the synthetic matrix. This could indicate that additional interactions with the NOM were present. The adsorption of 2,4,6-TCP and PCP on PLA were the only cases where the $q_{\max }$ values were significantly lower in the presence of NOM. NOM itself is a complex mixture of organic substances with various properties and functional groups. Earlier characterisation of the Danube river NOM [26] revealed that the majority of NOM present is mainly of hydrophilic character, while the hydrophobic fraction is relatively insignificant. This topic will certainly be of interest for future research, as also indicated by $\mathrm{Xu}$ et al. [21,25].

\section{Conclusions}

The results obtained in this work demonstrate that the presence of microplastics and bioplastics in aquatic environments may have a significant impact on the fate and transport of certain chlorinated phenols.

The adsorption of 4-CP was not significantly affected by the type of plastic present or the water matrix. In contrast, the type of plastic had a great impact on adsorption of 2,4-DCP, 2,4,6-TCP and PCP, with PCP demonstrating the most pronounced variation. In general, polypropylene showed the greatest affinity for the adsorption of CPs, whereas adsorption onto polyethylene and polylactic acid was more dependent on the structure of the compounds.

The differences observed between the adsorption behaviour of CPs in the investigated synthetic and natural water matrices demonstrate the need for further investigation, particularly in terms of how the role of different fractions of natural organic matter impact these interactions.

Author Contributions: conceptualization, A.T., J.A., S.M.; methodology, A.T., M.L.; investigation, M.L.; resources, J.A., J.T.; writing—original draft preparation, A.T., M.L.; writing—review and editing, J.M.J., M.W.; Visualization, A.T. and M.L.; project administration, J.T.; funding acquisition, J.A., J.T.

Funding: This research was funded by the Ministry of Education, Science and Technological Development of the Republic of Serbia (Project No. III43005).

Acknowledgments: The authors gratefully acknowledge the support of the Ministry of Education, Science and Technological Development of the Republic of Serbia (Project No. III43005).

Conflicts of Interest: The authors declare no conflict of interest.

\section{References}

1. Czaplicka, M. Sources and transformations of chlorophenols in the natural environment. Sci. Total. Environ. 2004, 322, 21-39. [CrossRef] [PubMed]

2. Vikesland, P.J.; Fiss, E.M.; Wigginton, K.R.; McNeill, K.; Arnold, W.A. Halogenation of Bisphenol-A, Triclosan, and Phenols in Chlorinated Waters Containing Iodide. Environ. Sci. Technol. 2013, 47, 6764-6772. [CrossRef] [PubMed]

3. Koelmans, A.A.; Nor, N.H.M.; Hermsen, E.; Kooi, M.; Mintenig, S.M.; De France, J. Microplastics in freshwaters and drinking water: Critical review and assessment of data quality. Water Res. 2019, 155, 410-422. [CrossRef] [PubMed]

4. Novotna, K.; Cermakova, L.; Pivokonska, L.; Cajthaml, T.; Pivokonsky, M. Microplastics in drinking water treatment-Current knowledge and research needs-review. Sci. Total. Environ. 2019, 667, 730-740. [CrossRef] [PubMed]

5. Michałowicz, J.; Duda, W. Phenols-sources and toxicity. Pol. J. Environ. Stud. 2007, 16, 347-362.

6. Gallard, H.; von Gunten, U. Chlorination of Phenols: Kinetics and Formation of Chloroform. Environ. Sci. Technol. 2002, 36, 884-890. [CrossRef] 
7. The European Parliament and the Council of the European Union. Directive 2013/39/EU of the European Parliament and of the Council of 12 August 2013 Amending Directives 2000/60/EC and 2008/105/EC as Regards Priority Substances in the Field of Water Policy Text with EEA Relevance: Directives 2000/60/EC and 2008/105/EC as Regards Priority Substances in the Field of Water Policy; The European Parliament and the Council of the European Union: Brussels, Belgium, 2013.

8. The European Parliament and the Council of the European Union. Directive 2008/105/EC of the European Parliament and of the Council of 16 December 2008 on Environmental Quality Standards in the Field of Water Policy, Amending and Subsequently Repealing Council Directives 82/176/EEC, 83/513/EEC, 84/156/EEC, 84/491/EEC, 86/280/EEC and Amending Directive 2000/60/EC of the European Parliament and of the Council: Directive on EQS in the Field of Water Policy; The European Parliament and the Council of the European Union: Strasbourg, France, 2008.

9. U.S. Environmental Protection Agency (EPA). 2004 Edition of the Drinking Water Standards and Health Advisories; EPA: Washington, DC, USA, 2004.

10. Wang, W.; Wang, J. Comparative evaluation of sorption kinetics and isotherms of pyrene onto microplastics. Chemosphere 2018, 193, 567-573. [CrossRef]

11. Guo, X.; Pang, J.; Chen, S.; Jia, H. Sorption properties of tylosin on four different microplastics. Chemosphere 2018, 209, 240-245. [CrossRef]

12. Mintenig, S.M.; Löder, M.G.J.; Primpke, S.; Gerdts, G. Low numbers of microplastics detected in drinking water from ground water sources. Sci. Total. Environ. 2019, 648, 631-635. [CrossRef]

13. Matsuzawa, Y.; Kimura, Z.-I.; Nishimura, Y.; Shibayama, M.; Hiraishi, A. Removal of Hydrophobic Organic Contaminants from Aqueous Solutions by Sorption onto Biodegradable Polyesters. JWARP 2010, 2, $214-221$.

14. Paszkiewicz, S.; Szymczyk, A.; Pawlikowska, D.; Subocz, J.; Zenker, M.; Masztak, R. Electrically and Thermally Conductive Low Density Polyethylene-Based Nanocomposites Reinforced by MWCNT or HybridMWCNT/Graphene Nanoplatelets with Improved Thermo-Oxidative Stability. Nanomaterials 2018, 8, 264. [CrossRef] [PubMed]

15. Maddah, H.A. Polypropylene as a Promising Plastic: A Review. AJOP 2016, 6, 1-11.

16. Mandolfino, C. Polypropylene surface modification by low pressure plasma to increase adhesive bonding: Effect of process parameters. Surf. Coat. Tech. 2019, 366, 331-337. [CrossRef]

17. Middleton, J.C.; Tipton, A.J. Synthetic biodegradable polymers as orthopedic devices. Biomaterials 2000, 21, 2335-2346. [CrossRef]

18. Kaavessina, M.; Ali, I.; Al-Zahrani, S.M. The Influences of Elastomer toward Crystallization of Poly (lactic acid). Procedia Chem. 2012, 4, 164-171. [CrossRef]

19. Liedermann, M.; Gmeiner, P.; Pessenlehner, S.; Haimann, M.; Hohenblum, P.; Habersack, H. A Methodology for Measuring Microplastic Transport in Large or Medium Rivers. Water 2018, 10, 414. [CrossRef]

20. Li, J.; Zhang, K.; Zhang, H. Adsorption of antibiotics on microplastics. Environ. Pollut. 2018, 237, 460-467. [CrossRef]

21. Xu, B.; Liu, F.; Brookes, P.C.; Xu, J. The sorption kinetics and isotherms of sulfamethoxazole with polyethylene microplastics. Mar. Pollut. Bull. 2018, 131, 191-196. [CrossRef]

22. Weber, T.W.; Chakravorti, R.K. Pore and solid diffusion models for fixed bed adsorbers. AICHE J. 1974, 20, 228-238. [CrossRef]

23. Foo, K.Y.; Hameed, B.H. Insights into Modeling of Adsorption Isotherm Systems. Chem. Eng. J. 2010, 156, 2-10. [CrossRef]

24. Huffer, T.; Hofmann, T. Sorption of non-polar organic compounds by micro-sized plastic particles in aqueous solution. Environ. Pollut. 2016, 214, 194-201. [CrossRef] [PubMed]

25. Xu, B.; Liu, F.; Brookes, P.C.; Xu, J. Microplastics play a minor role in tetracycline sorption in the presence of dissolved organic matter. Environ. Pollut. 2018, 240, 87-94. [CrossRef] [PubMed]

26. Tubić, A.; Leovac, A.; Molnar, J.; Krčmar, D.; Paunović, O.; Ivančev-Tumbas, I. Characterization of Dissolved Organic Matter from the Danube River Before and After Ozone Oxidation. In Proceedings of the 6th Symposium Chemistry and Environmental Protection EnviroChem, Vršac, Serbia, 21-24 May 2013; pp. 282-283.

(C) 2019 by the authors. Licensee MDPI, Basel, Switzerland. This article is an open access article distributed under the terms and conditions of the Creative Commons Attribution (CC BY) license (http://creativecommons.org/licenses/by/4.0/). 
MDPI

St. Alban-Anlage 66

4052 Basel

Switzerland

Tel. +41 616837734

Fax +41 613028918

www.mdpi.com

Water Editorial Office

E-mail: water@mdpi.com www.mdpi.com/journal/water

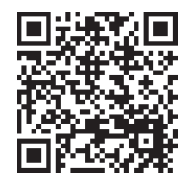



MDPI

St. Alban-Anlage 66

4052 Basel

Switzerland

Tel: +41 616837734

Fax: +41 613028918

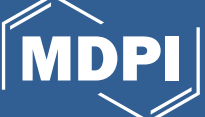

ISBN 978-3-03943-433-6 